ORNL/Sub/88-SA835/1

OAK RIDGE NATIONAL LABORATORY

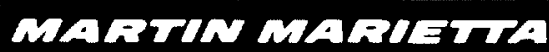
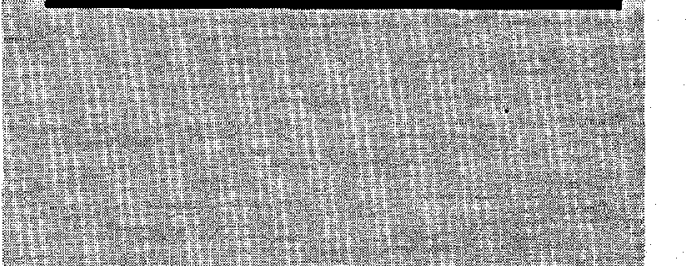

(5)

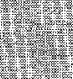

thit

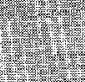

trex:

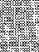

(2)
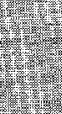

Research and Development Data to Define the Thermal Performance of Reflective Materials Used to Conserve Energy in Building Applications

A. O. Desjarlais

R. P. Tye 
This report has been reproduced directly from the best available copy.

Available to DOE and DOE contractors from the Office of Scientific and Technical Information, P.O. Box 62, Oak Ridge, TN 37831 ; prices available from (615) 576-8401, FTS 626-8401.

Available to the public from the National Technical Information Service, U.S. Department of Commerce, 5285 Port Royal Rd., Springfield, VA 22161.

NTIS price codes-Printed Copy: A13 Microfiche A01

This report was prepared as an account of work sponsored by an agency of the United States Government. Neither the United States Government nor any agency thereof, nor any of their employees, makes any warranty, express or implied, or assumes any legal liability or responsibility for the accuracy, completeness, or usefulness of any information, apparatus, product, or process disclosed, or represents that its use would not infringe privately owned rights. Reference herein to any specific commercial product, process, or service by trade name, trademark, manufacturer, or otherwise, does not necessarily constitute or imply its endorsement, recommendation, or favoring by the United States Government or any agency thereof. The views and opinions of authors expressed herein do not necessarily state or reflect those of the United States Government or any agency thereof. 


\section{RESEARCH AND DEVEIOPMENT DATA TO DEFINE THE THERMAL PERFORMANCE OF REFLECTIVE MATERIALS USED TO CONSERVE ENERGY IN BUILDING APPLICATIONS}

\section{Final Report}

by

A. O. Desjarlais and R. P. Tye

Date Published: March 1990

Report Prepared by:

THERMATEST DIVISION OF HOLOMETRIX, INC. 99 Erie street

Cambridge, MA 02139

Under subcontract Number $41 \mathrm{X}-\mathrm{SA} 835 \mathrm{C}$

\section{Prepared for:}

DOE Office of Buildings and Community systems EC $010100 \quad 0$ and

Building Thermal Envelope Systems and Materials Program Energy Division

OAK RIDGE NATIONAL LABORATORY

Oak Ridge, TN 37831

operated by

MARTIN MARIETTA ENERGY SYSTEMS, INC. for the

U.S. DEPARTMENT OF ENERGY

under contract DE-ACO5-84OR21400 

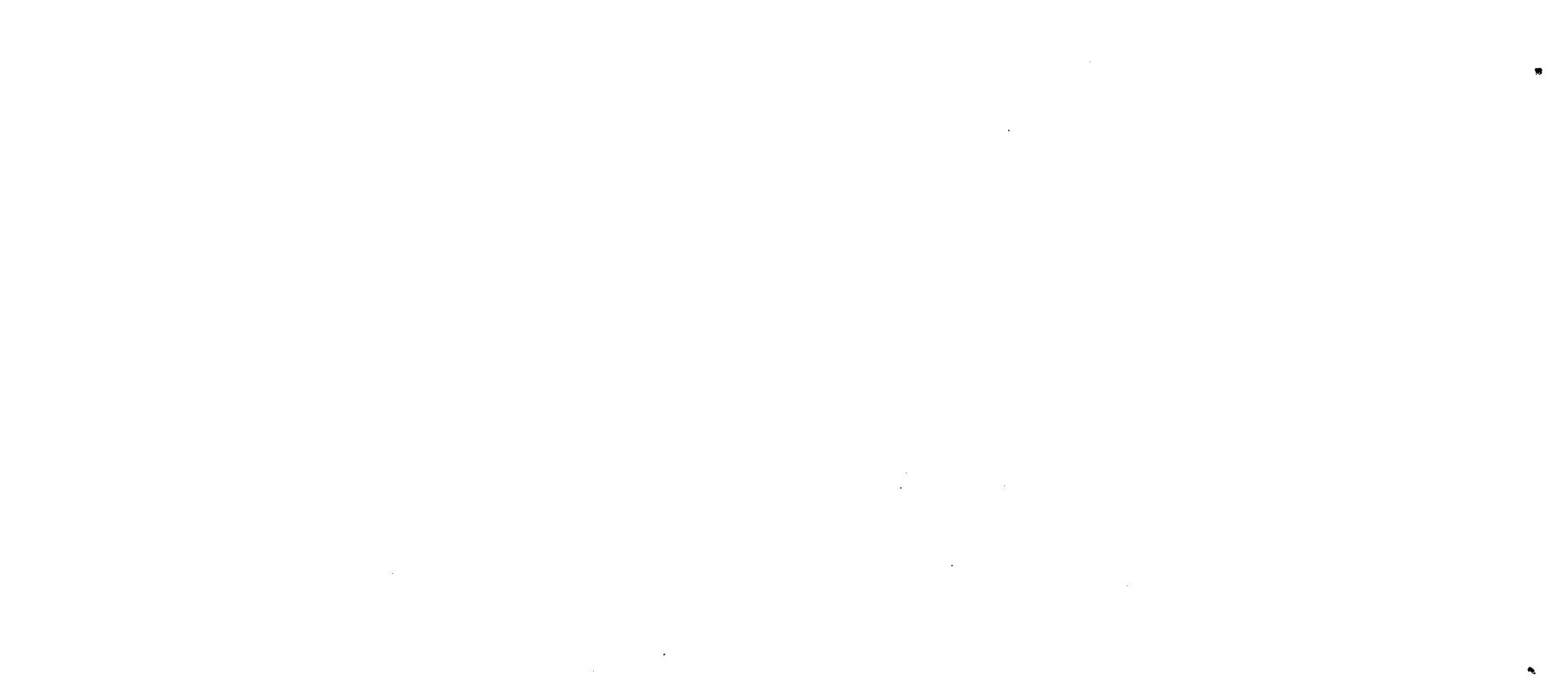

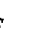


This is one of a series of reports to be published describing research, development, and demonstration activities in support of the National Program for Building Thermal Envelope Systems and Materials. The National Program involves several federal agencies and many other organizations in the public and private sectors who are addressing the national objective of decreasing energy wastes in the heating and cooling of buildings. Results described in this report are part of the National Program through delegation of management responsibilities for the DOE lead role to the Oak Ridge National Laboratory.

George E. Courville Program Manager

Building Thermal Envelope Systems and Materials Oak Ridge National Laboratory

M. P. Scofield

Program Manager

Building Systems Division Office of Buildings Energy R\&D Department of Energy 
RESEARCH AND DEVELOPMENT DATA TO DEFINE THE THERMAL PERFORMANCE OF REFLECTIVE MATERIALS USED TO CONSERVE ENERGY IN BUILDING APPLICATIONS

An experimental laboratory study has been conducted to measure the thermal performance of reflective insulation systems by the guarded hot box method. The goals of the study were to develop test and evaluation protocols, to measure and analyze thermal performance data on a selected number of idealized and commercial systems containing reflective airspaces, and to produce a consumer-oriented handbook pertaining to reflective insulation for building and commercial applications.

The ASTM C 236 Guarded Hot Box test procedure was modified and used to measure the thermal resistance of 17 different test panels. The test panel results were treated to extract the cavity thermal resistance. The cavity thermal resistance results were compared to predicted values based on data presented in the ASHRAE Handbook of Fundamentals. Table $i$ includes a summary description of the 17 test panels, the test conditions, and the guarded hot box results.

The steady-state thermal resistance tests on 17 different test panels included a large number of important test parameters. Table $i$ details these parameters and the ranges studied: heat flow direction (horizontal, up, and down), number of airspaces comprising the cavity $(1,2$, and 4), airspace effective emittance $(0.03,0.05)$, airspace aspect ratio $(0.24$ to 56$)$, airspace mean temperature ( 30 to $100 \mathrm{~F})$ and temperature difference (2.5 to 50F), framing 
TABLE $i$

SUMmaRY OESCRIPTION OF SEVENTEEN TEST DANELS, CONDITIONS, AND RESULTS FOR TME GUAROED HOT BOX STUOY

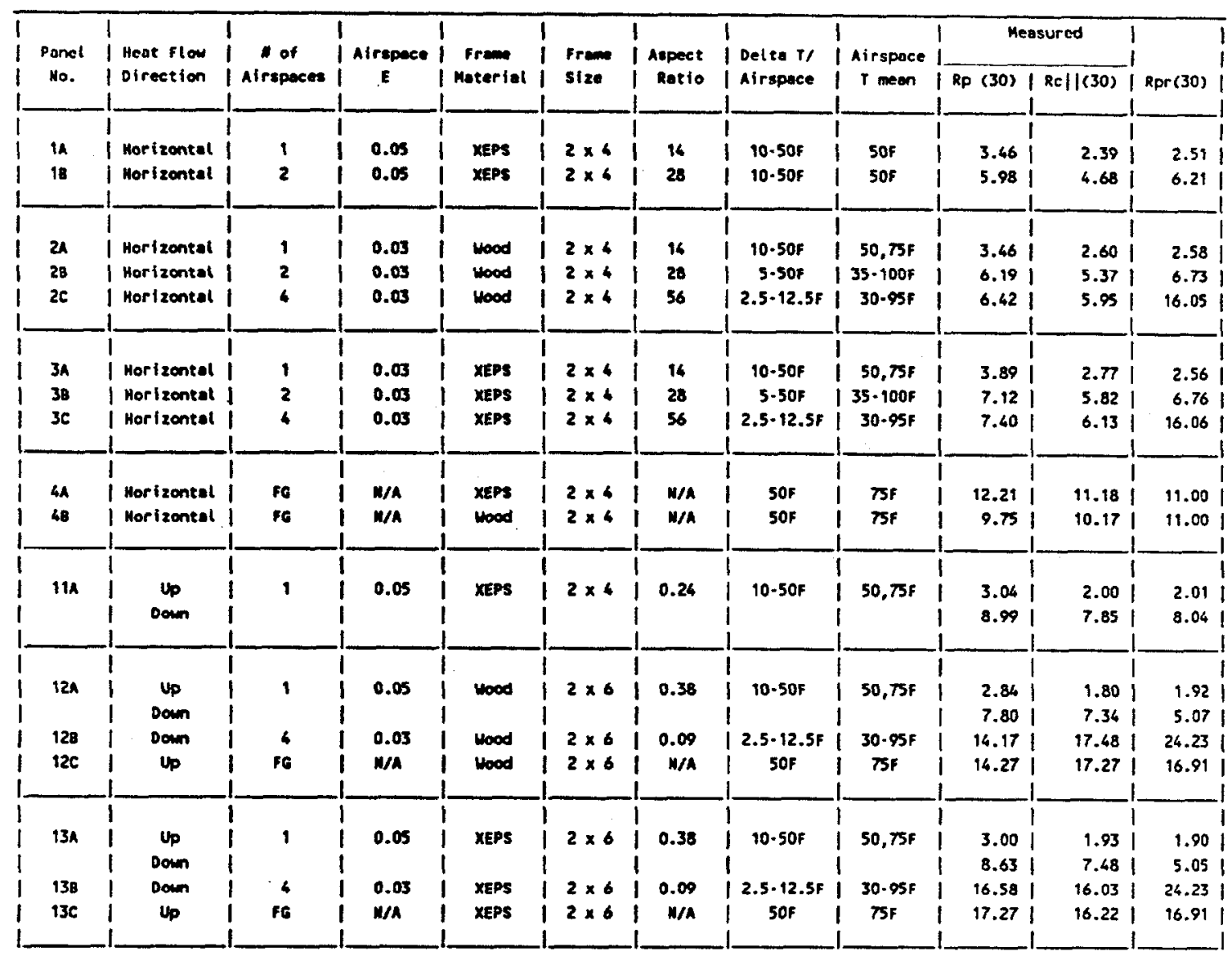


material (XEPS and wood) and framing material size (2x4, 2x6). Tests were performed on similar constructions insulated with mass insulation.

The test panel thermal resistance results were fitted as a function of temperature difference. To compare results from different test panels, these curve-fit coefficients were used to determine the panel thermal resistance with a temperature difference of $30 F, R_{p}(30)$. The test panel thermal resistance values include the effect of the framing material and were between 3.0 and $9.0 \mathrm{hr} \mathrm{ft}^{2} \mathrm{~F} / \mathrm{Btu}$ for airspace systems constructed with $2 \times 4$ framing members and between 2.8 and $16.6 \mathrm{hr} \mathrm{ft}^{2} \mathrm{~F} / \mathrm{Btu}$ for airspace systems constructed with $2 \times 6$ framing members. For test panels constructed with mass insulation, the test panel thermal resistances for systems constructed with $2 \times 4$ and $2 \times 6$ framing members ranged from 9.8 to 12.2 and 14.3 to $17.3 \mathrm{hr} \mathrm{ft}^{2}$ F/Btu respectively.

Two one-dimensional calculation techniques (ASHRAE and proposed ASTM) have been employed to determine the cavity thermal resistance from the measured test panel results. The cavity thermal resistance results were also fitted as a function of temperature difference and comparisons of results from different test panels are made utilizing these curve-fit coefficients calculated for a temperature difference of $30 F, R_{c}(30)$. The cavity thermal resistance values exclude the effect of the framing members. The $R_{C}(30)$ values derived from the test panels constructed with $2 \times 4$ framing members ranged from 2.0 to $7.9 \mathrm{hr} \mathrm{ft}^{2} \mathrm{~F} / \mathrm{Btu}$; for test panels constructed with $2 \times 6$ framing members, the $R_{C}(30)$ values ranged from 1.8 to $17.5 \mathrm{hr} \mathrm{ft}^{2} \mathrm{~F} / \mathrm{Btu}$. For test panels constructed with mass insulation, the $R_{c}(30)$ values 
for systems constructed with $2 \times 4$ and $2 \times 6$ framing members ranged from 10.2 to 11.2 and 16.2 to $17.3 \mathrm{hr} \mathrm{ft}^{2} \mathrm{~F} / \mathrm{Btu}$ respectively.

Where possible, the measured cavity thermal resistance is compared with literature data which is commonly employed to calculate the thermal resistance of reflective airspace assemblies, $R_{p r}(30)$. This comparison was made to ascertain the validity of calculating the thermal resistance of reflective insulations based on literature data. The $R_{p r}(30)$ values calculated for test panels constructed with $2 \times 4$ framing members ranged from 2.0 to $16.1 \mathrm{hr} \mathrm{ft}^{2} \mathrm{~F} / \mathrm{Btu}$; for test panels constructed with $2 \times 6$ framing members, the $R_{p r}(30)$ values ranged from 1.9 to $24.2 \mathrm{hr} \mathrm{ft}^{2} \mathrm{~F} / \mathrm{Btu}$. For test panels constructed with mass insulation, the $\mathrm{R}_{\mathrm{pr}}(30)$ values were determined by direct measurement of the mass insulation by ASTM C 518. For systems constructed with $2 \times 4$ and $2 \times 6$ framing members, the $R_{p r}(30)$ values were 11.0 and $16.9 \mathrm{hr} \mathrm{ft}^{2} \mathrm{~F} / \mathrm{Btu}$ respectively.

The major accomplishments of this study are stated below.

1. The necessary modifications to standard ASTM hot box methods for testing reflective insulations and extracting the cavity thermal resistance from the test panel result have been developed. See section 8 .

2. The ASTM guarded hot box method can accurately measure systems with large internal convective heat transfer components, similar to those present in reflective insulations. The maximum metering area perimeter to guard energy exchange was 5.4 percent but averaged less than 0.1 percent for the experiments performed. See section 10 . 
3. The test panel acceptance criteria in the proposed ASTM material specification for reflective insulations has been verified through the performance of four experiments on test panels filled with mass insulation. Comparison of the directly measured $R$-Values to the extracted cavity $R$-Values indicate agreement in the range of 2 to 9 percent. See Section 12.1 .

4. The impact of mean temperature and temperature difference on the thermal resistance of airspaces and test panels containing airspaces was quantified. For single airspace systems, an average decrease in thermal resistance of 0.2 percent per degree $F$ increase in mean temperature was measured. A five-fold increase in temperature difference decreased the test panel $R$-Value by an average of 23 percent. See sections $11.2,11.3,11.4$, and 11.5 .

5. The effect of the number of airspaces and their effective emittance on the thermal performance of a test panel and its cavity have been measured. The average cavity thermal resistances for 1-, 2-, and 4-airspace cavities were $4.0,5.3,11.4 \mathrm{hr} \mathrm{ft}^{2} \mathrm{~F} /$ Btu. See section 12.6. However, when comparing a single series of three test panels whose only difference is the number of airspaces comprising the cavity, the 2- and 4-airspace test panels were only 1.8 and 1.9 times more thermally resistive than the 1-airspace test panel. See section 11.3. A reduction in the airspace effective emittance from 0.05 to 0.03 increased the test panel thermal resistance of a 1- and 2-airspace test panel by 0.4 and $1.1 \mathrm{hr} \mathrm{ft}^{2} \mathrm{~F} / \mathrm{Btu}$, respectively. See section 11.2 .

6. The impact of heat flow direction and the thermal resistance of the stud or framing material on the cavity and 
test panel thermal resistance has been determined. The effect of the stud material on the test panel thermal resistance was determined by comparing a selected set of panels that were identical except for the stud material used in their construction. An average increase in test panel RValues of approximately 15 percent was measured when replacing wood studs with XEPS studs. The average cavity thermal resistance for heat flow up, down, and horizontal was 1.9, 11.2, and $4.5 \mathrm{hr} \mathrm{ft}^{2} \mathrm{~F} / \mathrm{Btu}$, respectively. See Sections 11.8 and 12.6 .

7. The two calculation methods used in this study for determining the cavity thermal resistance agree to better than 8 percent with the agreement improving as the cavity thermal resistance decreases. See Section 12:

8. Accurate data on the building materials used to construct test panels is imperative for the calculation of the cavity thermal resistance. Differences of up to 9 percent between measured and handbook material $R$-Values were noted. See sections 6 and 7 .

9. A consumer-oriented handbook pertaining to the use, installation, and performance of reflective insulations has been written. See Section 14 and Appendix $c$.

10. The literature data for single airspaces has been verified and the utilization of .this data to calculate multiple airspace cavities significantly overestimates their thermal resistance. Data on one-airspace cavities gathered this study agrees with the literature to better than 5 percent. However, the predicted thermal performance of twoand four-airspace systems were significantly higher (19 and 
48 percent, respectively) than measured results. See section 13.3 .

This experimental study has identified a number of issues that require additional investigation to further the understanding of the thermal performance of reflective airspaces and insulation materials. Refer to section 18 for a more comprehensive listing and discussion of this subject.

1. Expansion of the literature data for airspaces with depths exceeding $31 / 2$ inches is required. The primary use of reflective insulations are in systems that exceed this thickness.

2. Expansion the existing data base to cover the entire range of reflective insulation materials, including cavities with up to 9 airspaces, is needed.

3. Changes to the present government regulations regarding labelling of reflective insulation materials should be considered. These modifications should address the modifications to the test methods discussed in this report and allow the manufacturer to report $R$-Values for the cavity or material instead of for the system.

4. Extension of the data base to cover the temperature range typical for southern climates where the majority of reflective insulation materials are used in the U.S. is required.

5. The effect of aspect ratio on the thermal performance of reflective insulations needs to be determined to generalize the existing data base through modelling. 
6. A better understanding of the mechanisms of heat transfer in multi-airspace cavities and systems is necessary to understand why these cavities do not thermally perform as well as single airspace systems. This information could lead to the development of better reflective insulation products. 
TABLE OF CONTENTS

Section

Page

FOREWORD

EXECUTIVE SUMMARY

iii

TABLE OF CONTENTS

$x i$

LIST OF TABLES

xv

LIST OF FIGURES

xix

ABSTRACT

xxiii

1 INTRODUCTION

1

2 SCOPE AND OBJECTIVES 3

3 DETAILS OF THE TEST PANELS 5

4 THE TEST MATRIX 13

4.1 IDEALIZED PANELS: XEPS STUDS, $E=0.05$, 1 AND 2 AIRSPACES, HORIZONTAL AND VERTICAL HEAT FLOW

4.2 IDEALIZED AND COMMERCIAL PANELS: WOOD STUDS, NUMBER OF AIRSPACES, ASPECT RATIO, HORIZONTAL AND VERTICAL HEAT FLOW

4.3 XEPS VERSUS WOOD STUDS

4.4 TEST PANELS WITH MASS INSULATION

5 MATERIAL PROPERTIES OF TEST PANEL COMPONENTS

6 TEST PANEL COMPONENT THERMAL RESISTANCE TEST PROCEDURE

8 TEST PANEL TEMPERATURE INSTRUMENTATION

9 TEST PANEL THERMAL RESISTANCE TEST PROCEDURE 
TABLE OF CONTENTS (Continued)

Section

Page

11 TEST PANEL RESULTS

70

11.1 PANELS WITH MASS INSULATION -

75

STUD EFFECT

11.2 HORIZONTAL HEAT FLOW, XEPS STUDS:

76

NUMBER OF AIRSPACES, EMITTANCE, TEMPERATURE DIFFERENCE

11.3 HORIZONTAL HEAT FLOW, WOOD STUDS: NUMBER OF AIRSPACES, EMITTANCE, TEMPERATURE DIFFERENCE

11.4 VERTICAL HEAT FLOW, ASPECT RATIO, XEPS AND WOOD STUDS

11.5 SINGLE AIRSPACE SYSTEMS

11.5.1 SINGLE AIRSPACE SYSTEMS, EFFECT OF MEAN TEMPERATURE

11.5.2 SINGLE AIRSPACE SYSTEMS, EFFECT OF HEAT FLOW DIRECTION

11.6 TWO-AIRSPACE SYSTEMS

11.7 FOUR-AIRSPACE SYSTEMS

11.8 EFFECT OF STUD MATERIAL

12 DETERMINATION OF THE CAVITY THERMAL RESISTANCE

12.1 CAVITIES FIILED WITH MASS INSULATION 106

12.2 HORIZONTAL HEAT FLOW * XEPS STUDS 111

12.3 HORIZONTAL HEAT FLOW, WOOD STUDS 113

12.4 VERTICAL HEAT FLOW, XEPS AND WOOD 116 STUDS

121

12.5 STUD HEAT FLUX

12.6 EFFECTS OF HEAT FLOW DIRECTION AND 124 
TABLE OF CONTENTS (Continued)

Section

Page

13 CAVITY THERMAL RESISTANCE PREDICTION

13.1 EFFECT OF TEMPERATURE DIFFERENCE

138

13.2 EFFECT OF HEAT FLOW DIRECTION ON

139

13.3 EFFECT OF NUMBER OF AIRSPACES ON CAVITY THERMAL RESISTANCE

13.4 EFFECT OF FRAMING MATERIAL ON CAVITY THERMAL RESISTANCE

14 HANDBOOK ON REFLECTIVE INSULATIONS FOR RESIDENTIAL AND COMMERCIAL USES

15 THE ADVISORY PANEL

149

16 RECOMMENDED TEST PROTOCOL FOR REFLECTIVE INSULATIONS

16.1 THE TEST PANEL AND INSTRUMENTATION 153

16.2 THE TEST PROCEDURE AND DATA ANALYSIS 155

17 CONCLUSIONS 156

17.1 THE EXPERIMENTAL PROCEDURE AND THE 156 TEST PANEL RESULTS

17.2 DETERMINATION OF THE CAVITY THERMAL 158 RESISTANCE

17.3 COMPARISON OF THE MEASURED AND PRE- 160 DICTED CAVITY THERMAL RESISTANCE

18 RECOMMENDATIONS 161

18.1 THE EXPERIMENTAL PROCEDURE AND THE 162 TEST PANEL RESULTS

18.2 DETERMINATION OF THE CAVITY THERMAL 163 RESISTANCE 
TABLE OF CONTENTS (Continued)

Section

18.3 COMPARISON OF THE MEASURED AND PREDICTED CAVITY THERMAL RESISTANCE

Page

164

19 ACKNOWLEDGEMENTS 165

$\begin{array}{ll}20 & \text { REFERENCES } \\ & 166\end{array}$

Appendix

A PROPOSED STANDARD SPECIFICATION FOR 169 "REFLECTIVE INSULATION FOR BUILDING APPLICATIONS"

$\begin{array}{ll}\text { B EMITTANCE TEST REPORTS } & 181\end{array}$

C REFLECTIVE INSUIATION HANDBOOK 187

D ADVISORY PANEL AGENDAS, MEETING MINUTES, 219 AND BALLOTING 


\section{IIST OF TABLES}

Table

Page

i SUMMARY DESCRIPTION OF SEVENTEEN TEST

iv

PANELS, CONDITIONS, AND RESULTS FOR

THE GUARDED HOT BOX STUDY

1 SUMMARY DESCRIPTION OF TEST PANELS AND

6 CONDITIONS FOR THE GUARDED HOT BOX STUDY

PANELS - PANEL NO. IA

3 CONDITIONS FOR HORIZONTAL HEAT FLOW TEST

PANELS - PANEL NO. 1B

4 CONDITIONS FOR HORIZONTAL HEAT FLOW TEST

PANELS - PANEL NO. 2A

5 CONDITIONS FOR HORIZONTAL HEAT FLOW TEST

PANELS - PANEL NO. $2 \mathrm{~B}$

PANELS - PANEL NO. 2C

7 CONDITIONS FOR HORIZONTAL HEAT FLOW TEST PANELS - PANEL NO. 3A

8 CONDITIONS FOR HORIZONTAL HEAT FLOW TEST PANELS - PANEL NO. 3B

9 CONDITIONS FOR HORIZONTAL HEAT FLOW TEST

PANELS - PANEL NO. 3C

10 CONDITIONS FOR HORIZONTAL HEAT FLOW TEST PANELS - PANEL NO. 4A

11 CONDITIONS FOR HORIZONTAL HEAT FLOW TEST PANELS - PANEL NO. $4 \mathrm{~B}$

12 CONDITIONS FOR VERTICAL HEAT FLOW TEST

PANELS - PANEL NO. $11 \mathrm{~A}$

13 CONDITIONS FOR VERTICAL HEAT FLOW TEST

PANELS - PANEL NO. 12A

14 CONDITIONS FOR VERTICAL HEAT FLOW TEST PANELS - PANEL NO. 12B 
LIST OF TABLES (Continued)

Table

Page

15

CONDITIONS FOR VERTICAL HEAT FLOW TEST

PANELS - PANEL NO. $12 \mathrm{C}$

CONDITIONS FOR VERTICAL HEAT FLOW TEST

PANELS - PANEL NO. 13A

CONDITIONS FOR VERTICAL HEAT FLOW TEST

PANELS - PANEL NO. 13B

18 CONDITIONS FOR VERTICAL HEAT FLOW TEST

PANELS - PANEL NO. 13C

19 PURPOSES FOR THE INCLUSION OF TEST PANELS

IN THE GUARDED HOT BOX STUDY

20 THE APPARENT THERMAL CONDUCTIVITY AND THERMAL RESISTANCE OF ELEVEN SPECIMENS

OF BUILDING MATERIALS USED TO CONSTRUCT TEST PANELS

21 THE EMITTANCE OF NINE SPECIMENS OF BUILDING MATERIALS USED TO CONSTRUCT TEST PANELS

THE TEMPERATURES ACROSS THE CONVECTIVE BLOCKS

AND METERING AREA PERIMETER FRAMING MEMBERS

AND THE ASSOCIATED ENERGY EXCHANGES BETWEEN

THE METERING AND GUARD AREAS

23 THE EXPERIMENTAL CONDITIONS AND THE MEASURED THERMAL RESISTANCE OF SEVENTEEN TEST PANELS CONTAINING REFLECTIVE OR MASS INSULATION MATERIALS

24 THE FIT COEFFICIENTS USED TO DESCRIBE THE TEST PANEL THERMAL RESISTANCE AS A FUNCTION OF TEST PANEL TEMPERATURE DIFFERENCE 
Table

Page

26 THE FIT COEFFICIENTS USED TO DESCRIBE THE CAVITY THERMAL RESISTANCE DETERMINED BY THE R(||) METHOD AS A FUNCTION OF CAVITY TEMPERATURE DIFFERENCE

THE FIT COEFFICIENTS USED TO DESCRIBE THE CAVITY THERMAL RESISTANCE DETERMINED BY THE $R$ (ISO) METHOD AS A FUNCTION OF CAVITY TEMPERATURE DIFFERENCE

THE SURFACE EMITTANCE, EFFECTIVE CAVITY EMITTANCE, AND THE PREDICTED THERMAL RESISTANCE OF SEVENTEEN TEST CAVITIES CONTAINING REFLECTIVE OR MASS INSULATION MATERIALS

THE FIT COEFFICIENTS USED TO DESCRIBE THE PREDICTED CAVITY THERMAL RESISTANCE AS A FUNCTION OF CAVITY TEMPERATURE DIFFERENCE

REFLECTIVE INSULATIONS ADVISORY PANEL MEMBERSHIP 


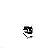




\section{LIST OF FIGURES}

\section{Figure}

Page

1 HORIZONTAL HEAT FLOW TEST PANEL STUD

IAYOUT

2 VERTICAL HEAT FLOW TEST PANEL STUD LAY-

8 OUT

3 TEST PANEL CAVITY CONFIGURATIONS

4 LOCATION OF CONVECTIVE BLOCKS IN HORIZONTAL HEAT FLOW TEST PANEL

5 CROSS-SECTIONAL VIEW OF 24 INCH SQUARE HEAT FLOW METER APPARATUS

6 SCHEMATIC OF 12 INCH SQUARE HEAT FLOW METER THERMAL CONDUCTIVITY INSTRUMENT

7 HORIZONTAL HEAT FLOW TEST PANEL SURFACE AND AIR T/C LAYOUT AIR T/C IAYYOUT

9 SINGLE AIRSPACE HORIZONTAL HEAT FLOW TEST PANEL INTERNAL T/C LAYOUT

10 TWO AIRSPACE HORIZONTAL HEAT FLOW TEST PANEL INTERNAL T/C LAYOUT

11 FOUR AIRSPACE HORIZONTAL HEAT FLOW TEST PANEL INTERNAL T/C LAYOUT

12 SINGLE AIRSPACE VERTICAL HEAT FLOW TEST PANEL INTERNAL T/C LAYOUT

13 FOUR AIRSPACE VERTICAL HEAT FLOW TEST PANEL INTERNAL T/C LAYOUT

14 SCHEMATIC OF GUARDED HOT BOX FACILITY

15 THE TEST PANEL THERMAL RESISTANCE AS A FUNCTION OF TEST PANEL TEMPERATURE DIFFERENCE FOR FIVE TEST PANELS CONSTRUCTED WITH XEPS STUDS AND TESTED WITH HORIZONTAL HEAT FLOW 
IIST OF FIGURES (Continued)

Figure

Page

16 THE TEST PANEL THERMAL RESISTANCE AS A

FUNCTION OF TEST PANEL TEMPERATURE DIFFERENCE FOR THREE TEST PANELS CONSTRUCTED

WITH WOOD STUDS AND TESTED WITH HORIZONTAL HEAT FLOW

17 THE TEST PANEL THERMAL RESISTANCE AS A FUNCTION OF TEST PANEL TEMPERATURE DIFFERENCE FOR THREE TEST PANELS CONSTRUCTED WITH XEPS STUDS AND TESTED WITH VERTICAL HEAT FLOW (UP AND DOWN)

18 THE TEST PANEL THERMAL RESISTANCE AS A FUNCTION OF TEST PANEL TEMPERATURE DIFFERENCE FOR THREE TEST PANELS CONSTRUCTED WITH WOOD STUDS AND TESTED WITH VERTICAL HEAT FLOW (UP AND DOWN)

19 THE TEST PANEL THERMAL RESISTANCE AS A FUNCTION OF TEST PANEI TEMPERATURE DIFFERENCE AND HEAT FLOW DIRECTION FOR TEST PANELS CONTAINING A SINGLE 3.5 INCH DEEP REFLECTIVE AIRSPACE WITH AN EFFECTIVE EMITTANCE OF 0.05

20 THE EFFECT OF STUD MATERIALS ON THE TEST PANEL THERMAL RESISTANCE OF TEST PANEL CONTAINING THREE DIFFERENT CAVITY CONFIGURATIONS

21 THE MEASURED CAVITY THERMAL RESISTANCE OF FIVE CAVITIES AS A FUNCTION OF CAVITY TEMPERATURE DIFFERENCE DETERMINED BY THE R(||) METHOD FROM EXPERIMENTS ON TEST PANELS WITH XEPS FRAMING MEMBERS AND TESTED WITH HORIZONTAL HEAT FLOW

22 THE MEASURED CAVITY THERMAL RESISTANCE OF THREE CAVITIES AS A FUNCTION OF CAVITY TEMPERATURE DIFFERENCE DETERMINED BY THE $R(||)$ METHOD FROM EXPERIMENTS ON TEST PANELS WITH WOOD FRAMING MEMBERS AND TESTED WITH HORIZONTAL HEAT FLOW 
LIST OF FIGURES (Continued)

\section{Figure}

Page

23 THE MEASURED CAVITY THERMAL RESISTANCE OF FIVE CAVITIES AS A FUNCTION OF CAVITY TEMPERATURE DIFFERENCE DETERMINED BY THE $R(\mid 1)$ METHOD FROM EXPERIMENTS ON TEST PANELS WITH XEPS FRAMING MEMBERS AND TESTED WITH VERTICAL HEAT FLOW (UP AND DOWN)

24 THE MEASURED CAVITY THERMAL RESISTANCE OF THREE CAVITIES AS A FUNCTION OF CAVITY TEMPERATURE DIFFERENCE DETERMINED BY THE R(II) METHOD FROM EXPERIMENTS ON TEST PANELS WITH WOOD FRAMING MEMBERS AND TESTED WITH VERTICAL HEAT FLOW (UP AND DOWN)

25 THE HEAT FLOW THROUGH THE STUD EXPRESSED AS A PERCENTAGE OF THE TOTAL HEAT FLOW FOR THE TEST PANEL THERMAL RESISTANCE EXPERIMENTS AS A FUNCTION OF HEAT FLOW DIRECTION

26 THE HEAT FLOW THROUGH THE STUD EXPRESSED AS A PERCENTAGE OF THE TOTAL HEAT FLOW FOR THE TEST PANEL THERMAL RESISTANCE EXPERIMENTS AS A FUNCTION OF THE NUMBER OF AIRSPACES COMPRISING THE CAVITY AND THE STUD OR FRAMING MATERIAL

27 THE AVERAGE CAVITY THERMAL RESISTANCE AS A FUNCTION OF HEAT FLOW DIRECTION CALCULATED BY THE PARALLEL PATH AND ISOTHERMAL PLANES METHODS

28 THE AVERAGE CAVITY THERMAL RESISTANCE AS A FUNCTION OF THE NUMBER OF AIRSPACES COMPRISING THE CAVITY CALCULATED BY THE PARALLEL PATH AND ISOTHERMAL PLANES METHODS

29 THE PERCENT DIFFERENCE BETWEEN THE AVERAGE PREDICTED AND MEASURED CAVITY THERMAL RESISTANCES FOR 1-AIRSPACE CAVITIES AS A FUNCTION OF THE CAVITY TEMPERATURE DIFFERENCE CALCULATED BY THE PARALLEL PATH AND ISOTHERMAL PLANES METHODS 
LIST OF FIGURES (Continued)

Figure

Page

30 THE PERCENT DIFFERENCE BETWEEN THE AVERAGE PREDICTED AND MEASURED CAVITY THERMAL RESISTANCES AS A FUNCTION OF THE HEAT FLOW DIRECTION CALCULATED BY THE PARALLEL PATH AND ISOTHERMAL PLANES METHODS

31 THE PERCENT DIFFERENCE BETWEEN THE AVERAGE PREDICTED AND MEASURED CAVITY THERMAL RESISTANCES AS A FUNCTION OF THE NUMBER OF AIRSPACES COMPRISING THE CAVITY CALCULATED BY THE PARALLEL PATH AND ISOTHERMAL PLANES METHODS

32 THE PERCENT DIFFERENCE BETWEEN THE AVERAGE PREDICTED AND MEASURED CAVITY THERMAL RESISTANCES AS A FUNCTION OF THE FRAMING MATERIAL AND THE NUMBER OF AIRSPACES COMPRISING THE CAVITY CALCULATED BY THE PARALIEL PATH METHOD 


\section{ABSTRACT}

RESEARCH AND DEVELOPMENT DATA TO DEFINE THE THERMAL PERFORMANCE OF REFLECTIVE MATERIALS USED TO CONSERVE ENERGY IN BUILDING APPIICATIONS

A comprehensive experimental laboratory study has been conducted on the thermal performance of reflective insulation systems. The goal of this study was to develop test and evaluation protocols and to obtain thermal performance data on a selected number of idealized and commercial systems containing reflective airspaces for use in analytical models.

Steady-state thermal resistance has been measured on 17 different test panels using two guarded hot boxes. Additional instrumentation was installed to measure the temperature of critical locations inside the test panels. The test parameters which have been studied are heat flow direction (horizontal, up, and down), number of airspaces comprising the cavity, airspace effective emittance, airspace aspect ratio, airspace mean temperature and temperature difference, and the thermal resistance of the stud material. Tests have also been performed on similar constructions with mass insulation.

Two one-dimensional calculation techniques (ASHRAE and proposed ASTM) have been employed to determine the cavity thermal resistance from the measured test panel results. The measured cavity thermal resistance is compared with literature data which is commonly employed to calculate the thermal resistance of reflective airspace assemblies.

A consumer-oriented handbook pertaining to reflective insulation for building and commercial applications has also been prepared as part of this study. 
*

$*$

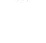


RESEARCH AND DEVELOPMENT DATA TO DEFINE THE THERMAL PERFORMANCE OF REFLECTIVE MATERIALS USED TO CONSERVE ENERGY IN BUILDING APPLICATIONS

\section{INTRODUCTION}

A reflective insulation is defined as a thermal insulation consisting of one or more low emittance surfaces bounding one or more enclosed airspaces. The term "enclosed" is critical in this definition since the major distinction between reflective insulations and radiant barriers is the airspace condition. A radiant barrier system is defined as a building construction that consists of a low emittance surface bounded by an open airspace. These insulations are available in a variety of forms from single thickness foils bonded to backing materials to multilayered structures which create a series of parallel airspaces when installed in a conventional stud cavity. Their thermal performance depends on the reduction of the radiative heat transfer across these airspaces while minimizing convective and conductive heat transfer through the airspace and the conductive heat transfer through the insulation structure (flanges and foils).

Reflective insulations alter the systems in which they are installed by modifying the surface emittance of the airspace(s) and/or the number of airspaces within the system; they therefore must be tested as a system. The supporting structure (studs, joists) of the system is required for their application and this structure invariably acts as a parallel path for heat transfer. The measured system thermal performance must then be treated such that the reflective insulation "material" thermal resistance can 
be determined to allow for the direct comparison of this product to other types of thermal insulation materials.

Unlike mass insulation, the thermal resistance of reflective insulation is not a material property which can be defined as the ratio of its thickness and apparent thermal conductivity. Since the total heat transfer through a reflective insulation can have a significant convective component, factors such as heat flow direction and temperature difference have a major impact on its thermal resistance.

A comprehensive assessment was undertaken for the Department of Energy[1] on the subject of reflective insulations. This assessment discussed the controversial issues relating to the thermal performance of these systems. These issues included questions regarding applicability of current data on airspaces bounded by reflective surfaces $[2,3,4]$, appropriate test methods, specimen configurations and analytical models used to derive results $[4,5,6,7,8]$, and the resultant disparities in thermal performance data. Some recommendations were made in this assessment on how these issues could be resolved. The major short-term recommendation was that a comprehensive experimental laboratory study, supported by well validated heat transfer models, be undertaken.

As a result, an investigation designed to address some of the issues raised in the assessment was developed and performed by the Thermatest Division of Holometrix through the sponsorship of the Department of Energy Building Thermal Envelope systems and Materials (BTESM) program. 
The objectives of this program were to develop an acceptable test and evaluation protocol, generate an initial data base on some idealized systems, and extend this data base to a limited number of commercial product types such that adequate analytical models to predict thermal performance could be developed and verified.

The program involved the laboratory analysis of thermal resistance on 17 different test panels insulated with reflective or mass insulations. Ninety-eight different experiments on these test panels have been performed at Holometrix, Inc. in accordance with ASTM C 236-87, standard Test Method for "Steady-state Thermal Performance of Building Assemblies by Means of a Guarded Hot Box"[9]. The thermal resistance and emittance of all the materials used to construct the test panels were characterized.

The test panels varied in construction details and cavity insulation material, and were tested with different heat flow directions and temperature conditions. The parameters studied were the number of airspaces in the cavity, the effective emittance of the airspace, the aspect ratio of the airspace, the framing or stud material used in the construction of the test panel, and the heat flow direction.

From the system thermal resistance measurements, two one-dimensional calculation techniques were applied to determine the "material" or cavity thermal resistance. These calculation methods use the material properties and/or internal temperature measurements to deduce cavity thermal performance. one of the calculation procedures used for 
determining "material" thermal performance has been recommended for inclusion in the proposed ASTM standard Specification for "Reflective Insulation for Building Applications"[10]. The latest draft of this standard specification is presented in Appendix $A$.

The calculated cavity thermal resistance data has been compared to predictions based on the measurements of Robinson and Powlitch[2]. The data from this reference is widely accepted and forms the basis for the thermal resistance of airspaces summarized in the ASHRAE Handbook of Fundamentals[4].

The final task of this program was to prepare a booklet for distribution to potential users of reflective insulation such as home builders and weatherization contractors containing information regarding the results of the experimentation, factors affecting the actual thermal performance when installed in buildings, the effects of framing members, and a discussion of installation procedures. Due to the anticipated audience, the emphasis of the booklet was to be practical in nature.

An important feature of this program was establishing a review or advisory panel consisting of individuals from industry, government and, academia. Each member of the panel had some relevant experience in the subject of reflective insulations. The purpose of this panel was to monitor the progress of the program and advise the investigators. Thus, all industry sectors were periodically updated on the status of the program, allowing for the rapid dissemination of data information generated during the course of the program. 


\section{DETAILS OF THE TEST PANELS}

Seventeen test panels were constructed by Holometrix, Inc. and were subsequently tested in a guarded hot box. A summary description of the test panels is presented in Table 1 .

Test panels that were to be analyzed with horizontal heat flow (wall configuration) were approximately dimensioned 94 inches square. These test panels were constructed with $2 \times 4$ studs placed 16 inches on center such that the center of the test panel aligned with the center of the central cavity with three full cavities in the metering area. Test panels that were to be tested with vertical heat flow (floor and ceiling configurations) were 75 by 78 inches with the structural members paralleling the 75 inch dimension. They were constucted such that a stud aligned with the center line of the test panel and two full width cavities were in the metering area. With the exception of Test Panel 11A which was constructed with $2 \times 4$ studs, all of the vertical heat flow test panels were comprised of $2 x$ 6 studs spaced 16 inches on center. The cavities in these panels were oriented such that the center line of the test panel aligned with a stud member.

The perimeter of all the test panels was fabricated with appropriately sized wood studs. Figures 1 and 2 detail the layout of the stud members for the horizontal and vertical heat flow experiments respectively. Schematics of the cavity cross-sections are shown in Figure 3 .

A $1 / 4$ inch thick plywood material was used to sheath both sides of each test panel. The $1 / 4$ inch plywood is an atypical sheathing but was selected to minimize the 
TABLE $\uparrow$

SUMMARY DESCRIPTION OF SEVENTEEN TEST PANELS AND CONDITIONS FOR THE GUARDED HOT BOX STUDY

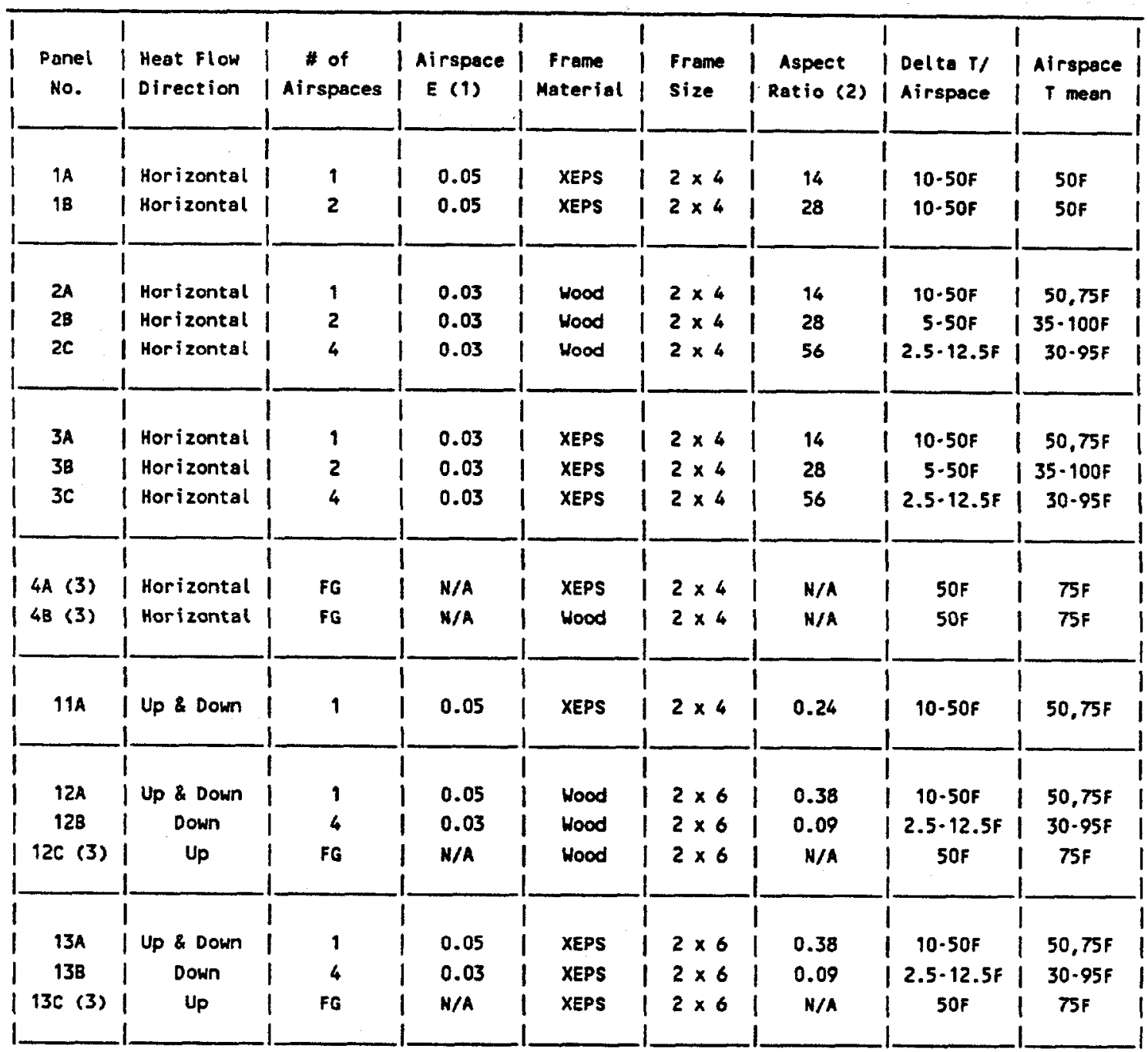

Notes: 1. E is the effective emittance of each airspace in the cavity calculated by $E=1 /[1 / e 1+1 / e 2-1]$ where $e 1$ and $e 2$ are the emittances of the surfaces bounding the airspace.

2. The aspect ratio of the airspace is defined as the ratio of airspace height and the airspace thickness for horizontal heat flow. For vertical hest flow, the aspect ratio is defined as the airspace thickness divided by the airspace width.

3. The cavities of Test panels 4A, 4B, 12C, and $13 \mathrm{C}$ are filled with a fiberglass batt material. 


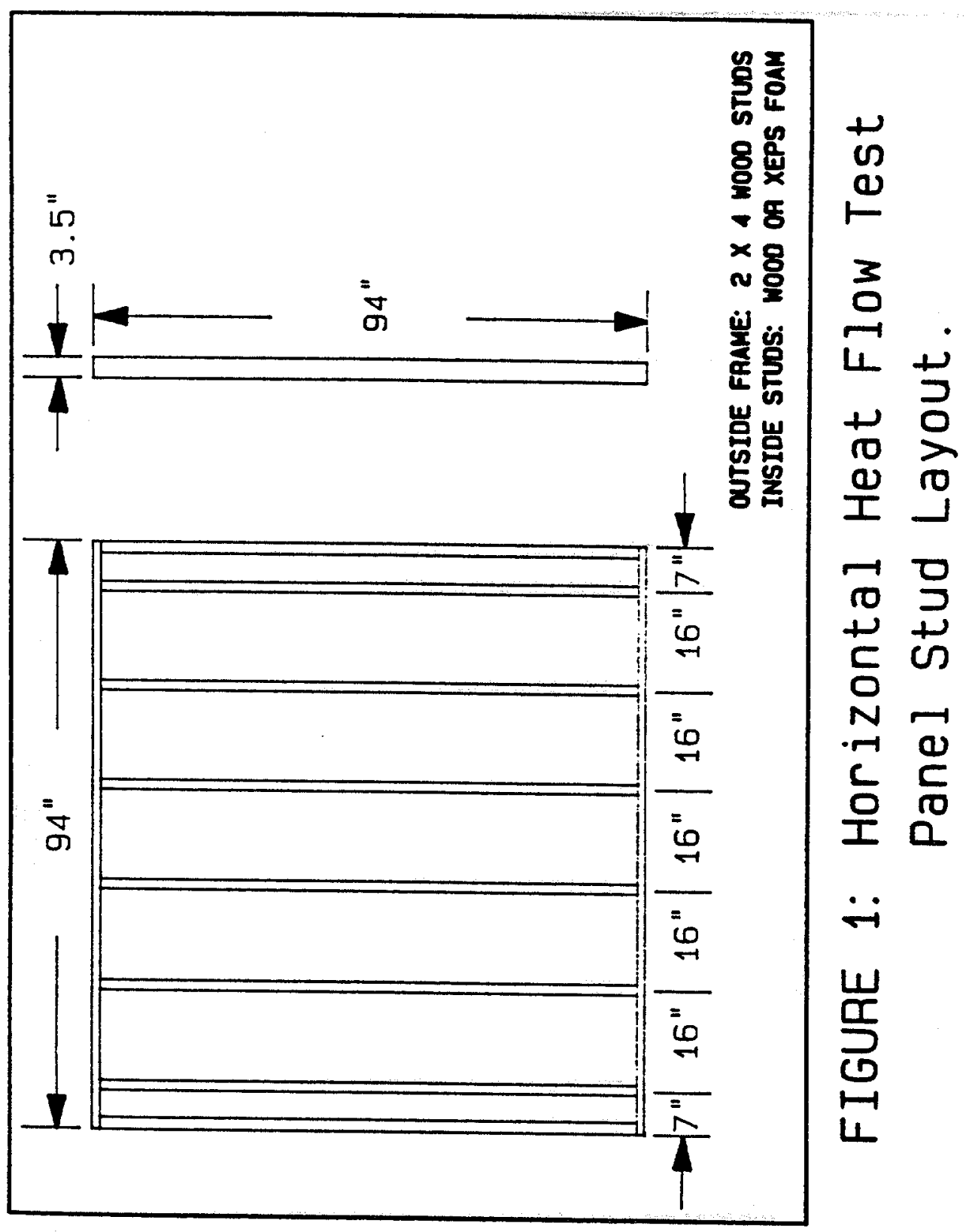




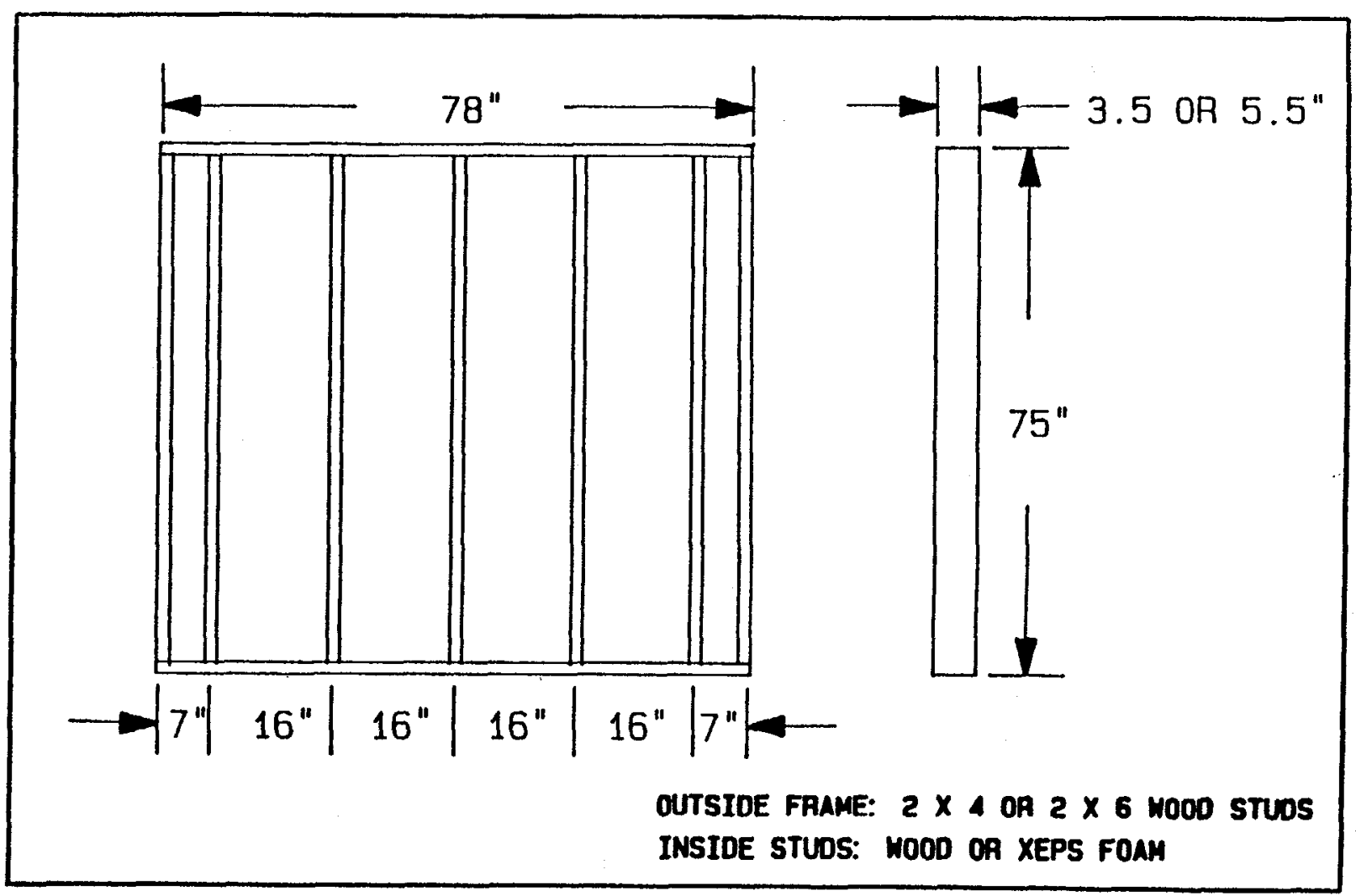

Figure 2: Vertical Heat Flow Test Pãnel Stud Layout 
Test Panels 1A, 11A.

12A, and 13A. $E=0.05$

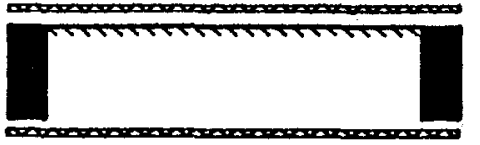

Test Panels $2 B$ and $3 B$

$$
E=0.03
$$

Test Pane 1s 2C, 3C. 12B, and 13B. $E=0.03$

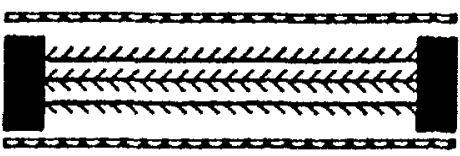

सt

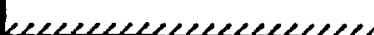

com

Framing Material

$$
1
$$$$
\bigotimes
$$

Mass Insulation$$
\text { Reflective Surface }
$$

Test Panel 1B

$E=0.05$

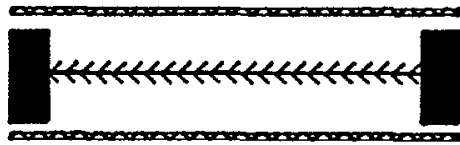

Test Panels 4A, 4B, 12C, and $13 \mathrm{C}$.

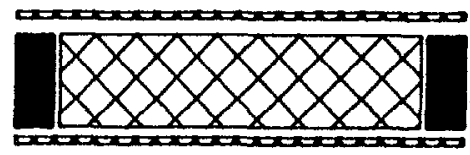

Non-Reflective Surface

\section{Figure 3: Test Panel Cavity Configurations}


additional thermal resistance that typical sheathing adds to the test panel.

Ten panels (1A, 1B, 3A, 3B, 3C, 4A, 11A, 13A, 13B, and 13C) were constructed with extruded polystyrene foam (XEPS) studs. These studs were fabricated by slicing $31 / 2$ or 5 $1 / 2$ inch wide strips from a nominal $11 / 2$ inch thick board and installing them in the test panel such that the predominant heat flow direction in the stud would be along the width of the extruded polystyrene foam board. Seven panels (2A, 2B, 2C, 4B, 12A, 12B, and 12C) were constructed with $2 \times 4$ or $2 \times 6$ kiln-dried eastern spruce balsam fir wood studs.

The plywood sheathing was attached to the wood studs with 1 1/4 inch hardened steel drywall screws located 12 inches on center. To attach the sheathing to the XEPS studs, 1/4 inch diameter nylon threaded rods were installed into holes which were drilled through the sheathings and XEPS studs. These holes were situated 16 inches on center; there were 8 or 6 nylon rods in the metering area for the horizontal and vertical heat flow tests respectively. The sheathing was held in-place by tightening nylon nuts onto each side of the threaded rods, pressing the sheathing onto the framing material.

Single reflective airspaces having an effective emittance of 0.05 were incorporated into Test Panels $1 \mathrm{~A}$, 11A, 12A, and 13A. To create a single reflective airspace having an effective emittance of approximately 0.05, a sheet of 0.010 inch thick single thickness reflective insulation material, supplied by a reflective insulation manufacturer, was adhered to the interior side of the hot side sheathing material. 
A single airspace having an effective emittance of 0.03 was constructed by applying the single thickness reflective insulation material to the interior sides of both sheathings. This type of cavity insulation was installed in Test panels $2 \mathrm{~A}$ and $3 \mathrm{~A}$.

Test Panel $1 \mathrm{~B}$ was insulated with a two-airspace cavity with each airspace having an effective emittance of 0.05 . To construct this cavity insulation system, a sheet of single thickness reflective insulation material with a reflective surface on both sides was installed in the exact center of the cavity thickness. To decrease the effective emittance of each airspace in the two-airspace cavity from 0.05 to 0.03 , both sheathings were laminated with the single thickness reflective insulation material. This cavity insulation system was installed in Test panels $2 \mathrm{~B}$ and $3 \mathrm{~B}$. To hold the central foil in place, the width of the reflective insulation material installed in the center of the cavity was adjusted so that the material could be folded and attached directly to the stud. The width of the attachment flange was 1 inch. In the wood stud test panel, the flanges were stapled to the stud. Staples were applied 12 inches on center. To hold the central foil to the XEPS studs, the flanges were pressed against the stud with a $1 \times$ $1 / 2$ inch fiberglass angle and held in place with $1 / 8$ inch diameter threaded nylon rods and nuts spaced 12 inches on center.

The four-airspace cavities, each having an effective emittance of 0.03 , were created by utilizing a commercial three-layer product supplied by a reflective insulation manufacturer. This insulation system was installed in Test Panels 2C, 3C, 12B, and 13B. The interior layer of this insulation material was foil and the two exterior layers 
were foil laminated to a kraft paper backing material. The foil on the exterior layers was attached to the outside surface. The foil and foil/kraft paper laminates are adhered to cardboard flanges to facilitate installation and create the appropriate layer spacing. This combination of foil and paper backed foil provided one low emittance surface for each airspace. When applied to a $2 \times 4$ stud cavity, the thickness of each airspace in this cavity was approximately $7 / 8$ inches. When incorporated into $a 2 \times 6$ cavity, the two exterior airspaces were $17 / 8$ inches deep while the two interior airspaces were $7 / 8$ inches thick. The application of this product was performed following the manufacturer's instructions. Attachment to the wood and XEPS studs was identical to the methods used on the central foils of the two-airspace cavity systems.

Tests were also performed on test panels insulated with fiberglass batt insulation. Test panels $4 \mathrm{~A}$ and $4 \mathrm{~B}$ were insulated with nominal $R-11$ ( $31 / 2$ inches) unfaced fiberglass blankets, while Test panels $12 \mathrm{C}$ and $13 \mathrm{C}$ were insulated with nominal $R-19$ (6 $1 / 4$ inches) unfaced fiberglass blankets which were acquired from a local retail source. These experiments were performed to verify that the subsequent calculations could accurately deduce the material thermal resistance of the cavity insulation from the system R-Value test.

Whenever a single thickness reflective insulation was laminated to the sheathing, a $1 / 8$ inch wide thermal break was cut into the laminate around the perimeter of the metering area. Appropriately sized convective breaks or stops fabricated from 1 1/2 inch thick XEPS foam were used along the open portion of the metering box perimeter to prevent air exchange between the metering and guard areas of 
the test panel. These convective stops were installed such that they were physically outside of the metering area with one side of the stop aligned with the perimeter of the metering area. Convective stops were also installed in the adjoining guard area cavities in an attempt to replicate the convective loops of the metering area. A thin layer of mass insulation was installed between the convective stops and the cut edges of the foils to guarantee an adequate seal. The location of the convective breaks for a typical horizontal heat flow test panel is shown schematically in Figure 4 .

\section{THE TEST MATRIX}

Forty-eight experiments were performed on the ten different horizontal heat flow test panels and fifty tests were undertaken on the seven vertical heat flow test panels. Targeted test conditions for each individual test panel are detailed in Tables 2 through 18 and Table 19 summarizes the reasons for including each panel in the test matrix. The individual test panels are discussed below.

4.1 IDEALIZED PANELS: XEPS STUDS, $E=0.05,1$ AND 2 AIRSPACES, HORIZONTAL AND VERTICAL HEAT FLOW

Test panels 1A, 1B, and 11A were designed to be identical to configurations analyzed by Robinson and Powlitch[2] except that the framing members were fabricated with a material of high thermal resistance and the cavity width was narrower than Robinson and Powlitch had tested. These test panels contained idealized airspaces; the construction of the airspace(s) was accomplished by carefully attaching layers of a single thickness reflective 


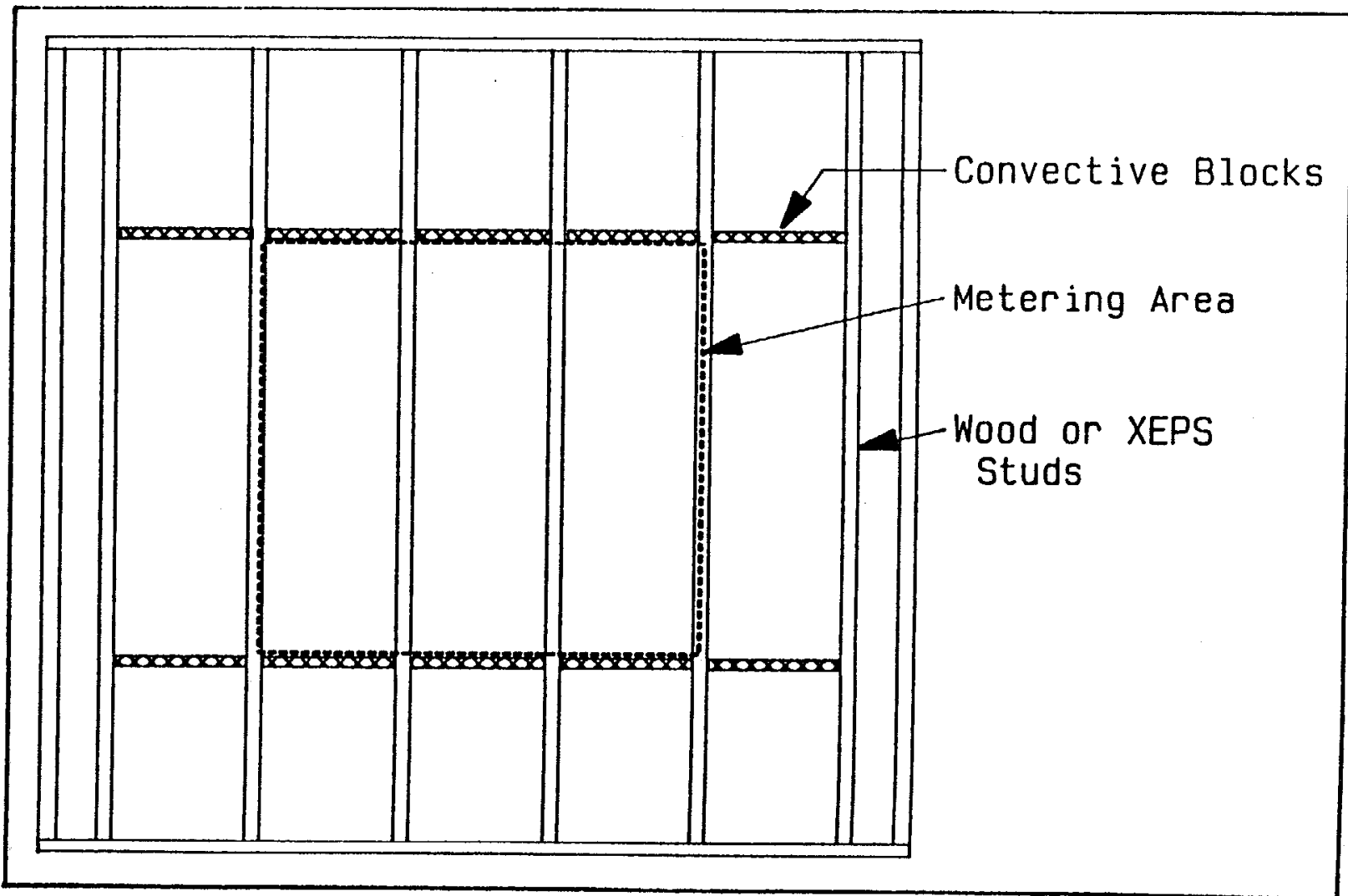

FIGURE 4: Location of Convective Blocks in Horizontal Heat Flow Test Panel. 
TABLE 2

CONDITIONS FOR HORIZONTAL HEAT FLOW TEST PANELS

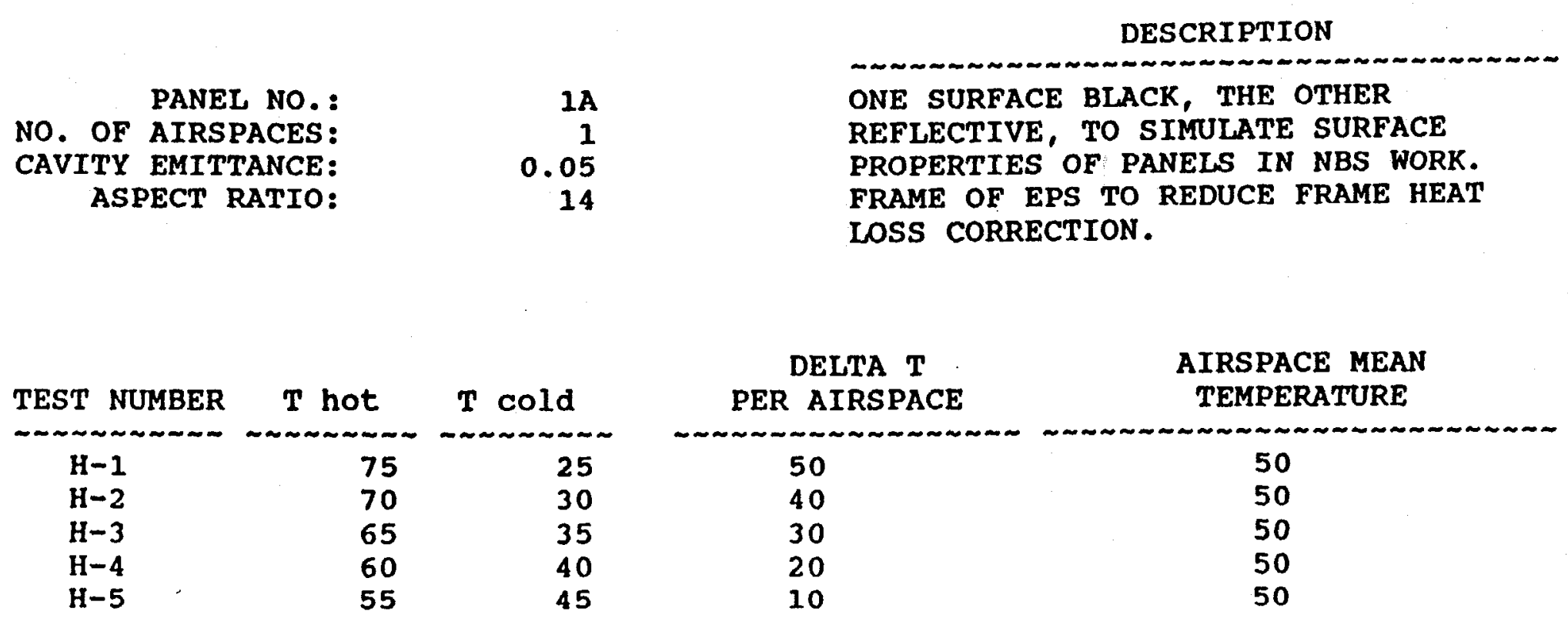

NOTES: (1) TEMPERATURES ARE GIVEN IN DEGREES FAHRENHEIT.

(2) $T$ hot AND $T$ cold ARE THE INTERIOR TEMPERATURES OF THE SHEATHINGS. 
TABLE 3

CONDITIONS FOR HORIZONTAL HEAT FLOW TEST PANELS

DESCRIPTION

$\begin{array}{rrl}\text { PANEL NO.: } & \text { IB } & \text { SINGLE FOIL INSTALLED IN CENTER } \\ \text { NO. OF AIRSPACES: } & 2 & \text { OF } 3 \text { 1/2 INCH CAVITY TO PRODUCE } \\ \text { CAVITY EMITTANCE: } & 0.05 & \text { TWO AIRSPACES WITH SURFACE PROPERTIES } \\ \text { ASPECT RATIO: } & 28 & \text { IDENTICAL TO PANEL 1A. FRAME OF } \\ & & \text { EPS TO REDUCE FRAME HEAT LOSS } \\ & \text { CORRECTION. }\end{array}$

\begin{tabular}{ccc} 
& \multicolumn{2}{c}{ AIRSPACE MEAN } \\
DELTA T & 1 & 2 \\
PER AIRSPACE & 1 & 50 \\
50 & 100 & 50 \\
40 & 90 & 50 \\
30 & 80 & 50 \\
20 & 70 & 50 \\
10 & 60 &
\end{tabular}

NOTES: (1) TEMPERATURES ARE GIVEN IN DEGREES FAHRENHEIT.

(2) $T$ hot AND $T$ cold ARE THE INTERIOR TEMPERATURES OF THE SHEATHINGS. 
TABLE 4

CONDITIONS FOR HORIZONTAL HEAT FLOW TEST PANELS

\begin{tabular}{rrl} 
& & \multicolumn{1}{c}{ DESCRIPTION } \\
PANEL NO.: & $2 A$ & BOTH INTERIOR SURFACES REFLECTIVE. \\
NO. OF AIRSPACES: & 1 & STANDARD STUD WALL WITH WOOD \\
CAVITY EMITTANCE: & 0.03 & FRAME. \\
ASPECT RATIO: & 14 &
\end{tabular}

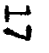

\begin{tabular}{crccc} 
& & & DELTA & AIRSPACE MEAN \\
TEST NUMBER & T hot & T cold & PER AIRSPACE & TEMPERATURE \\
\hline H-11 & 100 & 50 & 50 & 75 \\
H-12 & 95 & 55 & 40 & 75 \\
H-13 & 90 & 60 & 30 & 75 \\
H-14 & 85 & 65 & 20 & 75 \\
H-15 & 80 & 70 & 10 & 50 \\
H-16 & 75 & 25 & 50 &
\end{tabular}

NOTES: (1) TEMPERATURES ARE GIVEN IN DEGREES FAHRENHEIT.

(2) $T$ hot AND $T$ cold ARE THE INTERIOR TEMPERATURES OF THE SHEATHINGS. 
TABLE 5

CONDITIONS FOR HORIZONTAL HEAT FLOW TEST PANELS

$\begin{array}{rrr} & & \text { DESCRIPTION } \\ \text { PANEL NO.: } & 2 B & \text { ALL INTERIOR SURFACES REFLECTIVE. } \\ \text { NO. OF AIRSPACES: } & 2 & \text { STANDARD STUD WALL WITH WOOD FRAME. } \\ \text { CAVITY EMITTANCE: } & 0.03 & \\ \text { ASPECT RATIO: } & 28 & \end{array}$

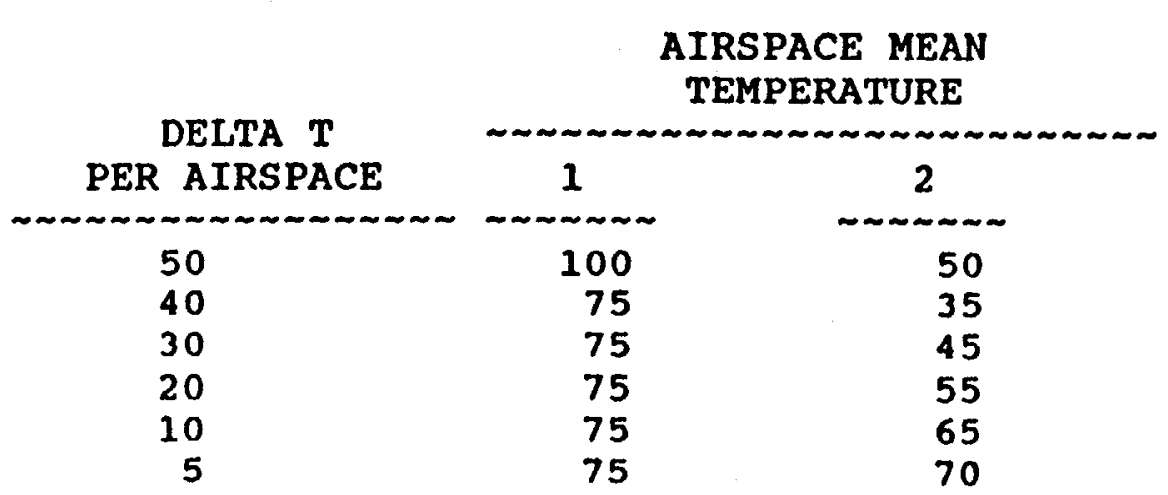

NOTES: (1) TEMPERATURES ARE GIVEN IN DEGREES FAHRENHEIT.

(2) $T$ hot AND $T$ cold ARE THE INTERIOR TEMPERATURES OF THE SHEATHINGS. 
TABLE 6

CONDITIONS FOR HORIZONTAL HEAT FLOW TEST PANELS

$\begin{array}{rrl} & & \\ & & \text { DESCRIPTION } \\ \text { PANEL NO.: } & & \text { COMMERCIAL THREE-FOIL PRODUCT } \\ \text { NO. OF AIRSPACES: } & 2 C & \text { INSTALLED IN STANDARD STUD WALL WITH } \\ \text { CAVITY EMITTANCE: } & 0.03 & \text { WOOD FRAME. ALL AIRSPACES ARE BOUNDED } \\ \text { ASPECT RATIO: } & 56 & \text { BY ONE HIGH EMITTANCE SURFACE AND }\end{array}$

\begin{tabular}{|c|c|c|c|c|c|c|c|}
\hline \multirow{3}{*}{$\begin{array}{l}\text { TEST NUMBR } \\
\sim \sim \sim \sim \sim \sim \sim \sim\end{array}$} & \multirow{2}{*}{ T hot } & \multirow{2}{*}{$T \operatorname{col} d$} & \multirow[b]{2}{*}{ DELTA $T$} & \multicolumn{4}{|c|}{$\begin{array}{l}\text { AIRSPACE MEAN } \\
\text { TEMPERATURE }\end{array}$} \\
\hline & & & & 1 & 2 & 3 & 4 \\
\hline & 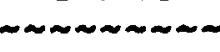 & & 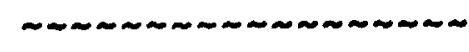 & $\sim \sim \sim \sim$ & $\sim \sim \sim \sim \sim$ & $\sim \infty \sim$ & . $\sim$ \\
\hline $\mathrm{H}-23$ & 100 & 50 & 12.5 & 94 & 81 & 69 & 56 \\
\hline$H-24$ & 95 & 55 & 10 & 90 & 80 & 70 & 60 \\
\hline$H-25$ & 90 & 60 & 7.5 & 86 & 79 & 71 & 64 \\
\hline$H-26$ & 85 & 65 & 5 & 82 & 78 & 72 & 68 \\
\hline$H-27$ & 80 & 70 & 2.5 & 79 & 76 & 74 & 71 \\
\hline$H-28$ & 75 & 25 & 12.5 & 69 & 56 & 44 & 31 \\
\hline
\end{tabular}

NOTES: (1) TEMPERATURES ARE GIVEN IN DEGREES FAHRENHEIT.

(2) $T$ hot AND $T$ cold ARE THE INTERIOR TEMPERATURES OF THE SHEATHINGS. 
TABLE 7

CONDITIONS FOR HORIZONTAL HEAT FLOW TEST PANELS

\begin{tabular}{rrl} 
& & \multicolumn{1}{c}{ DESCRIPTION } \\
PANEL NO.: & $3 A$ & BOTH INTERIOR SURFACES REFLECTIVE. \\
NO. OF AIRSPACES: & 1 & LOW CONDUCTANCE FRAME, SAME \\
CAVITY EMITTANCE: & 0.03 & GEOMETRY AS PANEL 2A. \\
ASPECT RATIO: & 14 &
\end{tabular}

\begin{tabular}{crccc} 
& & & DELTA T & AIRSPACE MEAN \\
TEST NUMBER & T hot & T cold & PER AIRSPACE & TEMPERATURE \\
\hline H-29 & 100 & 50 & 50 & 75 \\
H-30 & 95 & 55 & 40 & 75 \\
H-31 & 90 & 60 & 30 & 75 \\
H-32 & 85 & 65 & 20 & 75 \\
H-33 & 80 & 70 & 10 & 75 \\
H-34 & 75 & 25 & 50 & 50
\end{tabular}

NOTES: (1) TEMPERATURES ARE GIVEN IN DEGREES FAHRENHEIT.

(2) T hot AND $T$ cold ARE THE INTERIOR TEMPERATURES OF THE SHEATHINGS. 
TABLE 8

CONDITIONS FOR HORIZONTAL HEAT FLOW TEST PANELS

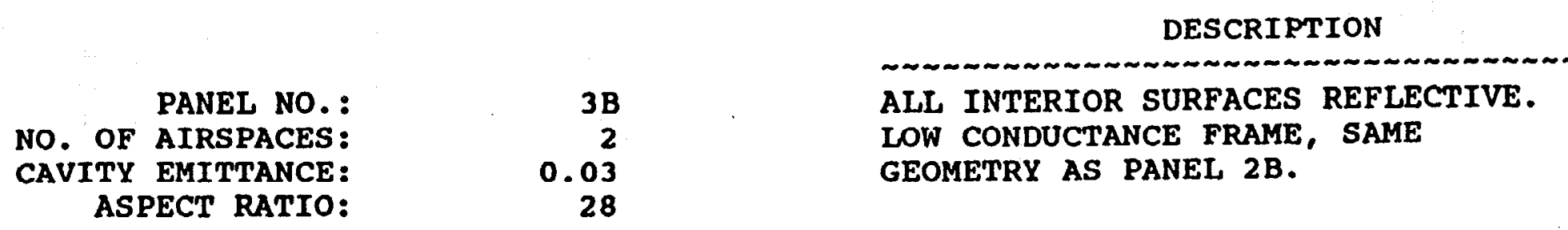

\begin{tabular}{ccc} 
& \multicolumn{2}{c}{ AIRSPACE MEAN } \\
DELTA T & & 2 \\
TEMPERATURE & & \\
PER AIRSPACE & 1 & 50 \\
50 & 100 & 35 \\
40 & 75 & 45 \\
30 & 75 & 55 \\
20 & 75 & 65 \\
10 & 75 & 70 \\
5 & 75 &
\end{tabular}

NOTES: (1) TEMPERATURES ARE GIVEN IN DEGREES FAHRENHEIT.

(2) T hot AND T cold ARE THE INTERIOR TEMPERATURES OF THE SHEATHINGS. 
TABLE 9

CONDITIONS FOR HORIZONTAL HEAT FLOW TEST PANELS

$\begin{array}{rrl} & & \text { DESCRIPTION } \\ \text { PANEL NO.: } & & \text { COMMERCIAL THREE-FOIL PRODUCT } \\ \text { NO. OF AIRSPACES: } & 3 C & \text { INSTALLED IN STANDARD STUD WALL WITH } \\ \text { CAVITY EMITTANCE: } & 0.03 & \text { LOW CONDUCTANCE EPS FRAME. ALL } \\ \text { ASPECT RATIO: } & 56 & \text { AIRSPACES ARE BOUNDED BY ONE HIGH } \\ & & \text { EMITTANCE SURFACE AND ONE } \\ & & \end{array}$

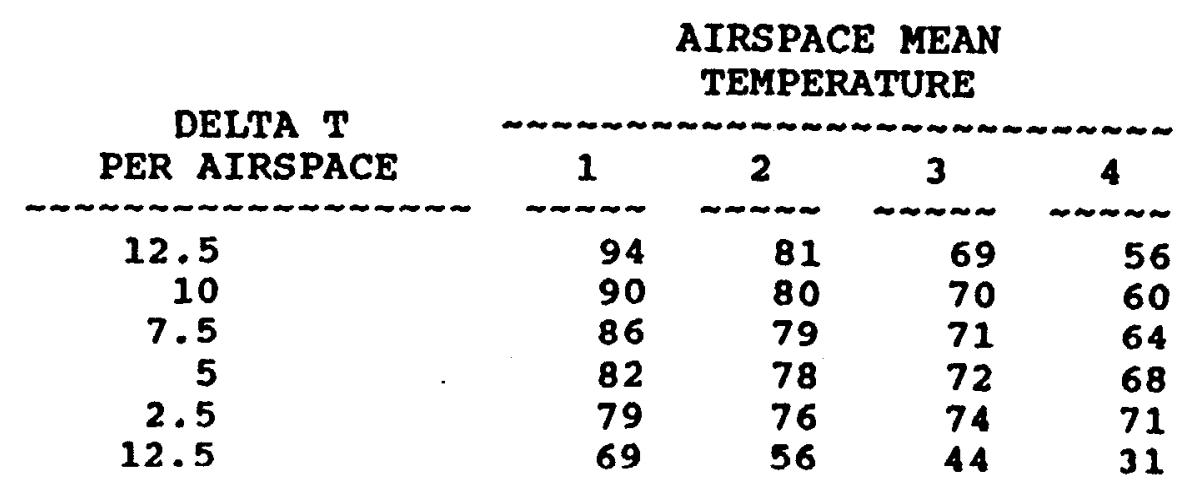

NOTES: (1) TEMPERATURES ARE GIVEN IN DEGREES FAHRENHEIT.

(2) T hot AND T cold ARE THE INTERIOR TEMPERATURES OF THE SHEATHINGS. 


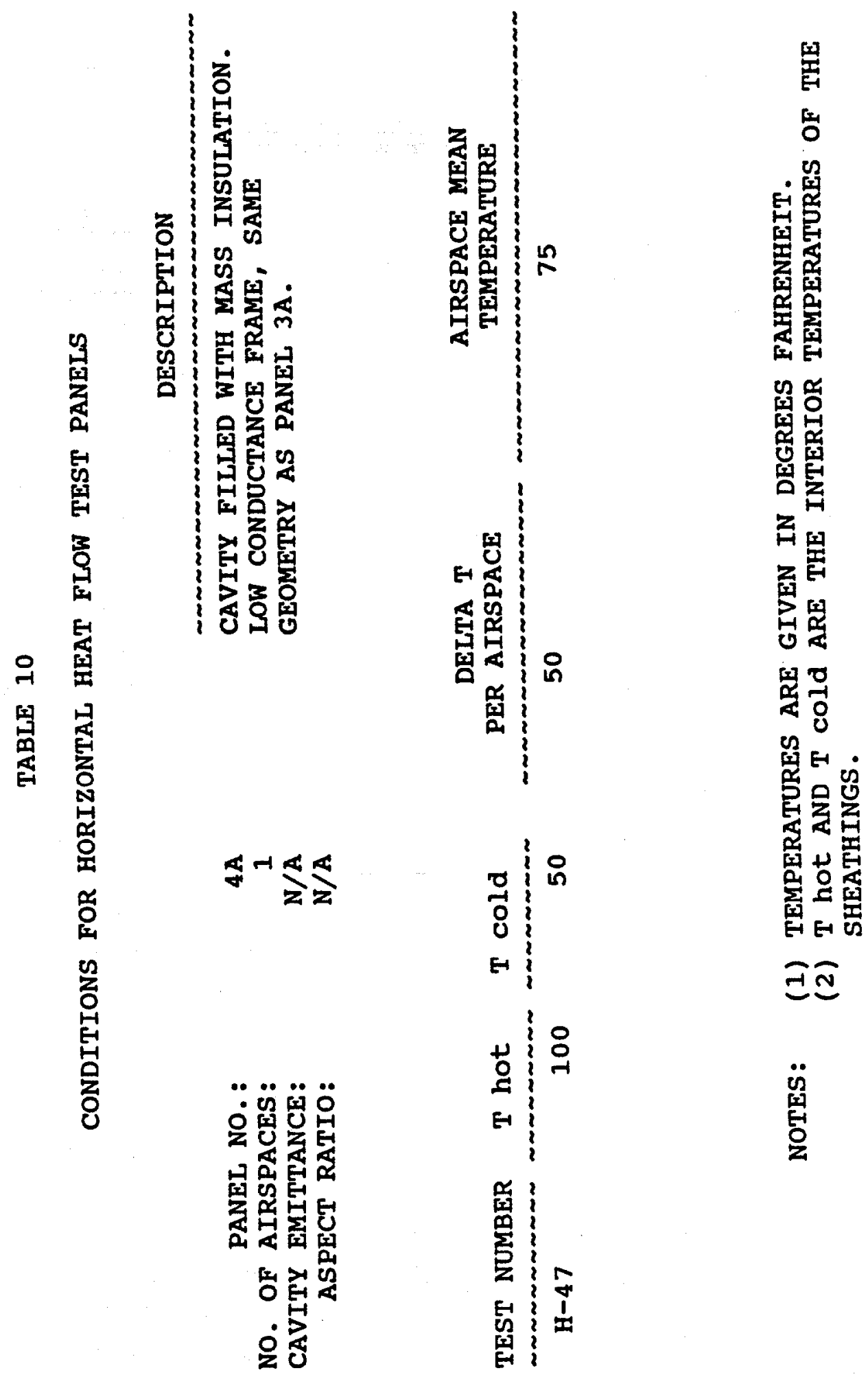


TABLE 11

CONDITIONS FOR HORIZONTAL HEAT FLOW TEST PANELS

\begin{tabular}{|c|c|c|c|}
\hline & & 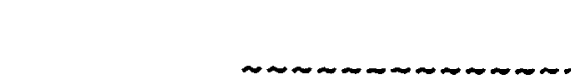 & DESCRIPTION \\
\hline $\begin{array}{l}\text { PANEL NO.: } \\
\text { NO. OF AIRSPACES: } \\
\text { CAVITY EMITTANCE: } \\
\text { ASPECT RATIO: }\end{array}$ & $\begin{array}{r}4 B \\
1 \\
N / A \\
N / A\end{array}$ & $\begin{array}{l}\text { CAVITY FILLED } \\
\text { STANDARD STUD } \\
\text { SAME GEOMETRY }\end{array}$ & $\begin{array}{l}\text { WITH MASS INSULATION. } \\
\text { WALL WITH WOOD FRAME. } \\
\text { AS PANEL } 2 A \text {. }\end{array}$ \\
\hline TEST NUMBER & $\mathrm{T}$ cold & $\begin{array}{c}\text { DELTA T } \\
\text { PER AIRSPACE }\end{array}$ & $\begin{array}{l}\text { AIRSPACE MEAN } \\
\text { TEMPERATURE }\end{array}$ \\
\hline $\mathrm{H}-48$ & 50 & 50 & 75 \\
\hline
\end{tabular}

NOTES: (1) TEMPERATURES ARE GIVEN IN DEGREES FAHRENHEIT.

(2) $T$ hot AND $T$ cold ARE THE INTERIOR TEMPERATURES OF THE SHEATHINGS. 
TABLE 12

CONDITIONS FOR VERTICAL HEAT FLOW TEST PANELS

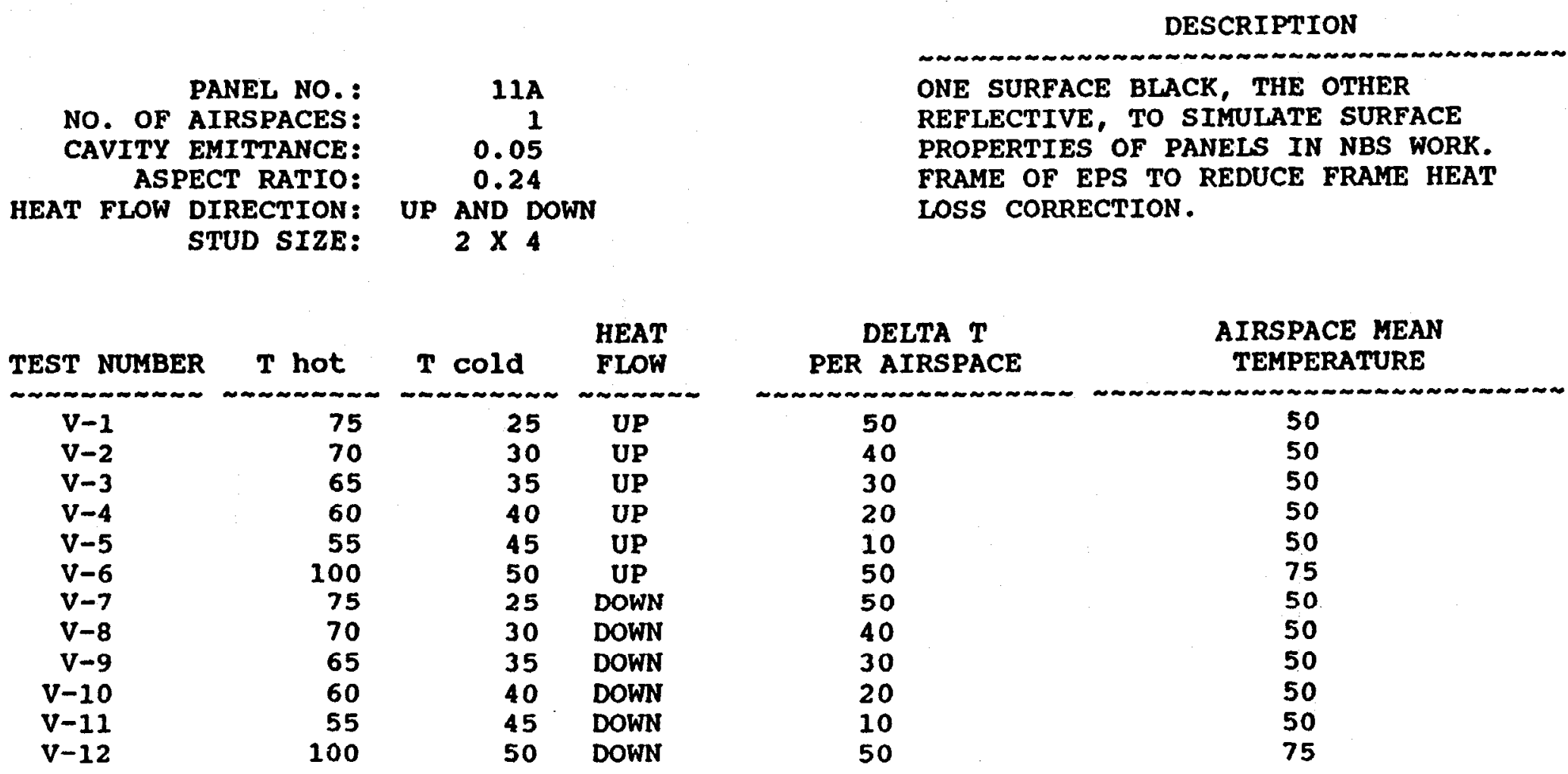

NOTES: (1) TEMPERATURES ARE GIVEN IN DEGREES FAHRENHEIT.

(2) $T$ hot AND $T$ cold ARE THE INTERIOR TEMPERATURES OF THE SHEATHINGS. 
TABLE 13

CONDITIONS FOR VERTICAL HEAT FLOW TEST PANELS

$\begin{array}{rc}\text { PANEL NO.: } & 12 \mathrm{~A} \\ \text { NO. OF AIRSPACES: } & 1 \\ \text { CAVITY EMITTANCE: } & 0.05 \\ \text { ASPECT RATIO: } & 0.38 \\ \text { HEAT FLOW DIRECTION: } & \text { UP AND DOWN } \\ \text { STUD SIZE: } & 2 \times 6\end{array}$

DESCRIPTION

ONE SURFACE BLACK, THE OTHER REFLECTIVE, TO SIMULATE SURFACE PROPERTIES OF PANELS IN NBS WORK. STANDARD STUD CONSTRUCTION WITH WOOD FRAME.

N

$\begin{array}{crrc} & & & \text { HEAT } \\ \text { TEST NUMBER } & T \text { hot } & \text { T cold } & \text { FLOW } \\ V-13 & 100 & 50 & \text { UP } \\ V-14 & 95 & 55 & \text { UP } \\ V-15 & 90 & 60 & \text { UP } \\ V-16 & 85 & 65 & \text { UP } \\ V-17 & 80 & 70 & \text { UP } \\ V-18 & 75 & 25 & \text { UP } \\ V-19 & 100 & 50 & \text { DOWN } \\ V-20 & 95 & 55 & \text { DOWN } \\ V-21 & 90 & 60 & \text { DOWN } \\ V-22 & 85 & 65 & \text { DOWN } \\ V-23 & 80 & 70 & \text { DOWN } \\ V-24 & 75 & 25 & \text { DOWN }\end{array}$

DELTA T
PER AIRSPACE
50
40
30
20
10
50
50
40
30
20
10
50

AIRSPACE MEAN
TEMPERATURE
75
75
75
75
75
50
75
75
75
75
75
50

NOTES :

(1) TEMPERATURES ARE GIVEN IN DEGREES FAHRENHEIT.

(2) T hot AND T cOld ARE THE INTERIOR TEMPERATURES OF THE SHEATHINGS. 
TABLE 14

CONDITIONS FOR VERTICAL HEAT FLOW TEST PANELS

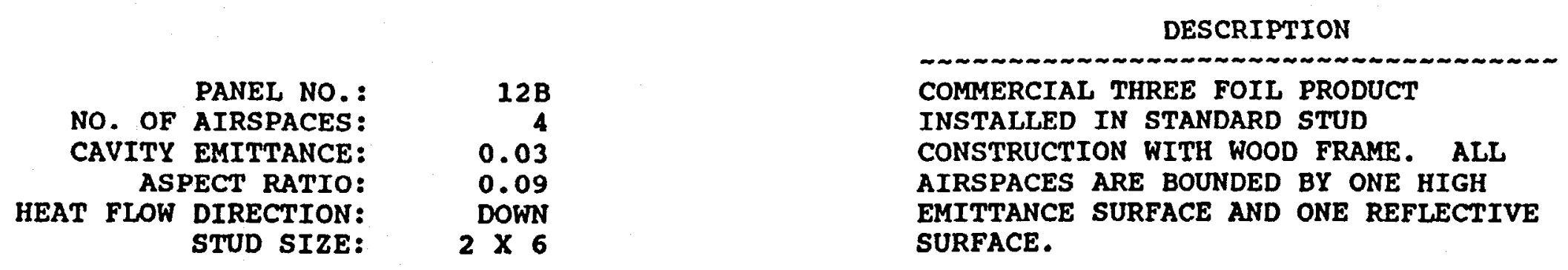

\begin{tabular}{|c|c|c|c|c|c|c|c|c|}
\hline \multirow{2}{*}{ TEST NUMBER } & \multirow{2}{*}{ T hot } & \multirow{2}{*}{ T cold } & \multirow[b]{2}{*}{$\begin{array}{l}\text { HEAT } \\
\text { FLOW }\end{array}$} & \multirow[b]{2}{*}{$\begin{array}{c}\text { DELTA } T \\
\text { PER AIRSPACE }\end{array}$} & \multicolumn{4}{|c|}{$\begin{array}{l}\text { AIRSPACE MEAN } \\
\text { TEMPERATURE }\end{array}$} \\
\hline & & & & & 1 & 2 & 3 & 4 \\
\hline 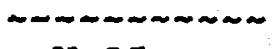 & $\sim \sim \sim \sim \sim a$ & 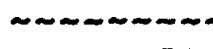 & $\sim \sim \sim \sim c$ & na & 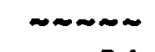 & 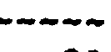 & 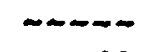 & \\
\hline$V-25$ & 100 & 50 & DOWN & 12.5 & 94 & 81 & 69 & 56 \\
\hline$v-26$ & 95 & 55 & DOWN & 10 & 90 & 80 & 70 & 60 \\
\hline$v-27$ & 90 & 60 & DOWN & 7.5 & 86 & 79 & 71 & 64 \\
\hline$V-28$ & 85 & 65 & DOWN & 5 & 82 & 78 & 72 & 68 \\
\hline$V-29$ & 80 & 70 & DOWN & 2.5 & 79 & 76 & 74 & 71 \\
\hline$V-30$ & 75 & 25 & DOWN & 12.5 & 69 & 56 & 44 & 31 \\
\hline
\end{tabular}

NOTES: (1) TEMPERATURES ARE GIVEN IN DEGREES FAHRENHEIT.

(2) $T$ hOt AND $T$ cold ARE THE INTERIOR TEMPERATURES OF THE SHEATHINGS. 
TABLE 15

CONDITIONS FOR VERTICAL HEAT FLOW TEST PANELS

$\begin{array}{rr} & \\ \text { PANEL NO.: } & 12 \mathrm{C} \\ \text { NO. OF AIRSPACES: } & 1 \\ \text { CAVITY EMITTANCE: } & \mathrm{N} / \mathrm{A} \\ \text { ASPECT RATIO: } & \mathrm{N} / \mathrm{A} \\ \text { HEAT FLOW DIRECTION: } & \mathrm{UP} \\ \text { STUD SIZE: } & 2 \times 6\end{array}$

DESCRIPTION

CAVITY FILLED WITH MASS INSULATION. STANDARD STUD CONSTRUCTION WITH WOOD FRAME.

$\tilde{\infty}$

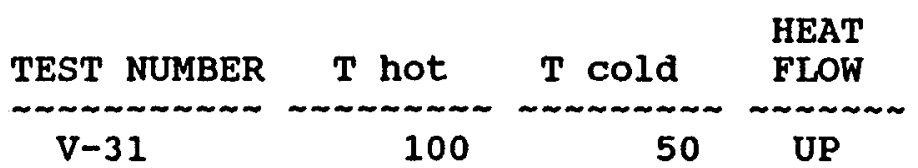

DELTA T
PER AIRSPACE

AIRSPACE MEAN

TEMPERATURE

$$
\mathrm{v}-31
$$$$
100
$$$$
50
$$$$
\text { UP }
$$$$
50
$$$$
75
$$

NOTES: (1) TEMPERATURES ARE GIVEN IN DEGREES FAHRENHEIT.

(2) T hot AND T cold ARE THE INTERIOR TEMPERATURES OF THE SHEATHINGS. 
TABLE 16

CONDITIONS FOR VERTICAL HEAT FLOW TEST PANELS

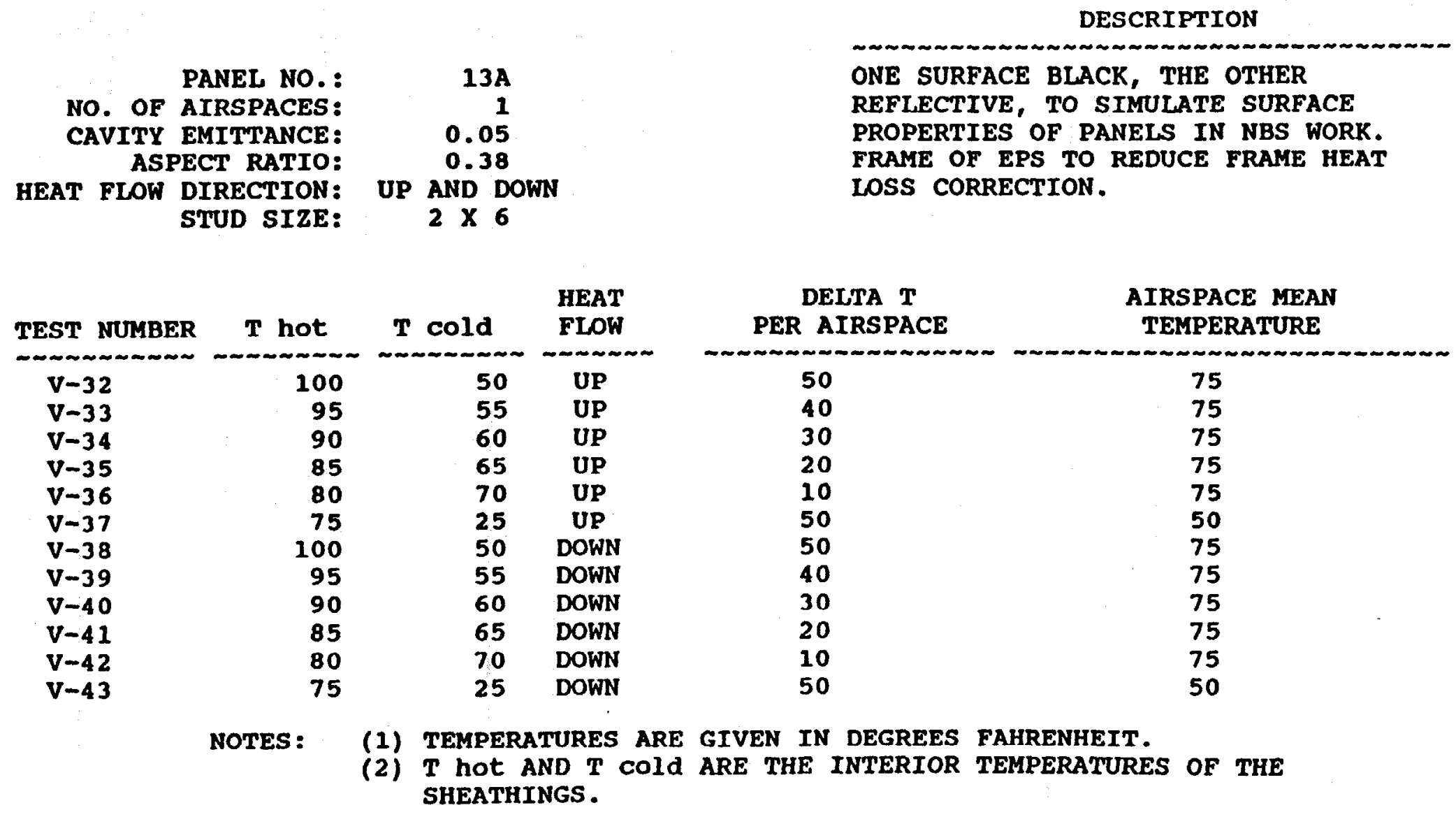


TABLE 17

CONDITIONS FOR VERTICAL HEAT FLOW TEST PANELS

$\begin{array}{rrl} & & \\ \text { PANEL NO.: } & 13 B & \text { DESCRIPTION } \\ \text { NO. OF AIRSPACES: } & 4 & \text { COMMERCIAL THREE FOIL PRODUCT } \\ \text { CAVITY EMITTANCE: } & 0.03 & \text { INSTALLED IN STANDARD STUD } \\ \text { ASPECT RATIO: } & 0.09 & \text { CONSTRUCTION WITH EPS FRAME. ALL } \\ \text { HEAT FLOW DIRECTION: } & \text { DOWN } & \text { AIRSPACES ARE BOUNDED BY ONE HIGH } \\ \text { STUD SIZE: } & 2 \mathrm{X} 6 & \text { EMITTANCE SURFACE AND ONE REFLECTIVE } \\ & & \text { SURFACE. }\end{array}$

$\ddot{o}$

\begin{tabular}{|c|c|c|c|c|c|c|c|c|}
\hline \multirow[b]{2}{*}{ TEST NUMBER } & \multirow[b]{2}{*}{ T hot } & \multirow[b]{2}{*}{$T$ cold } & \multirow{2}{*}{$\begin{array}{l}\text { HEAT } \\
\text { FLOW }\end{array}$} & \multirow{2}{*}{$\begin{array}{c}\text { DELTA T } \\
\text { PER AIRSPACE }\end{array}$} & \multicolumn{4}{|c|}{$\begin{array}{l}\text { AIRSPACE MEAN } \\
\text { TEMPERATURE }\end{array}$} \\
\hline & & & & & 1 & 2 & 3 & 4 \\
\hline $\begin{array}{l}v-44 \\
v-45 \\
v-46 \\
v-47 \\
v-48 \\
v-49\end{array}$ & $\begin{array}{r}100 \\
95 \\
90 \\
85 \\
80 \\
75\end{array}$ & $\begin{array}{l}50 \\
55 \\
60 \\
65 \\
70 \\
25\end{array}$ & $\begin{array}{l}\text { DOWN } \\
\text { DOWN } \\
\text { DOWN } \\
\text { DOWN } \\
\text { DOWN } \\
\text { DOWN }\end{array}$ & $\begin{array}{r}12.5 \\
10 \\
7.5 \\
5 \\
2.5 \\
12.5\end{array}$ & $\begin{array}{l}94 \\
90 \\
86 \\
82 \\
79 \\
69\end{array}$ & $\begin{array}{l}81 \\
80 \\
79 \\
78 \\
76 \\
56\end{array}$ & $\begin{array}{l}69 \\
70 \\
71 \\
72 \\
74 \\
44\end{array}$ & $\begin{array}{l}56 \\
60 \\
64 \\
68 \\
71 \\
31\end{array}$ \\
\hline
\end{tabular}

NOTES: (1) TEMPERATURES ARE GIVEN IN DEGREES FAHRENHEIT.

(2) T hot AND $T$ cold ARE THE INTERIOR TEMPERATURES OF THE SHEATHINGS. 
TABLE 18

CONDITIONS FOR VERTICAL HEAT FLOW TEST PANELS

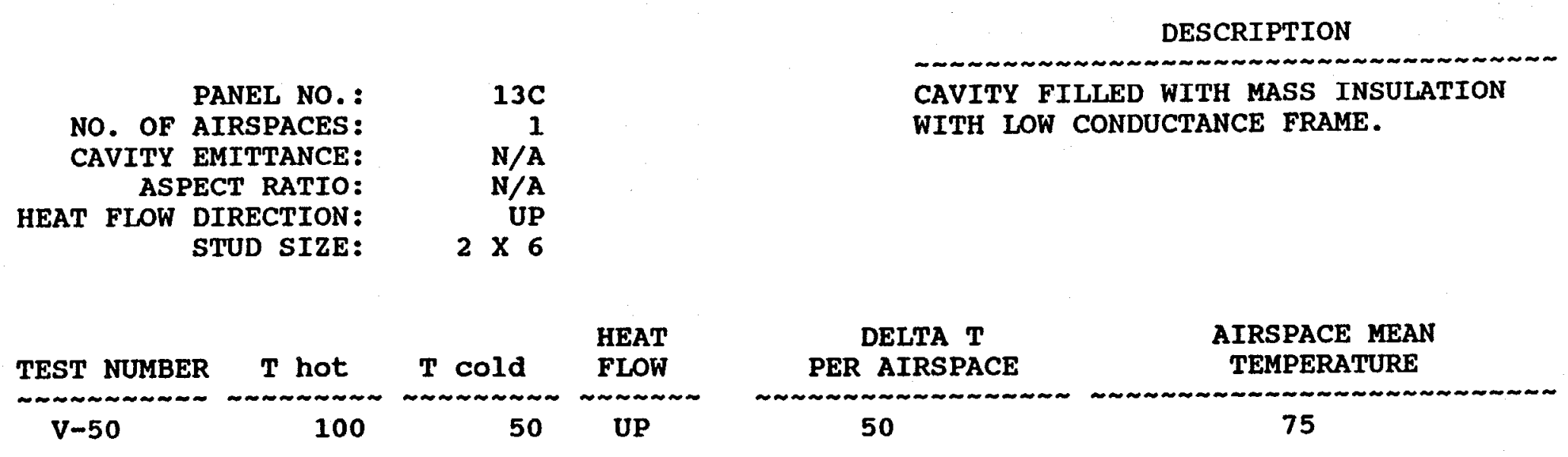

NOTES: (1) TEMPERATURES ARE GIVEN IN DEGREES FAHRENHEIT.

(2) $T$ hot AND $T$ cold ARE THE INTERIOR TEMPERATURES OF THE SHEATHINGS. 
TABLE 19

PURPOSES FOR THE INCLUSION OF TEST PANELS IN THE GUARDED HOT BOX STUDY

\begin{tabular}{|c|c|c|c|}
\hline $\begin{array}{c}\text { Panel } \\
\text { No. }\end{array}$ & Panel Type & $\begin{array}{l}\text { \# of } \\
\text { Tests }\end{array}$ & Reason for Inclusion in Matrix \\
\hline $\begin{array}{l}1 A \\
1 B\end{array}$ & $\begin{array}{l}\text { Wall } \\
\text { Wall }\end{array}$ & $\begin{array}{l}5 \\
5\end{array}$ & $\begin{array}{l}\text { Idealized configurations to simulate } \\
\text { XBS study. }\end{array}$ \\
\hline $\begin{array}{l}2 \mathrm{~A} \\
2 \mathrm{~B} \\
2 \mathrm{C}\end{array}$ & $\begin{array}{l}\text { Wall } \\
\text { Wall } \\
\text { Wall }\end{array}$ & $\begin{array}{l}6 \\
6 \\
6\end{array}$ & \multirow{2}{*}{$\begin{array}{l}\text { A and } B \text { series are idealized conflgur- } \\
\text { ations and } C \text { series contain a commer- } \\
\text { cial product. Test series } 2 \text { and } 3 \text { are } \\
\text { identical except for framing materials } \\
\text { to evaluate the effects of frame } \\
\text { thexmal resistance. }\end{array}$} \\
\hline $\begin{array}{l}3 \mathrm{~A} \\
3 \mathrm{~B} \\
3 \mathrm{C}\end{array}$ & $\begin{array}{l}\text { Wall } \\
\text { Wall } \\
\text { Wall }\end{array}$ & $\begin{array}{l}6 \\
6 \\
6\end{array}$ & \\
\hline $\begin{array}{l}4 \mathrm{~A} \\
4 \mathrm{~B}\end{array}$ & $\begin{array}{l}\text { Wall } \\
\text { Wall }\end{array}$ & $\begin{array}{l}1 \\
1\end{array}$ & $\begin{array}{l}\text { Same construction as } 2 A \text { and } 3 A \text {; mass } \\
\text { insulation in cavity to verify } \\
\text { absequent calculations. }\end{array}$ \\
\hline $12 A$ & Floor/Ceiling & 12 & similar to Panels $1 \mathrm{~A}$ and $1 \mathrm{~B}$. \\
\hline $\begin{array}{l}12 \mathrm{~A} \\
12 \mathrm{~B} \\
12 \mathrm{C}\end{array}$ & $\begin{array}{l}\text { Floor/ceiling } \\
\text { Ceiling } \\
\text { Floor }\end{array}$ & $\begin{array}{r}12 \\
6 \\
1\end{array}$ & \multirow{2}{*}{$\begin{array}{l}\text { Serles A panels contain a single air- } \\
\text { space, series B panels contain a } \\
\text { commercial three-foil product, and } \\
\text { series c a mass insulation. series } 12 \\
\text { and } 13 \text { are identical except for } \\
\text { framing material. }\end{array}$} \\
\hline $\begin{array}{l}13 A \\
13 B \\
13 C\end{array}$ & $\begin{array}{l}\text { Floor/Ceiling } \\
\text { Ceiling } \\
\text { Floor }\end{array}$ & $\begin{array}{r}12 \\
6 \\
1\end{array}$ & \\
\hline
\end{tabular}


insulation material into the cavity such that all the airspaces were bounded by parallel surfaces and that there was no additional structure added to the cavity.

Test Panel 1A was analyzed under five different sets of cavity temperature conditions. The airspace mean temperature for all five experiments was 50F and the temperature difference across the airspace was varied from 10 to $50 \mathrm{~F}$ in $10 \mathrm{~F}$ increments. A mean temperature of $50 \mathrm{~F}$ was selected because the Federal Trade Commission Trade Regulations[11] state that R-Values of single airspaces can be calculated utilizing data from the ASHRAE Handbook of Fundementals and that these calculations must be performed at a mean temperature of 50F. Test panel 1B was also tested under five different sets of thermal conditions. For this series of experiments, the airspace on the cold side of the cavity was maintained at a mean temperature of $50 \mathrm{~F}$ and the mean temperature of the second airspace decreased in $10 \mathrm{~F}$ increments from 100 to $60 \mathrm{~F}$ as the temperature difference across each airspace in the cavity was decreased in $10 F$ increments from 50 to $10 \mathrm{~F}$. This combination of temperature conditions was selected because the thermal conditions imposed on the airspace abutting the cold side of the cavity would be identical to the conditions imposed on the single airspace of Test Panel $1 \mathrm{~A}\left(\mathrm{~T}_{\text {mean }}=50 \mathrm{~F}, \mathrm{dT}=10,20,30,40\right.$, and 50F). The airspace on the hot side of the cavity would be analyzed at a second mean temperature $\left(T_{\text {mean }}=100,90\right.$, 80,70 , and 60F). Test Panel $11 \mathrm{~A}$ was analyzed at six different airspace mean temperature/temperature difference combinations in two heat flow directions (heat flow up and down). Five of these combinations were identical to the conditions imposed on Test Panel 1A. In addition, a sixth set of conditions $\left(\mathrm{T}_{\text {mean }}=75 \mathrm{~F}, \mathrm{dT}=50 \mathrm{~F}\right)$ was included in the test matrix to supply data at a different airspace mean 
temperature. Summaries of the targeted test conditions for these test panels are given in Tables 2,3 , and 12 .

4.2 IDEALIZED AND COMMERCIAL PANELS: WOOD STUDS, NUMBER OF AIRSPACES, ASPECT RATIO, HORIZONTAL AND VERTICAL HEAT FLOW

Test Panels $2 \mathrm{~A}, 2 \mathrm{~B}$, and $2 \mathrm{C}$ were included in the test matrix to measure the effect of the number of airspaces in the cavity and the aspect ratio of those airspaces on the thermal performance of the cavity with horizontal heat flow. Test Panels $12 \mathrm{~A}$ and $12 \mathrm{~B}$, identical in construction to Test Panels $2 \mathrm{~A}$ and $2 \mathrm{C}$ with the exception of the size of the framing member and the effective emittance of the single airspace cavity, were included to determine the impact of the same parameters on the thermal performance of the cavity with vertical heat flow. All five test panels were constructed with wood studs to simulate real-life construction practices. The horizontal heat flow test panels contained 1,2 , and 4 airspaces in the cavity while the vertical heat flow test panels contained 1 and 4 airspaces in the cavity respectively. Test Panels 2A, 2B, and $12 \mathrm{~A}$ contained idealized airspaces while Test Panels $2 \mathrm{C}$ and 12B were insulated with a commercially available three layer (creating four airspaces) reflective insulation product which included a flange for mounting purposes. The purpose for including of a commercial product in the test matrix was to test the impact of nonidealized airpaces and the effect of the reflective insulation structure on the thermal performance of the cavity.

Test Panel 2A was analyzed under six different sets of cavity mean temperature/temperature difference combinations. For the first five conditions, the airspace mean temperature 
was maintained at $75 \mathrm{~F}$ and the temperature difference across the airspace was varied from 10 to $50 \mathrm{~F}$ in $10 \mathrm{~F}$ increments. The sixth set of conditions $\left(\mathrm{T}_{\text {mean }}=50 \mathrm{~F}, \mathrm{dT}=50 \mathrm{~F}\right)$ was included in the test matrix to supply data at a different airspace mean temperature. Test Panel 2B was also analyzed under six different sets of thermal conditions. For the first five experiments, the airspace on the hot side of the cavity was maintained at a mean temperature of $75 \mathrm{~F}$ and the temperature difference across each airspace decreased incrementally from 50 to $5 \mathrm{~F}$. The cold side airspace mean temperature varied from 35 to $70 \mathrm{~F}$, supplying a second mean temperature with the same temperature differences as the hot side airspace. The sixth set of temperature conditions imposed on this test panel yielded a mean temperature of 100 and $50 \mathrm{~F}$ for the two airspaces and a temperature difference of 50F across each airspace. Twelve experiments were performed on Test panel 12A. The six sets of thermal conditions imposed on Test Panel 2A were used for both the heat flow up and down directions. Tables 4, 5, and 13 contain detailed information regarding the target temperature conditions for these three test panels.

The identical cavity mean temperature/temperature differences imposed on Test Panel $2 \mathrm{~A}$ were used for evaluating Test panels $2 \mathrm{C}$ and 12B. In this instance, the temperature differences across each individual airspace was smaller due to the multiple airspaces in the test cavity; the airspace temperature differences ranged from 12.5 to 2.5F. Tables 6 and 14 summarize these test conditions. 


\subsection{XEPS VERSUS WOOD STUDS}

During the historical development of an ASTM material specification for reflective insulation, the issue of test configurations has been controversial; one group has favored using high thermal resistance studs in the test configuration because of the lower overall heat flow correction while a second group has championed the use of wood studs because of their use in real-life systems. To address this issue, Test Panels $3 \mathrm{~A}, 3 \mathrm{~B}$, and $3 \mathrm{C}$ with horizontal heat flow and Test panels $13 \mathrm{~A}$ and $13 \mathrm{~B}$ were included in the test matrix. These five test panels (3A, $3 \mathrm{~B}, 3 \mathrm{C}, 13 \mathrm{~A}$, and 13B) were identical to Test panels 2A, 2B, $2 \mathrm{C}, 12 \mathrm{~A}$, and $12 \mathrm{~B}$ respectively with the exception of the framing or stud material used in their construction. The Series 2 and 12 test panels used wood studs while the series 3 and 13 test panels used XEPS foam studs. one of the objectives of this program was to ultimately deduce the thermal resistance of the cavity by accounting for the heat transfer through the framing members. The proposed variation in the material used for the framing members yields two significantly different percentages of the total heat flow which would be transferred by the framing members and test the ability to account for this heat flow. Comparisons between the test panels with wood and foam studs would quantify the effect of thermal short circuiting through the supporting structure and determine whether that thermal shunting could be accurately quantified.

The test conditions for Test Panels 3A, 3B, 3C, 13A, and $13 \mathrm{~B}$ were identical to their counterparts in the series 2 and 12 test panels and are summarized in Tables 7, 8, 9, 16, and 17 respectively. 


\subsection{TEST PANELS WITH MASS INSUIATION}

The proposed ASTM material specification for reflective insulation requires that the heat flow correction for framing members must be corroborated by performing an experiment with the test panel cavities filled with a mass insulation of known thermal performance. A representative sample of the mass insulation would be tested and the calculated thermal resistance of the mass insulation in the cavity must agree with its directly measured thermal resistance to within 10 percent. To test the stringency of this requirement, four test panels, namely 4A, 4B, 12C, and 13C, were included in the test matrix. Test panels $4 \mathrm{~A}$ and $4 \mathrm{~B}$ were tested with horizontal heat flow and the remaining two panels were analyzed with vertical heat flow (up). The horizontal and vertical heat flow test panels were insulated with unfaced nominal $R-11$ ( 3 1/2 inches) and nominal $R-19$ ( 6 $1 / 4$ inches) fiberglass batts respectively. Test Panels $4 \mathrm{~A}$ and $13 \mathrm{C}$ were constructed with XEPS foam framing members; the other two test panels utilized wood studs for framing members.

The four test panels insulated with fiberglass batts were tested at a cavity mean temperature of $75 \mathrm{~F}$ with a cavity temperature difference of 50F. Tables $10,11,15$, and 18 summarize the test conditions for these four test panels respectively.

\section{MATERIAL PROPERTIES OF TEST PANEL COMPONENTS}

Sufficient quantities of the building materials required to build all of the test panels were acquired at the outset of the program to guarantee that all test panels 
would be fabricated from materials of similar thermophysical properties. The construction of the test panels required $2 \times 4$ and $2 \times 6$ wood studs, $1 / 4$ inch thick plywood sheet for sheathing, 1 1/2 inch thick extruded polystyrene foam (XEPS) for the high thermal resistance studs and the convective stops, single thickness and three layer reflective insulation, $R-11$ and $R-19$ fiberglass batts for cavity mass insulation for the calculation verification testing, and reflective and non-reflective adhesive tapes for the attachment of the temperature instrumentation.

The subsequent calculations used to determine cavity thermal resistance require accurate knowledge of the thermal resistance and emittance of these materials. Samples of the wood and XEPS framing materials, sheathing, and the two fiberglass batt materials were randomly selected from the stock of materials used to construct the test panels for thermal resistance testing. All of the above-listed materials were similarly sampled for measuring their surface emittance.

The thermal resistance of all the samples was determined in accordance with ASTM C 518-85, standard Test Method for "steady-state Heat Flux Measurements and Thermal Transmission Properties By Means of the Heat Flow Meter Apparatus"[12]. Samples of the stud materials approximately dimensioned 24 inches square in cross-section by $31 / 2$ or $51 / 2$ inches thick were prepared by stacking sixteen $11 / 2$ inch wide by 24 inch long by thickness sections of stud material together. This sample preparation technique allowed for testing the stud material in the same orientation as their use in the test panel. After the two wood stud materials were analyzed for thermal performance, these samples were altered by installing one $11 / 4$ inch long 
drywall screw per linear foot of stud on each side of the sample in the metering area of the apparatus. The inclusion of the drywall screws was to simulate the actual building construction of the test panels.

A similar exercise was employed with the XEPS studs and the nylon threaded rods. After the completion of the initial analyses on these stud materials, the samples were modified by installing a nylon rod per 16 linear inches of stud (4 total) in the metering area of the heat flow meter apparatus. The nylon rods were cut flush with the surface of the stud.

A 24 inch square sample of each fiberglass batt insulation material was prepared by sandwiching two $43 / 4$ inch wide by 24 inch long sections of material around a full width ( $141 / 2$ inch) by 24 inch long section. These samples were analyzed utilizing a large heat flow meter apparatus which has been previously described[13] at the cavity thickness and, where necessary, at the same density as the batts in the metering area of the guarded hot box test panel. Due to the nonrepresentativeness of the $31 / 2$ inch batt selected for materials properties testing, a second batt removed from the guarded hot box metering section was also analyzed. This second sample more closely approximated the density of the material applied to the test panel. A 12 inch square sample of the sheathing was prepared and tested in a small heat flow meter apparatus. This instrument has also been previously described [14]. 
6. TEST PANEL COMPONENT THERMAL RESISTANCE TEST PROCEDURE

Each sample was evaluated in accordance with ASTM C 518-85, "Steady-state Heat Flux Measurements and Thermal Transmission Properties by Means of the Heat Flow Meter Apparatus". Samples in excess of 2 inches in thickness were analyzed utilizing a Holometrix Model R-Matic heat flow meter instrument. Samples less than 2 inches thick were tested with a Holometrix Model Rapid-k heat flow meter instrument. Schematic diagrams of the two instruments are shown in Figures 5 and 6 . The samples were installed horizontally between 24 or 12 inch square aluminum surface plates treated to have a total hemispherical emittance of 0.82 at $75 \mathrm{~F}$. The surface plates were smoothly finished to conform to a true plane to within 0.25 percent. Above the upper (cold) and below the lower (hot) surface plates, heaters, heat sinks and insulation were installed. In the 24 inch heat flow meter instrument, the lower plate and heater were in two sections, an inner 12 inch square central section surrounded by a 6 inch wide annular guard section with a 0.1 inch wide gap between them. A differential thermopile was fitted into this surface plate such that alternate junctions were in the central and annular guard sections respectively and within 0.25 inches of the gap between them.

The two heat sink assemblies were connected to a refrigeration system capable of maintaining $-20 \mathrm{~F}$ at the heat sink. Temperature control of the surface plates was accomplished by operating the refrigeration system continuously and reheating with the electrical resistance heaters. The temperatures of the surface plates were controlled and monitored by temperature sensors mounted near the heaters and in the surface plates. 


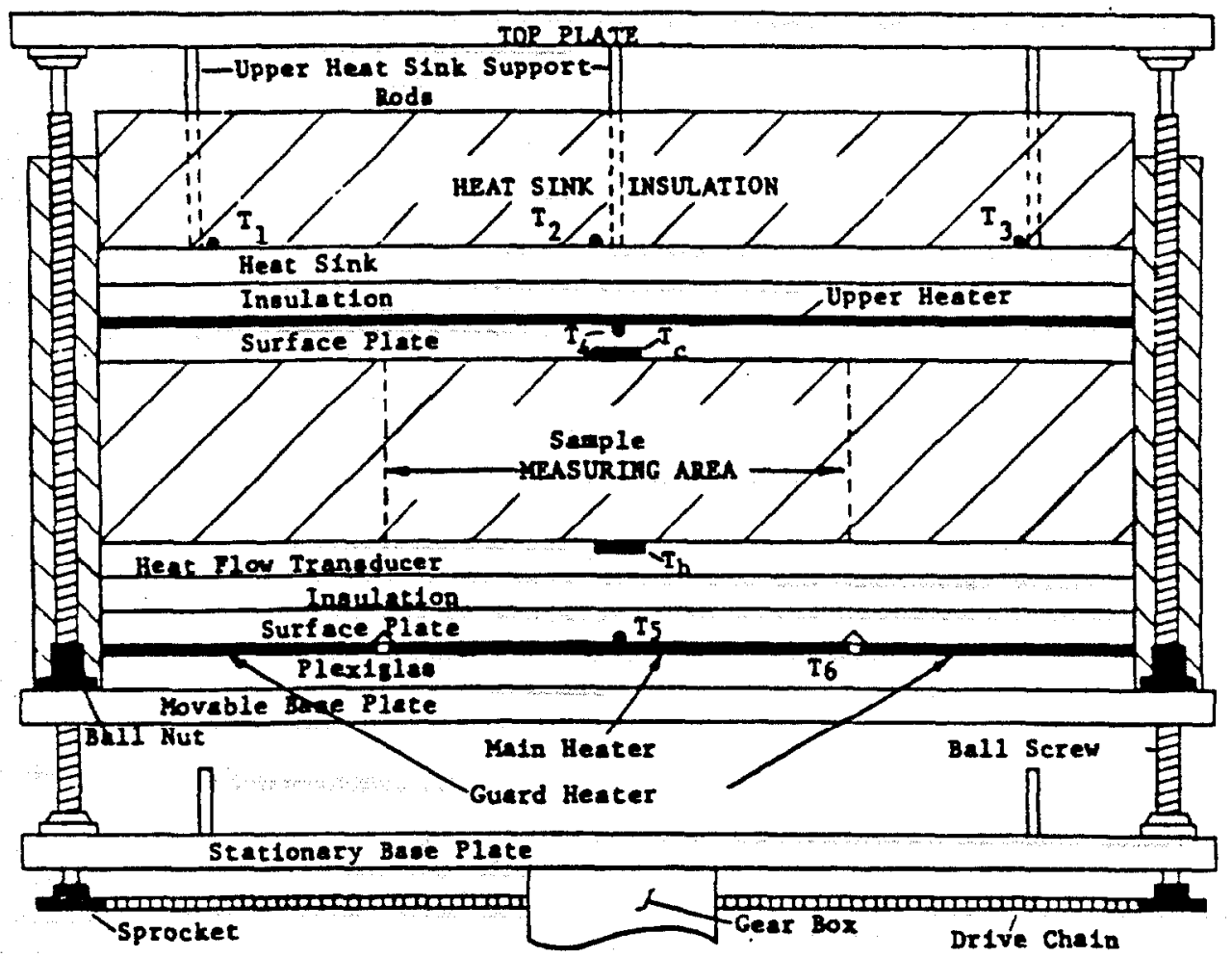

$\begin{aligned} T_{1}, T_{2}, T_{3} & =\text { upper (cold eide) heat olak tenperaturea (cu/con therrocouplea) } \\ T_{4} & \text { - upper (cold face) heater control feedbeck cenor }\end{aligned}$

$T_{\text {cold }}-T_{c}$ - naple upper (cold face) temprature (platian resiatance temperature

$T_{\text {hot }} I_{b}=$ eaple lover (hot face) temperature (platiau realotance temperature detector

$I_{5}$ - lower (hot face) anin beater control feedback senuor

$T_{6}$ - differential feedback thermpile between $m$ in and guard heater

$\Delta T$ - $T_{h}-T_{c}$, texperature difference acrose saple

Figure 5 .

CROSS-SECTIONAL VIEW OF 24 INCH SQUARE

HEAT FLOW METER APPARATUS 


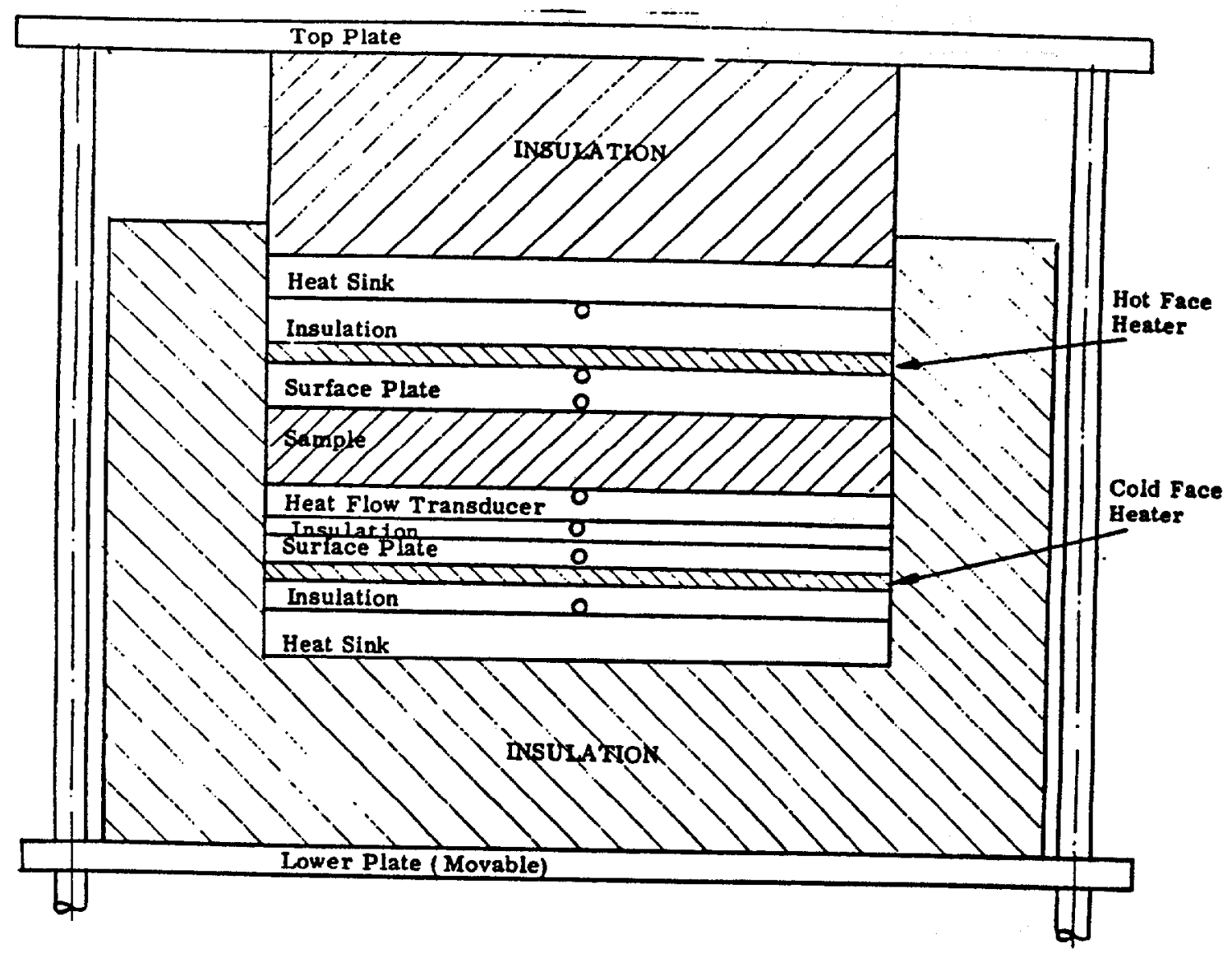

Figure 6.

SCHEMATIC OF 12 INCH SQUARE HEAT FLOW METER THERMAL CONDUCTIVITY INSTRUMENT 
Between the bottom of the test specimen and the bottom surface plate, a heat flux transducer was installed. The 24 inch square heat flow meter instrument utilizes a heat flux transducer that has a sensing area 10 inches square located in the center of its 24 inch square overall area. The 12 inch square heat flow meter instrument has a 4 inch square sensing area similarly located in the center of its overall area.

Temperature measurements except for the surface
temperatures on the 24 inch square heat flow meter
instrument were performed by utilizing Type $T$
Copper/Constantan thermocouples calibrated to the special
limits of error specified in ASTM E $230-83$, "Temperature-
Electromotive Force (EMF) Tables for standardized
Thermocouples"[15].
fabricated with No. 30 AWG wire. The surface temperatures
on the large format heat flow meter instrument were measured
with platinum resistance temperature detectors. single
temperature sensors were used for measuring the hot and cold
surface plate temperatures in the center of the sensing area
of the instrument heat flux transducer. All temperature
sensors were individually connected to a digital millivolt
meter having a resolution of \pm 1 microvolt.

The bottom surface plate assembly of the 24 inch square and 12 inch square heat flow meter instruments could be adjusted to accommodate surface plate separations from 0 to 8 inches and 0 to 3.5 inches respectively. The opening between the surface plates was measured by using linear motion potentiometers. The periphery of the test stack was lined with 2 inches of an extruded polystyrene foam insulation having a thermal resistance of about $10 \mathrm{hr} . \mathrm{ft}^{2}$ F/Btu at $75 \mathrm{~F}$. 
In operation, the plate separation was adjusted to accommodate the test thickness of the specimen being evaluated. Typically the thickness of the specimen was measured prior to its insertion into the instrument and the plates were closed such that the thickness readout corresponded to the average test specimen thickness. The temperature of the top and bottom surface plates were adjusted such that the mean temperature and temperature difference test requirements were satisfied. If no temperature difference requirements were given, 50F was used. To ensure that the temperature of the hot surface plate of the 24 inch heat flow meter instrument was uniform, the annular guard was controlled automatically by utilizing the output of the differential thermopile so that the temperatures of the central and annular guard sections were similar.

At equilibrium, established after ensuring that during five consecutive observations at intervals of approximately 1200 seconds the test specimen apparent thermal conductivity changed less than 1 percent and not monotonically, the temperatures of both hot and cold faces were evaluated from the sensors embedded in the plates, and the heat flux through the specimen was derived from the heat flux transducer output.

The specimen apparent thermal conductivity was calculated from

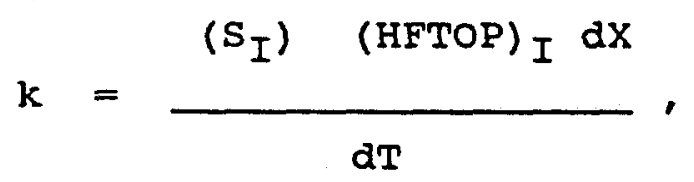

and the specimen thermal resistance was calculated from 


$$
R=d x / k \text {, }
$$

where

$$
\begin{aligned}
\mathbf{k} & =\begin{array}{l}
\text { test specimen apparent thermal conductivity, } \\
\text { Btu-in/hr } \mathrm{ft}^{2} \mathrm{Fi}
\end{array} \\
\mathrm{s}_{\mathrm{I}} & =\begin{array}{l}
\text { instrument heat flux transducer sensitivity, } \\
\text { Btu/hr ft } \mathrm{mV} ;
\end{array} \\
\text { HFTOP }_{I} & =\text { instrument heat flux transducer output, } \mathrm{mV} ; \\
\mathrm{dX} & =\text { test specimen thickness, inches; } \\
\mathrm{dT} & =\text { temperature difference across test specimen, } \mathrm{F} ; \\
\mathrm{R} & =\text { thermal resistance, } \mathrm{hr} \mathrm{ft}^{2} \mathrm{~F} / \mathrm{Btu} .
\end{aligned}
$$

The instrumentation is calibrated using the National Institute of standards and Technology low density fibrous glass Certified Transfer Standards Numbers 2515, 4921, 6541, and 6521 and standard Reference Material SRM 1450b. The transfer standards are 1.00 and 6.00 inches thick, and have thermal resistances of approximately 3.12 or $18.2 \mathrm{hr} \mathrm{ft}^{2}$ F/Btu at 75F. The tests were certified on 24 July 1981. The overall uncertainty of the thermal resistance of the transfer standards is estimated to be 2.25 percent. The standard reference material is a high density fiberglass board, 1.00 inches thick, and has a thermal resistance of approximately $4.20 \mathrm{hr} \mathrm{ft}^{2} \mathrm{~F} / \mathrm{Btu}$ at $75 \mathrm{~F}$. The instrumentation was calibrated before and after each series of experiments. 
The reproducibility and the accuracy of these instruments are estimated to be 1 and 4 percent respectively at 75F.

The test results are summarized in Table 20 .

7. EMITTANCE OF TEST PANEL COMPONENTS

The emittance of the single thickness and each surface of the three-foil multilayer reflective insulation materials along with samples of the wood and XEPS studs, wood sheathing, and foil and duct tapes that were used to attach the temperature instrumentation to the various surfaces of the test panel were measured using a Devices and Services Company Model AE Emissometer. Multiple measurements were performed on each material at Tennessee Technological University by Dr. David Yarbrough and Mr. Joe Cook [16]. A copy of their test report is given in Appendix $B$ of this report. The emittance results of these test panel components are presented in Table 21.

\section{TEST PANEL TEMPERATURE INSTRUMENTATION}

Temperature measurements were performed by utilizing Type $T$ Copper/Constantan thermocouples calibrated to the special limits of error specified in ASTM E 230-83. All thermocouple sensors were fabricated with No.30 AWG wire. Up to seventy-four thermocouples were utilized during the thermal testing.

Figures 7 and 8 depict the location of all of the test panel metering area surface and air temperature instrumentation for the two guarded hot boxes utilized in 
TABLE 20

THE APPARENT THERMAL CONDUCTIVITY ANO THERMAL RESISTANCE OF ELEVEN SPECIMENS OF BUILDING MATERIALS USED TO CONSTRUCT TEST PANELS

\begin{tabular}{|c|c|c|c|c|c|c|}
\hline Specimen & $\begin{array}{l}\text { Test } \\
\text { Number }\end{array}$ & $\begin{array}{c}\text { Test } \\
\text { Thickness }\end{array}$ & Density & $\begin{array}{c}\text { Mean } \\
\text { Temperature }\end{array}$ & $\begin{array}{l}\text { Apparent Thermal } \\
\text { Conductivity }\end{array}$ & $\begin{array}{c}\text { Thermal } \\
\text { Resistance }\end{array}$ \\
\hline & & inches & Ibs/ft^3 & $\mathbf{F}$ & Btu-in/hr $f t^{\wedge} 2$ F & hr ft^2 F/Btu \\
\hline \multirow[t]{2}{*}{ XEPS stud } & 1 & 3.50 & 1.95 & 76.9 & 0.214 & 16.35 \\
\hline & 2 & 5.49 & 1.96 & 76.9 & 0.216 & 25.38 \\
\hline \multirow{2}{*}{$\begin{array}{l}\text { XEPS Stud } w / \\
\text { Nylon Rod (1) }\end{array}$} & 3 & 3.50 & 1.95 & 76.1 & 0.218 & 16.08 \\
\hline & 4 & 5.49 & 1.96 & 76.0 & 0.220 & 24.99 \\
\hline \multirow[t]{2}{*}{ Wood Stud } & 5 & 3.53 & 27.2 & 76.9 & 0.754 & 4.67 \\
\hline & 6 & 5.52 & 28.1 & 75.8 & 0.808 & 6.83 \\
\hline \multirow[t]{2}{*}{$\begin{array}{l}\text { Wood stud W/ } \\
\text { Drrwall Screw (2) }\end{array}$} & 7 & 3.53 & 27.2 & 76.3 & 0.798 & 4.42 \\
\hline & 8 & 5.52 & 28.1 & 76.5 & 0.842 & 6.56 \\
\hline Sheathing & 9 & 0.24 & 31.4 & 81.9 & 0.752 & 0.32 \\
\hline Fiberolass & 10 & 3.50 & 0.737 & 75.1 & 0.293 & 11.93 \\
\hline \multirow[t]{4}{*}{ Batt (3) } & $10 \mathrm{~A}$ & 4.25 & 0.607 & $75: 2$ & 0.318 & 13.36 \\
\hline & 108 & 3.50 & $\cdots$ & & 0.318 & 11.00 \\
\hline & 11 & 3.50 & 0.582 & 73.5 & 0.324 & 10.79 \\
\hline & 12 & 5.50 & 0.472 & 75.1 & 0.325 & 16.91 \\
\hline
\end{tabular}

Notes: 1. Test Numbers 3 and 4 were performed on the same test samples used for Test Numbers 1 and 2 respectively after installing one $1 / 4$ inch diameter nylon rod per 16 inches of length of stud in the metering area of the HFM apparatus.

2. Test Numbers 7 and 8 were performed on the same test samples used for Test Numbers 5 and 6 respectively ofter installing one $i 1 / 4$ inch long drywall screw per linear foot of stud in the metering area of the HFM apparatus.

3. After the completion of the ASTM C $51 B$ experiment on the 3.50 inch thick fiberglass bett (Test 10), it was discovered that the density of the HFM and GHB samples were signiflcantly different. The HFM experiment was repeated after expanding the test sample to match the density of the GHB sample (Test 10A). Based on the apparent thermal conductivity messured during Test 10A, the thermal resistance of this sample was determined for a thickness of 3.50 inches and is reported as Test 108 . In oddition, a second sample (Test 11) was renoved from the metering area of the GHB test panel and analysed. 
TABLE 21

THE EMITTANCE OF NINE SPECIMENS OF BUILDING MATERIALS USED TO CONSTRUCT TEST PANELS

\begin{tabular}{|c|c|c|c|}
\hline Specimen & $\begin{array}{l}\text { No. of } \\
\text { Samples }\end{array}$ & $\begin{array}{l}\text { Total No. } \\
\text { of Tests }\end{array}$ & Emittance \\
\hline XEPS stud & 2 & $N / A$ & 0.51 \\
\hline Wood stud & 2 & $N / A$ & 0.77 \\
\hline Sheathing & 2 & $N / A$ & 0.77 \\
\hline $\begin{array}{c}\text { Single Layer } \\
\text { Foil }\end{array}$ & 7 & 61 & 0.052 \\
\hline Foil Tape & 2 & 8 & 0.029 \\
\hline Duct Tape & 1 & 4 & 0.70 \\
\hline $\begin{array}{l}\text { Multilayer } \\
\text { Outer Foil }\end{array}$ & 3 & 12 & 0.027 \\
\hline $\begin{array}{l}\text { Multilayer } \\
\text { Inner Foil }\end{array}$ & 3 & 15 & 0.029 \\
\hline $\begin{array}{l}\text { Multilayer } \\
\text { Inner Paper }\end{array}$ & 3 & 15 & 0.85 \\
\hline
\end{tabular}




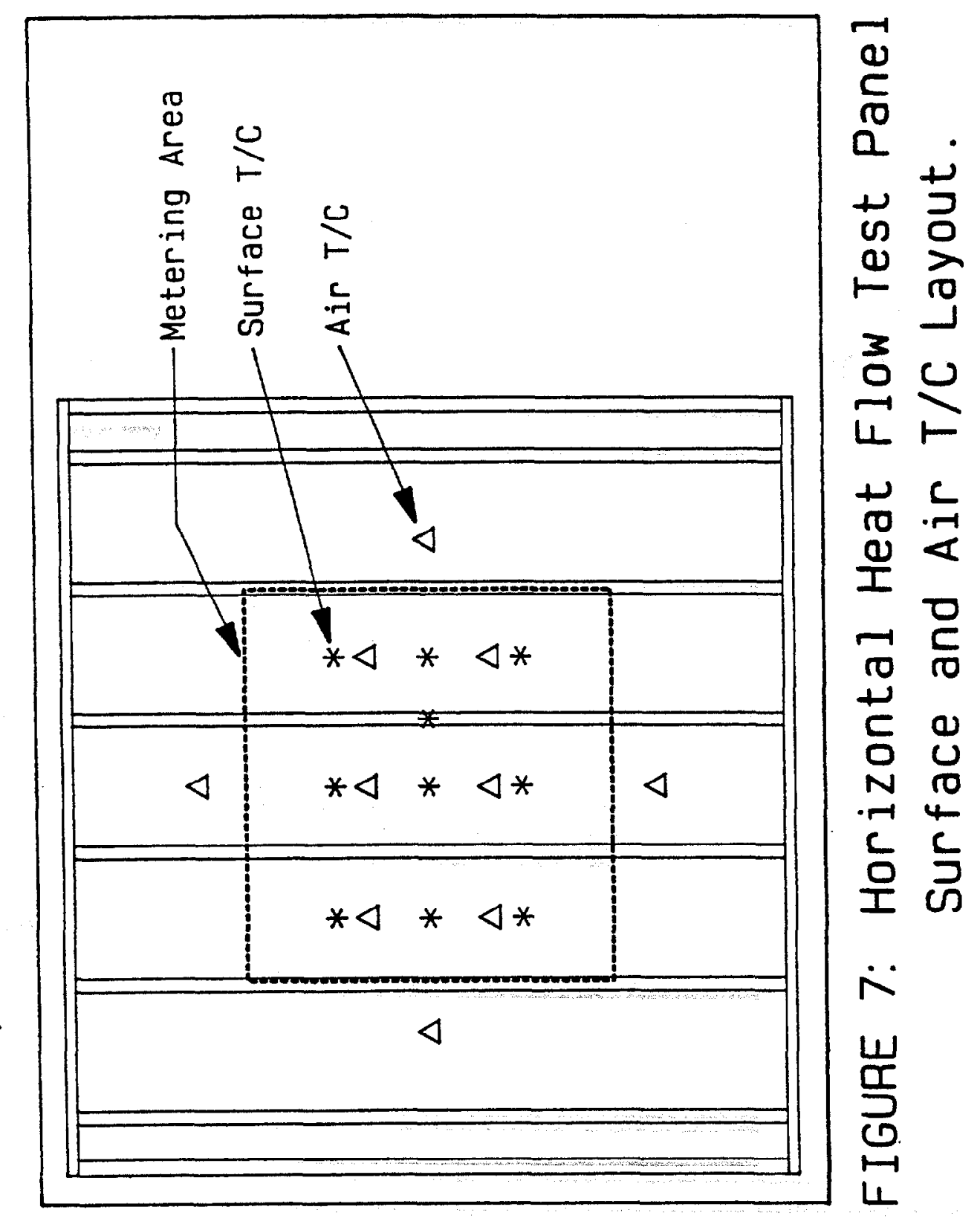




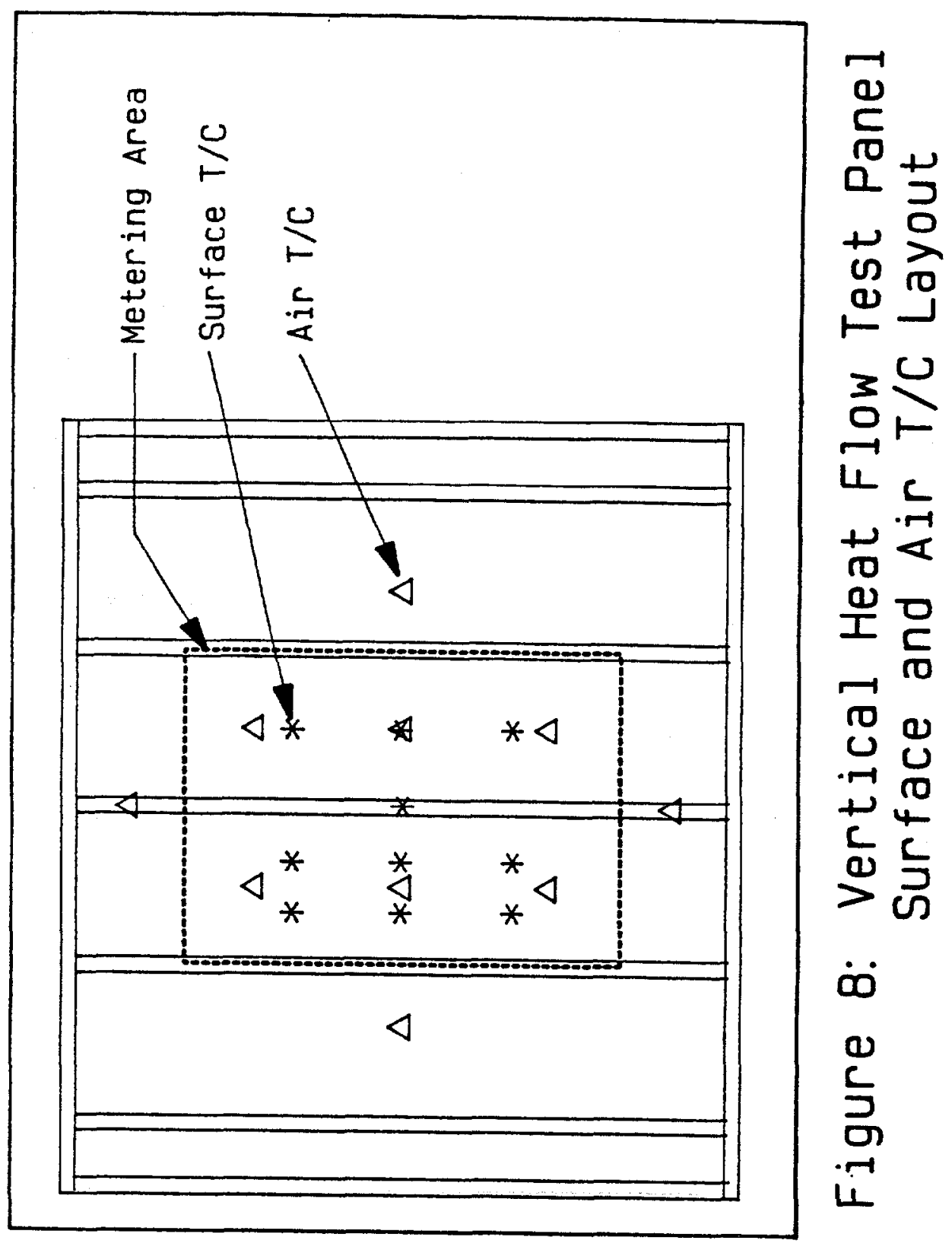


this program. on each side of the test panel, ten thermocouples (twenty total) were used for measuring the metering area surface temperature. For the horizontal heat flow experiments, nine of these sensors were attached to the hot surface of the test panel in an area weighted array along the centerline of each of the three metering area cavities. For the vertical heat flow experiments, three thermocouples were attached to the hot surface of the test panel in an area weighted array along the centerline of one of the two metering area cavities. The remaining six thermocouples were installed in a two by three array along lines trisecting the width of the cavity. For all experiments, the tenth thermocouple was located near the center of the metering area directly on top of a stud. The cold surface instrumentation was mounted directly opposite the hot side thermocouples. All surface thermocouples were "thermally grounded by taping at least 4 inches of wire to the panel surface.

An array of six hot side air temperature sensors were mounted in an equal area array in the metered area on the hot side. Four additional air temperature sensors were mounted inside the guard box, 6 inches from the centerpoint of each side of the metering box. A similar array of ten thermocouples were installed to measure the cold side air temperature. All air temperature sensors were mounted in the middle of the air space between the test panel surfaces and baffles, 3 inches from the test panel surfaces.

In addition to the instrumentation routinely used when performing guarded hot box experiments, 34 thermocouples were installed to measure the temperature of critical locations inside the test panel. A set of thermocouples was installed in an area weighted array on each major internal 
surface (inside each sheathing, on the central foil in a two-airspace cavity, and on each foil in four-airspace cavity). Depending on the emittance of the instrumented surface, the thermocouples were attached and thermally grounded to the surface with either aluminum foil or duct tape. These sensors directly measured the temperature difference across the cavity and each individual airspace within the cavity. Five thermocouples were installed in a "X" pattern on one of the central studs to measure the temperature of the interfaces between the stud and sheathings and therefore the temperature difference across the stud. Small grooves were cut into the faces of the studs to accomodate these sensors. Thermocouples were also installed on each side on the convective breaks and the studs forming the boundaries of the metering area to measure the temperature difference and therefore the energy exchange between the metering area and the surrounding cavities.

Figures 9 through 13 detail the typical locations of the internal temperature sensors installed in the test panels. A different distribution of sensors was utilized for the different heat flow directions and for test panels containing a different number of air spaces within the cavity.

\section{TEST PANEL THERMAL RESISTANCE TEST PROCEDURE}

The test panels were evaluated in accordance with ASTM C 236-87, "steady-state Thermal Performance of Building Assemblies by Means of a Guarded Hot Box". A schematic diagram of the test facility is shown in Figure 14. Two guarded hot boxes were used in the performance of this program; all horizontal heat flow experiments were performed 


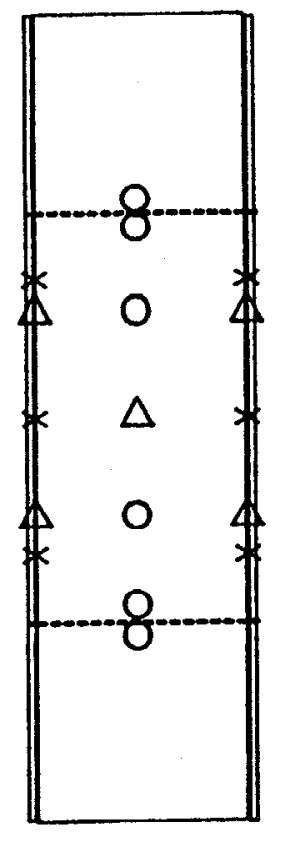

.........- Metering Area

$\triangle \quad$ Stud $T / C$

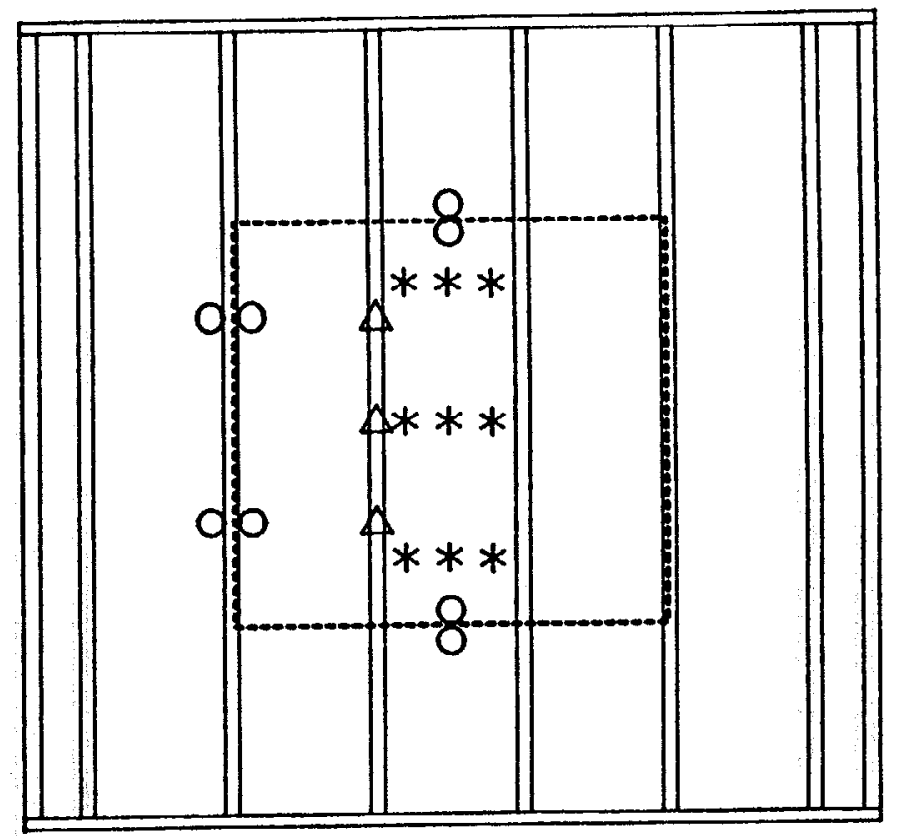

* Inside Surface $\mathrm{T} / \mathrm{C}$

O Metering Box Perimeter T/C

FIGURE 9: Single Airspace Horizontal Heat Flow Test Panel Internal T/C Layout. 


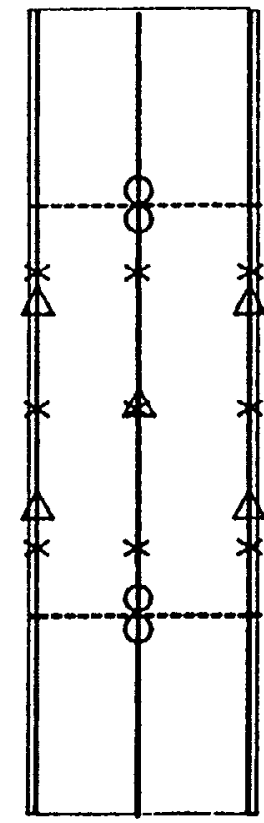

Metering Area

$\triangle \quad$ stud $T / C$

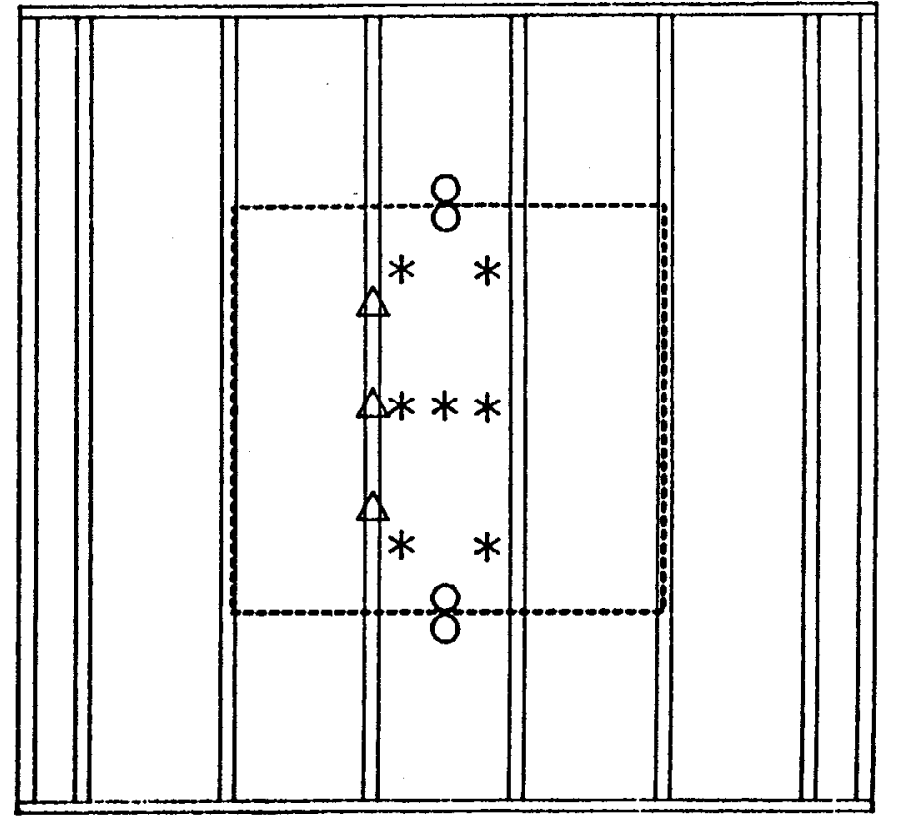

* Inside Surface T/C

O Metering Box Perimeter T/C

FIGURE 10: Two Airspace Horizontal Heat Flow Test Panel Internal T/C Layout. 


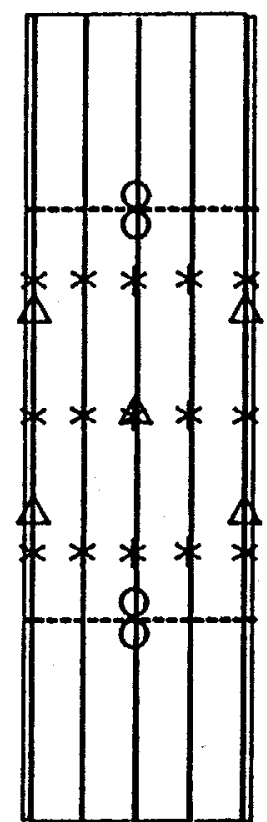

-...... Metering Area $\triangle \quad$ Stud T/C

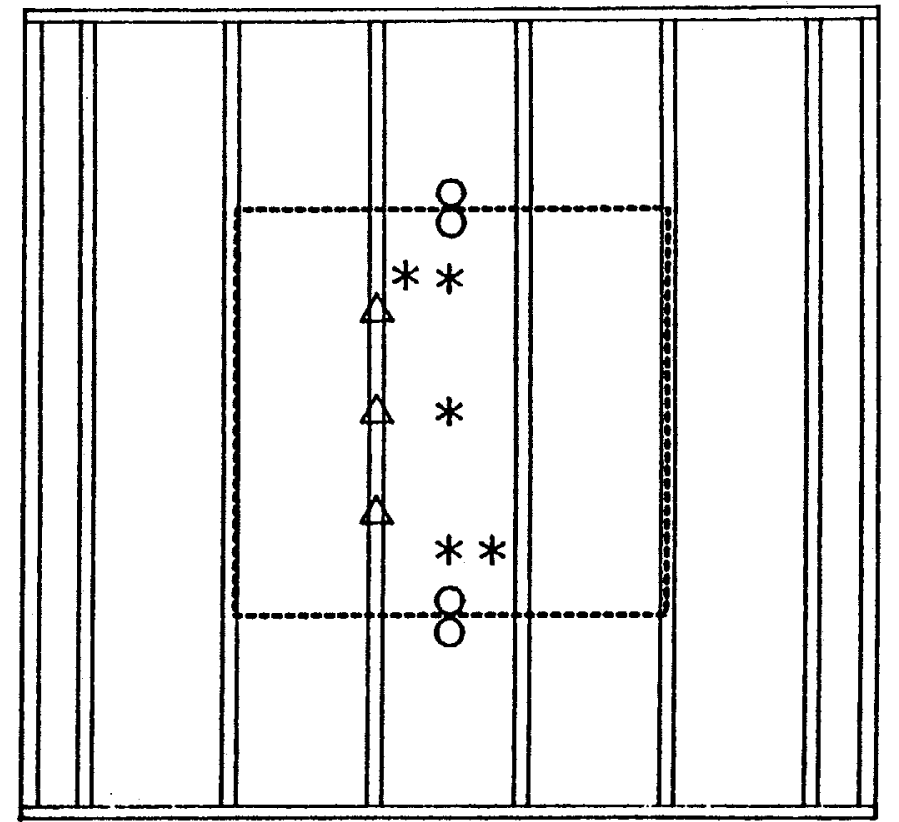

* Inside Surface $\mathrm{T} / \mathrm{C}$

O Metering Box Perimeter T/C

FIGURE 11: Four Airspace Horizontal Heat Flow Test Panel Internal T/C Layout. 


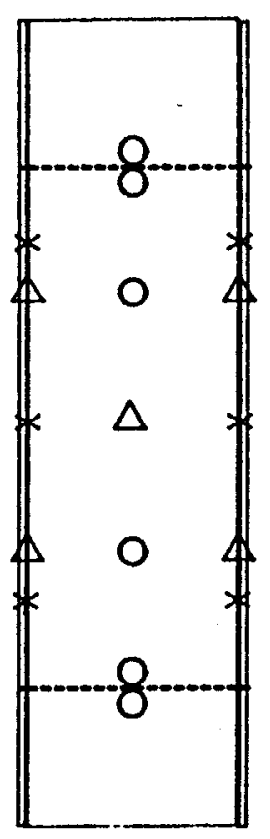

Metering Area

$\triangle$ Stud T/C

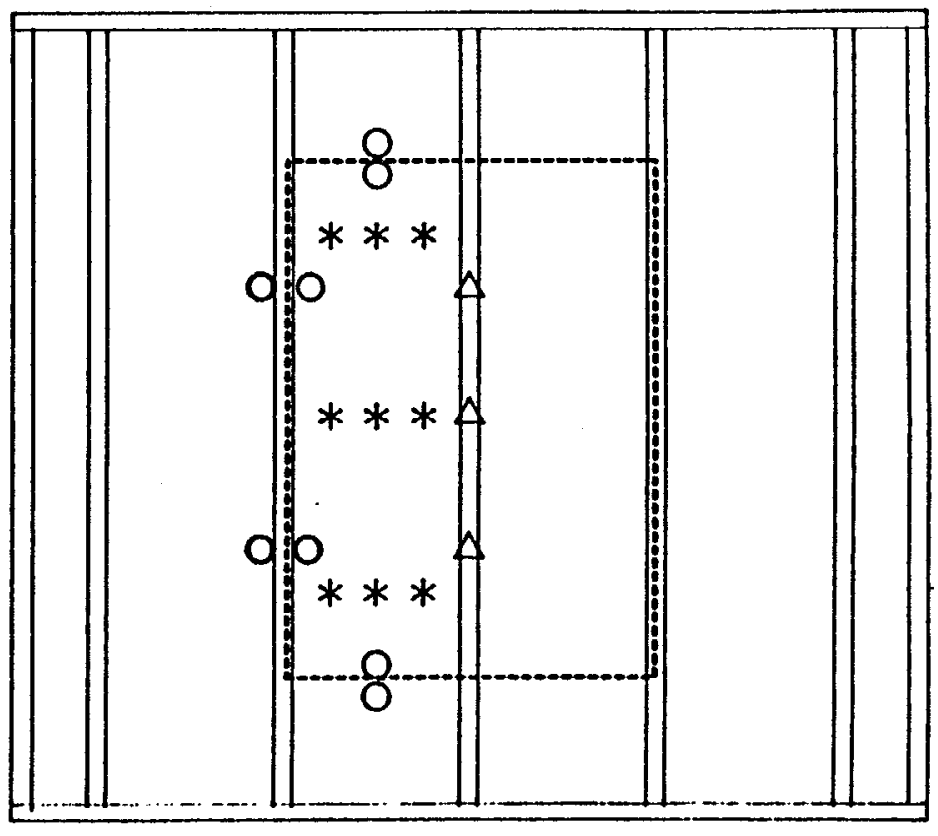

Inside Surface $T / C$

O Metering Box Perimeter T/C

FIGURE 12: Single Airspace Vertical Heat Flow Test Panel Internal T/C Layout. 


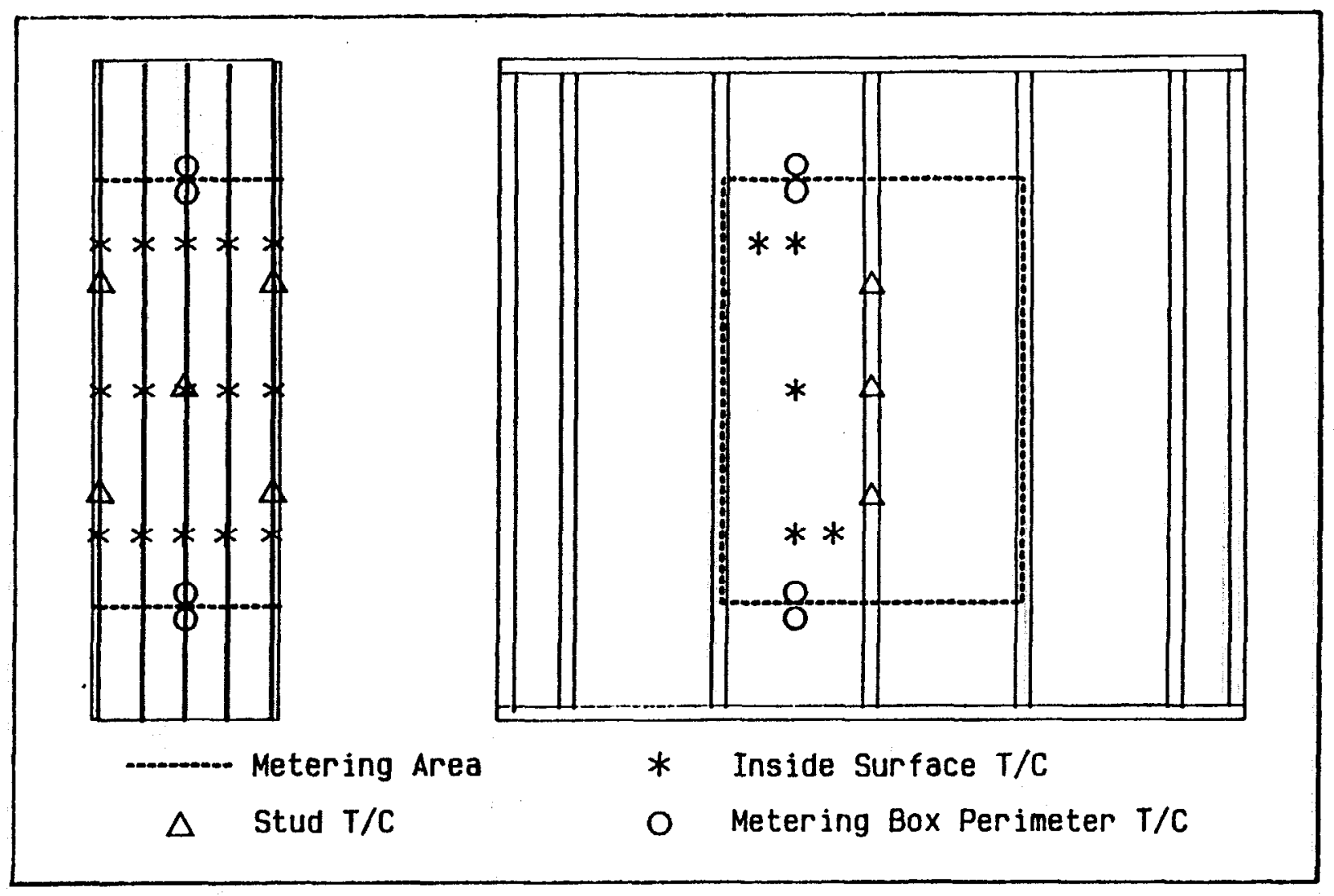

FIGURE 13: Four Airspace Vertical Heat Flow Test Panel Internal T/C Layout. 


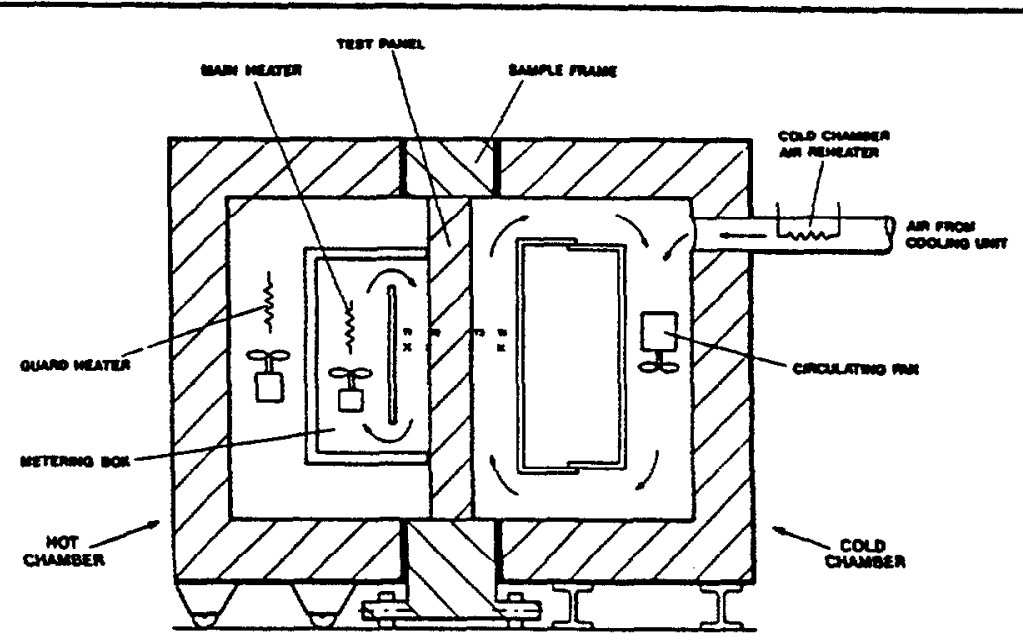

GUARDED HOT BOX FACIUTY FOR LARGE-SCALE THERMML PERFORMANCE TESTING

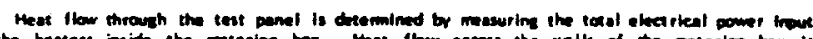

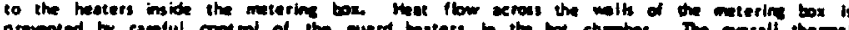
resistence, $k$, of the test paral is enkuloted at folbom:

$$
A=\frac{S\left(T_{2}-T_{3}\right)}{E T}
$$

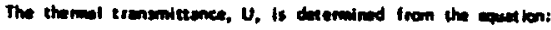

$$
\begin{aligned}
& U=\frac{E I}{S\left(T_{1}-T_{1}\right)} \\
& \text { meres }
\end{aligned}
$$

Figure 14.

SCHEMATIC OF GUARDED HOT BOX FACILITY 
in one test facility and all vertical heat flow experiments were performed in the second test facility. The horizontal heat flow test panels were installed vertically in the center of a 96 by 96 by 96 inch insulated chamber. Vertical heat flow test panels were installed horizontally in the center of a 84 by 84 by 84 inch insulated chamber. The periphery of the test panels was insulated with an extruded polystyrene foam. The thickness of the peripheral foam insulation was equivalent to that of the test panel and adjusted the test panel cross-section to match the instrument requirements. Insertion of the test wall across the center of the chamber created two separate chambers whose temperatures could be independently controlled.

In the cold environmental chamber, a baffle was mounted 6 inches from the test panel. Temperature control in this chamber was accomplished by the insertion of a refrigeration system and an electrical resistance heater in series with an air blower. The refrigeration system was operated continuously and reheating of the air stream was monitored and controlled by temperature sensors in the discharge of the air circulation system. The arrangement of the equipment was such that the air was forced through the refrigerating coils and heater and through the space between the baffle and the test panel. The air velocity parallel to the cold surface of the test panel was controlled to 1.0 ft/sec.

In the center of the hot chamber a metering box was pressed against the test panel. The metering boxes used for the horizontal and vertical heat flow experiments were 48.5 inches square by 24 inches deep and 32.5 inches wide by 48.5 inches high by 24 inches deep respectively. The walls of the metering boxes were constructed of 2 inch thick aged 
extruded polystyrene foam having an approximate thermal resistance of $10 \mathrm{hr} \mathrm{ft}^{2} \mathrm{~F} / \mathrm{Btu}$ at $75 \mathrm{~F}$. These walls were reinforced with an aluminum frame on the interior and exterior surfaces with no physical connections through the insulation.

The edge of the metering box which contacted the test panel was tapered to a thickness of 0.75 inches without affecting the continuity of the internal surface or metering box area and a 0.5 inch square silicone rubber gasket was attached to this tapered edge. A baffle was mounted inside the metering box 6 inches from the exposed edge of the gasket. Behind the baffle, an electrical resistance heater and D.C. fan were installed, arranged such that the fan circulated the air through the heater and between the baffle and test panel. To minimize air impingement on the surfaces of the metering box and to provide a smooth transition into the baffle space, a perforated curved vane was installed near the edge of the baffle downstream from the fan.

A thirty-junction (fifteen pair) differential thermopile was applied on the interior and exterior walls of the metering box to sense the temperature imbalance between the metering and guard boxes. Each interior junction was mounted opposite a corresponding exterior junction with each junction located at the center of equivalent surface areas. Two heaters and fans were mounted in the guard box in opposing corners to supply heat and to circulate the air. The orientation of these units was chosen to prevent the heated air from directly impinging upon the metering box.

Temperature measurements were performed by utilizing Type $T$ copper/Constantan thermocouples. The amount of instrumentation, their location, and the methods of 
attachment are detailed in section 8, Test Panel Temperature Instrumentation. All temperature sensors were individually connected to a digital millivolt meter having a resolution of 1 microvolt.

In operation, the temperature of the cold environmental chamber was set at the desired level. A controllable D.C. power supply was utilized to maintain the required hot surface temperature. A separate D.C. power supply was used to supply energy to the metering box fan. The air velocity in the metering box was controlled by adjustment of this energy input. The air velocity for this series of experiments was $0.6 \mathrm{ft} / \mathrm{sec}$. The output of the differential thermopile was used to drive the heaters in the guard box by utilizing a differential controller. By this technique the temperature difference across the walls of the metering box could be minimized, thereby permitting negligible heat leaks into or out of the metering box. These conditions were maintained until temperatures and heat flows equilibrated. The heat flow generated by the heater and fan in the metering box was measured with precision resistor networks which had been previously calibrated with a NIST traceable voltage source. once steady-state was achieved, the test period was continued until two consecutive four-hour periods produced results that varied nonmonotonically by less than one percent. The data for each four-hour period was the average of hourly results for the period.

The thermal resistance was calculated by

$$
R=\frac{A\left(t_{1}-t_{2}\right)}{q_{H}+q_{F}}
$$


where

$$
\begin{aligned}
\mathrm{R} & =\text { thermal resistance, } \mathrm{hr} \mathrm{ft}^{2} \mathrm{~F} / \mathrm{Btu} ; \\
\mathrm{A} & =\text { sample area, } 16.34 \text { or } 10.95 \mathrm{ft}^{2} ; \\
t_{1}= & \text { area weighted average hot surface temperature, } \mathrm{F} ; \\
t_{2}= & \text { area weighted average cold surface temperature, } \\
& \mathrm{F} ; \\
\mathrm{q}_{\mathrm{H}}= & \text { metering box heater power, Btu/hr; and } \\
q_{F}= & \text { metering box fan power, Btu/hr. }
\end{aligned}
$$

To verify the performance of the two guarded hot boxes operated at Holometrix, measurements have been undertaken on homogeneous test specimens from lots of material that have been evaluated by ASTM C 177 guarded hot plate instrumentation[17] previously verified utilizing the National Institute of standards and Technology Transfer standards. Results have been found to agree within the quoted uncertainty on the standards used. Through participation in one round-robin series of measurements on polyisocyanurate foam board products, the precision of the hot boxes has been shown to be better than 5 percent [18]. More recently, through involvement in the ASTM C-16/NBS Hot Box Round-Robin, the precision of the hot box used for horizontal heat flow testing was shown to be better than 2 percent when compared to the group mean. This round-robin indicated that results with a precision of better than $+/-$ seven percent may be achieved.[19]. The laboratory is also accredited by the Department of commerce through the National Voluntary Laboratory Accredition Program (NVIAP) for performing tests in accordance with ASTM C 236.

The experimental phase of this program lasted 18 months. During this period, the test panel that was 
evaluated for the ASTM C-16/NBS Hot Box Round-Robin was tested five times, twice in the guarded hot box used for vertical heat flow testing and three times in the GHB used to perform horizontal heat flow experiments. The average difference between the round-robin group mean and these experiments was $0.4 \mathrm{hrft}^{2} \mathrm{~F} / \mathrm{Btu}$ or $21 / 2$ percent.

\section{HEAT FIOW THROUGH METERING AREA PERIMETER}

Due to the presence of convective loops within the airspaces, convective blocks were installed at the perimeter of the metering area to prevent any air exchange between the metered and guard areas. Sections of $11 / 2$ inch thick XEPS foam were used along the open portion of the perimeter while the framing members (wood or XEPS) aligned with the remaining perimeter of the metered area (see Figure 4). To determine the energy exchange between the metered and guard areas on selected test panels, temperature sensors were installed on the convective blocks and framing members that formed the exterior boundary of the metering area.

Table 22 details all of the temperature difference measurements performed across the XEPS convective blocks and wood or XEPS framing members forming the outside perimeter of the metering area. A positive temperature difference indicates that the metering area is warmer than the guard area.

The energy exchange between the metering and guard areas was determined using these temperature difference data. The thermal resistances of the XEPS and wood studs in the direction of interest were assumed to be 7.5 and $1.9 \mathrm{hr}$ $\mathrm{ft}^{2} \mathrm{~F} / \mathrm{Btu}$. The same numerical value of thermal resistance 
TABLE 2

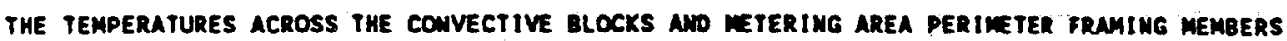
ANO THE ASSOCIATED EMERGT EXCHANGES BETMEEN THE METERING NDO GUND AREAS

\begin{tabular}{|c|c|c|c|c|c|c|c|c|c|c|}
\hline \multirow{2}{*}{$\begin{array}{l}\text { Test } \\
\text { Panel }\end{array}$} & \multirow{2}{*}{$\begin{array}{c}\text { Stud } \\
\text { Material }\end{array}$} & \multirow{2}{*}{$\begin{array}{l}\text { Test } \\
\text { Number }\end{array}$} & \multirow{2}{*}{ o Total } & \multicolumn{4}{|c|}{ Temperature Difference, $f$} & \multicolumn{2}{|c|}{$\begin{array}{l}\text { Meterino Area } \\
\text { a Lost. Itu/hr }\end{array}$} & \multirow{2}{*}{$\frac{\text { a Lost/a Total }}{\text { Percent }}$} \\
\hline & & & & Block 1 & Block 2 & Frene 1 & Frame 2 & block & Prame & \\
\hline \multirow[t]{5}{*}{ in } & XEPS & $H-1$ & 360.7 & 26.8 & -26.9 & 3.4 & $\cdot 9.2$ & 0.0 & -0.9 & -0.3 \\
\hline & & $H \cdot 2$ & 265.0 & 21.1 & -21.7 & 2.9 & .8 .7 & .0 .1 & -0.9 & .0 .4 \\
\hline & & $H-3$ & 189.0 & 15.4 & -15.9 & 2.1 & -5.8 & -0.1 & -0.6 & -0.3 \\
\hline & & $H-6$ & 117.3 & 10.0 & -10.3 & 1.5 & .4 .0 & 0.0 & -0.6 & .0 .4 \\
\hline & & $H \cdot 5$ & 50.8 & 6.7 & -6.6 & 0.8 & -4.2 & 0.0 & -0.5 & $\cdot 1.0$ \\
\hline \multirow[t]{5}{*}{18} & XEPS & $n \cdot 6$ & 626.7 & 62.4 & .32 .8 & $\cdots$ & $\cdots$ & 4.7 & & 1.1 \\
\hline & & $H \cdot 7$ & 356.0 & 54.6 & -28.1 & $\cdots$ & $\cdots$ & 4.1 & & 1.2 \\
\hline & & $H-8$ & 246.4 & 41.1 & -19.8 & $\cdots$ & $\cdots$ & 3.3 & & 1.4 \\
\hline & & H-9 & 143.0 & 25.9 & $\cdot 12.2$ & $\cdots$ & $\cdots$ & 2.2 & & 1.5 \\
\hline & & $n-90$ & 60.2 & 12.5 & -4.8 & $\cdots$ & $\cdots$ & 1.2 & & 2.0 \\
\hline \multirow[t]{6}{*}{$2 A$} & 1000 & $H \cdot 11$ & 330.9 & 23.6 & -26.2 & 3.4 & $\cdot 5.2$ & -0.6 & 0.1 & .0 .1 \\
\hline & & $\mathrm{H}-12$ & 251.9 & 18.5 & -19.1 & 4.3 & -4.1 & -0.1 & 0.1 & 0.0 \\
\hline & & $H-13$ & 191.0 & 14.1 & $\cdot 16.3$ & 3.2 & -3.2 & 0.0 & 0.0 & 0.0 \\
\hline & & $H \cdot 14$ & 111.7 & 8.5 & -8.4 & 2.0 & .2 .0 & 0.0 & 0.0 & 0.0 \\
\hline & & $H-15$ & 51.5 & 4.0 & -3.9 & 1.2 & $=0.7$ & 0.0 & 0.3 & 0.6 \\
\hline & & $y \cdot 16$ & 333.1 & 25.4 & -26.0 & 3.0 & $\cdot 7.2$ & -0.1 & -1.4 & .0 .4 \\
\hline \multirow[t]{6}{*}{28} & 10000. & $H-17$ & 416.2 & 69.0 & -58.9 & $\cdots$ & $\cdots$ & 1.6 & & 0.4 \\
\hline & & $H-18$ & 350.6 & 60.3 & -51.8 & $\cdots$ & $\cdots$ & 1.3 & & 0.4 \\
\hline & & $H-19$ & 236.7 & 41.6 & $\cdot 36.5$ & $\cdots$ & $\cdots$ & 0.8 & & 0.3 \\
\hline & & $N-20$ & 137.5 & 25.3 & -23.1 & $\cdots$ & $\ldots$ & 0.3 & & 0.3 \\
\hline & & $N-21$ & 56.9 & 11.0 & -10.1 & $\cdots$ & $\cdots$ & 0.1 & & 0.2 \\
\hline & & H.22 & 23.7 & 4.5 & .4 .1 & $\cdots$ & $\cdots$ & 0.1 & & 0.3 \\
\hline \multirow[t]{6}{*}{$2 c$} & 10000 & $H-23$ & 154.2 & 30.3 & -32.1 & $\cdots$ & $\cdots$ & -0.3 & & .0 .2 \\
\hline & & H. 24 & 196.0 & 23.2 & -24.3 & $\cdots$ & $\cdots$ & -0.2 & & -0.1 \\
\hline & & $11 \cdot 25$ & 81.7 & 16.2 & -17.7 & $\cdots$ & $\cdots$ & -0.2 & & -0.3 \\
\hline & & $n-26$ & 55.2 & 10.2 & -11.3 & $\cdots$ & $\cdots$ & -0.2 & & -0.3 \\
\hline & & $H \cdot 27$ & 22.7 & 3.9 & -4.3 & $\cdots$ & $\cdots$ & -0.1 & & -0.3 \\
\hline & & $k-28$ & 149.6 & 32.8 & .33 .6 & $\cdots$ & $\cdots$ & -0.1 & & -0.1 \\
\hline \multirow[t]{6}{*}{$3 A$} & XEPS & H-29 & 292.3 & 22.9 & .21 .9 & 5.6 & .5 .5 & 0.2 & 0.0 & 0.1 \\
\hline & & $k \cdot 30$ & 230.7 & 18.8 & .17 .6 & 4.8 & -6.1 & 0.2 & 0.1 & 0.1 \\
\hline & ' & $n-31$ & 153.7 & 13.2 & -10.9 & 3.4 & -3.3 & 0.6 & 0.0 & 0.2 \\
\hline & & $N \cdot 32$ & 95.3 & 8.5 & .6 .9 & 2.3 & -2.2 & 0.3 & 0.0 & 0.3 \\
\hline & & H.33 & 49.5 & 4.9 & -3.3 & 1.6 & -0.9 & 0.3 & 0.1 & 0.7 \\
\hline & & H.34 & 292.8 & 23.4 & -22.4 & 4.0 & -8.2 & 0.2 & -0.7 & -0.2 \\
\hline
\end{tabular}

Note: For horizontal heat flow experiments, Blocks 1 and 2 are at the top and botton of the metering area respectively and frames 1 and 2 are at the top and bottom of a single framing menber. See Figures 9 thragh 13 . 
TABLE 22 (Cont)

THE TEMPERATURES ACROSS TME CONVECTIVE BLOCKS AND METERIMG AREA PERIMETER FRAMING WEMBERS AND THE ASSOCIATED ENERGY EXCHANGES BETMEEN THE METERING AND EUND AREAS

\begin{tabular}{|c|c|c|c|c|c|c|c|c|c|c|c|}
\hline \multirow{2}{*}{$\begin{array}{l}\text { Test } \\
\text { Penel }\end{array}$} & \multirow[b]{2}{*}{$\begin{array}{c}\text { Stud } \\
\text { Heterial }\end{array}$} & \multirow[b]{2}{*}{$\begin{array}{l}\text { Test } \\
\text { Number }\end{array}$} & \multirow{2}{*}{ O Total } & \multicolumn{2}{|c|}{ Tempersture } & Difference, & $F$ & \multicolumn{2}{|c|}{ Metering area } & \multicolumn{2}{|c|}{ a Lost/a Totel } \\
\hline & & & & 8 lock 1 & Block 2 & Frane $1 \mathrm{f}$ & Frane 2 & Block & Prene & Percent & \\
\hline \multirow[t]{6}{*}{38} & XEPS & $H \cdot 35$ & 367.1 & 52.3 & .37 .6 & $\cdots$ & $\cdots$ & 2.3 & & & 0.6 \\
\hline & & $H \cdot 36$ & 299.4 & 40.1 & .31 .2 & $\cdots$ & $\cdots$ & 1.6 & & & 0.5 \\
\hline & & $n \cdot 37$ & 205.6 & 29.0 & -20.9 & $\cdots$ & $\cdots$ & 1.3 & & & 0.6 \\
\hline & & $H=\mathbf{3 8}$ & 119.2 & 18.0 & -12.5 & $\cdots$ & $\cdots$ & 0.9 & & & 0.7 \\
\hline & & $H \cdot 39$ & 50.1 & 8.3 & -4.8 & $\cdots$ & $\cdots$ & 0.6 & & & 1.1 \\
\hline & & $H \cdot 40$ & 21.1 & 3.7 & -1.8 & $\cdots$ & $\cdots$ & 0.3 & & & 1.6 \\
\hline \multirow[t]{6}{*}{$3 C$} & XEPS & $n-41$ & 146.3 & 36.3 & .29 .8 & $\cdots$ & $\cdots$ & 1.0 & & & 0.7 \\
\hline & & $H-42$ & 109.0 & 26.6 & $\cdot 18.8$ & $\cdots$ & $\cdots$ & 1.2 & & & 1.1 \\
\hline & & $H-43$ & 73.2 & 16.2 & .14 .7 & $\cdots$ & $\cdots$ & 0.2 & & & 0.3 \\
\hline & & $n-44$ & 44.9 & 11.6 & .8 .8 & $\cdots$ & $\cdots$ & 0.4 & & & 1.0 \\
\hline & & $n-45$ & 20.7 & 4.8 & -3.1 & $\cdots$ & $\cdots$ & 0.3 & & & 1.3 \\
\hline & & $x-46$ & 133.4 & 32.5 & -32.0 & $\cdots$ & $\cdots$ & 0.1 & & & 0.1 \\
\hline $4 A$ & XEPS & $H \cdot 47$ & 73.6 & $\cdots$ & $\cdots$ & $\cdots$ & $\cdots$ & & & & \\
\hline 48 & $\$ 000$ & $H=48$ & 83.6 & $\cdots$ & $\cdots$ & $\cdots$ & $\therefore$ & & & & \\
\hline \multirow[t]{12}{*}{ IIA } & XEPS & $v-10$ & 277.1 & -1.0 & 3.4 & 0.2 & 1.6 & 0.3 & 0.3 & & 0.2 \\
\hline & & $v-2 u$ & 217.5 & .0 .9 & 2.7 & 0.1 & 1.3 & 0.2 & 0.2 & & 0.2 \\
\hline & & $v-3 u$ & 155.9 & -0.9 & 2.1 & 0.2 & 1.1 & 0.1 & 0.2 & & 0.2 \\
\hline & & $v \cdot 4 v$ & 93.6 & -0.7 & 1.4 & 0.1 & 0.7 & 0.1 & 0.1 & & 0.2 \\
\hline & & $v-5 u$ & 43.6 & -0.1 & 0.8 & 0.3 & 0.7 & 0.1 & 0.2 & & 0.5 \\
\hline & & $v-6 u$ & 301.4 & $\cdot 2.2$ & 1.9 & -0.3 & 1.0 & 0.0 & 0.1 & & 0.0 \\
\hline & & $v=70$ & 68.5 & -0.5 & 1.4 & $\cdots$ & $\therefore$ & 0.1 & & & 0.1 \\
\hline & & $v-80$ & 55.1 & $\cdot 0.3$ & 1.1 & $\therefore$ & $\cdots$ & 0.1 & & & 0.2 \\
\hline & & $v-90$ & 37.7 & -0.2 & 0.9 & $\cdots$ & $\cdots$ & 0.1 & & & 0.2 \\
\hline & & $v-100$ & 25.2 & 0.1 & 0.5 & $\cdots$ & $\cdots$ & 0.1 & & & 0.2 \\
\hline & & $y-110$ & 10.3 & 0.1 & 0.3 & $\cdots$ & $\cdots$ & 0.0 & & & 0.5 \\
\hline & & $y-120$ & 75.9 & -0.8 & 0.1 & $\cdots$ & $\cdots$ & -0.1 & & & -0.1 \\
\hline \multirow[t]{6}{*}{$12 a$} & 1000 & $v-13 u$ & 313.6 & -0.3 & .0 .4 & -1.3 & -2.0 & .0 .1 & -3.3 & & -1.1 \\
\hline & & $V-16 U$ & 239.8 & .0 .9 & -3.1 & -0.4 & -2.0 & -0.7 & -2.6 & & -1.3 \\
\hline & & $v-15 U$ & 160.4 & $\cdot 0.1$ & $\cdot 2.1$ & 0.6 & -1.8 & .0 .4 & .1 .2 & & -1.0 \\
\hline & & $v-16 u$ & 103.5 & 0.3 & -1.5 & 1.0 & -0.5 & -0.2 & 0.5 & & 0.3 \\
\hline & & $v-17$ & 32.1 & 0.2 & -1.0 & $\cdot 0.2$ & -1.4 & -0.1 & -1.6 & & -5.6 \\
\hline & & $v-18 u$ & 294.6 & 0.2 & .5 .6 & .0 .8 & -2.3 & .0 .9 & -3.1 & & -1.6 \\
\hline
\end{tabular}


TABLE 22 (Cont)

THE teMPERATURES ACROSS THE CONVECTIVE OLOCKS AND METERING AREA PERINETER FRUING MEMBERS AMD THE ASSOCIATED EMERGT EXCHAMGES BETMEEM THE METERIMG ANO QURO AREAS

\begin{tabular}{|c|c|c|c|c|c|c|c|c|c|c|}
\hline \multirow{2}{*}{$\begin{array}{l}\text { Pest } \\
\text { Panet }\end{array}$} & \multirow{2}{*}{$\begin{array}{c}\text { stud } \\
\text { Material }\end{array}$} & \multirow{2}{*}{$\begin{array}{c}\text { Test } \\
\text { Number }\end{array}$} & \multirow{2}{*}{ o Potal } & \multicolumn{4}{|c|}{ Temperature Difference, $F$} & \multicolumn{2}{|c|}{$\begin{array}{l}\text { Metering Area } \\
\text { - Lost. Btw/hr }\end{array}$} & \multirow{2}{*}{ Q Lost/a Totel } \\
\hline & & & & Block 1 & Block 2 & Frame 1 & Frame 2 & Block & freme & \\
\hline \multirow[t]{6}{*}{$12 \AA$} & 1000 & $v \cdot 190$ & 81.9 & $\cdot 1.2$ & 2.1 & 0.4 & -0.1 & 0.1 & 0.3 & 0.5 \\
\hline & & $v \cdot 200$ & 63.7 & .0 .9 & 1.7 & 0.4 & -0.1 & 0.1 & 0.6 & 0.8 \\
\hline & & $V \cdot 210$ & 45.5 & -0.6 & 9.4 & 0.2 & .0 .1 & 0.1 & 0.1 & 0.6 \\
\hline & & $v \cdot 220$ & 30.7 & -0.3 & 0.5 & 0.3 & 0.1 & 0.0 & 0.4 & 1.4 \\
\hline & & $v \cdot 230$ & 17.5 & 0.1 & 0.4 & 0.2 & 0.0 & 0.1 & 0.2 & 1.7 \\
\hline & & $v \cdot 240$ & 75.0 & -1.0 & 1.6 & 0.6 & $\cdot 0.3$ & 0.1 & 0.2 & 0.4 \\
\hline \multirow[t]{6}{*}{128} & 10000 & $v-250$ & 40.1 & 0.6 & -3.5 & $\cdots$ & $\cdots$ & .0 .5 & & $\cdot 9.2$ \\
\hline & & $v-260$ & 31.7 & 0.9 & -1.9 & $\cdots$ & $\cdots$ & .0 .2 & & -0.5 \\
\hline & & $v-270$ & 24.8 & 1.1 & .1 .1 & $\ldots$ & $\ldots$ & 0.0 & & 0.0 \\
\hline & & $v \cdot 280$ & 14.5 & 0.8 & .0 .2 & $\cdots$ & $\cdots$ & 0.1 & & 0.7 \\
\hline & & $v-290$ & 7.4 & -0.3 & 0.0 & $\cdots$ & $\cdots$ & 0.0 & & .0 .6 \\
\hline & & $v-300$ & 40.3 & 1.1 & -2.5 & $\cdots$ & $\cdots$ & -0.2 & & -0.6 \\
\hline $12 c$ & 1000 & $v-3 w$ & 39.6 & $\cdots$ & $\cdots$ & $\cdots$ & $\ldots$ & & & \\
\hline \multirow[t]{12}{*}{131} & XEPS & $v \cdot 32 v$ & 287.7 & $=0.7$ & .4 .1 & -0.2 & -2.9 & -0.8 & -0.8 & -0.5 \\
\hline & & $v-33 u$ & 218.6 & -0.6 & -3.0 & 0.1 & -3.0 & -0.6 & -0.7 & -0.6 \\
\hline & & $v \cdot 340$ & 153.9 & $\cdot 1.0$ & -2.2 & 0.8 & -1.7 & -0.5 & -0.2 & -0.5 \\
\hline & & $v-35 U$ & 94.7 & .0 .6 & -1.6 & 0.5 & .0 .8 & -0.3 & -0.1 & -0.4 \\
\hline & & $v \cdot 36 u$ & 38.8 & .0 .2 & 0.6 & 0.8 & -1.9 & 0.1 & -0.3 & .0 .5 \\
\hline & & $v-370$ & 291.7 & -2.3 & -0.8 & -0.3 & -4.2 & -0.5 & -1.1 & .0 .6 \\
\hline & & $V \cdot 380$ & 72.7 & -2.6 & -1.8 & 0.3 & -0.1 & -0.7 & 0.0 & -0.9 \\
\hline & & $v \cdot 390$ & 58.4 & .0 .6 & -2.0 & -0.1 & -0.1 & -0.4 & 0.0 & -0.8 \\
\hline & & $v \cdot 400$ & 42.7 & 0.0 & -9.6 & 0.0 & -0.3 & -0.3 & -0.1 & $\cdot 0.8$ \\
\hline & & $v \cdot 410$ & 26.2 & 0.5 & $\cdot 0.5$ & 0.0 & -0.2 & 0.0 & 0.0 & .0 .1 \\
\hline & & $v-420$ & 13.0 & 0.4 & $\cdot 0.2$ & 0.1 & 0.0 & 0.0 & 0.0 & 0.4 \\
\hline & & $v \cdot 430$ & 67.4 & -1.2 & -1.8 & 0.6 & -0.2 & -0.5 & 0.1 & -0.6 \\
\hline \multirow[t]{6}{*}{ 13B } & XEPS & $v \cdot 640$ & 36.7 & 2.5 & -1.4 & $\cdots$ & $\ldots$ & 0.2 & & 0.5 \\
\hline & & $v-450$ & 26.8 & 2.1 & .1 .1 & $\ldots$ & $\cdots$ & 0.2 & & 0.6 \\
\hline & & $v-460$ & 19.9 & 1.9 & -0.9 & $\ldots$ & $\ldots$ & 0.2 & & 0.8 \\
\hline & & $v \cdot 470$ & 12.7 & 1.1 & -0.2 & $\cdots$ & $\cdots$ & 0.1 & & 1.1 \\
\hline & & $v \cdot 480$ & 5.9 & 0.8 & 0.1 & $\cdots$ & ... & 0.1 & & 2.4 \\
\hline & & $v \cdot 490$ & 31.8 & 1.7 & -1.4 & $\cdots$ & $\cdots$ & 0.0 & & 0.2 \\
\hline 136 & XEPS & $v \cdot 500$ & 33.4 & $\cdots$ & $\cdots$ & $\cdots$ & $\cdots$ & & & \\
\hline
\end{tabular}


used for the XEPS stud was assigned to the convective blocks. The individual energy exchanges were calculated by dividing the product of the temperature difference and perimeter cross-sectional area by the thermal resistance of the material comprising the perimeter. The net energy exchange was determined by summing the heat flows through the framing members and convective blocks. A positive energy exchange or $Q$ Lost indicates a metering area heat loss.

The metering area energy exchanges in Btu/hr through the convective blocks ( $Q$ Lost LI $_{\mathrm{B}}$ ), through the framing members ( $Q$ Lost $_{\mathrm{Fr}}$ ), and their percentage of the total energy input ( $Q$ Lost $/ Q$ Total) were determined by:

$$
\begin{aligned}
& Q \text { Lost }_{\mathrm{Bl}}=\left[\left(d \mathrm{~T}_{\mathrm{Bl} 1}+d \mathrm{~T}_{\mathrm{Bl2}}\right) / 2\right] * \mathrm{~A}_{\mathrm{Bl}} / \mathrm{R}_{\mathrm{Bl}} ; \\
& Q \text { Lost }_{\mathrm{Fr}}=\left[\left(\mathrm{dT}_{\mathrm{Fr} 1}+\mathrm{dT}_{\mathrm{Fr} 2}\right) / 2\right] * \mathrm{~A}_{\mathrm{Fr}} / \mathrm{R}_{\mathrm{Fr}} ; \text { and }
\end{aligned}
$$

$Q$ Lost $/ Q$ Total $=\left[\left(Q\right.\right.$ Lost $_{B I}+Q$ Lost $\left._{F r}\right) / Q$ Total $] * 100$

where

$$
\begin{aligned}
& \mathrm{dT}_{\mathrm{Bl}}=\underset{\text { temperature }}{\text { block } 1, \mathrm{~F} ;} \text { difference across convective } \\
& \mathrm{dT}_{\mathrm{B} 12}=\underset{\text { temperature difference across convective }}{\text { block 2, F; }} \\
& A_{B 1}=\text { total cross-sectional area of the convec- }
\end{aligned}
$$

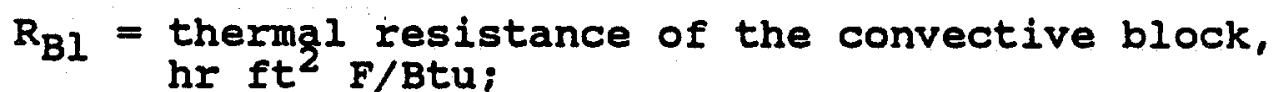

$$
\begin{aligned}
& d T_{\text {Fr1 }}=\begin{array}{l}
\text { temperature difference across framing mem- } \\
\text { ber at one location, } F ;
\end{array} \\
& \begin{aligned}
& \mathrm{dT}_{\mathrm{Fr} 2}= \text { temperature difference across' framing mem- } \\
& \text { ber at a second location, } \mathrm{F} ;
\end{aligned}
\end{aligned}
$$




$$
\begin{aligned}
\mathrm{A}_{\mathrm{Fr}}= & \text { total cross-sectional area of the framing } \\
& \text { materials on perimeter of the metering } \\
& \text { area, ft } ; \\
\mathrm{R}_{\mathrm{Fr}}= & \text { thermal resistance of the framing material, } \\
& \mathrm{hr} \mathrm{ft}^{2} \mathrm{~F} / \mathrm{Btu} \text {; and } \\
\mathrm{Q} \text { Total = } & \text { the total metering box energy input, Btu/ } \\
& \mathrm{hr} .
\end{aligned}
$$

For example, Test Number $\mathrm{H}-11$ had temperature differences of 23.6 and $-26.2 F$ across the two convective blocks and 5.4 and $-5.2 F$ at two locations across a wood framing member. The average temperature differences across the convective blocks and the framing members were $[23.6+$ $(-26.2)] / 2$ and $[5.4+(-5.2)] / 2$ or $-1.3 F$ and $0.1 F$ respectively. The areas of the convective blocks and framing members for this experiment were $2.36 \mathrm{ft}^{2}$ [(48.5 inches) (2) (3.5 inches)/(144 inches $\left.\mathrm{ft}^{-2}\right)$ ]. For this test, the energy exchange across the convective blocks was -0.4 $\mathrm{Btu} / \mathrm{hr}\left[(-1.3 \mathrm{~F})\left(2.36 \mathrm{ft}^{2}\right) /\left(7.5 \mathrm{hr} \mathrm{ft}^{2} \mathrm{~F} / \mathrm{Btu}\right)\right]$. Since this test panel was constructed with wood framing members, the energy exchange across the framing members was $0.1 \mathrm{Btu} / \mathrm{hr}$ $\left[(0.1 \mathrm{~F})\left(2.36 \mathrm{ft}^{2}\right) /\left(1.9 \mathrm{hr} \mathrm{ft}^{2} \mathrm{~F} / \mathrm{Btu}\right)\right]$. The areas used for the convective blocks for the test panels constructed with 2 $x 4$ and $2 \times 6$ framing members and tested with vertical heat flow were 1.58 and $2.48 \mathrm{ft}^{2}$ respectively. The areas used for the framing members in conjunction with the same test panels were 2.36 and $3.71 \mathrm{ft}^{2}$ respectively.

As anticipated, the temperature gradients across the framing members and convective blocks were much smaller for the vertical heat flow experiments because of the smaller temperature gradients along the perimeter of the metering area for these experiments. Temperature differences of up to $69 \mathrm{~F}$ (Test Number $\mathrm{H}-17$ ) were noted across the convective 
blocks but these differences were always coupled with an approximately equivalent temperature difference across the opposing block. The largest mismatch between the temperature differences across the convective blocks was 14.8F (Test Number H-6). Temperature differences across the framing members were performed at two length-weighted locations across a single stud. The largest single temperature difference across a framing member was $9.2 \mathrm{~F}$ (Test $\mathrm{H}-1$ ) and the largest net temperature difference across the framing members for a single experiment was $2.9 \mathrm{~F}$ (Test $\mathrm{H}-1$ ).

Table 22 lists the calculated energy losses through the convective blocks and framing members and expresses those losses as a percentage of the total metering area energy input. The metering area perimeter energy exchange had its largest input on Test $v-17 U$, accounting for 5.4 percent of the total metering area energy input. The average metering area energy exchange with the guard was less than 0.1 percent.

This energy exchange is not included any subsequent calculations. ASTM C 236 does not include a protocol for accounting for this exchange, and the average effect of this exchange is small. The results of this section indicate that guarded hot boxes can be used to accurately measure test panels with large convective heat transfer components when convective blocks are utilized because of the symmetry of the experiment. 
The test panel hot and cold surface temperatures (HS and $(S)$, mean temperature and temperature difference ( $T_{\text {mean }}$ and $\mathrm{dT}$ ), the measured total energy input ( $\left.Q_{\text {total }}\right)$, and the test panel surface-to-surface thermal resistance for the experiments performed are summarized in the Table 23 and graphically represented in Figures 15 through 20 . The reported temperatures were determined by averaging all the temperature sensors on the surface in question. Each experiment performed on a test panel was given a two-digit test number: the first digit designated the heat flow direction ( $H$ for horizontal and $V$ for vertical heat flow) and the second digit identified the test number ( 1 to 48 and 1 to 50 for the horizontal and vertical heat flow experiments respectively). A suffix (U or D) was added to the vertical heat flow experiments to designate whether the experiment was performed with heat flow up (U) or down (D).

The panel thermal resistance test results gathered at the predominant airspace mean temperature were fitted as a function of test panel temperature difference. These curvefit coefficients are listed in Table 24. When comparisons between test panels are discussed in the following sections of this report, the panel thermal resistance with a temperature difference of 30F, $R_{p}(30)$, calculated based on these curve-fit coefficients, is frequently used. Table 24 also lists $R_{p}(30)$ values for the test panels.

To compare these test results to data previously gathered by other researchers, it is necessary to adjust the results for the sheathing materials used. A composite stud/cavity thermal resistance can be computed. by subtracting twice the sheathing thermal resistance found in 
TABLE 23

THE EXPERIMENTAL CONDITIONS AMD THE MEASURED PANEL THERMAL RESISTANCE OF SEVENTEEN TEST PANELS CONTAINING REFLECTIVE OR MASS INSULATION MATERIALS

\begin{tabular}{|c|c|c|c|c|c|c|c|c|c|c|c|}
\hline \multirow{2}{*}{$\begin{array}{l}\text { Test } \\
\text { Panel }\end{array}$} & \multirow{2}{*}{$\begin{array}{c}\text { Stud } \\
\text { Material }\end{array}$} & \multirow{2}{*}{$\begin{array}{l}\text { No. of } \\
\text { Airspaces }\end{array}$} & \multirow{2}{*}{$\begin{array}{c}\text { Airspace } \\
\text { E }\end{array}$} & \multirow{2}{*}{$\begin{array}{l}\text { Test } \\
\text { Number }\end{array}$} & \multicolumn{4}{|c|}{ Temperature, $\mathbf{p}$} & \multirow{2}{*}{ a Total } & \multicolumn{2}{|c|}{ Panel } \\
\hline & & & & & HS & cs & Tmeen & dT & & \multicolumn{2}{|c|}{$\mathrm{hr}+\mathrm{ft}^{\wedge} \mathbf{2} \mathrm{F} / \mathrm{Btu}$} \\
\hline \multirow[t]{5}{*}{ 1A } & XEPS & 1 & 0.05 & $H-1$ & 82.6 & 18.7 & 50.7 & 63.9 & 340.7 & & 3.06 \\
\hline & & & & $H \cdot 2$ & 76.3 & 25.0 & 50.7 & 51.3 & 265.0 & & 3.16 \\
\hline & & & & $\mathrm{H} \cdot 3$ & 69.3 & 31.5 & 50.4 & 37.8 & 189.0 & & 3.27 \\
\hline & & & & $H \cdot 4$ & 64.0 & 38.4 & 51.2 & 25.6 & 117.3 & & 3.57 \\
\hline & & & & $H \cdot 5$ & 56.6 & 44.2 & 50.4 & 12.4 & 50.8 & & 3.99 \\
\hline \multirow[t]{5}{*}{18} & XEPS & 2 & 0.05 & $H-6$ & 128.5 & 17.1 & 72.8 & 111.4 & 426.7 & & 4.26 \\
\hline & & & & $H \cdot 7$ & 121.4 & 24.3 & 72.9 & 97.1 & 356.0 & & 4.46 \\
\hline & & & & $H \cdot 8$ & 101.9 & 30.7 & 66.3 & 71.2 & 244.4 & & 4.76 \\
\hline & & & & $H \cdot 9$ & 84.2 & 37.3 & 60.8 & 46.9 & 143.0 & & 5.36 \\
\hline & & & & $H \cdot 10$ & 67.0 & 43.9 & 55.5 & 23.1 & 60.2 & & 6.27 \\
\hline \multirow[t]{6}{*}{$2 A$} & woon & 1 & 0.03 & $M-11$ & 107.8 & 44.8 & 76.3 & 63.0 & 330.9 & & 3.11 \\
\hline & & & & $H \cdot 12$ & 100.0 & 50.4 & 75.2 & 49.6 & 251.9 & & 3.22 \\
\hline & & & & $H-13$ & 94.3 & 55.5 & 74.9 & 38.8 & 191.0 & & 3.32 \\
\hline & & & & $H-14$ & 87.4 & 63.2 & 75.3 & 24.2 & 111.7 & & 3.54 \\
\hline & & & & $n-15$ & 81.8 & 69.5 & 75.7 & 12.3 & 51.5 & & 3.91 \\
\hline & & & & $H-16$ & 83.7 & 20.3 & 52.0 & 63.4 & 333.1 & & 3.11 \\
\hline \multirow[t]{6}{*}{28} & 1000 & 2 & 0.03 & $H-17$ & 127.5 & 18.4 & 73.0 & 109.1 & 416.2 & & 4.28 \\
\hline & & & & $H-18$ & 103.1 & 9.4 & 56.3 & 93.7 & 350.6 & & 4.37 \\
\hline & & & & $H-19$ & 95.2 & 26.1 & 60.7 & 69.1 & 236.7 & & 4.77 \\
\hline & & & & $H-20$ & 89.1 & 43.8 & 66.5 & 45.3 & 137.5 & & 5.38 \\
\hline & & & & H-21 & 81.8 & 59.3 & 70.6 & 22.5 & 56.9 & & 6.46 \\
\hline & & & & $H=22$ & 79.2 & 68.3 & 73.8 & 10.9 & 23.7 & & 7.52 \\
\hline \multirow[t]{6}{*}{$2 c$} & 10000 & 4 & 0.03 & $H=23$ & 101.4 & 47.5 & 74.5 & 53.9 & 154.2 & & 5.71 \\
\hline & & & & H-24 & 96.8 & 54.4 & 75.6 & 42.4 & 116.0 & & 5.97 \\
\hline & & & & $H \cdot 25$ & 92.0 & 59.8 & 75.9 & 32.2 & 81.7 & & 6.44 \\
\hline & & & & $H \cdot 26$ & 87.4 & 65.0 & 76.2 & 22.4 & 55.2 & & 6.63 \\
\hline & & & & $H \cdot 27$ & 79.7 & 69.4 & 74.6 & 10.3 & 22.7 & & 7.41 \\
\hline & & & & H-28 & 80.7 & 24.6 & 52.7 & 56.1 & 149.6 & & 6.13 \\
\hline \multirow[t]{6}{*}{$3 A$} & XEPS & 1 & 0.03 & $H-29$ & 106.9 & 45.9 & 76.4 & 61.0 & 292.3 & & 3.41 \\
\hline & & & & $H=\mathbf{3 0}$ & 102.5 & 52.5 & 77.5 & 50.0 & 230.7 & & 3.54 \\
\hline & & & & $H-31$ & 94.4 & 58.8 & 76.6 & 35.6 & 153.7 & & 3.78 \\
\hline & & & & H-32 & 87.7 & 64.3 & 76.0 & 23.4 & 95.3 & & 4.01 \\
\hline & & & & $H \cdot 33$ & 82.5 & 69.1 & 75.8 & 13.4 & 49.5 & & 4.42 \\
\hline & & & & $H \cdot 34$ & 81.5 & 20.2 & 50.9 & 61.3 & 292.8 & & 3.42 \\
\hline
\end{tabular}

Hotes: The panel thermal resistance, $R$, was determined from $R=(A)(d T) /(0 t o t a l)$ where $A$ is equal to $16.34 \mathrm{ft}^{\wedge} 2$ for Test Panels $1 A$ through $4 B$ and $10.94 \mathrm{ft}^{\wedge} 2$ for Test Panels 11A through 13C. Ho framing heat flow corrections are applied to data. 
TABLE 23 (Cont)

THE EXPERIMENTAL CONOITIONS ANO THE MEASURED PANEL THERMAL RESISTANCE OF SEVENTEEN TEST PANELS CONTAINING RFFLECTIVE OR MASS IHSULATION MATERIALS

\begin{tabular}{|c|c|c|c|c|c|c|c|c|c|c|c|}
\hline \multirow[b]{2}{*}{$\begin{array}{l}\text { Test } \\
\text { Panel }\end{array}$} & \multirow[b]{2}{*}{$\begin{array}{l}\text { Stud } \\
\text { Material }\end{array}$} & \multirow[b]{2}{*}{$\begin{array}{l}\text { No. of } \\
\text { Airspaces }\end{array}$} & \multirow[b]{2}{*}{$\begin{array}{l}\text { Airspace } \\
\text { E }\end{array}$} & \multirow[b]{2}{*}{$\begin{array}{l}\text { Test } \\
\text { Number }\end{array}$} & \multicolumn{4}{|c|}{ Temperature, $F$} & \multirow{2}{*}{ a Total } & \multicolumn{2}{|c|}{$\begin{array}{c}\text { Panel } \\
\text { Thermal Resistance }\end{array}$} \\
\hline & & & & & HS & cs & Tmean & $d T$ & & $h r f t^{\wedge} 2$ & F/Btu \\
\hline \multirow[t]{6}{*}{38} & XEPS & 2 & 0.03 & $H \cdot 35$ & 130.2 & 18.8 & 74.5 & 111.4 & 367.1 & & 4.96 \\
\hline & & & & $H \cdot 36$ & 103.0 & 10.4 & 56.7 & 92.6 & 299.4 & & 5.05 \\
\hline & & & & $H \cdot 37$ & 95.8 & 26.8 & 69.3 & 69.0 & 205.6 & & 5.48 \\
\hline & & & & $H=38$ & 88.6 & 43.4 & 66.0 & 45.2 & 119.2 & & 6.19 \\
\hline & & & & $H-39$ & 81.9 & 59.3 & 70.6 & 22.6 & 50.1 & & 7.38 \\
\hline & & & & $H-40$ & 78.7 & 67.5 & 73.1 & 11.2 & 21.1 & & 8.66 \\
\hline \multirow[t]{6}{*}{$3 c$} & XEPS & 4 & 0.03 & $H=41$ & 104.5 & 47.4 & 76.0 & 57.1 & 146.3 & & 6.38 \\
\hline & & & & $H-42$ & 99.1 & 54.6 & 76.9 & 44.5 & 109.0 & & 6.67 \\
\hline & & & & $H-43$ & 91.6 & 59.3 & $\pi .5$ & 32.3 & 73.2 & & 7.20 \\
\hline & & & & $H-44$ & 86.9 & 64.8 & 75.9 & 22.1 & 44.9 & & 8.04 \\
\hline & & & & $H-45$ & 81.2 & 70.2 & 75.7 & 11.0 & 20.7 & & 8.68 \\
\hline & & & & $H-46$ & 80.0 & 23.2 & 51.6 & 56.8 & 133.4 & & 6.95 \\
\hline $4 A$ & XEPS & N/A & $N / A$ & $H-47$ & 104.2 & 49.2 & 76.7 & 55.0 & 73.6 & & 12.21 \\
\hline 48 & woon & $N / A$ & H/A & $H-48$ & 99.8 & 49.9 & 74.9 & 49.9 & 83.6 & & 9.75 \\
\hline \multirow[t]{12}{*}{$19 A$} & XEPS & 1 & 0.05 & $v \cdot 10$ & 83.3 & 15.5 & 49.4 & 67.8 & 277.1 & & 2.68 \\
\hline & & & & $v-2 u$ & 77.8 & 23.0 & 50.4 & 54.7 & 217.5 & & 2.75 \\
\hline & & & & $v-3 u$ & 70.7 & 29.4 & 50.0 & 41.3 & 155.9 & & 2.90 \\
\hline & & & & $v-4 u$ & 63.0 & 36.5 & 49.8 & 26.4 & 93.6 & & 3.09 \\
\hline & & & & $v \cdot 5 u$ & 56.8 & 43.5 & 50.1 & 13.3 & 43.6 & & 3.34 \\
\hline & & & & $v-6 u$ & 910.2 & 40.5 & 75.4 & 69.7 & 301.4 & & 2.53 \\
\hline & & & & $v-70$ & 74.5 & 21.0 & 47.8 & 53.5 & 68.5 & & 8.55 \\
\hline & & & & $v-80$ & 71.0 & 26.9 & 49.0 & 44.1 & 55.1 & & 8.77 \\
\hline & & & & $v-90$ & 63.5 & 32.7 & 48.1 & 30.8 & 37.7 & & 8.94 \\
\hline & & & & $v-100$ & 59.4 & 38.1 & 48.8 & 21.3 & 25.2 & & 9.27 \\
\hline & & & & $v \cdot 110$ & 53.7 & 44.3 & 49.0 & 9.4 & 10.3 & & 10.00 \\
\hline & & & & $v-120$ & 100.7 & 45.6 & 73.2 & 55.1 & $\pi .9$ & & 7.94 \\
\hline \multirow[t]{6}{*}{$12 A$} & 1000 & 1 & 0.05 & $v-13 u$ & 108.1 & 39.4 & 73.8 & 68.7 & 313.6 & & 2.40 \\
\hline & & & & $v-94 U$ & 101.3 & 46.1 & 73.7 & 55.2 & 239.8 & & 2.52 \\
\hline & & & & $v-15 u$ & 92.6 & 53.8 & 73.2 & 38.8 & 160.4 & & 2.65 \\
\hline & & & & $V \cdot 16 U$ & 87.3 & 60.2 & 73.8 & 27.1 & 103.5 & & 2.87 \\
\hline & & & & $v-17 u$ & 75.0 & 64.8 & 69.9 & 10.2 & 32.1 & & 3.48 \\
\hline & & & & $v-180$ & 84.7 & 16.0 & 50.4 & 68.7 & 294.6 & & 2.55 \\
\hline
\end{tabular}


TABLE 23 (Cont)

THE EXPERIMENTAL CONDITIONS AND THE MEASURED THERMAL RESISTANCE OF SEVENTEEN TEST PANELS CONTAIMING REFLECTIVE OR MASS INSULATION MATERIALS

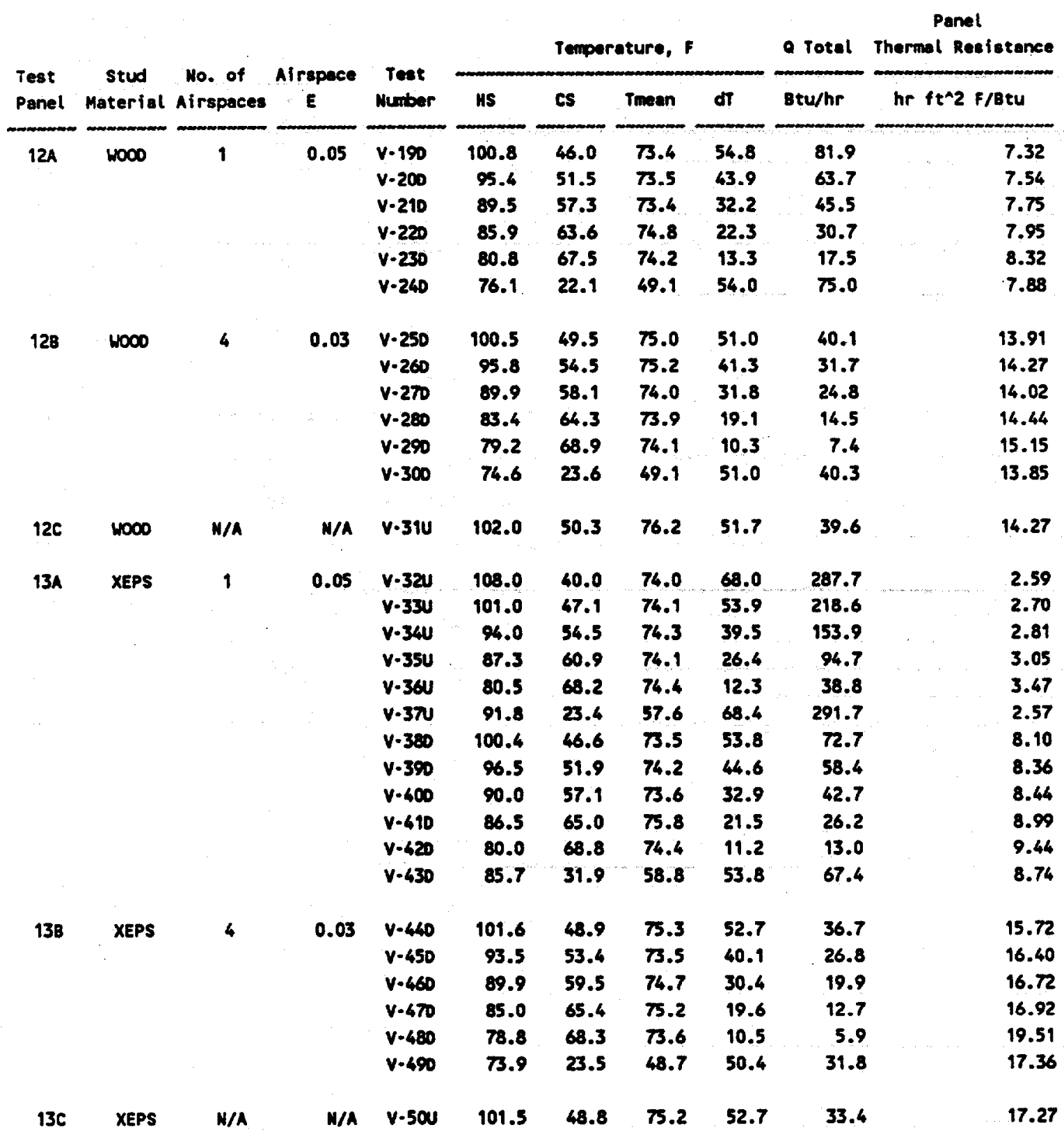


TABLE 24

THE FIT COEFFICIENTS USED TO DESCRIBE THE TEST PANEL THERMAL RESISTANCE AS A FUNCTION OF TEST PANEL TEMPERATURE DIFFERENCE

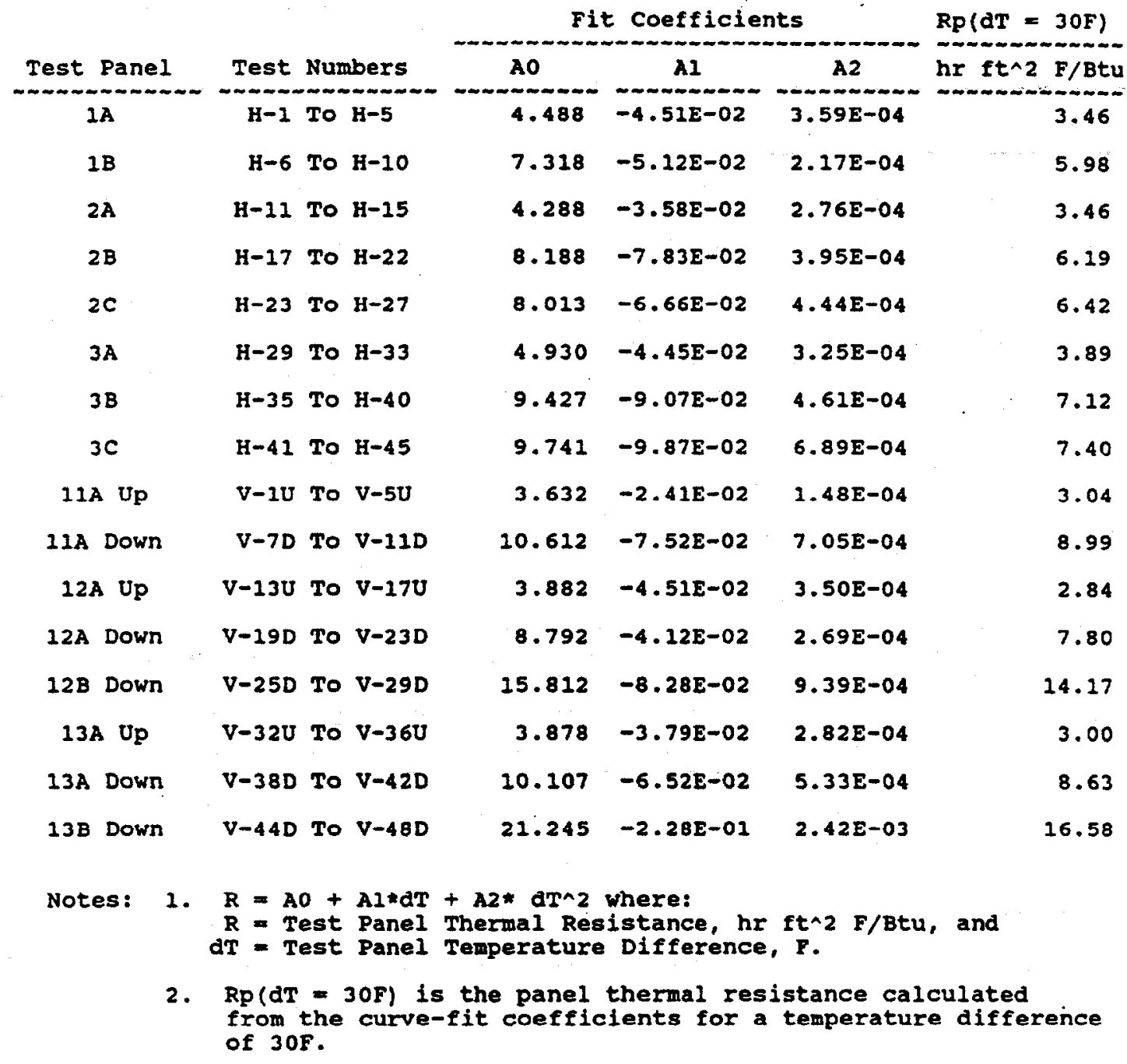


Table 20 from the test panel result $[(2)(0.32)=0.64 \mathrm{hr}$ $\mathrm{ft}^{2} \mathrm{~F} / \mathrm{Btu}$. A similar exercise employed on other data sets will yield results that are comparable.

The following sections present the measured test panel thermal resistance results and compares selected subsections of this data base.

\subsection{PANELS WITH MASS INSULATION - STUD EFFECT}

The impact of the stud material on the thermal resistance of the test panels can be measured by comparing the results of Test Panels $4 \mathrm{~A}, 4 \mathrm{~B}, 12 \mathrm{C}$ and $13 \mathrm{C}$. Test Panels $4 \mathrm{~A}$ and $13 \mathrm{C}$ were constructed with XEPS studs while wood studs were used in Test Panels $4 \mathrm{~B}$ and 12C. Test Panels $4 \mathrm{~A}$ and $4 \mathrm{~B}$ were constructed with $2 \times 4$ studs and tested with horizontal heat flow. Test Panels $12 \mathrm{C}$ and $13 \mathrm{C}$ and fabricated with $2 \mathrm{x}$ 6 studs and evaluated with heat flow up. The cavities of these test panels were filled with unfaced nominal $R-11$ or R-19 fiberglass batts. The same insulation batts were used in the metering area for the similarly sized test panels.

A Comparison of Four Test Panels Insulated With Mass Insulation

\begin{tabular}{|c|c|c|c|c|c|}
\hline Panel & stud & Cavity size & RPanel & $d R$ & $\operatorname{dR}(8)$ \\
\hline $4 A$ & XEPS & $2 \times 4$ & 12.21 & 346 & 25 \\
\hline $\begin{array}{r}4 \mathrm{~B} \\
12 \mathrm{C}\end{array}$ & $\begin{array}{l}\text { Wood } \\
\text { Wood }\end{array}$ & $\begin{array}{lll}2 & \times 4 \\
2 & \times & 6\end{array}$ & $\begin{array}{r}9.75 \\
14.27\end{array}$ & & \\
\hline $13 c$ & XEPS & $2 \times 6$ & 17.27 & 3.00 & 21 \\
\hline
\end{tabular}


The measured panel thermal resistances of Test Panels $4 \mathrm{~A}$ and $4 \mathrm{~B}$ were 12.21 and $9.75 \mathrm{hr} \mathrm{ft}^{2} \mathrm{~F} / \mathrm{Btu}$; Test Panels $12 \mathrm{C}$ and $13 \mathrm{C}$ had measured panel thermal resistances of 14.27 and $17.27 \mathrm{hr} \mathrm{ft}^{2} \mathrm{~F} / \mathrm{Btu}$ respectively. All four test panels were analyzed at the same approximate' test conditions. The differences in panel thermal resistance due to the substitution of the high thermal resistance XEPS studs for wood studs for the $2 \times 4$ and the $2 \times 6$ test panels were approximately 2.5 and $3.0 \mathrm{hr} \mathrm{ft}^{2} \mathrm{~F} / \mathrm{Btu}$ or 25 and 21 percent respectively.

11.2 HORIZONTAL HEAT FIOW, XEPS STUDS: NUMBER OF AIRSPACES, EMITTANCE, TEMPERATURE DIFFERENCE

Figure 15 depicts the test panel thermal resistance as a function of temperature difference across the test panel for all of the test panels containing reflective airspaces, constructed with XEPS foam studs, and tested with horizontal heat flow. Test results from five test panels, namely $1 A$, 1B, 3A, 3B, and 3C, are included on this figure and are summarized below.

A Comparison of Five Test Panels Fabricated with XEPS studs Tested With Horizontal Heat Flow

\begin{tabular}{|c|c|c|c|c|c|c|}
\hline Panel & $\begin{array}{l}\text { Number of } \\
\text { Airspaces }\end{array}$ & $\mathbf{E}$ & $R p(30)$ & dF & $\mathbf{R}$ & Patio \\
\hline $1 \mathrm{~A}$ & 1 & 0.05 & 3.46 & & 1.73 & $(1 \mathrm{~B} / 1 \mathrm{~A})$ \\
\hline $\begin{array}{l}1 B \\
3 A \\
3 B\end{array}$ & $\begin{array}{l}2 \\
1 \\
2\end{array}$ & $\begin{array}{l}0.05 \\
0.03 \\
0.03\end{array}$ & $\begin{array}{l}5.98 \\
3.89 \\
7.12\end{array}$ & $\begin{array}{l}0.43 \\
1.14\end{array}$ & $\begin{array}{r}(3 A-1 A) \\
(3 B-1 B) \\
1.83\end{array}$ & $(3 B / 1 B)$ \\
\hline$C$ & 4 & 0.03 & 7.40 & & & \\
\hline
\end{tabular}




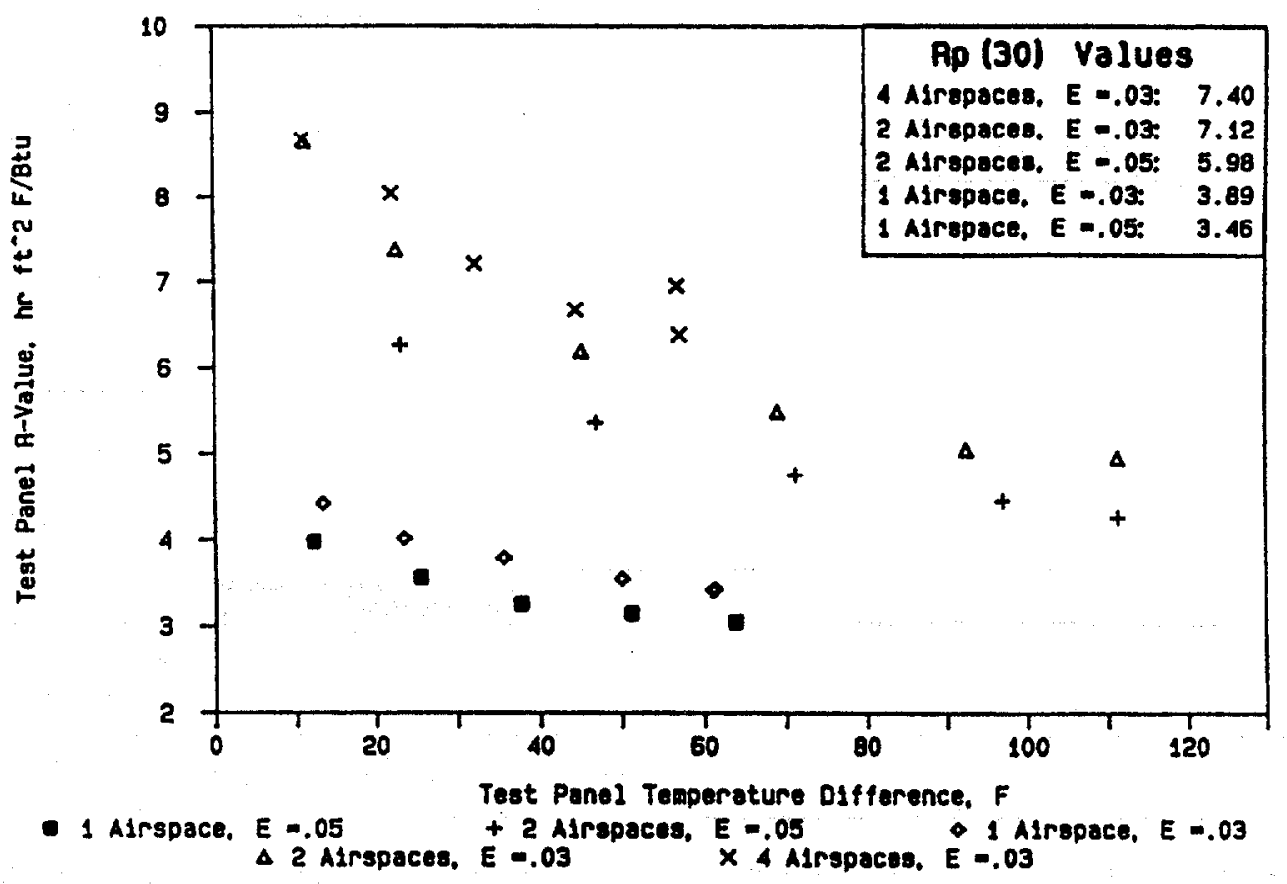

Figure 15: The test panel thermal resistance as a function of test panel temperature difference for five test panels constructed with XEPS studs and tested with horizontal heat flow. The test panel thermal resistances determined from the curve-fit coefficients for a temperature difference of $30 F, R_{p}(30)$, are tabulated for comparison. 
The cavities of Test Panels $1 \mathrm{~A}$ and $3 \mathrm{~A}$ contained single airspaces with effective emittances of 0.05 and 0.03 respectively. Test Panels $1 B$ and $3 B$ contained two-airspace cavities with effective emittances of 0.05 and 0.03 respectively and Test Panel $3 \mathrm{C}$ contained a four-airspace cavity with effective emittances of 0.03 .

The $R_{p}(30)$ values for $1 A$ (I airspace, XEPS, $E=0.05$, $\mathrm{T}_{\text {mean }}=50 \mathrm{~F}$ ) are $0.43 \mathrm{hr} \mathrm{ft}^{2} \mathrm{~F} / \mathrm{Btu}$ lower than $3 \mathrm{~A}$ (I airspace, XEPS, $\left.E=0.03, T_{\text {mean }}=75 F\right)$ while the $R_{p}(30)$ values for $1 \mathrm{~B}$ (2 airspaces, XEPS, $E=0.05, \mathrm{~T}_{\text {mean }}=56-73 \mathrm{~F}$ ) are $1.14 \mathrm{hr} \mathrm{ft}^{2} \mathrm{~F} / \mathrm{Btu}$ lower than 3B (2 airspaces, XEPS, $\mathrm{E}=$ $0.03, T_{\text {mean }}=57-75 \mathrm{~F}$ ). These differences in $\mathrm{R}$-Value are due to the combination of changes in the test panel mean temperature and the airspace effective emittance. The difference in $R-V a l u e$ in the two-airspace test panels is 2.7 times the difference noted for the same comparison on single airspace systems. This apparently high difference between the 1- and 2-airspace test panels is due to the fact that the temperature difference across the individual airspaces comprising the cavity is different (approx. 30F and 15F across each airspace in the 1 - and 2-airspace cavities respectively).

In general, the test panel thermal resistance increases with the number of airspaces within the cavity. For cavity effective emittances of 0.05 and 0.03 , the ratio of the 2and 1-airspace $R_{p}(30)$ values are 1.73 and 1.83 respectively. An exception to this occurs when comparing the test results of the 2- and 4-airspace test panels with a $10 F$ temperature difference. The difficulty in performing the 4-airspace experiments due to the small metering area energy inputs may account for this apparently anomalous result. In addition, the four-airspace test panel employed a commercial product 
to create the airspaces while the two-airspace cavity was produced by carefully inserting a central foil. The structure of the four-airspace product may account for its apparent loss in performance.

The thermal resistance of all five test panels decrease with increasing test panel temperature difference. A fivefold increase in the temperature difference yielded decreases of 23, 32, 23, 33, and 26 percent in panel R-Value for Test Panels 1A, 1B, 3A, 3B, and $3 C$ respectively or an average decrease of 27 percent for the five test panels.

The Effect of Temperature Difference on Five Test Panels Fabricated With XEPS Studs and Tested With Horizontal Heat Flow

\begin{tabular}{|c|c|c|c|c|}
\hline Panel & $\begin{array}{l}\text { Test } \\
\text { Number }\end{array}$ & $d T$ & $R$ (meas) & R Ratio \\
\hline $1 \mathrm{~A}$ & $\mathrm{H}-1$ & 64 & 3.06 & \\
\hline $\begin{array}{l}1 \mathrm{~A} \\
1 \mathrm{~B}\end{array}$ & $\begin{array}{l}H-5 \\
H-6\end{array}$ & $\begin{array}{r}12 \\
111\end{array}$ & $\begin{array}{l}3.99 \\
4.26\end{array}$ & . \\
\hline $\begin{array}{l}1 B \\
3 \mathrm{~A}\end{array}$ & $\begin{array}{l}H-10 \\
H-29\end{array}$ & $\begin{array}{l}23 \\
61\end{array}$ & $\begin{array}{l}6.27 \\
3.41\end{array}$ & 0.00 \\
\hline $\begin{array}{l}3 A \\
3 B\end{array}$ & $\begin{array}{l}\mathrm{H}-33 \\
\mathrm{H}-35\end{array}$ & $\begin{array}{r}13 \\
111\end{array}$ & $\begin{array}{l}4.42 \\
4.96\end{array}$ & . \\
\hline $\begin{array}{l}3 B \\
3 C\end{array}$ & $\begin{array}{l}H-39 \\
H-41\end{array}$ & $\begin{array}{l}23 \\
57\end{array}$ & $\begin{array}{l}7.38 \\
6.38\end{array}$ & 0.0 \\
\hline $3 c$ & H-45 & 11 & 8.68 & 0.14 \\
\hline
\end{tabular}


11.3 HORIZONTAL HEAT FLOW, WOOD STUDS: NUMBER OF AIRSPACES, EMITTANCE, TEMPERATURE DIFFERENCE

Figure 16 depicts the test panel thermal resistance as a function of temperature difference across the test panel for all of the test panels containing reflective airspaces, constructed with wood studs, and tested with horizontal heat flow. Results from Test Panels 2A, 2B, and $2 \mathrm{C}$ are presented on this figure and are summarized below. The cavities of these test panels were comprised of 1,2 and 4 airspaces respectively having effective emittances of 0.03 .

A Comparison of Three Test Panels Fabricated with wood studs and Tested with Horizontal Heat Flow

\begin{tabular}{|c|c|c|c|c|}
\hline Panel & $\begin{array}{l}\text { Number of } \\
\text { Airspaces }\end{array}$ & $\mathbf{E}$ & $R p(30)$ & R Ratio \\
\hline $\begin{array}{l}2 A \\
2 B\end{array}$ & $\begin{array}{l}1 \\
2\end{array}$ & $\begin{array}{l}0.03 \\
0.03\end{array}$ & $\begin{array}{l}3.46 \\
6.19\end{array}$ & \\
\hline $2 C$ & 4 & 0.03 & 6.41 & $\begin{array}{l}1.79(2 \mathrm{~B} / 2 \mathrm{~A}) \\
1.85(2 \mathrm{C} / 2 \mathrm{~A})\end{array}$ \\
\hline
\end{tabular}

Like the XEPS stud test panels previously described, the test panel thermal resistance increases with the number of airspaces within the cavity. The exception to this statement occurs when comparing the test results of the 2and 4-airspace test panels with a $10 \mathrm{~F}$ temperature difference, Test Numbers $\mathrm{H}-22$ and $\mathrm{H}-27$. The R-Values measured for these two tests ( $\mathrm{H}-22$ and $\mathrm{H}-27$ ) indicate that the performance of the test panel with the 2-airspace cavity, $R=7.52 \mathrm{hr} \mathrm{ft}^{2} \mathrm{~F} / \mathrm{Btu}$, exceeds the test panel with the 4-airspace cavity, $R=7.41 \mathrm{hr} \mathrm{ft}^{2} \mathrm{~F} / \mathrm{Btu}$. When evaluated with a temperature difference of $30 \mathrm{~F}$, the ratio of 


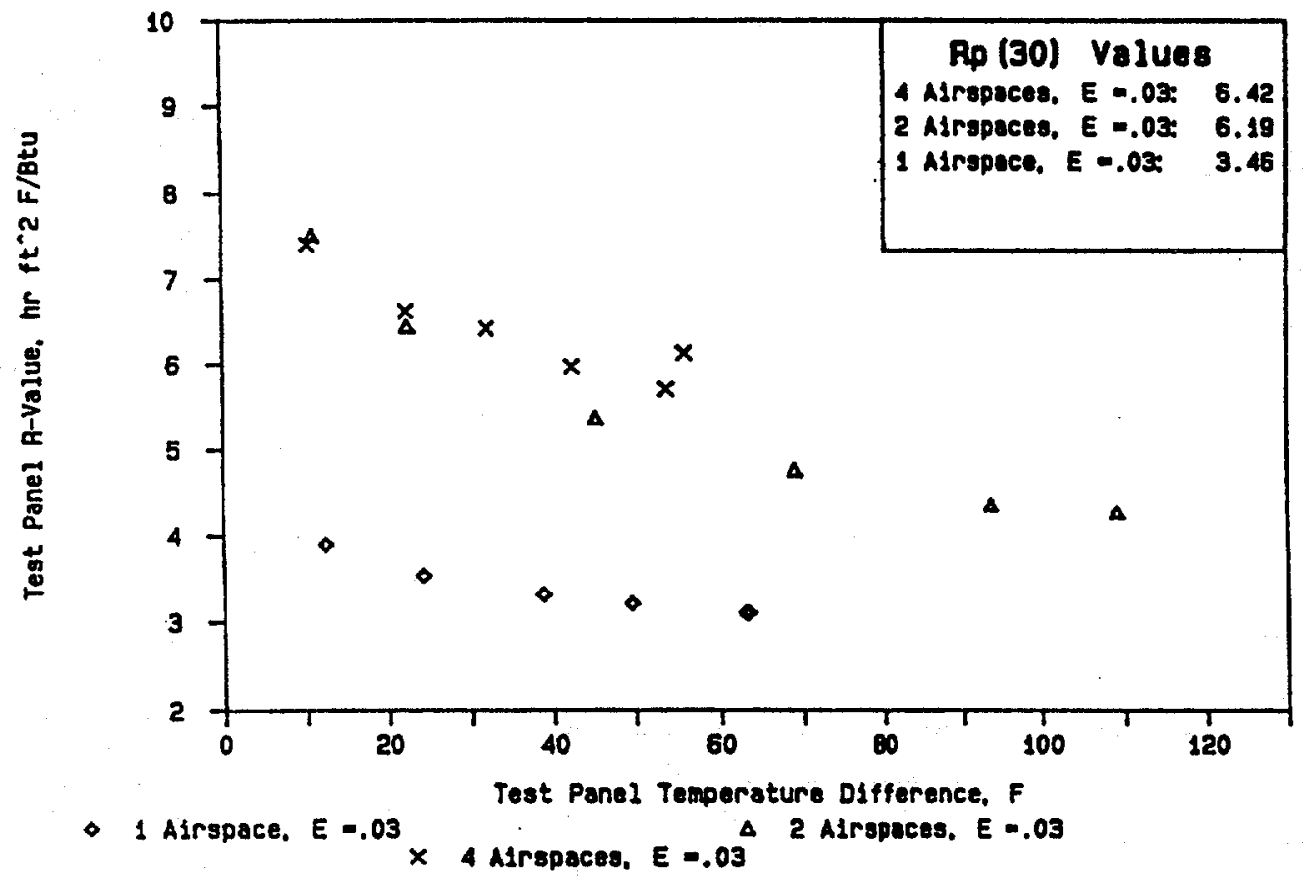

Figure 16: The test panel thermal resistance as a function of test panel temperature difference for three test panels constructed with wood studs and tested with horizontal heat flow. The test panel thermal resistances determined from the curve-fit coefficients for a temperature difference of $30 F, R_{p}(30)$, are tabulated for comparison. 
the 1-airspace to the 2 - and 4-airspace $R_{p}(30)$ values are 1.79 and 1.85 .

The thermal resistance of these test panels decrease with increasing test panel temperature difference. A fivefold increase in the temperature difference yielded decreases of 21,34 , and 23 percent in the test panel $R$ Value for Test Panels 2A, 2B, and $2 \mathrm{C}$ respectively or an average decrease of 26 percent for the three test panels. This reduction in test panel $R$-Value is similar to the reduction noted on similar test panels with XEPS studs.

The Effect of Temperature Difference on Three Test Panels Fabricated With Wood Studs and Tested with Horizontal Heat Flow

\begin{tabular}{|c|c|c|c|c|}
\hline Panel & $\begin{array}{c}\text { Test } \\
\text { Number }\end{array}$ & $d T$ & $R$ (meas) & R Ratio \\
\hline $2 \mathrm{~A}$ & $\mathrm{H}-11$ & 63 & 3.11 & \\
\hline $\begin{array}{l}2 \mathrm{~A} \\
2 \mathrm{~B}\end{array}$ & $\begin{array}{l}\mathrm{H}-15 \\
\mathrm{H}-17\end{array}$ & $\begin{array}{r}12 \\
109\end{array}$ & $\begin{array}{l}3.91 \\
4.28\end{array}$ & 0.79 \\
\hline $\begin{array}{l}2 \mathrm{~B} \\
2 \mathrm{C}\end{array}$ & $\begin{array}{l}\mathrm{H}-21 \\
\mathrm{H}-23\end{array}$ & $\begin{array}{l}23 \\
54\end{array}$ & $\begin{array}{l}6.46 \\
5.71\end{array}$ & 0.66 \\
\hline $2 \mathrm{C}$ & $\mathrm{H}-27$ & 10 & 7.41 & 0.77 \\
\hline
\end{tabular}

11.4 VERTICAL HEAT FLOW, ASPECT RATIO, XEPS AND WOOD STUDS

Figures 17 and 18 depict the test panel thermal resistance as a function of test panel temperature difference for all of the test panels containing reflective airspaces, tested with vertical heat flow, and constructed with XEPS and wood studs respectively. Results from Test 


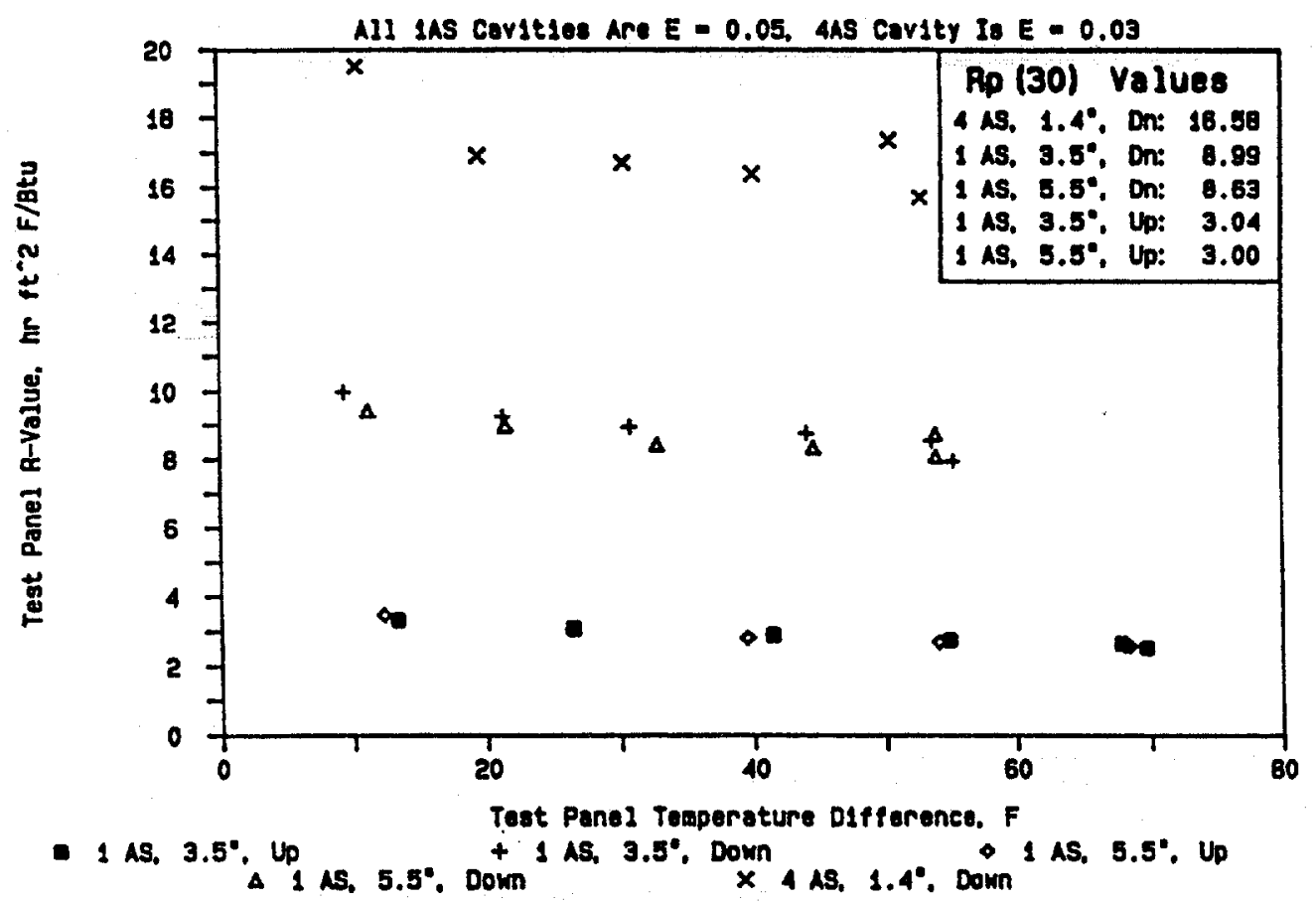

Figure 17: The test panel thermal resistance as a function
of test panel temperature difference for three test panels
constructed with Xeps studs and tested with vertical heat
flow (up and down). The test panel thermal resistances
determined from the curve-fit coefficients for a temperature
difference of $30 F, R_{p}(30)$, are tabulated for comparison. 


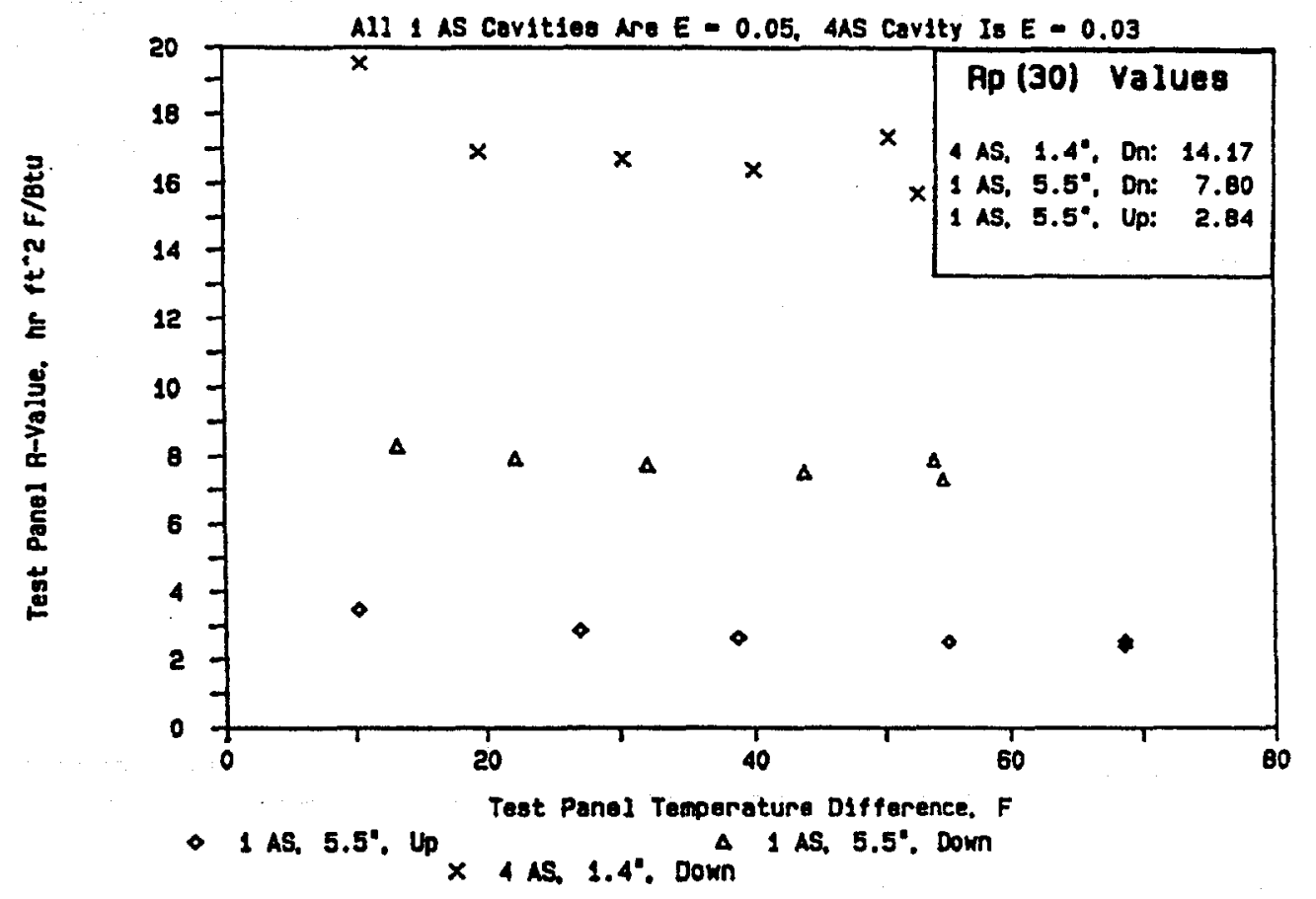

Figure 18: The test panel thermal resistance as a function of test panel temperature difference for three test panels constructed with wood studs and tested vith vertical heat llow (up and down). The test panel thermal resistances determined from the curve-fit coefficients for a temperature difference of $30 F, R_{p}(30)$, are tabulated for comparison. 
Panels 11A, 13A, 13B, and $13 \mathrm{C}$ are included in Figure 17 (XEPS studs); Figure 18 contains results from Test Panels 12A, 12B, and 12C (wood studs). Test panel 11A was constructed with $2 \times 4$ studs while all the remaining panels were fabricated with 2 x 6 studs. The cavities of Test Panels 11A, 12A, and 13A contained single airspaces with effective emittances of 0.05 . Test Panels $12 \mathrm{~B}$ and $13 \mathrm{~B}$ contained 4-airspace cavities with effective emittances of 0.03 . All the test panels were evaluated with heat flow down and the one-airspace test panels were also analyzed with heat flow up.

The thermal resistance of all vertical heat flow test panels decrease with increasing test panel temperature difference. An approximate five-fold increase in the temperature difference yielded decreases of 20, 31, and 25 percent in panel R-Values for the heat flow up experiments on Test Panels 11A, 12A, and 13A respectively or an average decrease in panel R-Value of 25 percent. The same change in temperature difference generated decreases of $14,12,8,12$, and 19 percent in panel R-Values for the heat flow down experiments on Test Panels 11A, 12A, 12B, 13A, and 13B respectively or an average decrease in panel R-value of 13 percent. Note that the data for the heat flow up experiments is limited to test panels with one-airspace cavities while the heat flow down data includes data from 1and 4-airspace cavity test panels. If only the 1-airspace cavity test panels (11A, $12 \mathrm{~A}$ and 13A) are included in the heat flow down averaging, the average decrease in Panel $R-$ value for heat flow down is still 13 percent. 
The Effect of Temperature Difference on Three Test Panels Tested With Vertical Heat Flow (Up)

\begin{tabular}{|c|c|c|c|c|}
\hline Panel & $\begin{array}{l}\text { Test } \\
\text { Number }\end{array}$ & $d T$ & $R$ (meas) & R Ratio \\
\hline $11 \mathrm{~A}$ & $V-I U$ & 68 & 2.68 & 0 . \\
\hline $\begin{array}{l}11 \mathrm{~A} \\
12 \mathrm{~A}\end{array}$ & $\begin{array}{l}V-5 U \\
V-13 U\end{array}$ & $\begin{array}{l}13 \\
69\end{array}$ & $\begin{array}{l}3.34 \\
2.40\end{array}$ & \\
\hline $\begin{array}{l}12 A \\
13 A\end{array}$ & $\begin{array}{l}V-17 U \\
V-32 U\end{array}$ & $\begin{array}{l}13 \\
68\end{array}$ & $\begin{array}{l}3.48 \\
2.59\end{array}$ & 0.69 \\
\hline $13 \mathrm{~A}$ & $\mathrm{~V}-36 \mathrm{U}$ & 12 & 3.47 & 0 \\
\hline
\end{tabular}

The Effect of Temperature Difference on Five Test Panels Tested with Vertical Heat Flow (Down)

\begin{tabular}{|c|c|c|c|c|}
\hline Panel & $\begin{array}{l}\text { Test } \\
\text { Number }\end{array}$ & $d T$ & $R$ (meas) & R Ratio \\
\hline $11 A$ & $V-7 D$ & 54 & 8.55 & \\
\hline $\begin{array}{l}11 \mathrm{~A} \\
12 \mathrm{~A}\end{array}$ & $\begin{array}{l}V-11 D \\
V-19 D\end{array}$ & $\begin{array}{r}9 \\
55\end{array}$ & $\begin{array}{r}10.00 \\
7.32\end{array}$ & 0.86 \\
\hline $\begin{array}{l}12 \mathrm{~A} \\
12 \mathrm{~B}\end{array}$ & $\begin{array}{l}V-23 D \\
V-25 D\end{array}$ & $\begin{array}{l}13 \\
51\end{array}$ & $\begin{array}{r}8.32 \\
13.91\end{array}$ & 0.88 \\
\hline $\begin{array}{l}12 B \\
13 A\end{array}$ & $\begin{array}{l}V-29 D \\
V-38 D\end{array}$ & $\begin{array}{l}10 \\
54\end{array}$ & $\begin{array}{r}15.15 \\
8.10\end{array}$ & 0.92 \\
\hline $\begin{array}{l}13 \mathrm{~A} \\
13 \mathrm{~B}\end{array}$ & $\begin{array}{l}V-42 D \\
V-44 D\end{array}$ & $\begin{array}{l}11 \\
53\end{array}$ & $\begin{array}{r}9.44 \\
15.72\end{array}$ & 0.88 \\
\hline $13 \mathrm{~B}$ & $V-48 D$ & 11 & 19.51 & 0.81 \\
\hline
\end{tabular}

The three one-airspace test panels were evaluated with the heat flow up and down. The test results are summarized below. The average $R_{p}(30)$ values for the heat flow up and down test results for these test panels were 2.96 and 8.47 
hr $f t^{2}$ F/Btu respectively. For the heat flow up experiments, the average $R_{p}(30)$ values for the XEPS and wood stud test panels were 3.02 and $2.85 \mathrm{hr} \mathrm{ft}^{2} \mathrm{~F} / \mathrm{Btu}$ respectively; the average $R_{p}(30)$ values for the XEPs and wood stud test panels tested with heat flow down were 8.81 and $7.80 \mathrm{hr} \mathrm{ft}^{2} \mathrm{~F} / \mathrm{Btu}$ respectively. The substitution of wood for XEPS studs reduced the $R_{p}(30)$ values by 0.2 and 1.0 hr $\mathrm{ft}^{2} \mathrm{~F} / \mathrm{Btu}$ for the 1-airspace heat flow up and down experiments respectively.

A Comparison of Three One-Airspace Test Panels Tested With Vertical Heat Flow

\begin{tabular}{|c|c|c|c|}
\hline Panel & stud MtI & $\begin{array}{l}\text { Heat Flow } \\
\text { Direction }\end{array}$ & $R p(30)$ \\
\hline $\begin{array}{l}11 \mathrm{~A} \\
12 \mathrm{~A} \\
13 \mathrm{~A}\end{array}$ & $\begin{array}{l}\text { XEPS } \\
\text { Wood } \\
\text { XEPS }\end{array}$ & $\begin{array}{l}\text { Up } \\
\text { Up } \\
\text { Up }\end{array}$ & $\begin{array}{l}3.04 \\
2.85 \\
3.00\end{array}$ \\
\hline $\begin{array}{l}\text { Average } \\
\text { Average } \\
\text { Average }\end{array}$ & $\begin{array}{r}\text { All } \\
\text { XEPS } \\
\text { Wood }\end{array}$ & $\begin{array}{l}\text { Up } \\
U p \\
U p\end{array}$ & $\begin{array}{l}2.96 \\
3.02 \\
2.85\end{array}$ \\
\hline $\begin{array}{l}11 \mathrm{~A} \\
12 \mathrm{~A} \\
13 \mathrm{~A}\end{array}$ & $\begin{array}{l}\text { XEPS } \\
\text { WoOd } \\
\text { XEPS }\end{array}$ & $\begin{array}{l}\text { Down } \\
\text { Down } \\
\text { Down }\end{array}$ & $\begin{array}{l}8.99 \\
7.80 \\
8.63\end{array}$ \\
\hline $\begin{array}{l}\text { Average } \\
\text { Average } \\
\text { Average }\end{array}$ & $\begin{array}{r}\text { A11 } \\
\text { XEPS } \\
\text { Wood }\end{array}$ & $\begin{array}{l}\text { Down } \\
\text { Down } \\
\text { Down }\end{array}$ & $\begin{array}{l}8.47 \\
8.81 \\
7.80\end{array}$ \\
\hline
\end{tabular}

The $R_{p}(30)$ values for the two 4-airspace test panels analyzed in this program with heat flow down are summarized below. The average $R_{p}(30)$ values for these two panels was $15.4 \mathrm{hr} \mathrm{ft}^{2} \mathrm{~F} / \mathrm{Btu}$. The substitution of wood for XEPS studs reduced the $R_{p}(30)$ value by $2.4 \mathrm{hr} \mathrm{ft}^{2} \mathrm{~F} / \mathrm{Btu}$ for the $4-$. airspace heat flow down experiment. 
A Comparison of Two Four-Airspace Test Panels Tested With Vertical Heat Flow

\begin{tabular}{ccccc} 
Panel & Stud MtI & $\begin{array}{c}\text { Heat Flow } \\
\text { Direction }\end{array}$ & $\operatorname{Rp}(30)$ \\
\cline { 5 - 5 } 12B & Wood & & Down & 14.17 \\
13B & XEPS & & Down & 16.58 \\
Average & AlI & & Down & 15.38
\end{tabular}

A comparison of the effect of the number of airspaces on the $R_{p}(30)$ values is summarized below. The four-airspace $R$-Values are less than twice the thermal resistance of the comparable one-airspace test results. The ratio of the 4airspace to the 1 -airspace $R_{p}(30)$ values are 1.82 and 1.88 for wood and XEPS studs respectively.

A Comparison of Four- and One-Airspace Test Panels Tested With Vertical Heat Flow (Down)

$\begin{array}{lcccc}\text { Stud MtI } & \begin{array}{c}\text { Rp }(30) \\ \text { 4-Airspace }\end{array} & \begin{array}{c}\text { Rp }(30) \\ \text { 1-Airspace }\end{array} & \text { Ratio } \\ \text { Wood } & 14.17 & & 7.80 & 1.82 \\ \text { XEPS } & 16.58 & 8.81 & 1.88\end{array}$

A comparison of the results from Test panels $11 \mathrm{~A}$ and $13 \mathrm{~A}$ are a measure of the effect of aspect ratio on the thermal resistance of the test panel. These two test panels were identical in construction with the exception of the depth of the airspace. The panels were constructed with $2 \mathrm{x}$ 4 and $2 \times 6$ studs, yielding aspect ratios of 0.24 and 0.38 respectively. The $R_{p}(30)$ values for these test panels are summarized below. Differences of 0.05 and $0.36 \mathrm{hr} \mathrm{ft}^{2} \mathrm{~F} / \mathrm{Btu}$ are noted between the heat flow up and down $R_{p}(30)$ results for airspace aspect ratios of 0.24 and 0.38 respectively. 
The Effect of Aspect Ratio on One-Airspace Test Panels Tested with Vertical Heat Flow

\begin{tabular}{|c|c|c|c|c|c|}
\hline Panel & $\begin{array}{l}\text { Aspect } \\
\text { Ratio }\end{array}$ & $R p(30)$ Up & $R p(30)$ & Down & Ratio \\
\hline $\begin{array}{l}11 A \\
13 A\end{array}$ & $\begin{array}{l}0.24 \\
0.38\end{array}$ & $\begin{array}{l}3.04 \\
2.99\end{array}$ & $\begin{array}{l}8.9 \\
8.6\end{array}$ & & $\begin{array}{l}0.34 \\
0.35\end{array}$ \\
\hline
\end{tabular}

\subsection{SINGLE AIRSPACE SYSTEMS}

Test Panels 1A, 2A, 3A, 11A, 12A, and 13A were constructed as single airspace systems. The differences in the construction of these six test panels were the framing material (XEPS for Test Panels 1A, 3A, 11A, and 13A, wood for Test Panels $2 A$ and $12 A$ ), the effective emittance of the airspace $(0.05$ for Test Panel 1A, 11A, 12A, and 13A, 0.03 for Test Panels $2 A$ and $3 A$ ), heat flow direction, (heat flow horizontal for Test panels $1 A, 2 A$, and $3 A$, heat flow vertical up and down for Test Panels 11A, 12A, and 13A, and cavity depth $(3.5$. inches for Test panels $1 \mathrm{~A}, 2 \mathrm{~A}, 3 \mathrm{~A}$, and 11A, 5.5 inches for Test Panels $12 \mathrm{~A}$ and $13 \mathrm{~A}$. Testing on Test Panel $1 \mathrm{~A}$ was performed exclusively with an airspace mean temperature of approximately 50F. Testing on Test Panels 2A, 3A, 12A, and 13A was undertaken predominantly at an airspace mean temperature of $75 \mathrm{~F}$ with single analyses at $50 F$ in each heat flow direction. Testing on Test panel $11 \mathrm{~A}$, was undertaken predominantly at an airspace mean temperature of 50F with single analyses at $75 \mathrm{~F}$ in each heat flow direction. A comparison of the test results gathered on these panels is summarized below. 
A Comparison of Six One-Airspace Test Panels

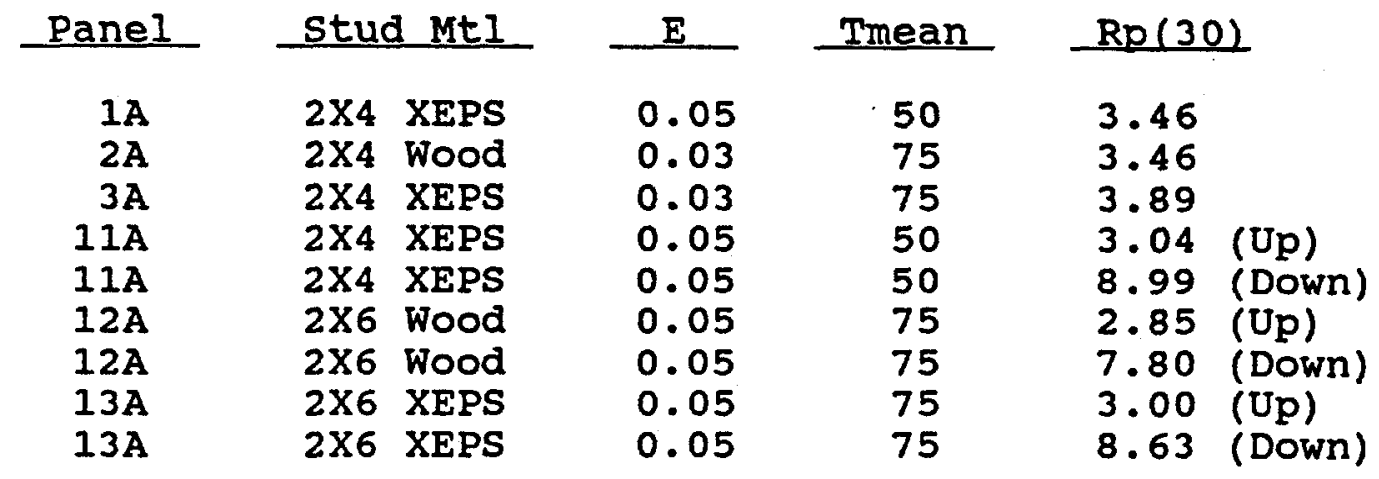

The $R_{p}(30)$ values for $1 \mathrm{~A}$ (XEPS, $E=0.05, T_{\text {mean }}=50 \mathrm{~F}$ ) and $2 \mathrm{~A}$ (Wood, $E=0.03, \mathrm{~T}_{\text {mean }}=75 \mathrm{~F}$ ) are identical. The increase in heat transfer due to the low thermal resistance wood stud and higher mean temperature of $2 \mathrm{~A}$ are offset by the lower effective emittance of the airspace. A comparison of Test panels 1A (XEPS, $E=0.05, T_{\text {mean }}=50 \mathrm{~F}$ ) and $3 \mathrm{~A}$ (XEPS, $E=0.03, T_{\text {mean }}=75 \mathrm{~F}$ ) demonstrates the effects of mean temperature and effective emittance. The difference in the $R_{p}(30)$ values for these two test panels is $0.43 \mathrm{hr} \mathrm{ft}^{2}$ F/Btu. The increase in the thermal resistance of the test panel due to a decrease in effective emittance more than compensates for its reduction due to an increase in mean temperature.

\subsubsection{SINGLE AIRSPACE SYSTEMS, EFFECT OF MEAN TEMPERATURE}

There are eight pairs of data on single-airspace cavity test panels which measure the effect of mean temperature on the panel $\mathrm{R}$-Value. These data pairs, namely Test Numbers H11 and $H-16, H-29$ and $H-34, V-1 U$ and $V-6 U, V-7 D$ and $V-12 D$, $V-13 U$ and $v-18 U, V-19 D$ and $v-24 D, V-32 U$ and $v-37 U$, and $V-38 D$ and $V-43 D$, are summarized below. 
The Effect of Mean Temperature on Five Test Panels containing single Airspace Cavities

\begin{tabular}{|c|c|c|c|c|}
\hline Panel & $\begin{array}{l}\text { Test } \\
\text { Number }\end{array}$ & Tmean & $d T$ & R(meas) \\
\hline $2 A$ & $\begin{array}{l}H-11 \\
H-16\end{array}$ & $\begin{array}{l}76 \\
52\end{array}$ & $\begin{array}{l}63 \\
63\end{array}$ & $\begin{array}{l}3.11 \\
3.11\end{array}$ \\
\hline $3 A$ & $\begin{array}{l}H-29 \\
H-34\end{array}$ & $\begin{array}{l}76 \\
50\end{array}$ & $\begin{array}{l}61 \\
61\end{array}$ & $\begin{array}{l}3.41 \\
3.42\end{array}$ \\
\hline $11 A$ & $\begin{array}{l}V-1 U \\
V-6 U\end{array}$ & $\begin{array}{l}49 \\
75\end{array}$ & $\begin{array}{l}68 \\
70\end{array}$ & $\begin{array}{l}2.68 \\
2.53\end{array}$ \\
\hline $11 \mathrm{~A}$ & $\begin{array}{r}V-7 D \\
V-12 D\end{array}$ & $\begin{array}{l}48 \\
73\end{array}$ & $\begin{array}{l}54 \\
55\end{array}$ & $\begin{array}{l}8.55 \\
7.94\end{array}$ \\
\hline $12 A$ & $\begin{array}{l}V-13 U \\
V-18 U\end{array}$ & $\begin{array}{l}74 \\
50\end{array}$ & $\begin{array}{l}69 \\
69\end{array}$ & $\begin{array}{l}2.40 \\
2.55\end{array}$ \\
\hline $12 \mathrm{~A}$ & $\begin{array}{l}V-19 D \\
V-24 D\end{array}$ & $\begin{array}{l}73 \\
49\end{array}$ & $\begin{array}{l}55 \\
54\end{array}$ & $\begin{array}{l}7.32 \\
7.88\end{array}$ \\
\hline $13 \mathrm{~A}$ & $\begin{array}{l}V-32 U \\
V-37 U\end{array}$ & $\begin{array}{l}74 \\
58\end{array}$ & $\begin{array}{l}68 \\
68\end{array}$ & $\begin{array}{l}2.59 \\
2.57\end{array}$ \\
\hline $13 \mathrm{~A}$ & $\begin{array}{l}V-38 D \\
V-43 D\end{array}$ & $\begin{array}{l}74 \\
59\end{array}$ & $\begin{array}{l}54 \\
54\end{array}$ & $\begin{array}{l}8.10 \\
8.74\end{array}$ \\
\hline
\end{tabular}

The average thermal resistances of these tests at mean temperatures of approximately 50 and $75 \mathrm{~F}$ are 4.92 and 4.68 hr $\mathrm{ft}^{2} \mathrm{~F} / \mathrm{Btu}$ respectively. An average decrease in themal resistance of approximately 0.2 percent per degree $F$ increase in mean temperature was measured. A $25 \mathrm{~F}$ change in mean temperature would yield approximately a 5 percent change in test panel thermal resistance. 
A comparison of Test Panels $1 \mathrm{~A}$ and $11 \mathrm{~A}$ provides a good measure of the effect of heat flow direction on the test panel thermal resistance. The construction of these panels was identical and there are five experiments performed on each panel at identical temperature conditions. The thermal resistance data from these two test panels are depicted as a function of test panel temperature difference in Figure 19. The $R_{p}(30)$ values for test panels incorporating a single airspace having an effective emittance of 0.05 were 3.46 , 3.04, and 8.99 hr $\mathrm{ft}^{2} \mathrm{~F} / \mathrm{Btu}$ for heat flow horizontal, up, and down respectively.

\subsection{TWO-AIRSPACE SYSTEMS}

A similar analysis can be performed on the two-airspace systems, Test panels 1B, 2B, and 3B. Testing on twoairspace test panels was limited to horizontal heat flow only. The differences in the construction of these three test panels were the framing material (XEPs for Test panels $1 \mathrm{~B}$ and 3B, wood for Test Panel 2B) and the effective emittance of the airspace $(0.05$ for Test Panel 1B, 0.03 for Test Panels $2 B$ and 3B). Testing on Test panel $1 B$ was performed such that the mean temperature of the airspace on the cold side of the cavity was 50F while the hot side airspace mean temperature varied from 60 to 100F. Testing conditions on the other two panels were designed such that the hot side airspace mean temperature was predominantly $75 \mathrm{~F}$ with single analyses at $50 \mathrm{~F}$ while the cold side airspace mean temperature varied from 35 to 70F. Since testing conditions on Panel $1 B$ are different than those imposed on 


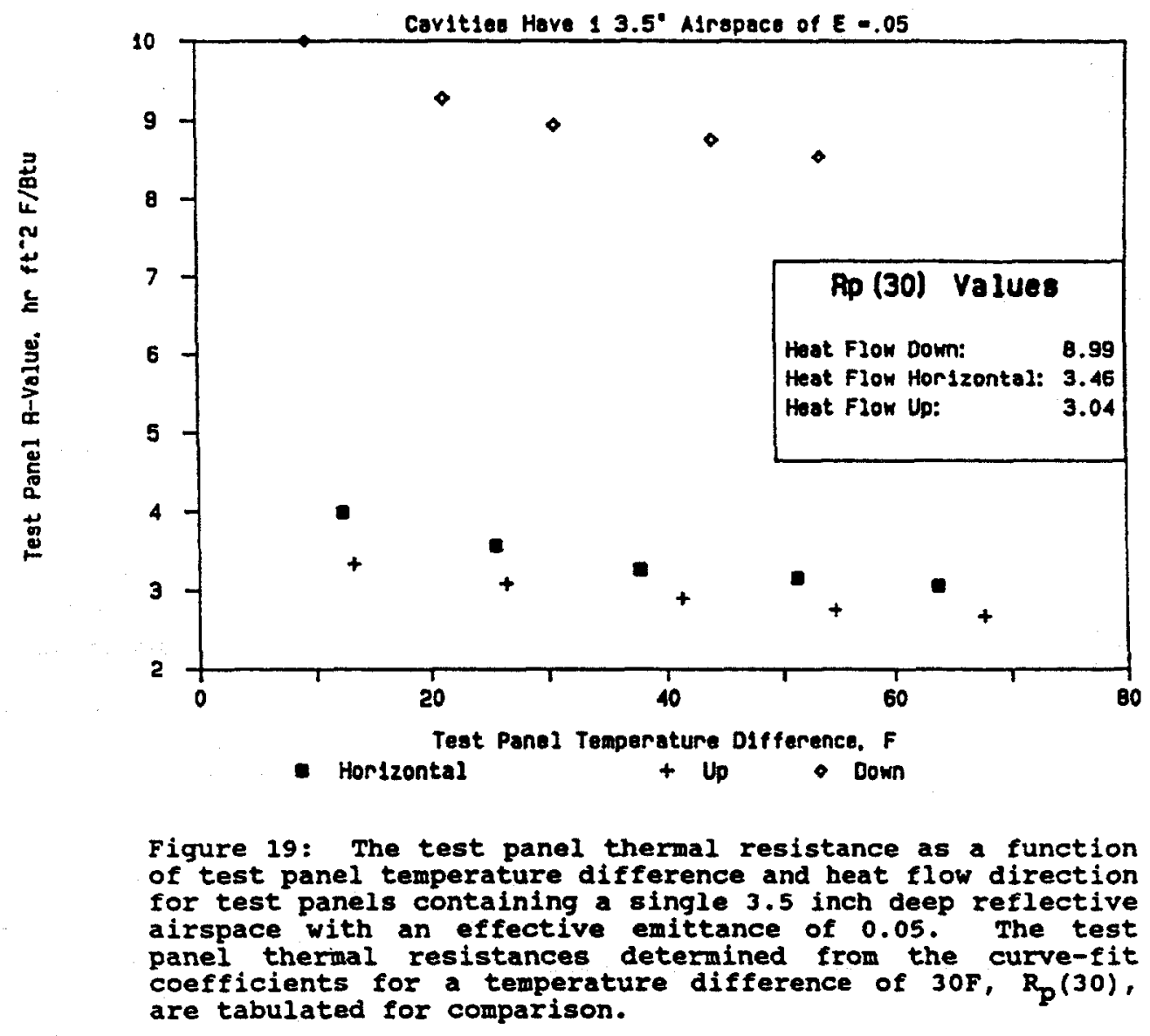


Panels $2 \mathrm{~B}$ and 3B, direct comparisons cannot be made. Test results on the two-airspace systems are summarized below.

A Comparison of Three Two-Airspace Test Panels

\begin{tabular}{|c|c|c|c|c|}
\hline Panel & stud MtI & $E$ & $\begin{array}{l}\text { Heat Flow } \\
\text { Direction }\end{array}$ & $R p(30)$ \\
\hline $\begin{array}{l}1 B \\
2 B \\
3 B\end{array}$ & $\begin{array}{ll}2 \times 4 & \text { XEPS } \\
2 \times 4 & \text { WOOd } \\
2 \times 4 & \text { XEPS }\end{array}$ & $\begin{array}{l}0.05 \\
0.03 \\
0.03\end{array}$ & $\begin{array}{l}\text { Horizontal } \\
\text { Horizontal } \\
\text { Horizontal }\end{array}$ & $\begin{array}{l}5.98 \\
6.19 \\
7.12\end{array}$ \\
\hline
\end{tabular}

The $R_{p}(30)$ values for $1 B$ (XEPS, $E=0.05, T_{\text {mean }}=56-$ $73 F$ ) and $2 \mathrm{~B}$ (wood, $E=0.03, \mathrm{~T}_{\text {mean }}=56-73 \mathrm{~F}$ ) agree to within $0.21 \mathrm{hr} \mathrm{ft}^{2} \mathrm{~F} / \mathrm{Btu}$. Similar to the one-airspace systems, the increases in heat transfer due to the low thermal resistance wood stud of $2 \mathrm{~B}$ are offset by the lower effective emittance of the airspace.

As stated earlier, the $R_{p}(30)$ values for $1 B$ (2 airspaces, XEPS, $E=0.05, T_{\text {mean }}=56-73 \mathrm{~F}$ ) are $1.1 \mathrm{hr} \mathrm{ft}^{2}$ F/Btu lower than 3B (2 airspaces, XEPS, $E=0.03, T_{\text {mean }}=$ 57-75F). The difference in R-Value in the two-airspace test panels is almost three times the difference noted for the same comparison on single airspace systems.

\subsection{FOUR-AIRSPACE SYSTEMS}

A comparison of the panel thermal resistance test results of the four-airspace systems, Test Panels $2 \mathrm{C}, 3 \mathrm{C}$, 12B, and 13B Indicate a behavior similar to the two-airspace systems. The only difference in the construction of these panels was the framing material (XEPS for Test Panels $3 \mathrm{C}$ and 
13B, wood for Test Panels 2C and 12B). Test panels 2C and $3 C$ were analyzed with horizontal heat flow, and Test panels $12 \mathrm{~B}$ and 13B were tested with vertical heat flow down. The panels were all subjected to identical test conditions. The results are summarized below.

A Comparison of Four Four-Airspace Test Panels

\begin{tabular}{|c|c|c|c|c|}
\hline Panel & stud MtI & $\mathbf{E}$ & $\begin{array}{l}\text { Heat Flow } \\
\text { Direction }\end{array}$ & $\operatorname{Rp}(30)$ \\
\hline $\begin{array}{r}2 \mathrm{C} \\
3 \mathrm{C} \\
12 \mathrm{~B} \\
13 \mathrm{~B}\end{array}$ & $\begin{array}{ll}2 \times 4 & \text { Wood } \\
2 \times 4 & \text { XEPS } \\
2 \times 6 & \text { Wood } \\
2 \times 6 & \text { XEPS }\end{array}$ & $\begin{array}{l}0.03 \\
0.03 \\
0.03 \\
0.03\end{array}$ & $\begin{array}{c}\text { Horizontal } \\
\text { Horizontal } \\
\text { Down } \\
\text { Down }\end{array}$ & $\begin{array}{r}6.41 \\
7.40 \\
14.17 \\
16.58\end{array}$ \\
\hline
\end{tabular}

Results on the four-airspace test panels show an increasing panel thermal resistance as the airspace temperature difference decreases.

The $R_{p}(30)$ value for $3 C$ (XEPS and horizontal heat flow) exceed $2 \mathrm{C}$ (Wood and horizontal heat flow) by approximately $1.0 \mathrm{hr} \mathrm{ft}^{2} \mathrm{~F} / \mathrm{Btu}$. For the vertical heat flow experiments, the $R_{p}(30)$ value of Test Panel 13B (XEPS studs) was greater than Test Panel 12B (Wood studs) by approximately $2.4 \mathrm{hr} \mathrm{ft}^{2}$ F/Btu.

The $R_{p}(30)$ value of Panel $2 C$ (four airspaces with wood studs and horizontal heat flow) is lower than the $R_{p}(30)$ value of Panel 3B (two airspaces with XEPS studs and horizontal heat flow) by $0.7 \mathrm{hr} \mathrm{ft}^{2} \mathrm{~F} / \mathrm{Btu}$ and is approximately equal $\left(\mathrm{dR}_{\mathrm{p}}(30)=0.2 \mathrm{hr} \mathrm{ft}^{2} \mathrm{~F} / \mathrm{Btu}\right)$ to Test Panel 2B. (two airspaces with wood studs and horizontal heat flow). 


\subsection{EFFECT OF STUD MATERIAL}

Another measure of the effect of the stud material is to compare R-Values of selected test panels that are identical in construction and were tested under similar test conditions. Figure 20 depicts the test panel R-Values for two different one-, two-, and four-airspace cavities as a function of test panel temperature difference. The results from Test Panels 2A, 2B, 2C, 3A, 3B, and $3 C$ are used for this comparison. The decreases in $R_{p}(30)$ values due to substituting wood for XEPS studs were $0.4,0.9$, and $1.0 \mathrm{hr}$ $\mathrm{ft}^{2}$ F/Btu respectively.

The Effect of stud Material on Six Test Panels Tested with Horizontal Heat Flow

\begin{tabular}{|c|c|c|c|c|c|}
\hline Panel & $\begin{array}{l}\text { Number of } \\
\text { Airspaces }\end{array}$ & stud & $\mathbf{E}$ & $R p(30)$ & dR (XEPS-WoOd) \\
\hline $\begin{array}{l}2 A \\
2 B \\
2 C\end{array}$ & $\begin{array}{l}1 \\
2 \\
4\end{array}$ & $\begin{array}{l}\text { Wood } \\
\text { Wood } \\
\text { Wood }\end{array}$ & $\begin{array}{l}0.03 \\
0.03 \\
0.03\end{array}$ & $\begin{array}{l}3.46 \\
6.19 \\
6.41\end{array}$ & \\
\hline $\begin{array}{l}3 A \\
3 B \\
3 C\end{array}$ & $\begin{array}{l}1 \\
2 \\
4\end{array}$ & $\begin{array}{l}\text { XEPS } \\
\text { XEPS } \\
\text { XEPS }\end{array}$ & $\begin{array}{l}0.03 \\
0.03 \\
0.03\end{array}$ & $\begin{array}{l}3.89 \\
7.12 \\
7.40\end{array}$ & $\begin{array}{l}0.43 \\
0.93 \\
0.99\end{array}$ \\
\hline
\end{tabular}




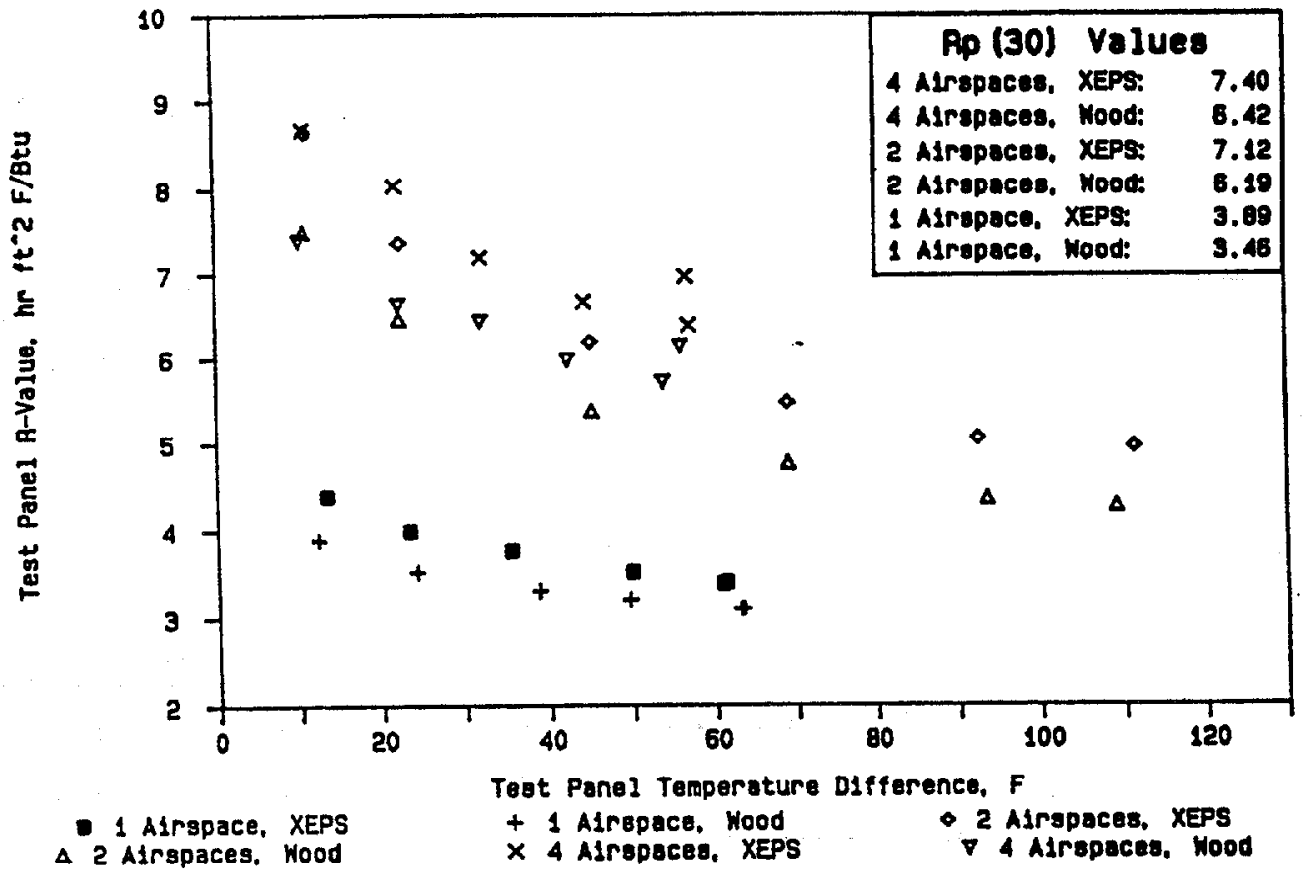

Figure 20: The effect of stud materials on the test panel thermal resistance of test panel containing three different cavity configurations. The test panel thermal resistances determined from the curve-fit coefficients for a temperature difference of $30 \mathrm{~F}, R_{\mathrm{p}}(30)$, are tabulated for comparison. 
The unique nature of reflective insulations require that they be analysed as part of a building system. The building system typically will contain thermal anomalies which will modify the thermal performance of the reflective insulation material. Furthermore, it is desirable to compare reflective insulation with other types of insulation materials on an equivalent basis. To allow for direct comparisons between reflective insulation and other products, it is necessary to accurately extract the cavity thermal resistance from the experimental test panel result.

Two different one-dimensional calculations were used to separate the thermal performance of the cavity from the test panel thermal performance: the parallel path method, $R(||)$, and the isothermal planes method, R(ISO)[4]. The parallel path method is identical to the procedure that is presently being recommended for inclusion into the proposed ASTM standard specification for reflective insulations. The highly instrumented test panels and the thermal performance experiments on the building components make it possible to perform these calculations. The following equations were used to perform these calculations:

$$
\begin{gathered}
Q_{\text {total }}=Q_{\text {stud }}+Q_{\text {cavity }} \\
Q_{\text {stud }}=d T_{\text {stud }}{ }^{* A_{\text {stud }} / R_{\text {stud }}} \\
R(I)=\left(\mathrm{dT}_{\text {cav }}\right) * A_{\text {cav }} /\left(Q_{\text {total }}-Q_{\text {stud }}\right) \\
R(I s 0)=A_{\text {cav }} /\left(A_{\text {total }} /\left(R_{\text {panel }}-R_{\text {sheath }}\right)-A_{\text {stud }} / R_{\text {stud }}\right)
\end{gathered}
$$


where

$$
\begin{aligned}
& Q_{\text {total }}=\text { total metering box energy input; } \\
& \mathbf{Q}_{\text {stud }}=\text { heat flow through studs calculated with the } \\
& \mathrm{dT}_{\text {stud }}=\underset{\text { temperature }}{\text { measured by } \mathrm{T} / \mathrm{Cs} \text { i }} \text {. } \\
& A_{\text {total }}=\text { the total metering area of the panel (16.34 } \\
& \begin{aligned}
& R_{\text {panel }}= \text { the measured surface-to-surface } R \text {-value of } \\
& \text { the panel including the sheathing; and }
\end{aligned} \\
& R_{\text {sheath }}=\text { the measured R-value of the sheathing by }
\end{aligned}
$$

Table 25 includes the results obtained for the cavity thermal resistance calculated by these two different methods ( R ( $\mid 1$ ) and $R$ (ISO)), the cavity and stud hot and cold surface temperatures (HS and CS) measured on the interior side of the sheathing, the cavity and stud mean temperatures 
TABLE 25

THE JMTERMAL TEMPERATURE CONDITIONS AND THE CALCULATEO THERMAL RESISTANCE

OF SEYENTEEM TEST CAVITIES COWTAIHING REFLECTIVE OR MASS INSULATION MATERIALS

\begin{tabular}{|c|c|c|c|c|c|c|c|c|c|c|c|c|c|c|c|}
\hline \multirow{2}{*}{$\begin{array}{l}\text { Test } \\
\text { Panel }\end{array}$} & \multirow{2}{*}{$\begin{array}{c}\text { stud } \\
\text { Material }\end{array}$} & \multirow{2}{*}{$\begin{array}{l}\text { Mo. of } \\
\text { Airspaces }\end{array}$} & \multirow{2}{*}{$\begin{array}{l}\text { Airspece } \\
\text { E }\end{array}$} & \multirow{2}{*}{$\begin{array}{l}\text { Teet } \\
\text { Number }\end{array}$} & \multicolumn{4}{|c|}{ Cavity Temperaturee, $F$} & \multicolumn{4}{|c|}{ Stud Tenperatures, F } & \multirow{2}{*}{$\begin{array}{l}\text { a stud } \\
\text { Btu/hr }\end{array}$} & \multicolumn{2}{|c|}{$\begin{array}{l}\text { Eovity R-Volue, } \\
\text { he ft-2 F/Btu }\end{array}$} \\
\hline & & & & & HS & cs & Tmean & oा & HS & cs & Tmean & dr & & $R(\|)$ & $R$ (1so) \\
\hline \multirow[t]{3}{*}{14} & XEPS & 1 & 0.05 & $H \cdot 1$ & 76.8 & 25.1 & 50.0 & 49.7 & 7.8 & 25.1 & 51.5 & 52.7 & 5.43 & 2.17 & 2.21 \\
\hline & & & & $\mathrm{H}-2$ & 70.2 & 29.9 & 50.1 & 40.3 & 72.5 & 24.7 & 48.6 & 47.8 & 6.92 & 2.27 & 2.30 \\
\hline & & & & $k-3$ & 64.8 & 36.8 & 49.8 & 30.0 & 66.3 & 31.1 & 48.7 & 35.2 & 3.62 & 2.37 & 2.40 \\
\hline \multirow[t]{11}{*}{18} & XEPS & 2 & 0.05 & $N-6$ & 116.9 & 24.4 & 70.7 & 92.5 & 127.1 & 17.4 & 72.3 & 109.7 & 11.30 & 3.26 & 3.33 \\
\hline & & & & $\mathrm{H} \cdot \mathrm{G}-\mathrm{CI}$ & $\$ 16.9$ & $7 t .1$ & 96.0 & 45.8 & & & & & & 1.62 & 1.65 \\
\hline & & & & $H \cdot 6 \cdot C 2$ & 71.1 & 24.4 & 47.8 & 46.7 & & & & & & 1.65 & 1.68 \\
\hline & & & & $H-7$ & 111.5 & 30.6 & 71.1 & 80.9 & 120.2 & 24.6 & 72.4 & 95.6 & 9.84 & 3.42 & 3.51 \\
\hline & & & & $\mathrm{H} \cdot 7-\mathrm{C1}$ & 111.5 & 71.5 & 91.5 & 40.0 & & & & & & 1.69 & 1.73 \\
\hline & & & & $H-9$ & 79.6 & 39.6 & 59.6 & 40.0 & 03.2 & 37.3 & 60.3 & 46.0 & 6.73 & 6.26 & 4.36 \\
\hline & & & & $\mathrm{H} \cdot 9 \cdot \mathrm{Cl}$ & 79.6 & 59.9 & 69.8 & 19.7 & & & & & & 2.09 & 2.15 \\
\hline & & & & H.9.c2 & 59.9 & 39.6 & 49.8 & 20.3 & & & & & & 2.15 & 2.21 \\
\hline & & & & $n-10$ & 64.8 & 44.5 & 54.7 & 20.3 & 66.2 & 43.5 & 56.9 & 22.7 & 2.34 & 5.14 & 5.23 \\
\hline & & & & $H-10-C 1$ & 64.8 & 54.8 & 59.8 & 10.0 & & & & & & 2.53 & 2.58 \\
\hline & & & & $H \cdot 10 \cdot c 2$ & 56.8 & 44.5 & 69.7 & 10.3 & & & & & & 2.61 & 2.65 \\
\hline \multirow[t]{5}{*}{$2 A$} & 1000 & 1 & 0.03 & $H=11$ & 99.6 & 48.9 & 74.3 & 50.7 & 98.7 & 49.7 & 74.2 & 49.0 & 17.62 & 2.37 & 2.34 \\
\hline & & & & $H=12$ & 93.8 & 53.5 & 73.7 & 40.3 & 92.9 & 54.1 & $\pi .5$ & 38.9 & 13.97 & 2.48 & 2.45 \\
\hline & & & & $H-13$ & 89.0 & 57.6 & 73.2 & 31.6 & 88.3 & 58.3 & 73.3 & 30.0 & 10.80 & 2.57 & 2.55 \\
\hline & & & & $M \cdot 14$ & 84.0 & 63.9 & 74.0 & 20.1 & 83.3 & 64.6 & 74.0 & 18.7 & 6.72 & 2.81 & 2.78 \\
\hline & & & & $x-15$ & 79.5 & 68.9 & 74.2 & 10.6 & 78.9 & 69.4 & 74.2 & 9.5 & 3.41 & 3.23 & 3.16 \\
\hline \multirow[t]{12}{*}{28} & 1000 & 2 & 0.03 & $H-17$ & 118.0 & 25.8 & 79.9 & 92.2 & 115.0 & 27.1 & 71.5 & 88.8 & 31.94 & 3.52 & 3.55 \\
\hline & & & & $N-17 \cdot c 1$ & 118.0 & 70.7 & 96.4 & 47.3 & & & & & & 1.80 & 1.82 \\
\hline & & & & $H=17-c 2$ & 70.7 & 25.8 & 48.3 & 44.9 & & & & & & 1.71 & 1.73 \\
\hline & & & & $n-18$ & 94.6 & 15.3 & 55.0 & 79.3 & 92.9 & 16.5 & 54.7 & 76.4 & 27.48 & 3.60 & 3.64 \\
\hline & & & & $H-18-c 1$ & 96.6 & 53.9 & 74.3 & 40.7 & & & & & & 1.85 & 1.87 \\
\hline & & & & $n-18 \cdot c 2$ & 53.9 & 15.3 & 36.6 & 38.6 & & & & & & 1.75 & $1 . \pi$ \\
\hline & & & & $H=19$ & 89.5 & 30.1 & 59.8 & 59.4 & 87.9 & 31.6 & 59.8 & 56.3 & 20.25 & 4.02 & 4.07 \\
\hline & & & & $H \cdot t 9 \cdot c t$ & 89.5 & 59.2 & 74.4 & 30.3 & & & & & & 2.05 & 2.08 \\
\hline & & & & $H \cdot 19 \cdot C 2$ & 59.2 & 30.1 & 46.7 & 29.1 & & & & & & 1.97 & 2.00 \\
\hline & & & & $H-20$ & 85.7 & 46.0 & 65.9 & 39.7 & 84.4 & 47.3 & 65.9 & 37.1 & 13.34 & 4.68 & 4.75 \\
\hline & & & & $H-20 \cdot c t$ & 85.7 & 65.7 & 75.7 & 20.0 & & & & & & 2.36 & 2.39 \\
\hline & & & & $\mathrm{H}-2 \mathrm{O} \cdot \mathrm{C2}$ & 65.7 & 46.0 & 55.9 & 19.7 & & & & & & 2.33 & 2.36 \\
\hline
\end{tabular}


TMBLE 25 (Cont)

THE INTERMAL TEMPERATUAE CONOITIOWS AMO THE CALCURATED THERAL RESISTANCE

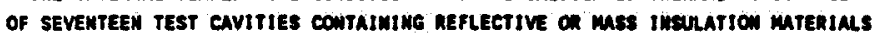

Covity R-Value,

\begin{tabular}{|c|c|c|c|c|c|c|c|c|c|c|c|c|c|c|c|}
\hline \multirow{2}{*}{$\begin{array}{l}\text { Test } \\
\text { Pancl }\end{array}$} & \multirow{2}{*}{$\begin{array}{c}\text { stud } \\
\text { Geterial }\end{array}$} & \multirow{2}{*}{$\begin{array}{l}\text { Mo. of } \\
\text { Alrspacee }\end{array}$} & \multirow{2}{*}{$\begin{array}{c}\text { Alrspece } \\
E\end{array}$} & \multirow{2}{*}{$\begin{array}{l}\text { Teat } \\
\text { Nuber }\end{array}$} & \multicolumn{4}{|c|}{ Covlty Temperetures, f } & \multicolumn{4}{|c|}{ stud Temperatures, f } & \multirow{2}{*}{$\frac{\text { o stud }}{\text { otw/hr }}$} & \multicolumn{2}{|c|}{ hr fent f/etu } \\
\hline & & & & & us & cs & Tmeen & $\pi$ & ms & es & Temen & dा & & $R(\|)$ & $R(150)$ \\
\hline \multirow[t]{6}{*}{28} & 1000 & 2 & 0.03 & H-21 & 80.2 & 59.0 & 70.1 & 20.3 & 79.2 & 60.7 & 69.9 & 18.5 & 6.65 & 5.92 & 5.90 \\
\hline & & & & $\mathrm{H} \cdot 21 \cdot \mathrm{C1}$ & 80.2 & 70.1 & 73.2 & 10.1 & & & & & & 2.95 & 2.98 \\
\hline & & & & $n-21-c 2$ & 70.1 & 59.9 & 65.0 & 10.2 & & & & & & 2.98 & 3.01 \\
\hline & & & & H-22 & 78.2 & $\mathbf{6 8 . 2}$ & 73.2 & 10.0 & 77.6 & 69.7 & 7.2 & 8.9 & 3.20 & 7.15 & 7.27 \\
\hline & & & & $H-22 \cdot c 1$ & 78.2 & 73.3 & 73.8 & 4.9 & & & & & & 3.50 & 3.56 \\
\hline & & & & $N-22-c 2$ & $\mathbf{7 3 . 3}$ & 68.2 & 70.8 & 3.1 & & & & & & 3.65 & 3.71 \\
\hline \multirow[t]{30}{*}{$2 c$} & 1000 & 4 & 0.03 & $n-23$ & 99.5 & 48.7 & $\mathbf{7 3 . 6}$ & 49.8 & 94.8 & 51.2 & 73.0 & 43.6 & 13.68 & 5.27 & 5.12 \\
\hline & & & & $H+23-C 1$ & 90.5 & 86.0 & 91.3 & 14.5 & & & & & & 1.53 & 1.49 \\
\hline & & & & $H \cdot-23-c 2$ & 86.0 & 71.6 & $\pi .8$ & 12.4 & & & & & & 1.31 & 1.28 \\
\hline & & & & $n-23-c 3$ & 71.6 & 61.5 & 66.6 & 10.1 & & & & & & 1.07 & 1.04 \\
\hline & & & & $y-23 \cdot C_{4}$ & 61.5 & 48.7 & 55.1 & 12.8 & & & & & & 1.35 & 1.32 \\
\hline & & & & $N-26$ & 96.6 & 55.0 & 76.7 & 39.4 & 91.3 & 57.0 & 76.2 & 34.3 & 12.34 & 5.57 & 5.42 \\
\hline & & & & $\mathrm{H}-26 \cdot \mathrm{Cl}$ & 94.6 & $\mathbf{8 3 . 3}$ & 86.9 & 11.1 & & & & & & 1.57 & 1.53 \\
\hline & & & & $H \cdot 26-C 2$ & 83.3 & $\mathbf{7 3 . 0}$ & 70.2 & 10.3 & & & & & & 1.46 & 1.42 \\
\hline & & & & $n-26-c 3$ & 78.0 & 65.0 & 69.0 & 8.0 & & & & & & 1.13 & 1.10 \\
\hline & & & & $n-24 \cdot c 6$ & 65.0 & 35.0 & 60.0 & 10.0 & & & & & & 1.61 & 1.38 \\
\hline & & & & $n \cdot 25$ & 90.0 & 60.1 & 75.1 & 29.9 & 87.6 & 61.7 & 74.6 & 25.7 & 9.24 & 6.06 & 5.96 \\
\hline & & & & $n-25 \cdot c 1$ & 90.0 & 81.5 & 85.8 & 8.5 & & & & & & 1.72 & 1.69 \\
\hline & & & & H-25-c2 & 81.5 & $\mathbf{B S . 7}$ & 7.6 & T.8 & & & & & & 1.58 & 1.55 \\
\hline & & & & $n \cdot 25 \cdot c 3$ & 73.7 & 67.6 & 70.7 & 8.1 & & & & & & 1.23 & 1.22 \\
\hline & & & & $H-25-C$ & 67.6 & 60.1 & 63.9 & 7.5 & & & & & & 1.52 & 1.49 \\
\hline & & & & $M-26$ & 85.8 & 64.8 & 7.3 & 21.0 & 83.9 & 66.0 & 75.0 & 17.9 & 6.46 & 6.31 & 6.19 \\
\hline & & & & $\mathrm{H}-26-\mathrm{Cl}$ & 85.8 & 79.9 & 82.9 & 5.9 & & & & & & 1.7 & 1.74 \\
\hline & & & & $\mathrm{H}-26-\mathrm{C2}$ & 79.9 & 74.2 & $\pi .1$ & 3.7 & & & & & & 1.71 & 1.68 \\
\hline & & & & $n \cdot 26 \cdot c 3$ & 76.2 & 69.9 & 72.1 & 4.3 & & & & & & 1.28 & 1.27 \\
\hline & & & & $H-26-C b$ & 69.9 & 64.8 & 67.6 & 5.1 & & & & & & 1.53 & 1.50 \\
\hline & & & & K-27 & 78.5 & 68.8 & 73.7 & 9.7 & $\pi .5$ & 69.4 & 73.5 & 8.1 & 2.91 & 7.18 & 7.13 \\
\hline & & & & $H-27 \cdot c t$ & 70.5 & 75.8 & 77.2 & 2.7 & & & & & & 2.00 & 1.98 \\
\hline & & & & $n \cdot-27 \cdot c 2$ & 75.8 & 73.1 & 76.5 & 2.7 & & & & & & 2.00 & 1.98 \\
\hline & & & & $n-27-c 5$ & 7.1 & 71.1 & 72.1 & 2.0 & & & & & & 1.48 & 1.67 \\
\hline & & & & $n \cdot 27 \cdot c 4$ & 71.1 & 68.8 & 70.0 & 2.3 & & & & & & 1.70 & 1.69 \\
\hline & & & & $H \cdot 28$ & 76.6 & 26.2 & 51.6 & 30.6 & 73.9 & 28.6 & 51.3 & 45.3 & 16.29 & 5.34 & 5.60 \\
\hline & & & & $\mathrm{H} \cdot 28 \cdot \mathrm{Cl}$ & 76.6 & 60.8 & 68.7 & 15.8 & & & & & & 1.74 & 1.75 \\
\hline & & & & $H-28 \cdot C 2$ & 60.8 & 69.9 & 55.6 & 10.9 & & & & & & 1.20 & 1.21 \\
\hline & & & & $H \cdot 28 \cdot c 3$ & 49.9 & 40.0 & 45.0 & 9.9 & & & & & & 1.00 & 1.10 \\
\hline & & & & $n \cdot 2 a \cdot c 4$ & 40.0 & 26.2 & 35.1 & 13.8 & & & & & & 1.52 & 1.53 \\
\hline \multirow[t]{6}{*}{$3 n$} & XEPS & 1 & 0.03 & $\boldsymbol{n} \cdot \mathbf{2 9}$ & 99.6 & 51.2 & 75.4 & 46.4 & 102.6 & 49.0 & 75.8 & 33.6 & 3.52 & 2.67 & 2.53 \\
\hline & & & & $M \cdot \mathbf{3 0}$ & 96.6 & 56.5 & 76.6 & 40.1 & 98.9 & 53.4 & $\pi .2$ & 43.5 & 6.60 & 2.60 & 2.65 \\
\hline & & & & $n-31$ & 90.0 & 61.2 & 75.6 & 28.8 & 91.7 & 60.6 & 76.1 & 31.1 & 3.20 & 2.80 & 2.88 \\
\hline & & & & H-32 & 8.7 & 65.3 & 7.0 & 19.6 & 85.6 & 65.1 & 75.3 & 20.5 & 2.11 & 3.05 & 3.09 \\
\hline & & & & H-33 & 80.4 & 69.2 & 74.8 & 11.2 & 80.8 & 69.1 & 73.0 & 11.7 & 1.20 & 3.40 & 3.47 \\
\hline & & & & $N \cdot 34$ & 74.6 & 23.5 & 50.1 & 69.1 & 70.3 & 23.5 & 50.9 & 56.8 & 3.64 & 2.51 & 2.56 \\
\hline
\end{tabular}


TABLE 25 (cont)

THE IWTERMAL TEMPERATURE CONOITIONS ANO THE CALCOLATED THERUAL RESISTAMCE

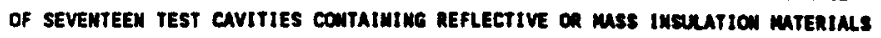

\begin{tabular}{|c|c|c|c|c|c|c|c|c|c|c|c|c|c|c|c|}
\hline \multirow{2}{*}{$\begin{array}{l}\text { Test } \\
\text { Panel }\end{array}$} & \multirow{2}{*}{$\begin{array}{c}\text { Stud } \\
\text { Material }\end{array}$} & \multirow{2}{*}{$\begin{array}{l}\text { No. of } \\
\text { Airspaces }\end{array}$} & \multirow{2}{*}{$\begin{array}{c}\text { Airspece } \\
\text { E }\end{array}$} & \multirow{2}{*}{$\begin{array}{l}\text { Test } \\
\text { Muaber }\end{array}$} & \multicolumn{4}{|c|}{ Covity Temperatures, F } & \multicolumn{4}{|c|}{ seud reaparatures, F } & \multirow{2}{*}{$\begin{array}{l}\text { estid } \\
\text { Dtwhr. }\end{array}$} & \multicolumn{2}{|c|}{$\begin{array}{l}\text { Covity R-Value, } \\
\text { hr ft^2 p/steu }\end{array}$} \\
\hline & & & & & ms & c: & Imen & d & ms & $\infty$ & Temen & $d$ & & $(11)$ & $R(120)$ \\
\hline \multirow[t]{18}{*}{38} & XEPS & 2 & 0.03 & $n-35$ & 121.2 & 26.8 & 73.0 & 96.4 & 124.3 & 22.7 & 73.5 & 101.6 & 10.66 & 3.96 & 3.90 \\
\hline & & & & $\mathrm{H} \cdot \mathbf{3 5} \cdot \mathrm{C1}$ & 121.2 & 72.0 & 96.6 & 49.2 & & & & & & 2.02 & 2.03 \\
\hline & & & & $\mathrm{H} \cdot 35 \cdot \mathrm{C2}$ & $\mathbf{7 2 . 0}$ & 26.8 & 48.4 & 47.2 & & & & & & 1.4 & 1.95 \\
\hline & & & & $M \cdot 36$ & 95.2 & 15.1 & 55.2 & 80.1 & 90.0 & 13.5 & 55.8 & 84.5 & 8.70 & 4.04 & 4.07 \\
\hline & & & & $H \cdot 36 \cdot \mathrm{Cl}$ & 95.2 & 54.5 & 74.9 & 40.7 & & & & & & 2.05 & 2.07 \\
\hline & & & & $N-36-C 2$ & 54.5 & 15.1 & 36.8 & 39.4 & & & & & & 1.99 & 2.00 \\
\hline & & & & $M-37$ & 90.4 & 30.0 & 60.2 & 60.4 & 92.1 & 29.1 & 60.6 & $\mathbf{6 3 . 0}$ & 6.49 & 4.45 & 4.60 \\
\hline & & & & $M-37 \cdot c 1$ & 90.4 & 59.9 & 7.2 & 30.5 & & & & & & 2.24 & 2.26 \\
\hline & & & & $N \cdot 37 \cdot c 2$ & 59.9 & 30.0 & 45.0 & 29.9 & & & & & & 2.20 & 2.22 \\
\hline & & & & $H-38$ & 85.3 & 45.1 & 65.2 & 40.2 & 6.0 & 44.7 & 65.4 & 41.3 & 4.25 & 5.12 & 3.16 \\
\hline & & & & $\mathrm{H}-38-\mathrm{Cl}$ & 85.3 & 63.1 & 73.2 & 20.2 & & & & & & 2.57 & 2.59 \\
\hline & & & & $\mathrm{H} \cdot 30 \cdot \mathrm{C2}$ & 65.1 & 45.1 & 55.1 & 20.0 & & & & & & 2.55 & 2.57 \\
\hline & & & & N-39 & 80.1 & 39.6 & 69.9 & 20.5 & 80.3 & 59.6 & 70.0 & 20.7 & 2.13 & 6.27 & 6.31 \\
\hline & & & & $H-30-61$ & 80.1 & 69.8 & 78.0 & 10.3 & & & & & & 3.15 & 3.17 \\
\hline & & & & $H-39-c 2$ & 69.8 & 59.6 & 64.7 & 10.2 & & & & & & 3.12 & 3.16 \\
\hline & & & & $N-40$ & 7.7 & 67.3 & r..5 & 10.6 & $\pi .7$ & 67.4 & $\mathbf{2 . 6}$ & 10.3 & 1.06 & 7.60 & 7.58 \\
\hline & & & & $\mathrm{H} \cdot 40 \cdot \mathrm{Cl}$ & $\pi .7$ & 72.5 & 75.1 & 5.2 & & & & & & 3.80 & 3.79 \\
\hline & & & & $H \cdot 40 \cdot c 2$ & r.s. & 67.3 & 69.9 & 5.2 & & & & & & 3.00 & 3.79 \\
\hline \multirow[t]{15}{*}{$3 c$} & XEPS & 4 & 0.03 & $n \cdot 41$ & 100.0 & 40.3 & 74.7 & 50.7 & 102.6 & 60.1 & 75.3 & 34.3 & 5.39 & 5.28 & 5.34 \\
\hline & & & & $\mathrm{H}-41 \cdot \mathrm{Cl}$ & 100.0 & 4.4 & 92.2 & 15.6 & & & & & & 1.62 & 1.64 \\
\hline & & & & $n-61-c 2$ & 84.4 & 73.4 & 78.9 & 11.0 & & & & & & 1.15 & 1.16 \\
\hline & & & & $n \cdot 61 \cdot c 3$ & 73.4 & 63.5 & 68.5 & 9.9 & & & & & & 1.03 & 1.06 \\
\hline & & & & $n-41 \cdot c 4$ & 63.5 & 49.3 & 56.4 & 14.2 & & & & & & 1.48 & 1.50 \\
\hline & & & & $H-42$ & 95.6 & 55.8 & 75.7 & 39.8 & 9.8 & 54.9 & 75.8 & 41.9 & 4.31 & 5.57 & 5.42 \\
\hline & & & & $\mathrm{H} \cdot \mathbf{6 2} \cdot \mathrm{Cl}$ & 95.6 & 83.5 & 89.6 & 12.1 & & & & & & 1.69 & 1.71 \\
\hline & & & & $H=62-c 2$ & $\mathbf{8 3 . 5}$ & 74.5 & 79.0 & 9.0 & & & & & & 1.26 & 1.27 \\
\hline & & & & $k-42-c 3$ & 74.5 & 66.6 & 70.6 & 7.9 & & & & & & 1.11 & 1.12 \\
\hline & & & & $\mathrm{K}-62-\mathrm{Cb}$ & 66.6 & 55.8 & 61.2 & 10.8 & & & & & & 1.51 & 1.52 \\
\hline & & & & $n-43$ & 89.0 & 59.8 & 76.6 & 29.2 & 88.8 & 59.4 & 74.1 & 29.4 & 3.03 & 6.09 & 6.14 \\
\hline & & & & $H-43-c t$ & 89.0 & 80.2 & 84.6 & 8.8 & & & & & & 1.84 & 1.85 \\
\hline & & & & $\mathrm{N}-63-\mathrm{C2}$ & 80.2 & 73.6 & 76.8 & 6.8 & & & & & & 1.42 & 1.43 \\
\hline & & & & $H-63-63$ & 73.6 & 67.5 & 70.5 & 5.9 & & & & & & 1.23 & 1.26 \\
\hline & & & & $H \cdot 43 \cdot c 6$ & 67.5 & 59.8 & 63.7 & 7.7 & & & & & & 1.61 & 1.62 \\
\hline \multirow[t]{5}{*}{$3 c$} & XEPS & 4 & 0.03 & H- 44 & 84.9 & 64.7 & 74.8 & 20.2 & 85.2 & 64.6 & 74.9 & 20.6 & 2.12 & 6.92 & 6.97 \\
\hline & & & & $\mathrm{H}-46 \cdot \mathrm{Cl}$ & 84.9 & $\mathbf{7 9 . 0}$ & 82.0 & 5.9 & & & & & & 2.02 & 2.03 \\
\hline & & & & $\mathrm{H}-44-\mathrm{C2}$ & 79.0 & 74.1 & 76.6 & 4.9 & & & & & & 1.68 & 1.69 \\
\hline & & & & $H \cdot 44 \cdot c 3$ & 74.1 & 69.9 & $\mathbf{r . 0}$ & 4.2 & & & & & & 1.44 & 1.45 \\
\hline & & & & $n+44-C_{4}$ & 69.9 & 64.7 & 67.3 & 5.2 & & & & & & 1.78 & $1 . \pi$ \\
\hline
\end{tabular}


TABLE 25 (cone)

THE IMTERHAL TEMPERATURE CONDITIONS ND THE CALCULATED TMERRAL RESISTAMCE OF SEVENTEEM TEST CAVITIES COUTAINIMG REFLECTIVE OR MASS IMSULATIOU MATERIALS

\begin{tabular}{|c|c|c|c|c|c|c|c|c|c|c|c|c|c|c|c|}
\hline \multirow{2}{*}{$\begin{array}{l}\text { Test } \\
\text { Panel }\end{array}$} & \multirow{2}{*}{$\begin{array}{c}\text { Stud } \\
\text { Material }\end{array}$} & \multirow{2}{*}{$\begin{array}{l}\text { Mo. of } \\
\text { Afrspeces }\end{array}$} & \multirow{2}{*}{$\begin{array}{c}\text { Airapace } \\
\text { E }\end{array}$} & \multirow{2}{*}{$\begin{array}{l}\text { Teat } \\
\text { Number }\end{array}$} & \multicolumn{4}{|c|}{ Cevity Temperatures, $F$} & \multicolumn{4}{|c|}{ stud temperetures, f } & \multirow{2}{*}{$\begin{array}{l}\text { a stud } \\
\text { stu/hr }\end{array}$} & \multicolumn{2}{|c|}{$\begin{array}{l}\text { Covfty A-Value, } \\
\text { hr ft^2 F/Btu }\end{array}$} \\
\hline & & & & & HE & cs & Tmen & dr & NS & cs & tmeen & dt & & $R(\mathrm{Il})$ & n (150) \\
\hline \multirow[t]{10}{*}{$3 C$} & XEPS & 4 & 0.03 & $H \cdot 45$ & 79.8 & 69.8 & 74.8 & 10.0 & 79.9 & 69.8 & 74.9 & 10.1 & 1.04 & 7.46 & 7.60 \\
\hline & & & & $H-45-61$ & 79.0 & $\pi .0$ & 70.4 & 2.8 & & & & & & 2.09 & 2.13 \\
\hline & & & & $H-45-C 2$ & $\pi .0$ & 74.6 & 75.7 & 2.6 & & & & & & 1.94 & 1.98 \\
\hline & & & & $H \cdot 45 \cdot c 3$ & 74.4 & $\mathbf{2} .2$ & 73.3 & 2.2 & & & & & & 1.06 & 1.67 \\
\hline & & & & $H \cdot 45 \cdot 64$ & 72.2 & 69.8 & 71.0 & 2.4 & & & & & & 1.79 & 1.82 \\
\hline & & & & $N-46$ & 76.6 & 25.2 & 40.9 & 49.4 & 7.6 & 23.8 & 50.7 & 53.8 & 5.54 & 5.66 & 5.90 \\
\hline & & & & $H-46-c 1$ & 74.6 & 58.1 & 66.4 & 16.5 & & & & & & 1.89 & 1.97 \\
\hline & & & & $\mathrm{H}-46-\mathrm{C2}$ & 58.1 & 48.2 & 53.2 & 9.9 & & & & & & 1.13 & 1.18 \\
\hline & & & & $H \cdot 46 \cdot 03$ & 40.2 & 39.6 & 43.9 & 8.6 & & & & & & 0.99 & 1.03 \\
\hline & & & & $H-46-c 4$ & 39.6 & 25.2 & 32.4 & 16.6 & & & & & & 1.65 & 1.72 \\
\hline 41 & XEPS & $N / A$ & $m / A$ & $N \cdot 67$ & 101.7 & 49.7 & 75.7 & 32.0 & 102.0 & 49.5 & 73.8 & 52.5 & 5.60 & 91.18 & 11.19 \\
\hline 48 & 1000 & $N / A$ & $m / a$ & $N \cdot 40$ & 97.9 & 50.2 & 74.0 & 47.6 & 96.0 & 32.2 & 73.1 & 69.8 & 15.03 & 10.17 & 10.22 \\
\hline \multirow[t]{12}{*}{$11 n$} & XEPS & 1 & 0.05 & $v \cdot 90$ & 74.7 & 25.5 & 50.1 & 49.2 & 78.3 & 14.7 & 46.5 & 63.6 & 4.22 & 1.76 & 1.84 \\
\hline & & & & $V \cdot \mathbf{z u}$ & 71.2 & 30.6 & 50.9 & 40.6 & 73.8 & 22.6 & 48.2 & 51.2 & 3.39 & 1.85 & 1.91 \\
\hline & & & & $v-3 u$ & 66.1 & 34.8 & 50.5 & 31.3 & 67.5 & 29.0 & 48.2 & 38.5 & 2.55 & 1.90 & 2.05 \\
\hline & & & & $v \cdot \mathbf{w}$ & 60.1 & 39.7 & 49.9 & 20.4 & 60.7 & 35.9 & 48.3 & 24.8 & 1.64 & 2.17 & 2.22 \\
\hline & & & & $v \cdot 50$ & 35.5 & 45.0 & 50.3 & 10.5 & 35.7 & 42.0 & 48.8 & 13.7 & 0.91 & 2.40 & 2.44 \\
\hline & & & & $v \cdot 6 u$ & 100.3 & 51.1 & 75.7 & 49.2 & 106.2 & 38.8 & 71.5 & 65.4 & 4.34 & 1.62 & 1.71 \\
\hline & & & & $v-70$ & 76.9 & 26.7 & 49.8 & 50.2 & 72.8 & 22.0 & 47.4 & 50.8 & 3.37 & 7.53 & 7.33 \\
\hline & & & & $v \cdot 6$ & 70.9 & 30.0 & 30.5 & 40.9 & 69.2 & 27.8 & 48.5 & 41.4 & 2.75 & 7.64 & 7.56 \\
\hline & & & & $v \cdot 90$ & 64.5 & 35.5 & 50.0 & 29.0 & 63.0 & 36.0 & 48.5 & 29.0 & 1.92 & 7.92 & 7.71 \\
\hline & & & & $v \cdot 100$ & 60.6 & 40.1 & 50.3 & 20.3 & 59.2 & 39.1 & 49.2 & 20.1 & 1.33 & 8.32 & 8.02 \\
\hline & & & & $v \cdot 110$ & 54.8 & 45.6 & 50.1 & 9.4 & 34.2 & 45.2 & 49.7 & 9.0 & 0.60 & 9.67 & 8.73 \\
\hline & & & & $v \cdot 120$ & 100.2 & 49.3 & 74.8 & 50.9 & 97.8 & 69.3 & 73.6 & 48.5 & 3.22 & 6.84 & 6.75 \\
\hline \multirow[t]{12}{*}{121} & 1000 & 1 & 0.05 & $v-130$ & 99.6 & 50.2 & 74.9 & 49.4 & 96.5 & 43.1 & 69.8 & 53.4 & 13.16 & 1.61 & 1.62 \\
\hline & & & & $v-140$ & 94.8 & 56.2 & 74.5 & 40.6 & 92.0 & 48.7 & 70.4 & 43.3 & 10.67 & 1.73 & 1.73 \\
\hline & & & & $v-150$ & 88.8 & 59.8 & 74.3 & $\mathbf{2 9 . 0}$ & 86.1 & 55.7 & 70.9 & 30.4 & 7.69 & 1.85 & 1.86 \\
\hline & & & & $v-160$ & o4. 8 & 64.4 & 74.6 & 20.4 & 02.6 & 61.7 & 72.2 & 20.9 & 5.15 & 2.03 & 2.07 \\
\hline & & & & $v-1 \pi$ & 76.2 & 65.6 & 69.9 & 8.6 & 73.5 & 65.5 & 69.5 & 8.0 & 1.97 & 2.79 & 2.66 \\
\hline & & & & $v \cdot 18$ & 75.2 & 25.3 & 50.3 & 49.9 & 73.0 & 19.8 & 46.4 & 53.2 & 13.11 & 1.73 & $1 . \pi$ \\
\hline & & & & $v-190$ & 100.3 & 50.1 & 73.2 & 50.2 & 98.3 & 52.1 & $\pi .2$ & 46.2 & 11.39 & 6.95 & 6.67 \\
\hline & & & & $v-200$ & 95.2 & 35.3 & 75.3 & 39.9 & 93.8 & 57.3 & 75.6 & 36.5 & 9.00 & 7.12 & 6.91 \\
\hline & & & & $V-210$ & 89.3 & 59.9 & 74.6 & 29.6 & 88.6 & 61.3 & 75.0 & 27.3 & 6.73 & 7.61 & 7.14 \\
\hline & & & & $v-220$ & 85.9 & 65.6 & 73.8 & 20.3 & 85.4 & 66.5 & 76.0 & 18.9 & 4.66 & 7.61 & 7.37 \\
\hline & & & & $v-250$ & 81.1 & 60.8 & $\pi .0$ & 12.3 & 80.9 & 69.3 & 75.1 & 11.6 & 2.86 & 8.21 & 7.79 \\
\hline & & & & $v-240$ & 75.5 & 26.0 & 50.8 & 49.5 & 73.3 & 28.6 & 51.0 & 44.7 & 11.02 & 7.56 & 7.29 \\
\hline
\end{tabular}


TABLE 25 (Cont)

THE INTEAMAL TEMPERATURE CONDITIONE ANO THE CALCULATED tHERMAL REStSTANCE OF SEVENTEEN TEST CAVITIES COWTAIMING REFLECTIVE OR MASS IMSULATIOW MATERIALS

\begin{tabular}{|c|c|c|c|c|c|c|c|c|c|c|c|c|c|c|c|}
\hline \multirow{2}{*}{$\begin{array}{l}\text { Test } \\
\text { Panel }\end{array}$} & \multirow{2}{*}{$\begin{array}{l}\text { Stud } \\
\text { Material }\end{array}$} & \multirow{2}{*}{$\begin{array}{l}\text { No. of } \\
\text { Airspaces }\end{array}$} & \multirow{2}{*}{$\begin{array}{c}\text { Airspace } \\
\text { E }\end{array}$} & \multirow{2}{*}{$\begin{array}{c}\text { Test } \\
\text { Number }\end{array}$} & \multicolumn{4}{|c|}{ Cavity Temperatures, $F$} & \multicolumn{4}{|c|}{ stud temperatures, $F$} & \multirow{2}{*}{ a stud } & \multicolumn{2}{|c|}{$\begin{array}{l}\text { Cavity R-Value, } \\
\text { hr ft^2 F/Btu }\end{array}$} \\
\hline & & & & & is & cs & Tween & $d$ & HS & $\operatorname{cs}$ & Tmean & dr & & $R(11)$ & $R(1 \mathrm{so})$ \\
\hline \multirow[t]{30}{*}{$12 \mathrm{~B}$} & 1000 & 4 & 0.03 & $v \cdot 250$ & 100.3 & 51.2 & 75.8 & 49.1 & 97.8 & 52.5 & 75.2 & 45.3 & 11.17 & 16.56 & 14.88 \\
\hline & & & & $V \cdot 250 \cdot c 1$ & 100.3 & 83.6 & 92.0 & 16.7 & & & & & & 5.63 & 5.06 \\
\hline & & & & $v-250-C 2$ & 83.6 & 73.5 & 78.6 & 10.1 & & & & & & 3.61 & 3.06 \\
\hline & & & & $v-250-c 3$ & 73.5 & 67.9 & 70.7 & 5.6 & & & & & & 1.89 & 1.70 \\
\hline & & & & $v-250-c_{4}$ & 67.9 & 51.2 & 59.6 & 16.7 & & & & & & 5.63 & 5.06 \\
\hline & & & & $v-260$ & 96.1 & 56.1 & 76.1 & 40.0 & 94.1 & 57.1 & 75.6 & 37.0 & 9.12 & 17.32 & 15.39 \\
\hline & & & & $v-260 \cdot c 1$ & 96.1 & 82.3 & 89.2 & 13.8 & & & & & & 5.97 & 5.31 \\
\hline & & & & $v-260 \cdot c 2$ & 82.3 & 73.9 & 78.1 & 8.4 & & & & & & 3.64 & 3.23 \\
\hline & & & & $v-260 \cdot c 3$ & 73.9 & 69.5 & 71.7 & 4.4 & & & & & & 1.90 & 1.69 \\
\hline & & & & $V-260 \cdot c 4$ & 69.5 & 56.1 & 62.8 & 13.4 & & & & & & 5.80 & 5.16 \\
\hline & & & & $v-270$ & 90.7 & 59.5 & $\pi .1$ & 31.2 & 89.0 & 60.3 & 74.7 & 28.7 & 7.07 & 17.17 & 15.04 \\
\hline & & & & $v-270 \cdot c 1$ & 90.7 & 79.8 & 85.3 & 10.9 & & & & & & 6.00 & 5.26 \\
\hline & & & & $y-270 \cdot c 2$ & 79.8 & 73.3 & 76.6 & 6.5 & & & $\cdot$ & & & 3.58 & 3.13 \\
\hline & & & & $v-270-c 3$ & 73.3 & 69.8 & 79.6 & 3.5 & & & & & & 1.93 & 1.69 \\
\hline & & & & $v-270-c_{4}$ & 69.8 & 59.5 & 66.7 & 10.3 & & & & & & 5.67 & 4.97 \\
\hline & & & & $v-200$ & 86.2 & 65.3 & 74.8 & 18.9 & 83.2 & 65.9 & 74.6 & 17.3 & 4.26 & 18.07 & 15.63 \\
\hline & & & & $v-280-c i$ & 4.2 & 77.5 & 80.9 & 6.7 & & & & & & 6.41 & 5.56 \\
\hline & & & & $v-280-c 2$ & 77.5 & 73.5 & 75.5 & 4.0 & & & & & & 3.82 & 3.31 \\
\hline & & & & $V-280 \cdot c 3$ & 73.5 & 79.3 & 72.4 & 2.2 & & & & & & 2.10 & 1.82 \\
\hline & & & & $v \cdot 280 \cdot C 4$ & 71.3 & 65.3 & 68.3 & 6.0 & & & & & & 5.74 & 4.96 \\
\hline & & & & $v-290$ & 79.9 & 70.1 & 75.0 & 9.8 & 79.3 & 70.2 & 74.8 & 9.1 & 2.24 & 18.42 & 16.67 \\
\hline & & & & $v-290 \cdot c 1$ & 79.9 & 76.4 & 78.2 & 3.5 & & & & & & 6.58 & 5.95 \\
\hline & & & & $v-290 \cdot c 2$ & 76.4 & 74.3 & 75.4 & 2.1 & & & & & & 3.95 & 3.57 \\
\hline & & & & $v \cdot 290 \cdot c 3$ & 76.3 & 73.1 & 73.7 & 1.2 & & & & & & 2.26 & 2.06 \\
\hline & & & & $v-290-c_{4}$ & 73.1 & 70.1 & 71.6 & 3.0 & & & & & & 5.64 & 5.10 \\
\hline & & & & $v-300$ & 76.2 & 25.8 & 51.0 & 50.4 & 73.5 & 27.1 & 50.3 & 46.4 & 11.46 & 17.04 & 14.79 \\
\hline & & & & $V-300 \cdot c 9$ & 76.2 & 58.6 & 67.4 & 17.6 & & & & & & 5.85 & 5.17 \\
\hline & & & & $v \cdot 300-c 2$ & 58.6 & 48.4 & 53.5 & 10.2 & & & & & & 3.45 & 2.90 \\
\hline & & & & $v-300 \cdot c 3$ & 68.6 & 62.7 & 45.6 & 5.7 & & & & & & 1.93 & 1.67 \\
\hline & & & & $v \cdot 300 \cdot c h$ & 62.7 & 25.8 & 34.3 & 16.9 & & & & & & 5.71 & 6.96 \\
\hline $12 \mathrm{C}$ & 10000 & $N / A$ & $H / A$ & $v+310$ & 101.2 & 51.2 & 76.2 & 49.9 & 99.1 & 52.9 & 76.0 & 46.3 & 11.40 & 17.27 & 15.40 \\
\hline \multirow[t]{6}{*}{$13 \AA$} & XEPS & 1 & 0.05 & $v-32 u$ & 99.7 & 49.9 & 74.8 & 49.8 & 103.1 & 38.4 & 70.8 & 66.7 & 4.29 & 1.72 & 1.76 \\
\hline & & & & $v \cdot 330$ & 94.7 & 54.8 & 74.8 & 39.9 & 97.1 & 46.1 & 71.6 & 51.0 & 3.38 & 1.81 & 1.86 \\
\hline & & & & $v-34 v$ & 90.0 & 59.9 & 75.0 & 30.1 & 91.2 & 53.9 & 72.6 & 37.3 & $2.4 T$ & 1.94 & 1.96 \\
\hline & & & & $v-350$ & 84.8 & 64.6 & 76.7 & 20.2 & 85.6 & 60.7 & 73.1 & 24.7 & 1.64 & 2.12 & 2.19 \\
\hline & & & & $v \cdot 360$ & 79.9 & 70.0 & 75.0 & 9.9 & 79.7 & 67.1 & 73.4 & 12.6 & 0.84 & 2.55 & 2.57 \\
\hline & & & & $v-37$ & 83.9 & 34.2 & 59.1 & 49.7 & 87.6 & 21.1 & 56.4 & 66.5 & 4.41 & 1.69 & 1.74 \\
\hline
\end{tabular}


TABLE 25 (cont)

THE INTERHAL TEMPERATURE CONDITIONS ANO THE CALCULATED TMEAML RESTSTANCE

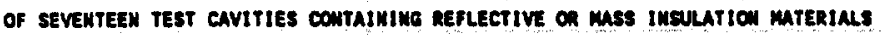

Corlty R-Volue

\begin{tabular}{|c|c|c|c|c|c|c|c|c|c|c|c|c|c|c|c|}
\hline \multirow[b]{2}{*}{$\begin{array}{l}\text { Test } \\
\text { Panel }\end{array}$} & \multirow[b]{2}{*}{$\begin{array}{c}\text { Stud } \\
\text { Material }\end{array}$} & \multirow{2}{*}{$\begin{array}{l}\text { No. of } \\
\text { Airspaces }\end{array}$} & \multirow{2}{*}{$\begin{array}{c}\text { Alirepace } \\
\cdot \text { E }\end{array}$} & \multirow[b]{2}{*}{$\begin{array}{l}\text { Teat } \\
\text { Nuber }\end{array}$} & \multicolumn{4}{|c|}{ Covity Tesperoturee, F } & \multicolumn{4}{|c|}{ seud temperatures, i } & \multirow{2}{*}{ a stud } & \multicolumn{2}{|c|}{$\begin{array}{l}\text { Corlty R-Volue, } \\
\text { hr tt^2 F/etu }\end{array}$} \\
\hline & & & & & us & CS & Tmen & d & MS. & $a$ & Tman & oा & & $R(11)$ & R $(150)$ \\
\hline \multirow[t]{6}{*}{$13 \AA$} & XEPS & 1 & 0.05 & $v \cdot 380$ & 100.7 & 50.6 & 75.7 & 50.1 & 98.7 & 47.5 & 7.1 & 51.2 & 3.40 & 7.06 & 6.90 \\
\hline & & & & $v-390$ & 96.5 & 55.0 & 75.8 & 61.5 & 96.6 & 52.5 & 73.6 & 42.1 & 2.79 & 7.29 & 7.15 \\
\hline & & & & $v-400$ & 90.3 & 59.3 & 74.9 & 30.8 & 8.9 & 57.7 & 73.3 & 31.2 & 2.07 & 7.41 & 7.23 \\
\hline & & & & $V-410$ & 86.8 & 66.7 & 76.8 & 20.1 & 85.6 & 65.6 & 75.6 & 20.0 & 1.33 & 7.90 & 7.75 \\
\hline & & & & $v-420$ & 80.7 & 69.9 & 75.3 & 10.8 & 79.9 & 69.3 & 74.6 & 10.6 & 0.70 & 8.59 & 8.19 \\
\hline & & & & $v-450$ & 85.6 & 35.7 & 60.7 & 49.9 & $\mathbf{8 3 . 6}$ & 32.6 & 57.9 & 51.0 & 3.38 & 7.62 & 7.52 \\
\hline \multirow[t]{26}{*}{138} & XEPS & 4 & 0.03 & $v-440$ & 101.5 & 50.8 & 76.2 & 50.7 & 102.0 & 50.7 & 76.4 & 51.3 & 3.40 & 16.87 & 16.41 \\
\hline & & & & $v-640-c 1$ & 101.5 & 84.6 & कs.1 & 16.9 & & & & & & 4.96 & 4.80 \\
\hline & & & & $y-640-c 2$ & 84.6 & 74.2 & 79.6 & 10.4 & & & & & & 3.05 & 2.96 \\
\hline & & & & $y \cdot 440 \cdot c 3$ & 74.2 & 66.9 & 70.6 & 7.3 & & & & & & 2.14 & 2.07 \\
\hline & & & & $v \cdot 460 \cdot 04$ & 66.9 & 50.8 & 58.9 & 16.1 & & $\cdot$ & & & & 4.72 & 4.57 \\
\hline & & & & $V-450$ & 98.7 & 53.0 & 74.4 & 38.7 & 94.0 & 54.9 & 74.5 & 39.1 & 2.50 & 15.63 & 15.10 \\
\hline & & & & $v \cdot 450-c 1$ & 93.7 & 60.5 & 67.1 & 13.2 & & & & & & 5.33 & 5.15 \\
\hline & & & & $V \cdot 450-c 2$ & 80.5 & $\mathbf{R . 6}$ & 76.6 & 7.9 & & & & & & 3.19 & 3.08 \\
\hline & & & & $v-450-c 3$ & 72.6 & 67.1 & 69.9 & 3.5 & & & & & & 2.22 & 2.15 \\
\hline & & & & $v-450-c h$ & 67.1 & 55.0 & 61.1 & 12.1 & & & & & & 4.89 & 4.72 \\
\hline & & & & $v-460$ & 9.5 & 60.6 & 73.6 & 20.9 & 90.7 & 60.0 & 75.8 & 29.9 & 1.90 & 16.30 & 15.43 \\
\hline & & & & $v \cdot 460-c 1$ & $\infty 0.5$ & 80.2 & 85.6 & 10.3 & & & & & & 5.62 & 5.32 \\
\hline & & & & $v-460-c 2$ & 80.2 & 74.1 & $\pi .2$ & 6.1 & & & & & & 3.33 & 3.15 \\
\hline & & & . & $v \cdot 460 \cdot c 3$ & 76.1 & 89.9 & 72.0 & 4.2 & & & & & & 2.29 & 2.17 \\
\hline & & & & $v-460-c 4$ & 69.9 & 60.6 & 65.3 & 9.3 & & & & & & 5.07 & 6.80 \\
\hline & & & & $v-670$ & 86.0 & 66.3 & 76.2 & 19.7 & 86.2 & 66.7 & 76.3 & 19.5 & 1.29 & 16.90 & 15.64 \\
\hline & & & & $V-470-c 1$ & 86.0 & 7.1 & 22.6 & 6.9 & & & & & & 5.92 & 5.48 \\
\hline & & & & $v-470-62$ & 79.1 & 78.1 & $\pi .1$ & 4.0 & & & & & & 3.63 & 3.17 \\
\hline & & & & $v \cdot 470 \cdot c 3$ & 7.1 & $\mathbf{2} .4$ & 73.8 & 2.7 & & & & & & 2.32 & 2.16 \\
\hline & & & & $v-670-04$ & $\mathbf{7 . 4}$ & 66.3 & 69.4 & 6.1 & & & & & & 5.23 & 4.8 \\
\hline & & & & $V \cdot 400$ & 79.7 & 68.9 & 74.3 & 10.8 & 78.9 & 60.4 & 74.7 & 10.5 & 0.70 & 20.31 & 18.33 \\
\hline & & & & $V: 400-c 1$ & 79.7 & 7.9 & 77.8 & 3.8 & & & & & & 7.15 & 6.45 \\
\hline & & & & $v-400-02$ & 75.9 & 73.8 & 76.9 & 2.1 & & & & & & 3.93 & 3.56 \\
\hline & & & & $y \cdot 400 \cdot 03$ & 73.8 & $\mathbf{2 . 3}$ & 78.1 & 1.5 & & & & & & 2.82 & 2.55 \\
\hline & & & & $V \cdot 400 \cdot c 4$ & $\mathbf{7 . 3}$ & 68.9 & 70.6 & 3.4 & & & & & & 6.39 & 3.77 \\
\hline & & & & $v \cdot 490$ & 74.3 & 23.7 & 50.0 & 48.6 & 74.6 & 25.6 & 50.0 & 49.2 & 3.26 & 16.65 & 16.09 \\
\hline & & & & $v-600 \cdot c 1$ & 76.3 & 57.7 & 6.0 & 16.6 & & & & & & 5.69 & 5.50 \\
\hline & & & & $Y-490-c 2$ & 57.7 & 48.0 & 32.0 & 9.7 & & & & & & 3.32 & 3.21 \\
\hline & & & & $v \cdot 490 \cdot c 3$ & 40.0 & 41.2 & 4.6 & 6.8 & & & & & & 2.33 & 2.25 \\
\hline & & & & $v-190-c 4$ & 41.2 & 25.7 & 33.5 & 15.5 & & & & & & 5.31 & 5.13 \\
\hline
\end{tabular}

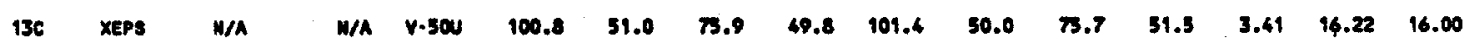


and temperature differences ( $T_{\text {mean }}$ and $d T$ ), as well as the calculated heat flux through the stud (Qstud). The cavity thermal resistance is graphically represented as a function of cavity temperature difference in Figures 21 through 24 and test results gathered at the predominant cavity mean temperature were fitted as a function of cavity temperature difference. The curve-fit coefficients determined for the cavity thermal resistance by the $R(||)$ and $R(I S O)$ methods are presented in Tables 26 and 27 respectively.

When there was more than a single airspace forming the cavity, the thermal resistance of each individual airspace was determined and summed. The temperature sensors installed in the test panels allowed for the direct measurement of the temperature difference across each airspace. The individual airspace thermal resistance results are also presented in Table 25. A suffix was added to the test number to indicate that the result was for an airspace instead of the entire cavity. The suffix "CI" was used to identify the first cavity when the test panel is viewed from the hot side. The remaining cavities were sequentially numbered.

\section{I CAVITIES FIILED WITH MASS INSUIATION}

The proposed ASTM standard specification requires that the heat flow correction for the framing members must be corroborated by performing an experiment with the test panel cavities filled with a mass insulation. A representative sample of the mass insulation would be tested using traditional test methods (ASTM C 518 or C 177) and the predicted thermal resistance of the mass insulation must agree with its directly measured thermal resistance to 
TABLE 26

THE FIT COEFFICIENTS USED TO DESCRIBE THE CAVITY THERMAL RESISTANCE DETERMINED BY THE R(I\|) METHOD AS A FUNCTION OF CAVITY TEMPERATURE DIFFERESCE

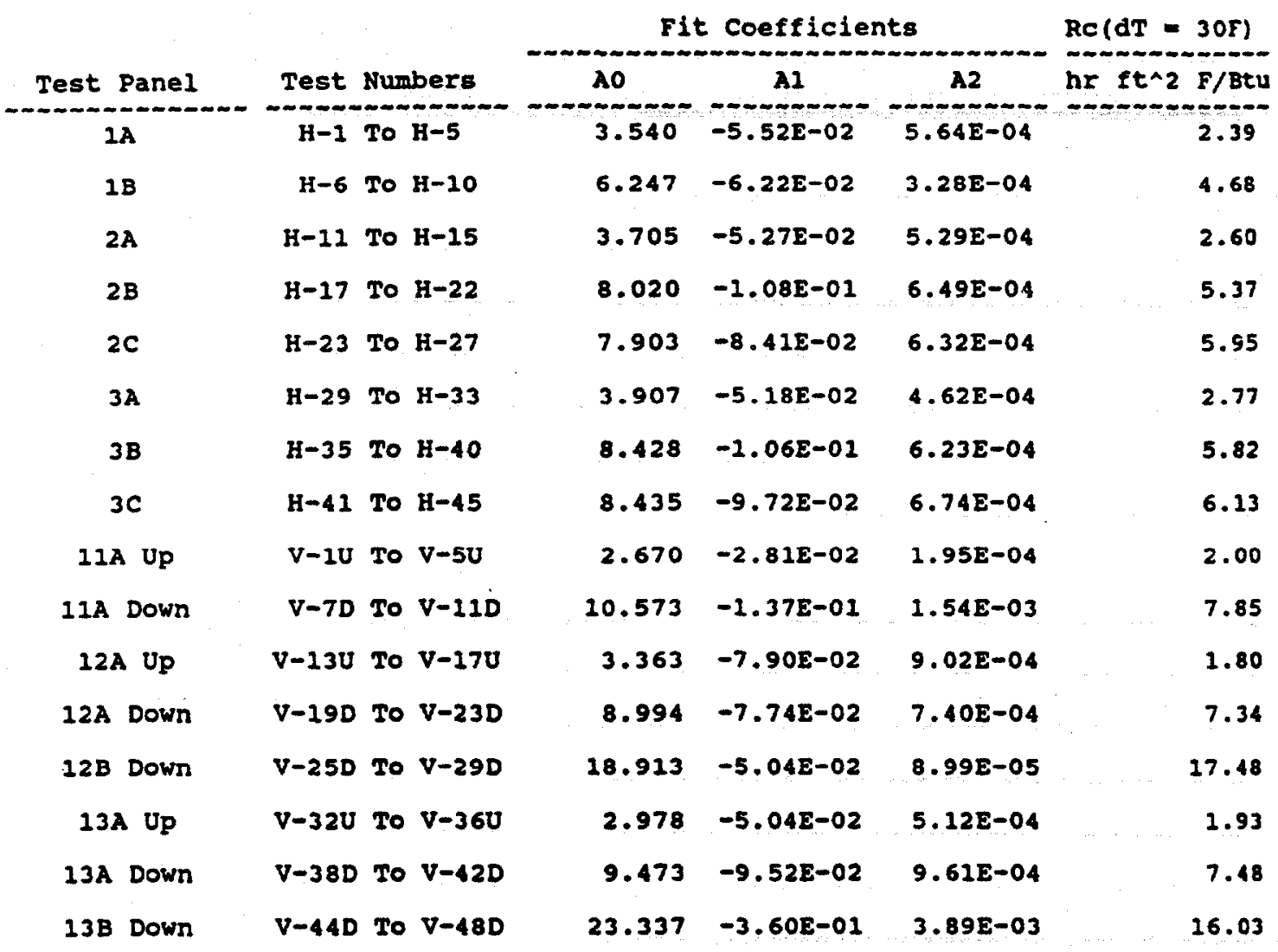

Notes: 2. $R=A O+A 2 * d T+A 2 * d T \wedge 2$ where:

$R$ = Cavity Thermal Resistance, hr ft^2 F/Btu, and $d T=$ Cavity Temperature Difference, $F$.

2. $\operatorname{RC}(\mathrm{dT}=3 \mathrm{OF}$ ) is the cavity thermal resistance calculated from the curve-fit coeficients for a temperature difference of $30 \mathrm{~F}$. 
TABLE 27

THE FIT COEFFICIENTS USED TO DESCRIBE THE CAVITY THERMAL RESISTANCE DETERMINED BY THE R(ISO) METHOD AS A FUNCTION OF CAVITY TEMPERATURE DIFFERENCE

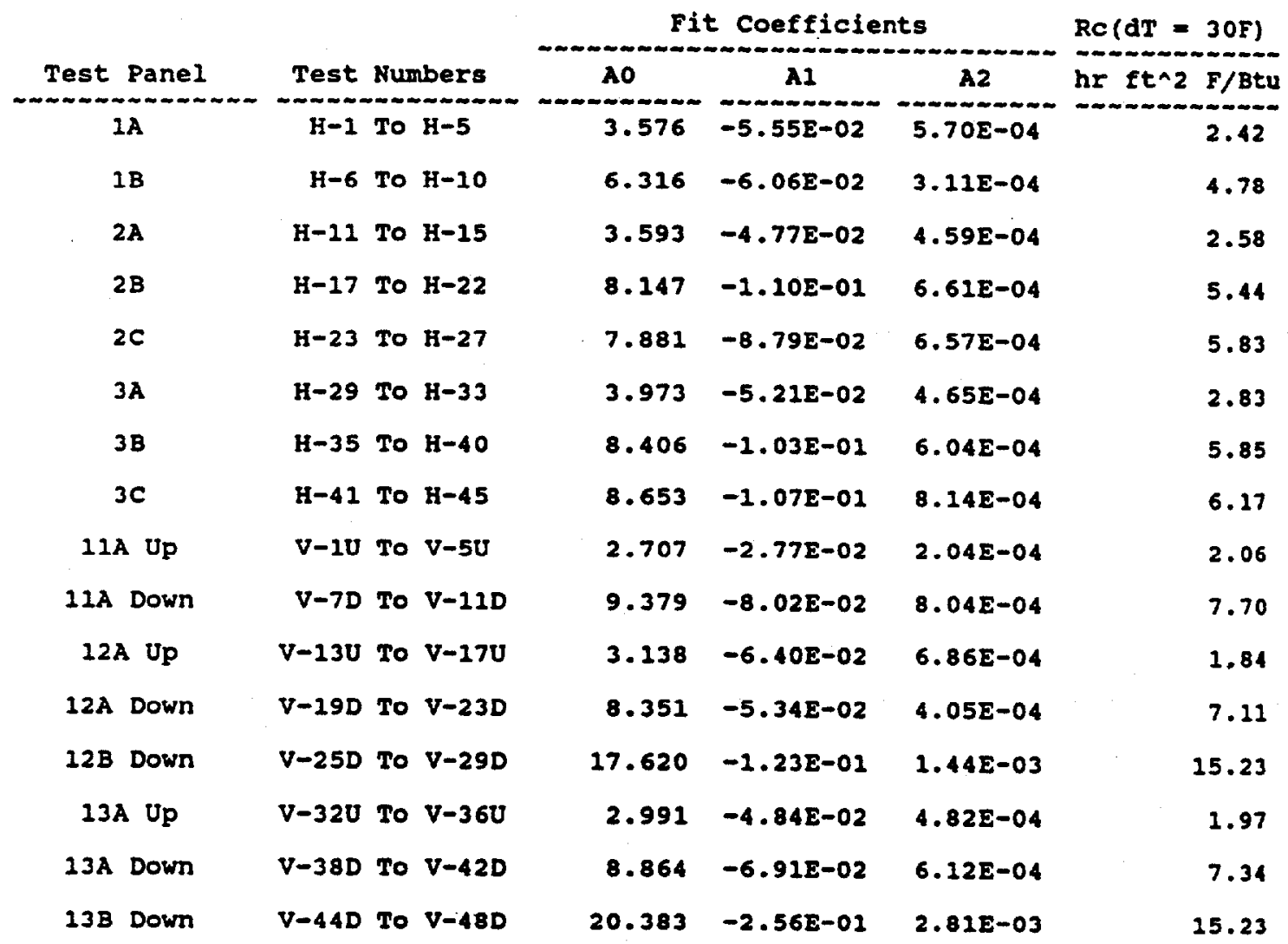

Notes: 1. $R=A O+A I * d T+A 2 * d T^{\wedge} 2$ where:

$R=$ Cavity Thermal Resistance, hr ft^2 $\mathrm{F} / \mathrm{Btu}$, and $d T=$ Cavity Temperature DIfference, $\mathbf{F}$.

2. $R C(d T=30 F)$ is the cavity thermal resistance calculated from the curve-fit coefficients for a temperature difference of $30 \mathrm{~F}$. 
within 10 percent. To check the stringency of this requirement, two test panels (4A and $4 \mathrm{~B}$ ) were insulated with unfaced R-11 fiberglass batts and tested with horizontal heat flow. The same insulation batts were used in the metering area for both test panels. The average density of these batts was $0.61 \mathrm{lbs} / \mathrm{ft}^{3}$. To determine the cavity thermal resistance, the fiberglass batt which had been originally tested at a thickness of 3.5 inches and a density of $0.74 \mathrm{lbs} / \mathrm{ft}^{3}$ was expanded to obtain the same density as the product in the metering area. The thermal resistance from retesting the fiberglass blanket at the same density as the metering area material was used, after correcting for the difference in thickness, as the predicted cavity thermal resistance (See Table 20 ).

A similar exercise was performed using Test Panels $12 \mathrm{C}$ and 13C. These two panels were insulated with unfaced $R-19$ fiberglass batts and analysed with vertical heat flow up. The average density of the metering area batts was 0.51 $\mathrm{lbs} / \mathrm{ft}^{3}$ and was similar to the test sample measured by ASTM C $518\left(0.47 \mathrm{lbs} / \mathrm{ft}^{3}\right)$. These results are summarized below.

A Comparison of the Measured and Calculated Thermal Resistance of Four Cavities Filled with Mass Insulation

\begin{tabular}{|c|c|c|c|c|c|}
\hline \multirow{2}{*}{ Panel } & \multirow{2}{*}{$\begin{array}{l}\text { Measured R } \\
\text { by C } 518\end{array}$} & \multicolumn{2}{|c|}{ Calculated R(C236) } & \multicolumn{2}{|c|}{$[(c 236-c 518) / C 518] * 10$} \\
\hline & & $R(11)$ & $R(I S O)$ & $R(1)$ & $R(I S O)$ \\
\hline $\begin{array}{r}4 \mathrm{~A} \\
4 \mathrm{~B} \\
12 \mathrm{C} \\
13 \mathrm{C}\end{array}$ & $\begin{array}{l}11.00 \\
11.00 \\
16.91 \\
16.91\end{array}$ & $\begin{array}{l}11.18 \\
10.17 \\
17.27 \\
16.22\end{array}$ & $\begin{array}{l}11.19 \\
10.22 \\
15.40 \\
16.00\end{array}$ & $\begin{array}{r}1.6 \\
-7.5 \\
2.1 \\
-4.1\end{array}$ & $\begin{array}{r}1.7 \\
-7.1 \\
-8.9 \\
-5.4\end{array}$ \\
\hline Averag & & & & $|3.8|$ & $|5.8|$ \\
\hline $\begin{array}{r}4 B(*) \\
12 C(*)\end{array}$ & $\begin{array}{l}11.00 \\
16.91\end{array}$ & $\begin{array}{l}10.31 \\
17.56\end{array}$ & $\begin{array}{l}10.38 \\
15.56\end{array}$ & $\begin{array}{r}-6.2 \\
3.8\end{array}$ & $\begin{array}{l}-5.6 \\
-8.0\end{array}$ \\
\hline
\end{tabular}

Note: Calculated R-Values on test panels designated with a (*) use a stud R-value based on tests including drywall screws. 
The cavity thermal resistance derived from all four guarded hot box experiments by both calculation procedures are within $+/-9$ percent of the thermal resistance values measured by ASTM C 518, satisfying the $+/-10$ percent tolerance proposed in the ASTM standard specification.

The averages of the absolute value of percentage differences between the measured and calculated cavity Rvalues for $R(||)$ and $R$ (ISO) are 3.8 and 5.8 percent respectively. Although the $R(||)$ technique shows better agreement than R(ISO), the difference between the two techniques is not as conclusive as initially anticipated.

Test Panels $4 \mathrm{~A}$ and $13 \mathrm{C}$ were constructed with XEPS studs while Test panels $4 \mathrm{~B}$ and $12 \mathrm{C}$ utilized wood studs. The averages of the percentage differences between the measured and calculated cavity R-Values (in absolute terms) for XEPS and wood studs were 2.8 and 4.8 percent respectively for $R(||)$ and 3.6 and 8.0 percent respectively for $R(I S O)$. For either calculation method, the agreement for test panels constructed with XEPS studs was better than test panels constructed with wood studs.

If the thermal resistance values of the wood studs used in the calculations were replaced with the wood stud/drywall screw results (see Table 20 and section 5, Material properties of Test Panel components), the cavity thermal resistance would have increased, improving the agreement between the measured and calculated R-Values for the cavity by approximately 0.5 percent. 


\subsection{HORIZONTAL HEAT FLOW, XEPS STUDS}

Figure 21 depicts the cavity thermal resistance as a function of cavity temperature difference for all of the experiments on test panels containing reflective airspaces, tested with horizontal heat flow, and constructed with XEPS studs. Test results from 5 test panels, namely $1 A, 1 B, 3 A$ $3 B$, and $3 C$ are included on this figure. Details regarding the differences of all these test panels are included in the Test Panel Results section of this report. The cavity thermal resistance data presented on this figure and subsequent figures in this section were calculated by the parallel path method, $R(||)$.

A Comparison of the Cavity Thermal Resistance of Five Test Panels Fabricated with XEPS studs and Tested with Horizontal Heat Flow

\begin{tabular}{|c|c|c|c|c|}
\hline Panel & $\begin{array}{l}\text { Number of } \\
\text { Airspaces }\end{array}$ & $E$ & $R C \perp \perp(30)$ & $\operatorname{RCISO}(30)$ \\
\hline $\begin{array}{l}1 A \\
1 B \\
3 A \\
3 B \\
3 C\end{array}$ & $\begin{array}{l}1 \\
2 \\
1 \\
2 \\
4\end{array}$ & $\begin{array}{l}0.05 \\
0.05 \\
0.03 \\
0.03 \\
0.03\end{array}$ & $\begin{array}{l}2.39 \\
4.68 \\
2.77 \\
5.82 \\
6.13\end{array}$ & $\begin{array}{l}2.42 \\
4.78 \\
2.83 \\
5.85 \\
6.17\end{array}$ \\
\hline Average & & & 4.36 & 4.41 \\
\hline
\end{tabular}

The average cavity thermal resistance for test cavities in test panels constructed with XEPS studs and tested with horizontal heat flow calculated by the parallel path $R(||)$ and isothermal planes $R$ (ISO) methods are 4.36 and $4.41 \mathrm{hr}$ $\mathrm{ft}^{2} \mathrm{~F} / \mathrm{Btu}$ respectively. The two calculation procedures agree to within $0.05 \mathrm{hr} \mathrm{ft}^{2} \mathrm{~F} /$ Btu with $\mathrm{R}(\mathrm{ISO})$ always predicting a slightly higher R-value. 


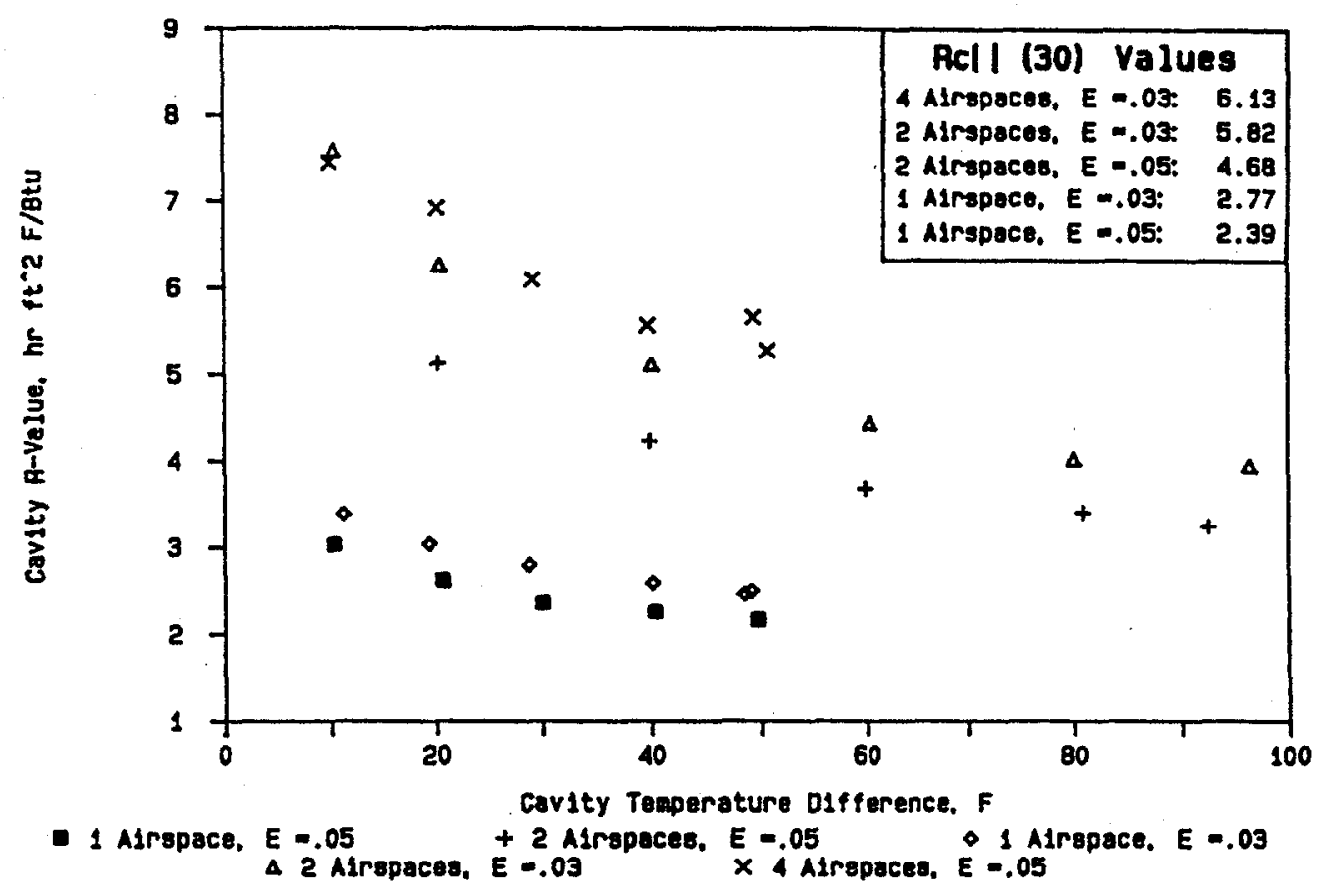

Figure 21: The measured cavity thermal resistance of five cavities as a function of cavity temperature difference determined by the $R(||)$ method from experiments on test panels with XEPS framing members and tested with horizontal heat flow. The cavity thermal resistances determined from the curve-tit coefficients for a temperature difference of 30F, $R_{C \mid \text { | }}(30)$, are tabulated for comparison. 
The $R_{c||}(30)$ values range from 2.4 to $6.1 \mathrm{hr} \mathrm{ft}^{2} \mathrm{~F} / \mathrm{Btu}$. For cavities having an effective emittance of 0.05 , the 2airspace cavity is 1.96 times the 1-airspace $R_{c \mid}(30)$ value. For cavities having an effective emittance of 0.03 , the 2and 4-airspace cavities are 2.1 and 2.2 times the 1-airspace $R_{c||}(30)$ value.

Decreasing the effective emittance from 0.05 to 0.03 increases the $R_{c \mid \text { | }}(30)$ values for the 1 - and 2 - airspace cavities by 0.4 and $1.1 \mathrm{hr} \mathrm{ft}^{2} \mathrm{~F} / \mathrm{Btu}$ respectively. As with the test panel test results, this apparent anomoly is due to the fact that the temperature difference across each airspace in the cavity is different (30 and $15 \mathrm{~F}$ for the 1and 2-airspace cavities respectively).

The $R_{C||}(30)$ values for these cavities are approximately $1.2 \mathrm{hr} \mathrm{ft}^{2} \mathrm{~F} / \mathrm{Btu}$ lower than the $R_{\mathrm{p}}(30)$ values for the test panels from which the cavity data is derived.

\subsection{HORIZONTAL HEAT FIOW, WOOD STUDS}

Figure 22 presents the cavity thermal resistance as a function of cavity temperature difference for all of the experiments on test panels containing reflective airspaces, tested with horizontal heat flow, and constructed with wood studs and contains data from Test panels $2 \mathrm{~A}, 2 \mathrm{~B}$, and $2 \mathrm{C}$. This data is summarized below. 


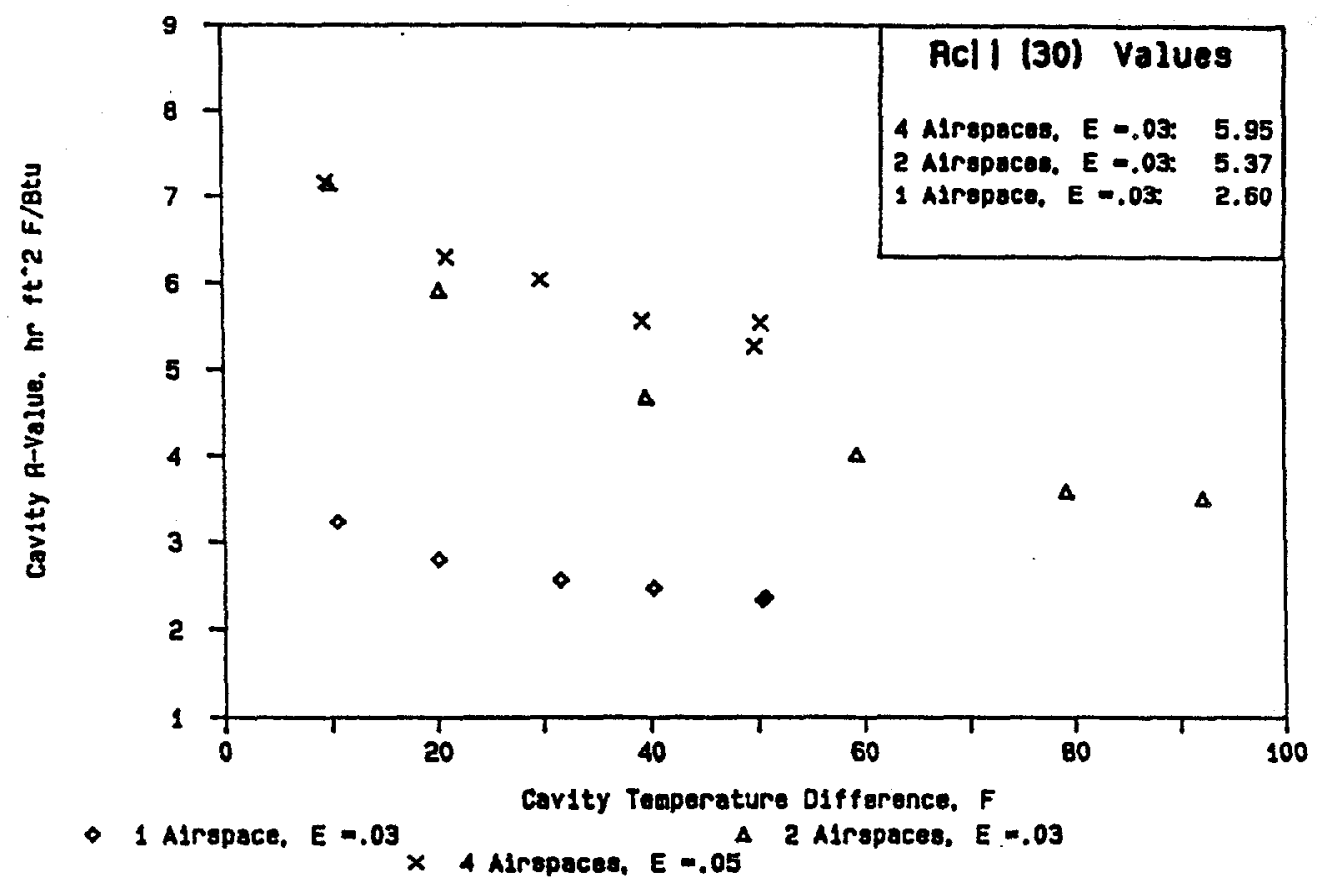

Figure 22: The measured cavity thermal resistance of three cavities as a function of cavity temperature difference determined by the $R(\mid 1)$ method from experiments on test panels with wood framing members and tested with horizontal heat llow. The cavity thermal resistances determined from the curve-fit coefficients for a temperature difference of 3OF, $R_{c||}(30)$, are tabulated for comparison. 
A Comparison of the Cavity Thermal Resistance of Three Test Panels Fabricated with Wood Studs and Tested with Horizontal Heat Flow

\begin{tabular}{|c|c|c|c|c|}
\hline Panel & $\begin{array}{l}\text { Number of } \\
\text { Airspaces }\end{array}$ & $E$ & $R C \perp(30)$ & $\operatorname{RCISO}(30)$ \\
\hline $\begin{array}{l}2 A \\
2 B \\
2 C\end{array}$ & $\begin{array}{l}1 \\
2 \\
4\end{array}$ & $\begin{array}{l}0.03 \\
0.03 \\
0.03\end{array}$ & $\begin{array}{l}2.60 \\
5.37 \\
5.95\end{array}$ & $\begin{array}{l}2.58 \\
5.44 \\
5.83\end{array}$ \\
\hline Average & & & 4.64 & 4.61 \\
\hline
\end{tabular}

The average cavity thermal resistance for test cavities in test panels constructed with wood and tested with horizontal heat flow calculated by the parallel path $R(1 \mid)$ and isothermal planes $R$ (ISO) methods are 4.64 and $4.61 \mathrm{hr}$ $\mathrm{ft}^{2} \mathrm{~F} / \mathrm{Btu}$ respectively. The two calculation procedures agree to within $0.03 \mathrm{hr} \mathrm{ft}^{2} \mathrm{~F} / \mathrm{Btu}$. Unlike the cavities from test panels fabricated with XEPS studs, there is no systematic difference between $R(||)$ and $R$ (ISO).

The $R_{C||}(30)$ values range from 2.6 to $6.0 \mathrm{hr} \mathrm{ft}^{2} \mathrm{~F} / \mathrm{Btu}$. The 2- and 4-airspace cavities are 2.1 and 2.3 times the 1airspace $R_{c \mid}(30)$ value for cavity effective emittances of 0.03 .

The $R_{C \mid l}(30)$ values for these cavities are approximately $0.7 \mathrm{hr} \mathrm{ft}^{2} \mathrm{~F} / \mathrm{Btu}$ lower than the $R_{\mathrm{p}}(30)$ values for the test panels from which the cavity data is derived. When compared to the test panels with XEPS studs, the smaller difference between the test panel and cavity $R-$ Values noted on the wood stud test panels is due to the lower thermal resistance of the wood stud. 
For similar constructions, the $R_{C||}(30)$ values calculated for the XEPs test panels $(3 \mathrm{~A}, 3 \mathrm{~B}$, and $3 \mathrm{C}$ ) are $6.5,7.7$, and 2.9 percent higher than the wood test panels (2A, 2B, and 2C) respectively.

\subsection{VERTICAL HEAT FLOW, XEPS AND WOOD STUDS}

Figures 23 and 24 depict the cavity thermal resistance as a function of cavity temperature difference for all of the experiments on test panels containing reflective airspaces, tested with vertical heat flow, and constructed with XEPS and wood studs respectively. These two figures contain test results from experiments performed on Test Panels 11A, 13A, $13 \mathrm{~B}$ and $12 \mathrm{~A}$ and $12 \mathrm{~B}$ respectively.

A Comparison of the Cavity Thermal Resistance of Five Test Panels Fabricated with XEPS or Wood studs and Tested with

Vertical Heat Flow

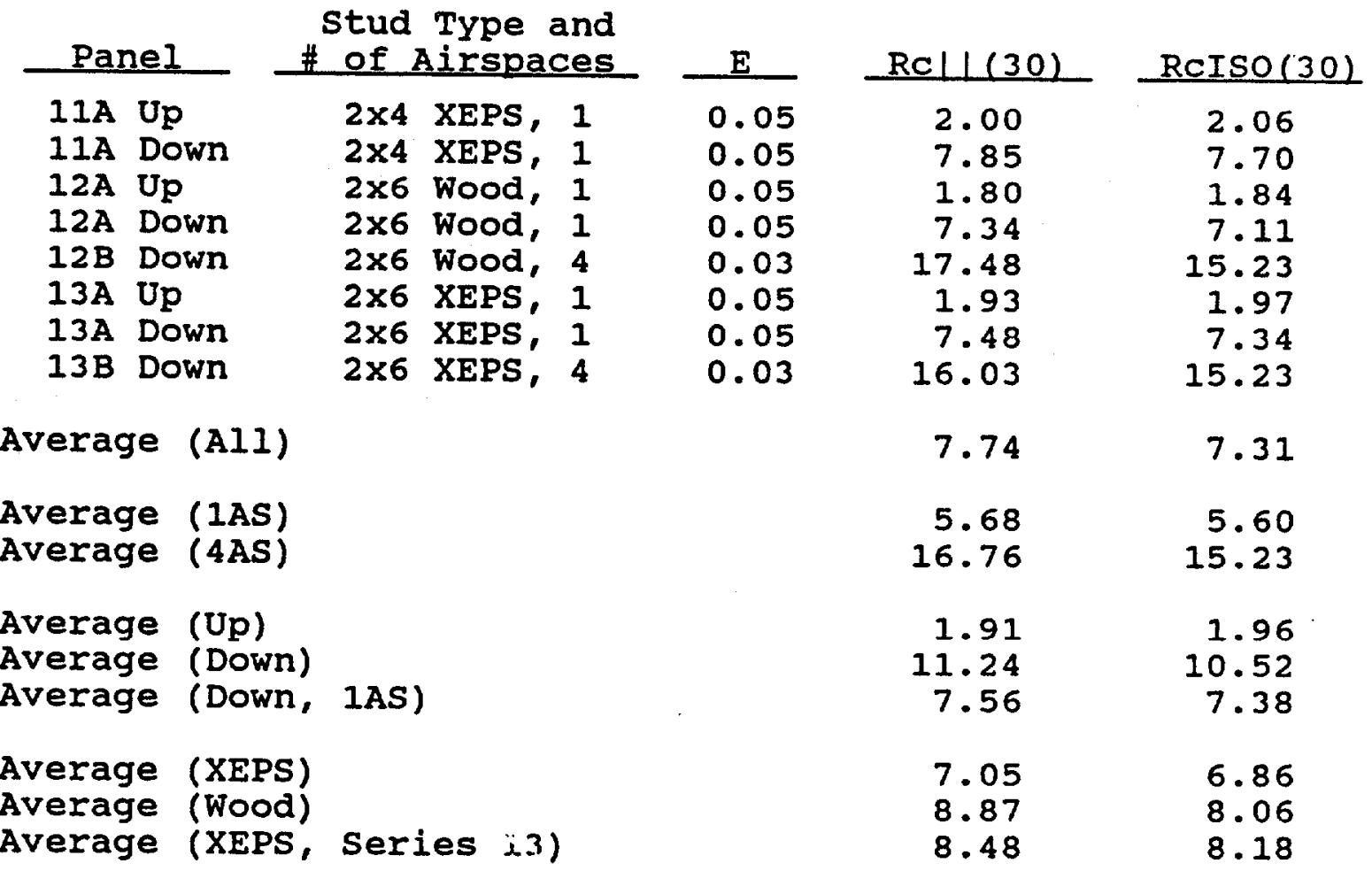




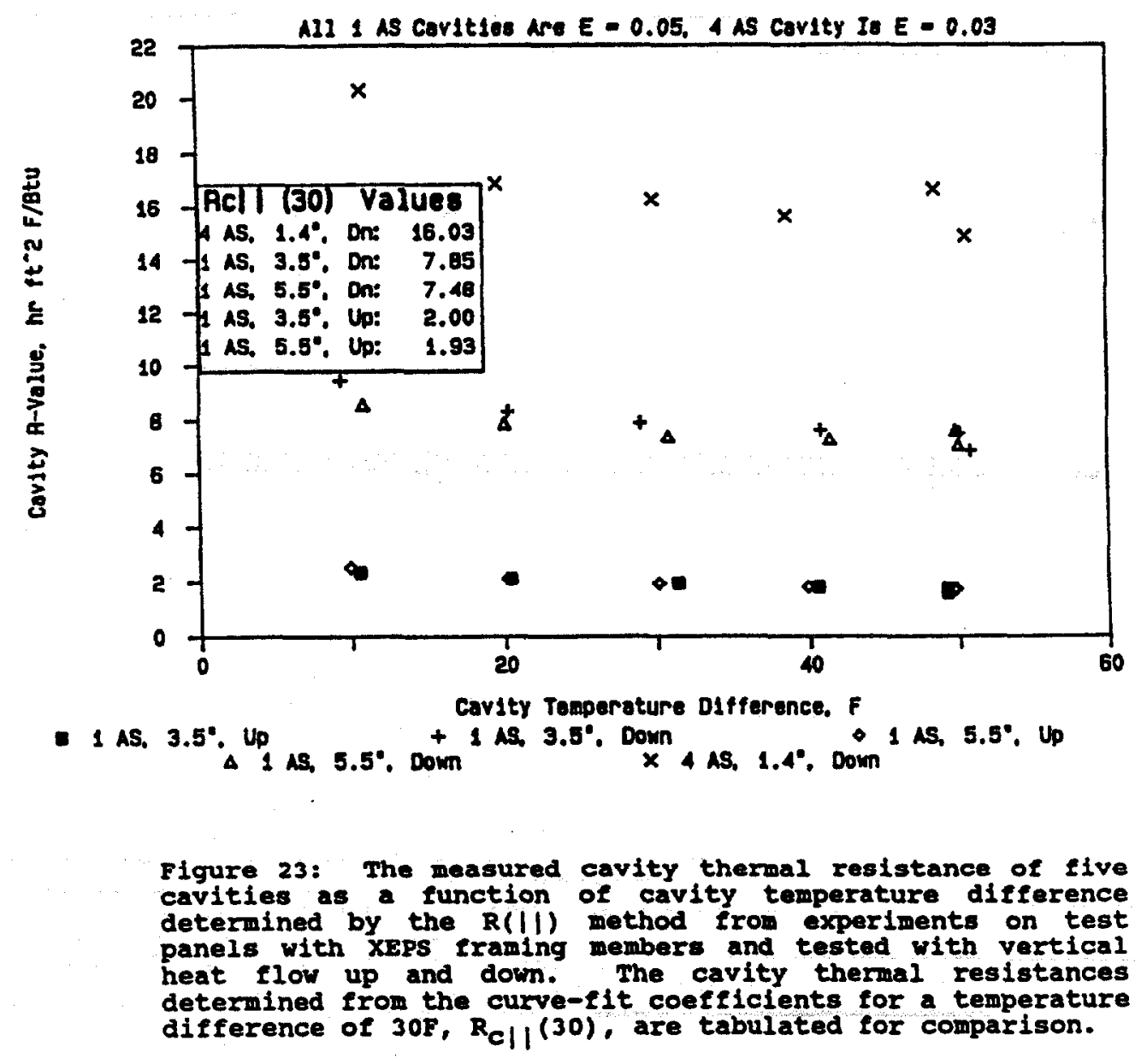




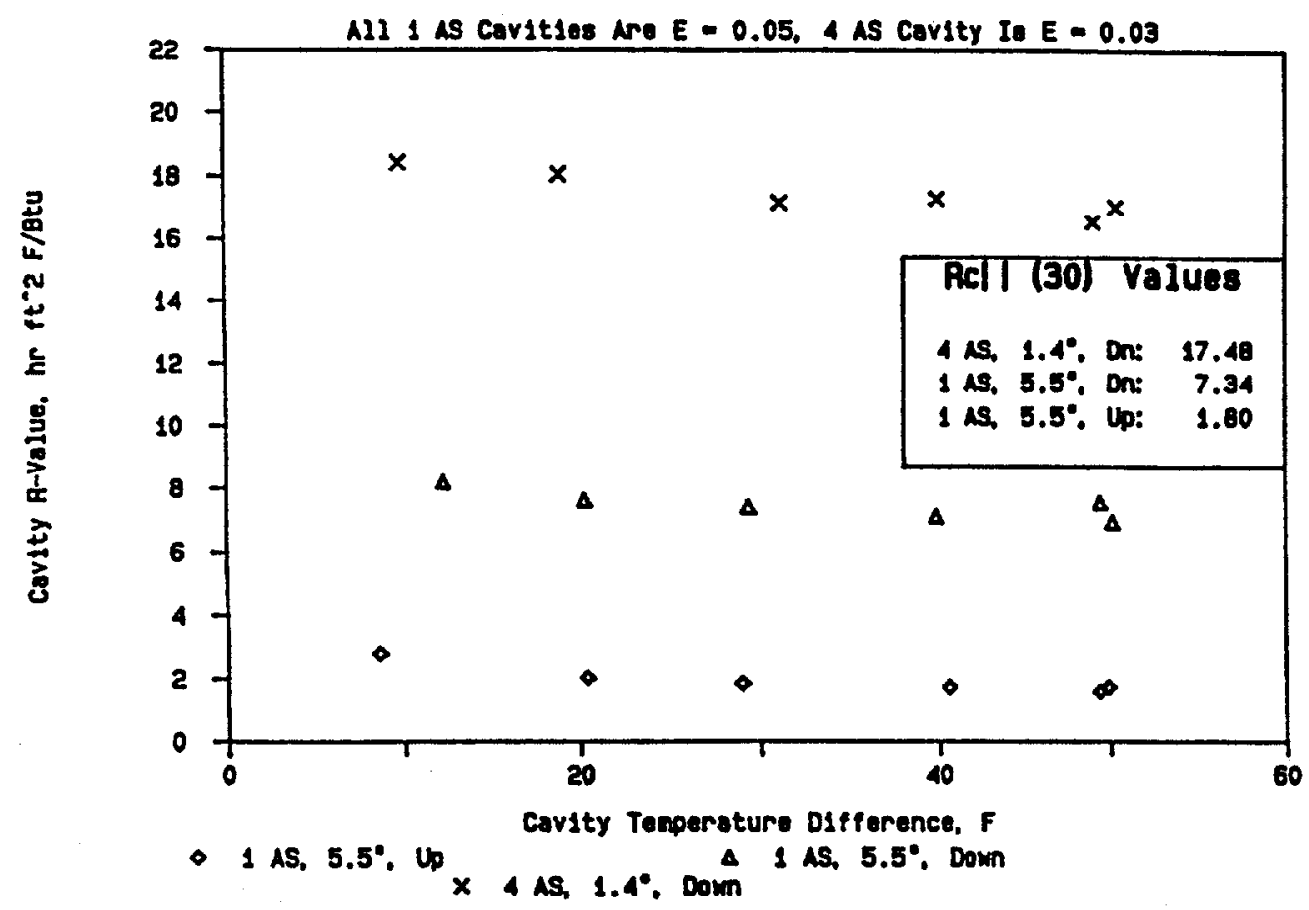

Figure 24: The measured cavity thermal resistance of three
cavities as a function of cavity temperature difference
determined by the R(||) method from experiments on test
panels with wood framing members and tested with vertical
heat flow up and down. The cavity thermal resistances
determined from the curve-fit coeffcients for a temperature
difference of $30 F, R_{c \mid}(30)$. are tabulated for comparison. 
The cavity thermal resistance for test cavities in all test panels tested with vertical heat flow calculated by the parallel path and isothermal planes methods, $R_{C \mid}(30)$ and $R_{\text {CISO }}(30)$, are 7.74 and $7.31 \mathrm{hr} \mathrm{ft}^{2} \mathrm{~F} / \mathrm{Btu}$ respectively. The two calculation procedures agree to within $0.43 \mathrm{hr} \mathrm{ft}^{2} \mathrm{~F} / \mathrm{Btu}$ or 5.5 percent. When the $R_{C}(30)$ value is greater than approximately $2 \mathrm{hr} \mathrm{ft}^{2} \mathrm{~F} / \mathrm{Btu}$, the $\mathrm{R}(\mid \mathrm{l})$ method predicts a higher thermal resistance than the R(ISO) method.

The average $R_{C||}(30)$ and $R_{C I S O}(30)$ values for 1airspace cavities are 5.68 and $5.60 \mathrm{hr} \mathrm{ft}^{2} \mathrm{~F} / \mathrm{Btu}$ respectively, agreeing to better than 2 percent. For the 4airspace cavities, the average $R_{C||}(30)$ and $R_{c I s o}(30)$ values are 16.76 and $15.23 \mathrm{hr} \mathrm{ft}^{2} \mathrm{~F} / \mathrm{Btu}$ respectively. In this instance, the agreement between the two calculation procedures is approximately 9 percent. The 4-airspace cavities tested with heat flow down exhibit the highest cavity thermal resistance in this test program and the greatest variation based on calculation technique.

A comparison of Panels 12A, 12B, 13A, and 13B yield an indication of the effect of the number of airspaces on the cavity thermal resistance for vertical heat flow down. For heat flow down, the $R_{C}||^{(30)}$ values for the $1-$ and 4airspace cavities are 7.41 (Panels $12 \mathrm{~A}$ and $13 \mathrm{~A}$ ) and 16.76 (Panels $12 \mathrm{~B}$ and $13 \mathrm{~B}$ ) hr $\mathrm{ft}^{2} \mathrm{~F} / \mathrm{Btu}$ respectively. The 4airspace cavity is 2.3 times more thermally resistive than the 1-airspace cavity. A similar analysis with the $R_{\text {cIso }}(30)$ values shows the 4 -airspace cavity is 2.1 times more thermally resistive.

The average $R_{C||}(30)$ and $R_{C I S O}(30)$ values for the heat flow up and down experiments agree to better than 3 and 7 percent respectively. Similar to the 1-airspace heat flow 
up testing, the 1-airspace $R_{C||}(30)$ and $R_{C I S O}(30)$ values for the heat flow down experiments agree to better than 3 percent. All R cIso(30) values were higher for the heat flow up experiments; $R_{C||}(30)$ exceeded all $R_{C I S O}(30)$ values for the heat flow down tests.

The three different 1-airspace heat flow up experiments ( $2 \times 4$ XEPS, $2 \times 6$ XEPS, and $2 \times 6$ wood) yielded an average $R_{\mathrm{Cl}}(30)$ value of $1.9 \mathrm{hr} \mathrm{ft}^{2} \mathrm{~F} / \mathrm{Btu}+/-5$ percent. The same test panels evaluated with heat flow down ranged in $R_{C / 1}$ (30) values from 7.3 to $7.8 \mathrm{hr} \mathrm{ft}^{2} \mathrm{~F} / \mathrm{Btu}$ with the XEPS studs yielding the higher values. The XEPS test panels yielded an average 4.5 .percent higher cavity thermal resistance when compared to the wood stud test panel.

The average $R_{c / \text { l }}(30)$ values for the cavities tested with vertical heat flow are approximately $0.4 \mathrm{hr} \mathrm{ft}^{2} \mathrm{~F} / \mathrm{Btu}$ lower than the $R_{p}(30)$ values for the test panels from which the cavity data is derived. With the exception of Test Panel 12B (4 airspaces with wood studs), the cavity exceeds the panel thermal resistance by approximately $1 \mathrm{hr} \mathrm{ft}^{2} \mathrm{~F} / \mathrm{Btu}$ for all the test panels. The $R_{c \mid}(30)$ value for Test panel $12 \mathrm{~B}$ is lower than the $R_{\mathrm{p}}(30)$ value by $3.3 \mathrm{hr} \mathrm{ft}^{2} \mathrm{~F} / \mathrm{Btu}$.

A comparison of Series 12 and 13 Test Panels shows the effect of the stud material on the $R_{c \mid}(30)$ values for test panels evaluated with vertical heat flow. The average $R_{C||}(30)$ values for these two series of test panels are 8.87 and $8.48 \mathrm{hr} \mathrm{ft}^{2} \mathrm{~F} / \mathrm{Btu}$ respectively. The average $\mathrm{R}_{\mathrm{C}} \mid(30)$ value for test panels with XEPS studs was $0.4 \mathrm{hr} \mathrm{ft}^{2} \mathrm{~F} / \mathrm{Btu}$ or 4.5 percent lower than the equivalent test panels constructed with wood studs. 
The parallel path method proposed for the ASTM reflective insulation material specification requires accurate knowledge of the temperature difference across the cavity and the heat flux through the stud, $Q_{\text {stud }} Q_{\text {stud }}$ is determined by measuring the temperature difference across the stud and dividing that temperature difference by the stud thermal resistance. A method of reducing the potential error due to uncertainty, in either the temperature difference across the stud or its R-Value is to increase the stud thermal resistance so that Qstud is a smaller percentage of the total energy input. Figure 25 details the average ratio of $Q_{\text {stud }}$ to $Q_{\text {total }}$ expressed as a percent for all the the test data and for each heat flow direction. On average, the heat flow through the studs accounted for 7.1 percent of the total energy input. For the horizontal and vertical heat flow experiments, the average $Q_{\text {stud }} / Q_{\text {total }}$ was 5.2 and 9.0 percent respectively. For the vertical heat flow data, the average heat flow through the stud for the heat flow up and heat flow down experiments was 2.7 and 12.8 percent respectively.

The amount of stud heat flow as a function of the number of airspaces in the cavity and the stud material is depicted in Figure 26. For all the test data, the percent of the total heat flow through the wood and XEPS studs were 12.6 and 3.9 percent respectively. The XEPS studs transferred approximately 31 percent of the energy transferred by the wood studs. This result is consistent with the ratio of the R-Values of the wood and XEPS studs; data in Table 20 would predict 27 percent. For 1-, 2-, and 4-airspace cavities, the ratio of XEPS to wood stud heat flow were 34,35 , and 34 percent respectively. 


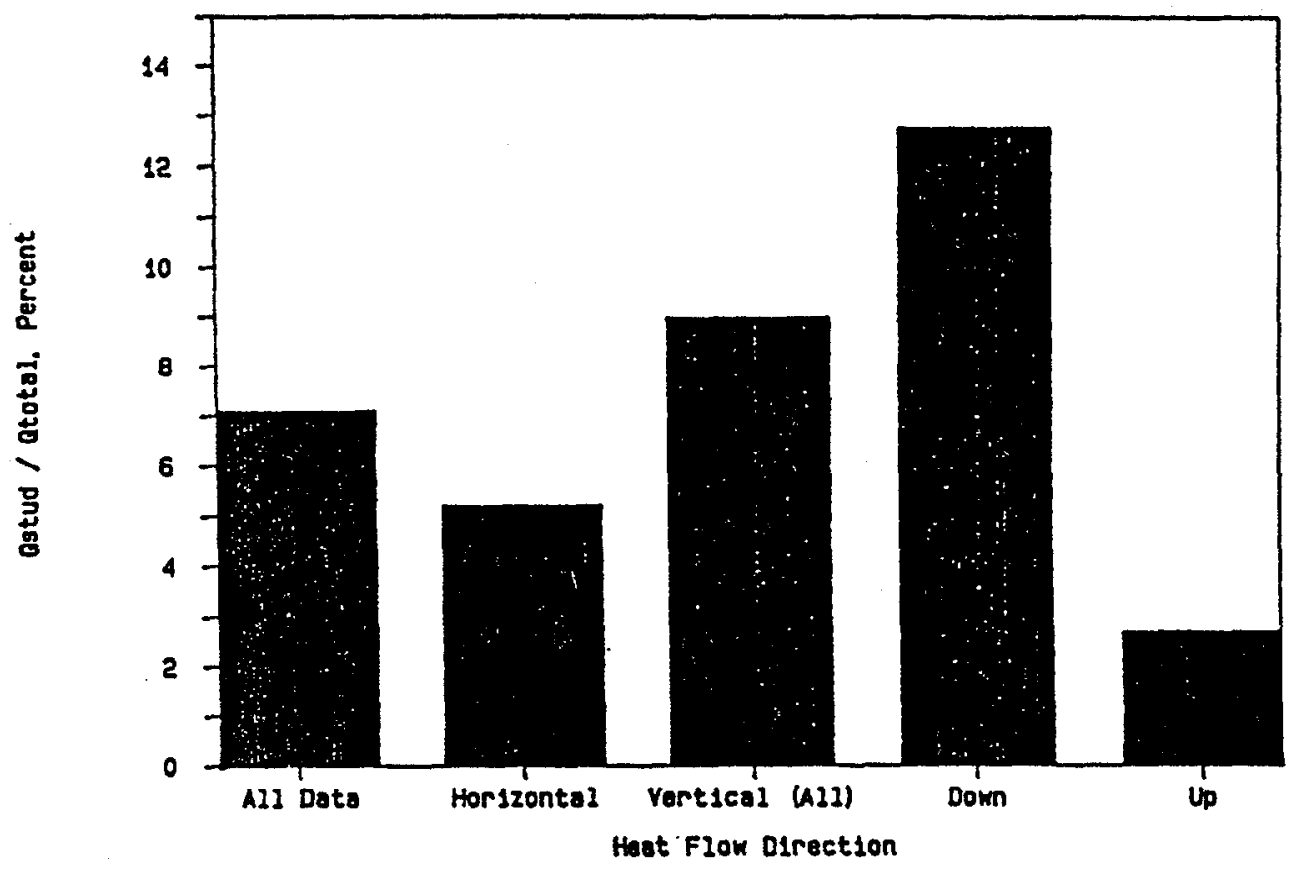

Figure 25: The heat flow through the stud expressed as a percentage of the total heat flow for the test panel thermal resistance experiments as a function of heat flow direction. 


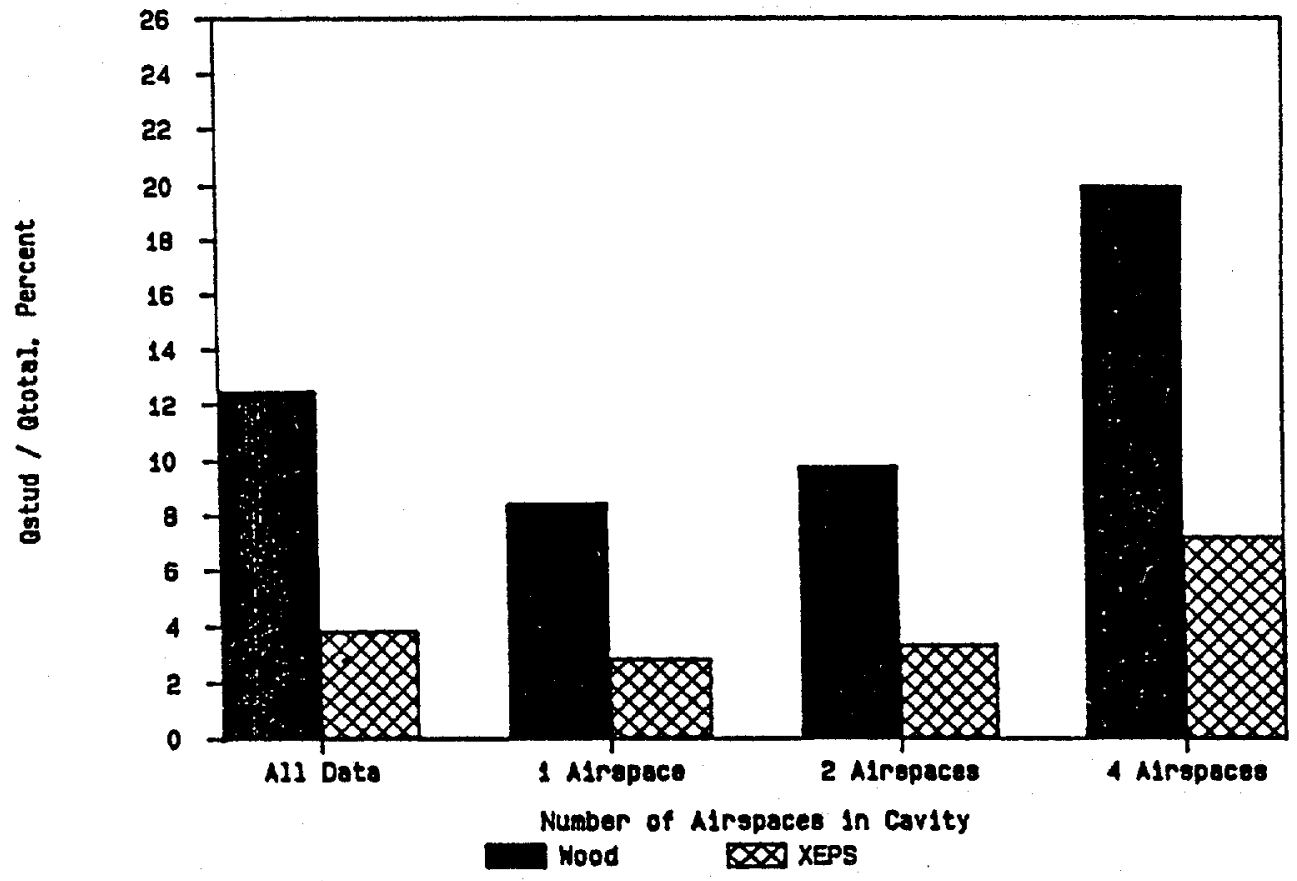

Figure 26: The heat flow through the stud expressed as a percentage of the total heat flow for the test panel thermal resistance experiments as a function of the number of airspaces comprising the cavity and the stud or framing material. 
As the thermal resistance of the cavity increases, the percent of the total heat flow through the stud increases. since the cavity thermal resistance generally increases with an increasing number of airspaces, the percent of stud heat flow should also increase. For wood studs, the stud heat flows for the 1-, 2-, and 4-airspace cavities were 8.5, 9.8, and 20.0 percent respectively. For XEPS studs, the stud heat flow is reduced to $2.9,3.4$, and 7.3 percent for the 1-, 2-, and 4-airspace cavities respectively.

\subsection{EFFECTS OF HEAT FLOW DIRECTION AND NUMBER OF AIRSPACES}

The average cavity thermal resistances calculated by both analytical methods for all experiments, horizontal and vertical experiments separately, and heat flow down and up experiments are shown in Figure 27 and are summarized below. The curve-fit coefficients for the cavity thermal resistance determined by the two calculation methods, solved for a temperature difference of $30 \mathrm{~F}$, were used for these comparisons. 


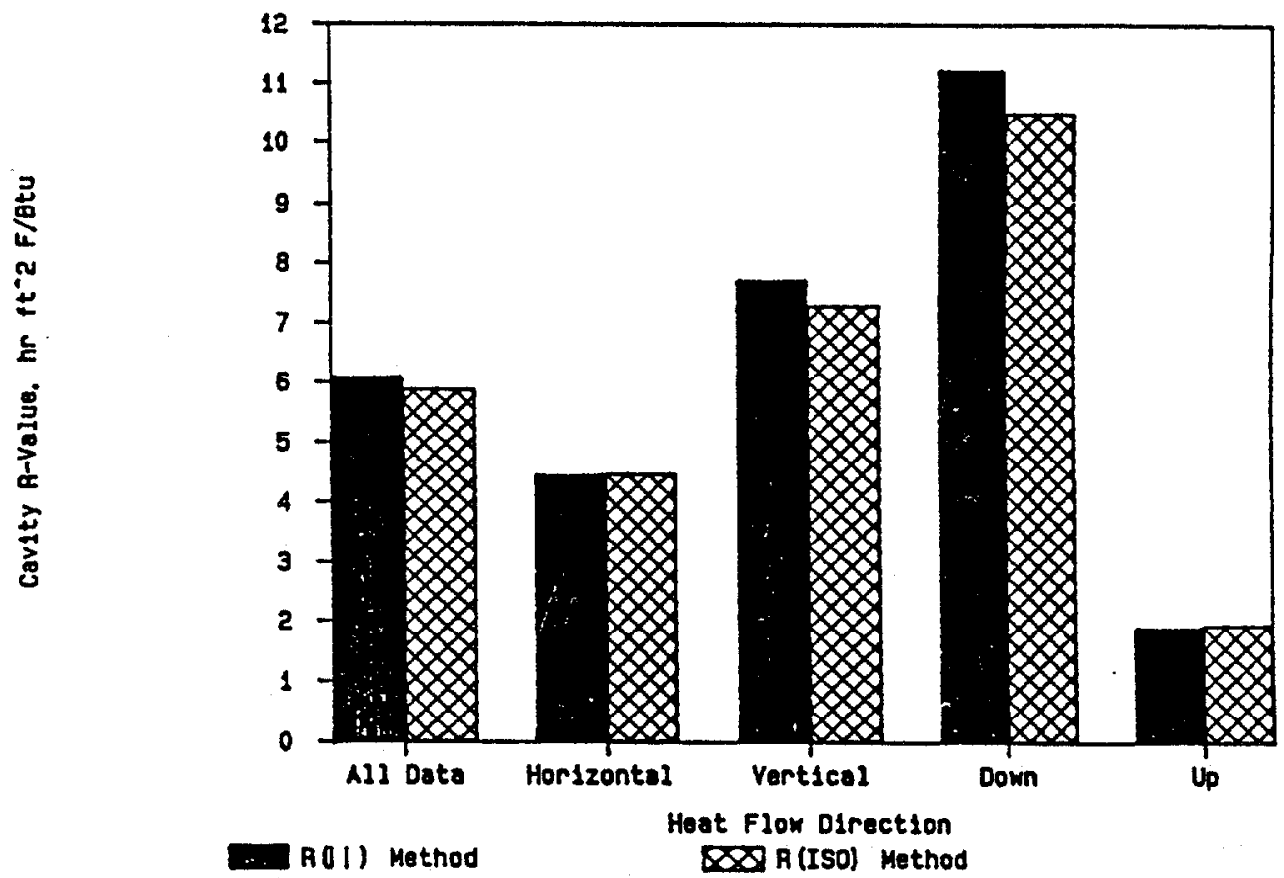

Figure 27: The average cavity thermal resistance as a function of heat flow direction calculated by the parallel path and isothermal planes methods. 


\section{Summary of the Cavity Thermal Resistances for Thirteen \\ Test Panels Determined at a Temperature Difference of $30 \mathrm{~F}$ From Curve-Fit coefficients}

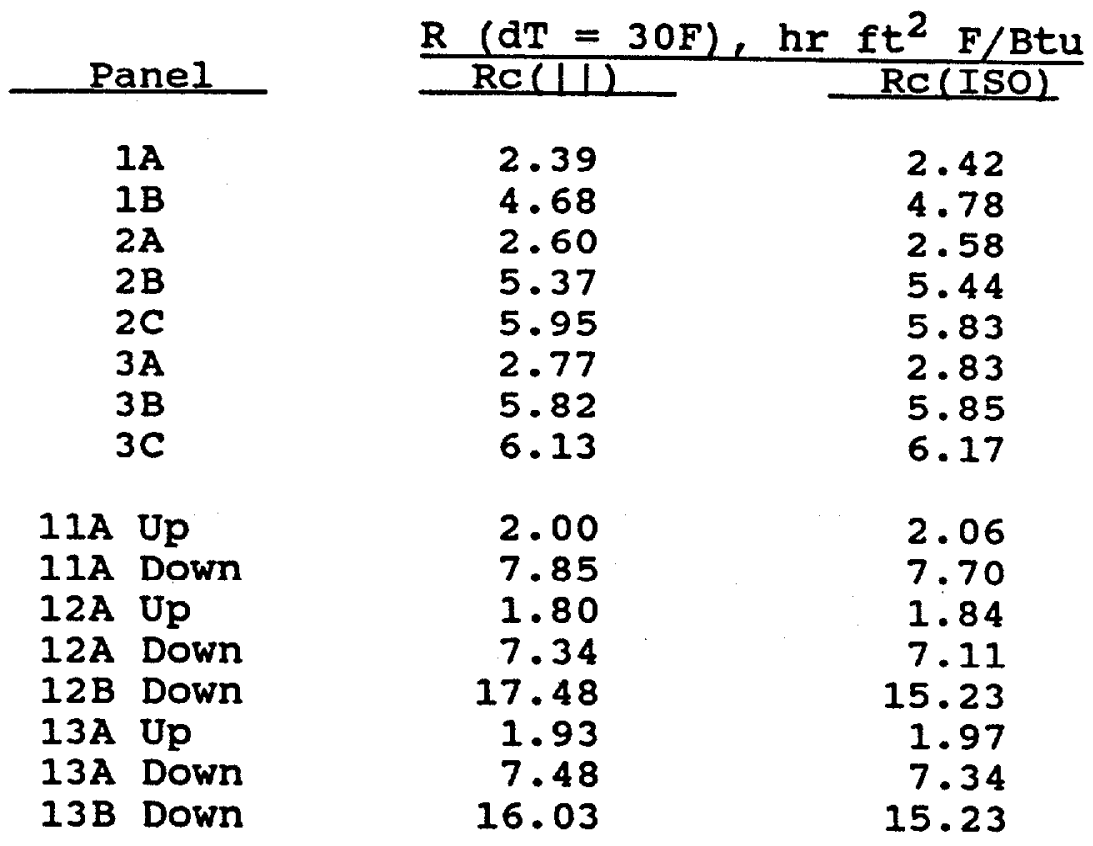

A Comparison of the Cavity Thermal Resistances for Thirteen Test Panels as a Function of Heat Flow Direction

Panel

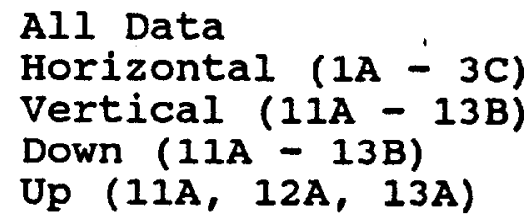

$\begin{array}{rr}\text { RC (U) } & \text { RC(ISO) } \\ 6.1 & \\ 4.5 & 5.9 \\ 7.7 & 4.5 \\ 11.2 & 7.3 \\ 1.9 & 10.5 \\ & 2.0\end{array}$

The average $R$-Values calculated by the parallel path and isothermal planes methods for all experiments were 6.1 and 5.9 hr $\mathrm{ft}^{2} \mathrm{~F} / \mathrm{Btu}$ respectively. The two procedures calculated an average $R$-Value difference of 3.5 percent. The average differences in the calculated R-Values from the two procedures for the horizontal heat flow, vertical heat 
flow, heat flow down, and heat flow up experiments were $0.5,5.8,6.8$, and -2.3 percent respectively. The calculation procedures showed their best agreement with cavities having a thermal resistance of approximately $4 \mathrm{hr}$ $\mathrm{ft}^{2} \mathrm{~F} / \mathrm{Btu}$. At lower cavity R-Values, the isothermal planes method predicted higher cavity R-values; lower cavity RValues were calculated by the isothermal planes model as the cavity R-value increased above $4 \mathrm{hr} \mathrm{ft}^{2} \mathrm{~F} / \mathrm{Btu}$.

Figure 28 depicts the same data as a function of the number of airspaces in the cavity. The average cavity thermal resistance calculated by the parallel path and isothermal planes methods for 1-, 2-, and 4-airspace cavities were $4.02,5.29,11.40$, and $3.98,5.36$, and 10.62 hr $\mathrm{ft}^{2} \mathrm{~F} / \mathrm{Btu}$ respectively. The average $\mathrm{R}-\mathrm{Val}$. Te differences calculated by the two methods were for $1-, 2-$, and 4airspace cavities were $0.9,-1.2$, and 7.4 percent respectively. As stated previously, the two calculations appear to exhibit their best agreement with cavity $R$-Values around $4 \mathrm{hr} \mathrm{ft}^{2} \mathrm{~F} / \mathrm{Btu}$.

A Comparison of the Cavity Thermal Resistances for Thirteen Test Panels as a Function of the Number of Airspaces Comprising the Cavity

Panel

All Data

1 Airspace (1A, 2A, 3A, 11A, 12A, 13A)

2 Airspaces (1B, 2B, 3B)

4 Airspaces (2C, 3C, 12B, 13B)
$R C(1)$

$$
6.1
$$

4.0

5.3

11.4
$\operatorname{RC}(\mathrm{ISO})$

5.9

4.0

5.4

10.6 


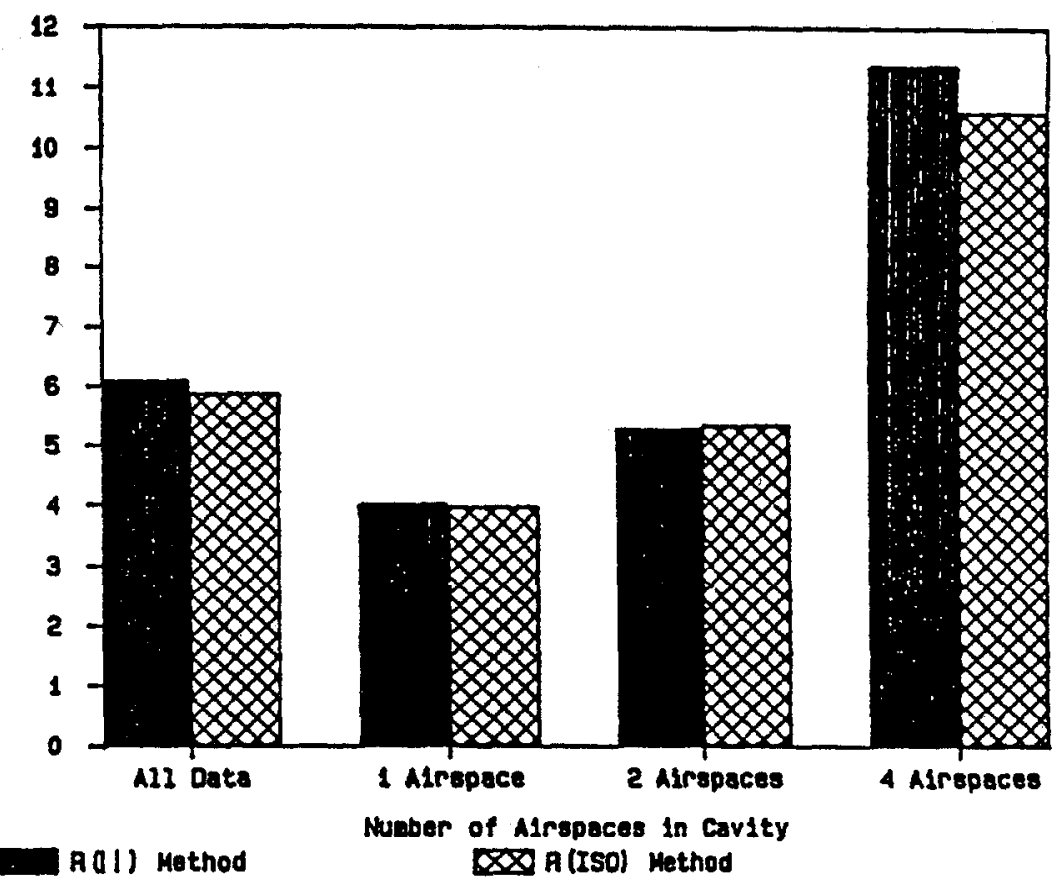

Figure 28: The average cavity thermal resistance as a function of the number of airspaces comprising the cavity calculated by the parallel path and isothermal planes methods. 
A prediction of the cavity thermal resistance was performed utilizing the curve-fitting coefficients developed by Yarbrough[1] when he applied the Method of Least squares to the data generated by Robinson and Powlitch[2]. The use of these coefficients allowed for the prediction of the cavity thermal resistance for the exact temperature conditions of the experiment. When there was more than a single airspace forming the cavity, the thermal resistance of each individual airspace was determined and summed.

The predicted cavity thermal resistance (R) and the percent difference between the prediction and the measured cavity thermal resistance for each calculation procedure is shown in Table 28. Included in Table 28 are the emittances of the hot and cold surfaces of the cavity (el and $e 2$ respectively), the effective emittance of the cavity (E), the coefficient of heat transfer by radiation $\left(H_{r}\right)$, and the combined conduction-convection coefficient of heat transfer $\left(\mathrm{H}_{\mathrm{C}}\right)$. The predicted cavity thermal resistances gathered at the predominant airspace mean temperature were fitted as a function of cavity temperature difference. These curve-fit coefficients are presented in Table 29.

The effective emittance of the cavity (E), the coefficient of heat transfer by radiation $\left(H_{r}\right)$, and the predicted cavity thermal resistance (R) were calculated from

$$
\begin{aligned}
E & =[1 / e 1+1 / e 2-1]^{-1} \\
H_{r} & =0.00686 *\left[T_{\text {mean }} / 100\right]^{3} \\
R & =\left[E * H_{r}+H_{C}\right]^{-1}
\end{aligned}
$$


TABLE 28

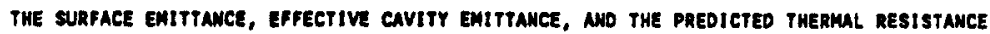

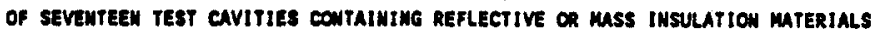

\begin{tabular}{|c|c|c|c|c|c|c|c|c|c|c|c|c|c|c|}
\hline \multirow{3}{*}{$\begin{array}{l}\text { Jest } \\
\text { Panel }\end{array}$} & \multirow{3}{*}{$\begin{array}{c}\text { Stud } \\
\text { Materiel }\end{array}$} & \multirow{3}{*}{$\begin{array}{l}\text { Wo. of } \\
\text { Airepacese }\end{array}$} & \multirow{3}{*}{$\begin{array}{c}\text { Airspace } \\
\text { E }\end{array}$} & \multirow{3}{*}{ Teat } & \multicolumn{3}{|c|}{ Ealitence } & \multirow{2}{*}{\multicolumn{3}{|c|}{$\begin{array}{l}\text { Predicted Covity } \\
\text { Therwal Performence }\end{array}$}} & \multirow{2}{*}{\multicolumn{2}{|c|}{$\begin{array}{c}\text { Moesured } \\
\text { Cevity R-Value, } \\
\text { hr ft^2 F/Beu }\end{array}$}} & \multirow{2}{*}{\multicolumn{2}{|c|}{$\begin{array}{l}\text { Y Diffarance, } \\
\text { pred. ve. Mese. }\end{array}$}} \\
\hline & & & & & \multicolumn{2}{|c|}{ surfece } & \multirow{2}{*}{ Covity } & & & & & & & \\
\hline & & & & & et (Hs) & 2 (cs) & & $\mathrm{Nr}$ & He & R & $a(1)$ & R $(150)$ & $R(\|)$ & R (150) \\
\hline \multirow[t]{5}{*}{ in } & XEPS & 1 & 0.05 & $n-1$ & 0.05 & 0.77 & 0.051 & 0.910 & 0.394 & 2.27 & 2.17 & 2.21 & 4.4 & 2.8 \\
\hline & & & & H-2 & 0.05 & 0.77 & 0.051 & 0.910 & 0.377 & 2.36 & 2.27 & 2.30 & 3.8 & 2.6 \\
\hline & & & & $n \cdot 3$ & 0.05 & 0.77 & 0.031 & 0.909 & 0.351 & 2.52 & 2.37 & 2.40 & 3.7 & 4.8 \\
\hline & & & & $H-6$ & 0.05 & 0.77 & 0.051 & 0.914 & 0.313 & 2.78 & 2.63 & 2.67 & 5.4 & 3.7 \\
\hline & & & & K-5 & 0.05 & $0 . \pi$ & 0.051 & 0.909 & 0.267 & 3.41 & 3.06 & 3.07 & 10.8 & 10.0 \\
\hline \multirow[t]{15}{*}{$1 B$} & XEPS & 2 & 0.05 & $n-6$ & & & & & & 4.25 & 3.26 & 3.33 & 23.3 & 21.8 \\
\hline & & & & $H \cdot 6 \cdot c 1$ & 0.77 & 0.05 & 0.051 & 1.166 & 0.426 & 2.06 & 1.62 & 1.65 & 21.5 & 19.9 \\
\hline & & & & $H-6-C 2$ & 0.05 & 0.77 & 0.051 & 0.898 & 0.409 & 2.20 & 1.65 & 1.68 & 25.0 & 23.5 \\
\hline & & & & $n-7$ & & & & & & 4.38 & 3.42 & 3.51 & 21.9 & 20.0 \\
\hline & & & & $H-7 \cdot c 1$ & $0 . \pi$ & 0.05 & 0.051 & 1.151 & 0.410 & 2.13 & 1.69 & 1.73 & 20.6 & 18.6 \\
\hline & & & & $M-7 \cdot c 2$ & 0.05 & 0.7 & 0.051 & 0.916 & 0.397 & 2.25 & 1.73 & $1 . \pi$ & 23.2 & 21.3 \\
\hline & & & & $\mathrm{H}-\mathbf{8}$ & & & & & & 4.82 & $3.7 !$ & 3.79 & 23.2 & 21.2 \\
\hline & & & & $H-8-c 1$ & 0.77 & 0.05 & 0.051 & 1.078 & 0.368 & 2.36 & 1.83 & 1.87 & 22.5 & 20.6 \\
\hline & & & & $M-8-c 2$ & 0.05 & 0.7 & 0.051 & 0.909 & 0.361 & 2.46 & 1.87 & 1.92 & 23.8 & 21.9 \\
\hline & & & & $H-9$ & & & & & & 5.53 & 6.24 & 4.36 & 23.4 & 21.2 \\
\hline & & & & $H \cdot \bullet-C 1$ & $0 . \pi$ & 0.05 & 0.051 & 1.020 & 0.314 & 2.73 & 2.00 & 2.15 & 23.7 & 21.5 \\
\hline & & & & $1+9 \cdot-c 2$ & 0.05 & 0.77 & 0.051 & 0.908 & 0.311 & 2.80 & 2.15 & 2.21 & 23.1 & 20.9 \\
\hline & & & & $n-10$ & & & & & & 6.92 & 5.16 & 5.23 & 25.8 & 26.4 \\
\hline & & & & $H-10-C 1$ & $0 . \pi$ & 0.05 & 0.051 & 0.963 & 0.241 & 3.45 & 2.53 & 2.58 & 26.5 & 25.2 \\
\hline & & & & $H-10-C 2$ & 0.05 & 0.77 & 0.051 & 0.908 & 0.261 & 3.48 & 2.61 & 2.65 & 25.0 & 23.7 \\
\hline \multirow[t]{6}{*}{$2 A$} & 10000 & 1 & 0.03 & H.11 & 0.05 & 0.05 & 0.027 & 1.046 & 0.405 & 2.31 & 2.37 & 2.34 & -2.6 & .1 .4 \\
\hline & & & & $H-12$ & 0.05 & 0.05 & 0.027 & 1.043 & 0.386 & 2.42 & 2.48 & 2.45 & -2.7 & -1.3 \\
\hline & & & & $H-13$ & 0.05 & 0.05 & 0.027 & 1.040 & 0.364 & 2.55 & 2.57 & 2.55 & -0.7 & -0.9 \\
\hline & & & & $n-14$ & 0.05 & 0.05 & 0.027 & 1.044 & 0.318 & 2.89 & 2.81 & 2.78 & 3.0 & 3.9 \\
\hline & & & & $w \cdot 15$ & 0.05 & 0.05 & 0.027 & 1.046 & 0.255 & 3.53 & 3.23 & 3.16 & 8.5 & 10.7 \\
\hline & & & & H-16 & 0.05 & 0.05 & 0.027 & 0.910 & 0.395 & 2.39 & 2.36 & 2.36 & 1.9 & 1.9 \\
\hline \multirow[t]{12}{*}{$2 B$} & 1000 & 2 & 0.03 & $H-17$ & & & & & & 4.50 & 3.52 & 3.55 & 21.8 & 21.0 \\
\hline & & & & $n=17-c 1$ & 0.05 & 0.05 & 0.027 & 1.169 & 0.430 & 2.17 & 1.80 & 1.82 & 16.9 & 16.0 \\
\hline & & & & $H \cdot 17 \cdot c 2$ & 0.05 & 0.05 & 0.027 & 0.901 & 0.406 & 2.33 & 1.71 & 1.73 & 26.6 & 25.7 \\
\hline & & & & $4 \cdot 18$ & & & & & & $4 . \pi$ & 3.60 & 3.64 & 24.6 & 23.7 \\
\hline & & & & $N+18-c 1$ & 0.05 & 0.05 & 0.027 & 1.046 & 0.405 & 2.31 & 1.85 & 1.87 & 20.0 & 19.0 \\
\hline & & & & $H-18 \cdot c 2$ & 0.05 & 0.05 & 0.027 & 0.830 & 0.384 & 2.46 & 1.75 & 1.77 & 28.9 & 28.9 \\
\hline & & & & $H=99$ & & & & & & 5.17 & 4.02 & 4.07 & 22.2 & 21.1 \\
\hline & & & & $\mathrm{H}-19-\mathrm{C1}$ & 0.05 & 0.05 & 0.027 & 1.047 & 0.370 & 2.52 & 2.05 & 2.08 & 18.5 & 17.4 \\
\hline & & & & $H \cdot 19 \cdot c 2$ & 0.05 & 0.05 & 0.027 & 0.882 & 0.354 & 2.65 & 1.97 & 2.00 & 25.7 & 24.7 \\
\hline & & & & $\mathbf{H} \cdot \mathbf{2 0}$ & & & & & & 5.89 & 4.69 & 4.75 & 20.4 & 19.3 \\
\hline & & & & $H-20-61$ & 0.05 & 0.05 & 0.027 & 1.055 & 0.317 & 2.90 & 2.36 & 2.39 & 18.5 & 17.4 \\
\hline & & & & $H-20-c 2$ & 0.05 & 0.05 & 0.027 & 0.962 & 0.309 & 2.99 & 2.33 & 2.36 & 22.3 & 21.2 \\
\hline
\end{tabular}

Mote: X Difference $a$ I(Predicted - Meseured)/Predicted * 100. 
TARLE 28 (cont)

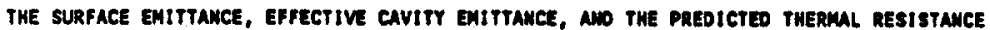

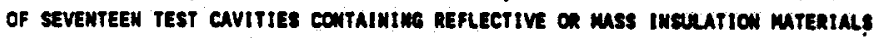

\begin{tabular}{|c|c|c|c|c|c|c|c|c|c|c|c|c|c|c|}
\hline \multirow{3}{*}{$\begin{array}{l}\text { Test } \\
\text { Panel }\end{array}$} & \multirow{3}{*}{$\begin{array}{c}\text { Stud } \\
\text { Material }\end{array}$} & \multirow{3}{*}{$\begin{array}{l}\text { Wo. of } \\
\text { Airspaces }\end{array}$} & \multirow{3}{*}{$\begin{array}{c}\text { A|rspece } \\
\text { E }\end{array}$} & \multirow{3}{*}{$\begin{array}{l}\text { Tese } \\
\text { Nunber }\end{array}$} & \multicolumn{3}{|c|}{ Eat teance } & \multirow{2}{*}{\multicolumn{3}{|c|}{$\begin{array}{l}\text { Prediceced Covity } \\
\text { Thorwal Parformanee }\end{array}$}} & \multirow{2}{*}{\multicolumn{2}{|c|}{$\begin{array}{l}\text { Measured } \\
\text { Cevity n-valus, } \\
\text { hr ftaz F/seu }\end{array}$}} & \multirow{2}{*}{\multicolumn{2}{|c|}{$\begin{array}{l}\text { X Difference, } \\
\text { pred. ve. weas. }\end{array}$}} \\
\hline & & & & & \multicolumn{2}{|c|}{ surfece } & \multirow{2}{*}{ Crvity } & & & & & & & \\
\hline & & & & & 1 (HS) & -2 (cs) & & $\mathrm{Mr}$ & Me & $\mathbf{n}$ & $A(\|)$ & $a(1 \infty 0)$ & $k(\|)$ & $R(t s o)$ \\
\hline 28 & 4000 & 2 & 0.03 & $M \cdot 21$ & & & & & & 7.36 & 5.92 & $5.9 \%$ & 19.5 & 18.5 \\
\hline & & & & $H-21-c 1$ & 0.05 & 0.05 & 0.027 & 1.051 & 0.245 & 3.66 & 2.95 & 2.98 & 19.6 & 18.5 \\
\hline & & & & H-21-C2 & 0.05 & 0.05 & 0.027 & 0.995 & 0.264 & 3.70 & 2.96 & 3.01 & 19.5 & 18.6 \\
\hline & & & & $N \cdot 22$ & & & & & & 8.83 & 7.15 & 7.27 & 19.0 & 17.7 \\
\hline & & & & $H \cdot 22 \cdot C 1$ & 0.05 & 0.05 & 0.027 & 1.055 & 0.198 & 4.42 & 3.30 & 3.56 & 20.7 & 19.4 \\
\hline & & & & $\mathrm{H} \cdot 22 \cdot \mathrm{C2}$ & 0.05 & 0.05 & 0.027 & 1.026 & 0.199 & 6.41 & 3.65 & 3.71 & 17.4 & 16.0 \\
\hline $2 C$ & 1000 & 4 & 0.03 & $H \cdot 23$ & & & & & & 14.60 & 5.27 & 5.12 & 63.9 & sh. 9 \\
\hline & & & & $H \cdot 23 \cdot c 1$ & 0.77 & 0.03 & 0.026 & 1.149 & 0.261 & 3.44 & 1.53 & 1.49 & 55.3 & 56.6 \\
\hline & & & & H-23-c2 & 0.05 & 0.03 & 0.028 & 1.067 & 0.267 & 3.61 & 1.31 & 1.28 & 63.6 & 64.7 \\
\hline & & & & H-25-t3 & 0.03 & 0.85 & 0.028 & 1.001 & 0.233 & 3.83 & 1.07 & 1.04 & 72.1 & 72.8 \\
\hline & & & & $11-23-c k$ & 0.03 & 0.7 & 0.026 & 0.938 & 0.264 & 3.73 & 1.35 & 1.32 & 63.7 & 64.7 \\
\hline & & & & $n-26$ & & & & & & 13.30 & 5.57 & 5.42 & 63.6 & 64.6 \\
\hline & & & & $n-26-c 1$ & 0.77 & 0.03 & 0.026 & 1.136 & 0.243 & 3.66 & 1.57 & 1.53 & 57.1 & 58.3 \\
\hline & & & & $n \cdot 26 \cdot c 2$ & 0.85 & 0.03 & 0.028 & 1.069 & 0.236 & 3.75 & 1.66 & 1.62 & 61.2 & 62.2 \\
\hline & & & & $11 \cdot 26 \cdot c 3$ & 0.03 & 0.85 & 0.028 & 1.016 & 0.222 & 3.90 & 1.13 & 1.10 & 71.6 & $\pi .6$ \\
\hline & & & & $N-24 \cdot C 4$ & 0.05 & $0 . \pi$ & 0.026 & 0.965 & 0.231 & 3.90 & 1.61 & 1.38 & 63.8 & 64.8 \\
\hline & & & & H-25 & & & & & & 16.07 & 6.04 & 5.96 & 62.4 & 62.9 \\
\hline & & & & $H \cdot 25 \cdot C 9$ & 0.7 & 0.03 & 0.026 & 1.115 & 0.229 & 3.87 & 1.72 & 1.60 & 55.6 & 56.3 \\
\hline & & & & $y \cdot 25 \cdot 62$ & 0.85 & 0.03 & 0.026 & 1.066 & 0.223 & 3.95 & 1.58 & 1.55 & 60.1 & 60.7 \\
\hline & & & & $n-25-c 3$ & 0.03 & 0.85 & 0.028 & 1.025 & 0.212 & 4.15 & 1.23 & 1.22 & 70.3 & 70.7 \\
\hline & & & $\cdot$ & $H \cdot 25 \cdot C_{6}$ & 0.03 & 0.7 & 0.026 & 0.986 & 0.218 & 4.09 & 1.52 & 1.69 & 62.9 & 63.4 \\
\hline & & & & $n \cdot 26$ & & & & & & 16.90 & 6.31 & 6.19 & 62.6 & 63.4 \\
\hline & & & & H:26-C1 & 0.77 & 0.03 & 0.026 & 1.097 & 0.244 & 4.12 & 1.77 & 1.76 & 57.0 & 57.8 \\
\hline & & & & $H \cdot 26-c 2$ & 0.85 & 0.03 & 0.028 & 1.063 & 0.211 & 4.15 & 1.71 & 1.68 & 58.7 & 59.5 \\
\hline & & & & $H \cdot 26 \cdot 03$ & 0.03 & 0.85 & 0.028 & 1.033 & 0.202 & 4.33 & 1.29 & 1.27 & 70.1 & 70.7 \\
\hline & & & & $\mathrm{H}-26 \cdot \mathrm{Ch}$ & 0.03 & 0.7 & 0.026 & 1.006 & 0.206 & 4.30 & 1.53 & 1.50 & 66.6 & 65.1 \\
\hline & & & & $H \cdot 27$ & & & & & & 18.21 & 7.18 & 7.13 & 60.6 & 60.8 \\
\hline & & & & $H-27-61$ & 0.77 & 0.03 & 0.026 & 1.063 & 0.196 & 4.51 & 2.00 & 1.98 & 55.7 & 56.0 \\
\hline & & & & $\mathrm{H}-27 \cdot \mathrm{C2}$ & 0.85 & 0.03 & 0.028 & 1.047 & 0.193 & 4.49 & 2.00 & 1.98 & 55.5 & 55.8 \\
\hline & & & & $H-27-03$ & 0.03 & 0.85 & 0.028 & 1.033 & 0.180 & 4.60 & 1.48 & 1.47 & 67.8 & 68.0 \\
\hline & & & & $n \cdot 27 \cdot c 4$ & 0.03 & 0.77 & 0.026 & 1.021 & 0.190 & 4.61 & 1.70 & 1.69 & 63.1 & 63.3 \\
\hline & & & & H.28 & & & & & & 15.06 & 5.56 & 5.60 & 63.2 & 62.8 \\
\hline & & & & $H \cdot 28-61$ & 0.77 & 0.03 & 0.026 & 1.014 & 0.261 & 3.67 & 1.76 & 1.75 & 50.0 & 49.5 \\
\hline & & & & $H-28-c 2$ & 0.85 & 0.03 & 0.028 & 0.939 & 0.234 & 3.86 & 1.20 & 1.21 & 68.8 & 68.5 \\
\hline & & & & $H \cdot 28 \cdot c 3$ & 0.03 & 0.85 & 0.028 & 0.003 & 0.227 & 3.97 & 1.09 & 1.10 & 72.6 & 72.3 \\
\hline & & & & $H \cdot 28 \cdot C 4$ & 0.03 & 0.77 & 0.026 & 0.822 & 0.243 & 3.7 & 1.52 & 1.53 & 59.9 & 59.4 \\
\hline $3 A$ & XEPS & 1 & 0.03 & H-29 & 0.05 & 0.05 & 0.027 & 1.053 & 0.401 & 2.33 & 2.47 & 2.53 & -6.2 & -8.6 \\
\hline & & & & H-30 & 0.05 & 0.05 & 0.027 & 1.060 & 0.387 & 2.41 & 2.60 & 2.65 & $\cdot 7.7$ & .9 .9 \\
\hline & & & & $M=31$ & 0.05 & 0.05 & 0.027 & 1.054 & 0.356 & 2.60 & 2.80 & 2.80 & $\cdot 7.7$ & -10.5 \\
\hline & & & & w-32 & 0.05 & 0.05 & 0.027 & 1.050 & 0.314 & 2.92 & 3.05 & 3.09 & -4.5 & .5 .8 \\
\hline & & & & $M-33$ & 0.05 & 0.05 & 0.027 & 1.069 & 0.260 & 3.47 & 3.40 & 3.47 & 1.8 & -0.1 \\
\hline & & & & $M \cdot 36$ & 0.05 & 0.05 & 0.027 & 0.910 & 0.393 & 2.40 & 2.51 & 2.56 & -4.5 & -5.8 \\
\hline
\end{tabular}


TABLE 28 (Cont)

THE sURface emittance, effective cavity entTtance, and the predicted thermal resistance

OF SEVEMTEEM TEST CAVITIES CONTAINING REFLECTIVE OR MASS INSULATION MATERIALS

\begin{tabular}{|c|c|c|c|c|c|c|c|c|c|c|c|c|c|c|}
\hline \multirow{3}{*}{$\begin{array}{l}\text { Text } \\
\text { Panel }\end{array}$} & \multirow{3}{*}{$\begin{array}{c}\text { Stud } \\
\text { Material }\end{array}$} & \multirow{3}{*}{$\begin{array}{l}\text { No. of } \\
\text { Airspoces }\end{array}$} & \multirow{3}{*}{$\begin{array}{l}\text { Airspece } \\
\text { E }\end{array}$} & \multirow{3}{*}{$\begin{array}{l}\text { rest } \\
\text { Number }\end{array}$} & \multicolumn{3}{|c|}{ Emittence } & \multicolumn{7}{|c|}{ Measured } \\
\hline & & & & & \multicolumn{2}{|c|}{ Surface } & \multirow{2}{*}{$\frac{\text { Covity }}{E}$} & \multicolumn{3}{|c|}{$\begin{array}{l}\text { Predicted Cavity } \\
\text { Thermat Performence }\end{array}$} & \multicolumn{2}{|c|}{$\begin{array}{l}\text { Covity R-Value, } \\
\text { hr ft^2 f/Btu }\end{array}$} & \multicolumn{2}{|c|}{$\begin{array}{l}\text { Xolfference, } \\
\text { Pred. va. Meas. }\end{array}$} \\
\hline & & & & & e1 (HS) & e2 (cs) & & $\mathrm{Hr}$ & He & R & $R(\|)$ & $R(t s o)$ & $R(I I)$ & $R(t s O)$ \\
\hline \multirow[t]{18}{*}{$3 B$} & XEPS & 2 & 0.03 & H-35 & & & & & & 4.64 & 3.96 & 3.98 & 10.9 & 10.4 \\
\hline & & & & $\mathrm{H} \cdot 35 \cdot \mathrm{Cl}$ & 0.05 & 0.05 & 0.027 & 1.183 & 0.435 & 2.14 & 2.02 & 2.03 & 5.7 & 5.2 \\
\hline & & & & $\mathrm{H}-35-\mathrm{C} 2$ & 0.05 & 0.05 & 0.027 & 0.901 & 0.411 & 2.30 & 1.94 & 1.95 & 15.7 & 15.3 \\
\hline & & & & $H-36$ & & & & & & 4.75 & 4.04 & 4.07 & 15.1 & 14.6 \\
\hline & & & & $H \cdot 36 \cdot C 1$ & 0.05 & 0.05 & 0.027 & 1.050 & 0.406 & 2.31 & 2.05 & 2.07 & 11.0 & 10.3 \\
\hline & & & & $\mathrm{H} \cdot 36-\mathrm{C2}$ & 0.05 & 0.05 & 0.027 & 0.831 & 0.386 & 2.45 & 1.99 & 2.00 & 18.9 & 18.2 \\
\hline & & & & $H \cdot 37$ & & & & & & 5.13 & 4.45 & 4.48 & 13.4 & 12.7 \\
\hline & & & & $\mathrm{H} \cdot 37-\mathrm{Cl}$ & 0.05 & 0.05 & 0.027 & 1.051 & 0.371 & 2.51 & 2.24 & 2.26 & 10.5 & 9.8 \\
\hline & & & & $H-37 \cdot C 2$ & 0.05 & 0.05 & 0.027 & 0.883 & 0.357 & 2.63 & 2.20 & 2.22 & 16.2 & 13.5 \\
\hline & & & & $\mathrm{H}+38$ & & & & & & 5.87 & 5.12 & 5.16 & 12.7 & 12.0 \\
\hline & & & & $\mathrm{H}-38 \cdot \mathrm{Cl}$ & 0.05 & 0.05 & 0.027 & 1.052 & 0.318 & 2.89 & 2.57 & 2.59 & 10.9 & 10.2 \\
\hline & & & & $\mathrm{H}-38-\mathrm{C2}$ & 0.05 & 0.05 & 0.027 & 0.938 & 0.311 & 2.98 & 2.55 & 2.57 & 14.4 & 13.8 \\
\hline & & & & $H=39$ & & & & & & 7.36 & 6.27 & 6.31 & 16.6 & 14.0 \\
\hline & & & & $H-39-61$ & 0.05 & 0.05 & 0.027 & 1.050 & 0.247 & 3.64 & 3.15 & 3.17 & 13.4 & 12.8 \\
\hline & & & & $H-39-62$ & 0.05 & 0.05 & 0.027 & 0.991 & 0.244 & 3.70 & 3.12 & 3.14 & 95.7 & 15.2 \\
\hline & & & & $H \cdot 40$ & & & & & & B. 77 & 7.60 & 7.58 & 13.3 & 13.5 \\
\hline & & & & $n-40-c 1$ & 0.05 & 0.05 & 0.027 & 1.051 & 0.201 & 4.36 & 3.80 & 3.79 & 13.0 & 13.2 \\
\hline & & & & $H-40-c 2$ & 0.05 & 0.05 & 0.027 & 1.021 & 0.200 & 4.40 & 3.80 & 3.79 & 13.7 & 13.9 \\
\hline \multirow[t]{20}{*}{$3 c$} & Xeps & 4 & 0.03 & $H-41$ & & & & & & 14.53 & 5.28 & 5.34 & 63.7 & 63.3 \\
\hline & & & & $n-41 \cdot c 1$ & 0.7 & 0.03 & 0.026 & 1.155 & 0.266 & 3.37 & 1.62 & 1.64 & 51.8 & $51^{\prime} .3$ \\
\hline & & & & $n-41 \cdot c 2$ & 0.85 & 0.03 & 0.028 & 1.076 & 0.260 & 3.70 & 1.15 & 1.16 & 69.0 & 68.7 \\
\hline & & & & $N \cdot 41 \cdot c 3$ & 0.03 & 0.85 & 0.028 & 1.012 & 0.232 & 3.84 & 1.03 & 1.04 & $\pi .1$ & 72.8 \\
\hline & & & & $\mathrm{H} \cdot 49-\mathrm{CH}_{4}$ & 0.03 & 0.77 & 0.026 & 0.043 & 0.251 & 3.63 & 1.48 & 1.50 & 39.3 & 58.8 \\
\hline & & & & $N \cdot 42$ & & & & & & 15.26 & 5.57 & 5.62 & 63.5 & 63.2 \\
\hline & & & & $M-42-C 1$ & 0.77 & 0.03 & 0.026 & 1.139 & 0.248 & 3.59 & 1.69 & 1.71 & 52.8 & 52.6 \\
\hline & & & & $H-42-C 2$ & 0.85 & 0.03 & 0.028 & 1.076 & 0.230 & 3.85 & 1.26 & 1.27 & 67.3 & 67.0 \\
\hline & & & & $H-42 \cdot C 3$ & 0.03 & 0.85 & 0.028 & 1.024 & 0.222 & 3.90 & 1.11 & 9.12 & 72.3 & $\pi 2.0$ \\
\hline & & & & $\mathrm{H}-42-\mathrm{C4}$ & 0.03 & 0.77 & 0.026 & 0.979 & 0.235 & 3.83 & 1.51 & 1.52 & 60.6 & 60.2 \\
\hline & & & & $H \cdot 63$ & & & & & & 16.15 & 6.09 & 6.14 & 62.3 & 62.0 \\
\hline & & & & $H-43-C 1$ & 0.77 & 0.03 & 0.026 & 1.108 & 0.230 & 3.86 & 1.84 & 1.85 & 52.4 & 52.0 \\
\hline & & & & $x-43-c 2$ & 0.85 & 0.03 & 0.028 & 1.061 & 0.217 & 4.05 & 1.42 & 1.43 & 64.9 & 64.6 \\
\hline & & & & $n \cdot 43-c 3$ & 0.03 & 0.85 & 0.028 & 1.024 & 0.211 & 4.17 & 1.23 & 1.26 & 70.5 & 70.2 \\
\hline & & & & $H \cdot 43-C_{4}$ & 0.03 & 0.77 & 0.026 & 0.985 & 0.219 & 4.07 & 1.61 & 1.62 & 60.5 & 60.2 \\
\hline & & & & $H-46$ & & & & & & 16.99 & 6.92 & 6.97 & 59.3 & 59.0 \\
\hline & & & & $\mathrm{H}-44-\mathrm{CI}$ & 0.77 & 0.03 & 0.026 & 1.092 & 0.213 & 4.13 & 2.02 & 2.03 & 51.0 & 50.7 \\
\hline & & & & $H-44-c 2$ & 0.85 & 0.03 & 0.028 & 1.060 & 0.206 & 4.23 & 1.68 & 1.69 & 60.3 & 60.1 \\
\hline & & & & $H-44-c 3$ & 0.03 & 0.85 & 0.028 & 1.033 & 0.202 & 4.34 & 1.44 & 1.45 & 66.8 & 66.6 \\
\hline & & & & $\mathrm{H}-64-\mathrm{Cb}_{6}$ & 0.03 & 0.77 & 0.026 & 1.006 & 0.206 & 4.29 & 1.78 & 1.79 & 58.5 & 58.2 \\
\hline
\end{tabular}


TABLE 20 (Cont)

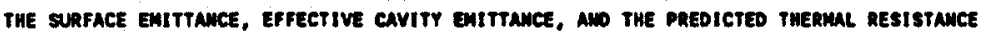

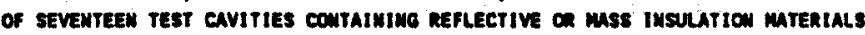

\begin{tabular}{|c|c|c|c|c|c|c|c|c|c|c|c|c|c|c|}
\hline \multirow{3}{*}{$\begin{array}{l}\text { Test } \\
\text { Panet }\end{array}$} & \multirow{3}{*}{$\begin{array}{c}\text { seud } \\
\text { Material }\end{array}$} & \multirow{3}{*}{$\begin{array}{l}\text { No. of } \\
\text { Airspeces }\end{array}$} & \multirow{3}{*}{$\begin{array}{c}\text { Airspece } \\
\text { E }\end{array}$} & \multirow{3}{*}{$\begin{array}{l}\text { Test } \\
\text { Nieber }\end{array}$} & \multicolumn{3}{|c|}{ Enitemee } & \multirow{2}{*}{\multicolumn{3}{|c|}{$\begin{array}{l}\text { Predicted Covity } \\
\text { Thermel Performance }\end{array}$}} & \multirow{2}{*}{\multicolumn{2}{|c|}{$\begin{array}{l}\text { Measured } \\
\text { Cavity R-Value, } \\
\text { hr ft"z Frotu }\end{array}$}} & \multirow{2}{*}{\multicolumn{2}{|c|}{$\begin{array}{l}\text { x offference, } \\
\text { Pred. va. Meas. }\end{array}$}} \\
\hline & & & & & \multicolumn{2}{|c|}{ surfece } & \multirow{2}{*}{$\frac{\text { Cevity }}{\text { e }}$} & & & & & & & \\
\hline & & & & & et (us) & 2 (cs) & & Mr & He & n & $2(11)$ & $R(150)$ & $R(\|)$ & (tso) \\
\hline $3 c$ & XEPS & 4 & 0.03 & $n \cdot 65$ & & & & & & 18.16 & 7.46 & 7.60 & 58.9 & 58.1 \\
\hline & & & & $H-45 \cdot C 1$ & 0.7 & 0.03 & 0.026 & 1.071 & 0.196 & 4.49 & 2.09 & 2.13 & 53.5 & 52.6 \\
\hline & & & & $N-45-c 2$ & 0.85 & 0.03 & 0.028 & 1.055 & 0.193 & 4.50 & 1.96 & 1.98 & 36.9 & 56.0 \\
\hline & & & & $n-45-c 3$ & 0.03 & 0.85 & 0.028 & 1.060 & 0.190 & 4.56 & 1.64 & 1.67 & 64.0 & 63.3 \\
\hline & & & & $n-45-26$ & 0.03 & 0.7 & 0.026 & 1.027 & 0.191 & 4.59 & 1.70 & 1.82 & 61.0 & 60.3 \\
\hline & & & & $H-46$ & & & & & & 15.20 & 5.66 & 5.90 & 62.8 & 61.2 \\
\hline & & & & $n-46-c 1$ & $0 . \pi$ & 0.03 & 0.026 & 1.000 & 0.264 & 3.45 & 1.89 & 1.97 & 45.2 & 42.8 \\
\hline & & & & $n-46-c 2$ & 0.85 & 0.03 & 0.028 & 0.927 & 0.220 & 3.93 & 1.13 & 1.18 & 74.1 & 69.0 \\
\hline & & & & $\mathrm{H} \cdot \mathrm{s6} \cdot \mathrm{c3}$ & 0.03 & 0.85 & 0.028 & 0.878 & 0.220 & 4.09 & 0.99 & 1.03 & 75.9 & 74.8 \\
\hline & & & & $n-46-c_{6}$ & 0.03 & $0 . \pi$ & 0.026 & 0.819 & 0.265 & 3.74 & 1.65 & 1.72 & 55.9 & 54.1 \\
\hline $4 A$ & XEPS & & $m / A$ & $H-67$ & $0 . \pi$ & 0.7 & 0.626 & $\cdots$ & $\cdots$ & 11.00 & 11.18 & 11.19 & -1.7 & -1.7 \\
\hline $4 B$ & 1000 & $N / A$ & $m / A$ & $H-48$ & 0.7 & $0 . \pi$ & 0.626 & $\cdots$ & $\cdots$ & 11.00 & 10.17 & 10.22 & 7.5 & 7.1 \\
\hline $11 A$ & XEPS & 1 & 0.05 & $v \cdot 10$ & 0.05 & $0 . \pi$ & 0.051 & 0.991 & 0.517 & 1.78 & 1.76 & 1.84 & 0.8 & $\cdot 3.8$ \\
\hline & & & & $V-2 J$ & 0.05 & 0.7 & 0.031 & 0.915 & 0.490 & 1.86 & 1.85 & 1.91 & 0.5 & -2.8 \\
\hline & & & & $v-3 v$ & 0.05 & 0.7 & 0.051 & 0.912 & 0.456 & 1.9 & 1.9 & 2.05 & -0.2 & -2.9 \\
\hline & & & & $v \cdot w$ & 0.05 & 0.7 & 0.051 & 0.909 & 0.402 & 2.23 & 2.17 & 2.22 & 2.8 & 0.3 \\
\hline & & & & $v-50$ & 0.05 & 0.7 & 0.051 & 0.911 & 0.336 & 2.62 & 2.40 & 2.46 & 8.5 & 6.9 \\
\hline & & & & $v \cdot 6 u$ & 0.05 & 0.77 & 0.051 & 1.055 & 0.530 & 1.71 & 1.62 & 1.7 & 5.5 & 0.3 \\
\hline & & & & $v-70$ & 0.05 & 0.77 & 0.051 & 0.909 & 0.086 & 7.55 & 7.53 & 7.33 & 0.2 & 2.9 \\
\hline & & & & $v \cdot c 0$ & 0.05 & 0.7 & 0.051 & 0.912 & 0.003 & 7.72 & 7.64 & 7.56 & 1.1 & 2.4 \\
\hline & & & & $v-90$ & 0.05 & 0.7 & 0.051 & 0.910 & 0.077 & 8.09 & 7.92 & 7.71 & 2.1 & 4.7 \\
\hline & & & & $v-100$ & 0.05 & $0 . \pi$ & 0.051 & 0.911 & 0.072 & 8.44 & 8.32 & 8.02 & 1.6 & 5.0 \\
\hline & & & & $v-110$ & 0.05 & 0.7 & 0.051 & 0.911 & 0.064 & 9.05 & 9.67 & 8.73 & .4 .6 & 3.6 \\
\hline & & & & $v-120$ & 0.05 & 0.77 & 0.051 & 1.069 & 0.088 & 7.06 & 6.24 & 6.75 & 2.9 & 4.1 \\
\hline $12 A$ & 1000 & 1 & 0.03 & $v=130$ & 0.05 & $0 . \pi$ & 0.051 & 1.050 & 0.586 & 1.36 & 1.61 & 1.62 & -2.8 & -3.7 \\
\hline & & & & $v \cdot 140$ & 0.05 & $0 . \pi$ & 0.031 & 1.048 & 0.554 & 1.44 & 1.73 & 1.73 & -5.2 & -5.5 \\
\hline & & & & $v-13 v$ & 0.05 & 0.7 & 0.051 & 1.046 & 0.468 & 1.92 & 1.85 & 1.86 & 3.4 & 3.1 \\
\hline & & & & $v \cdot 16 u$ & 0.05 & $0 . \pi$ & $0.05 t$ & 1.048 & 0.418 & 2.12 & 2.03 & 2.07 & 4.4 & 2.5 \\
\hline & & & & $v-17$ & 0.05 & $0 . \pi$ & 0.051 & 1.021 & 0.438 & 2.06 & 2.79 & 2.66 & -36.5 & -30.2 \\
\hline & & & & $v-18 u$ & 0.05 & 0.77 & 0.051 & 0.911 & 0.572 & 1.62 & 1.73 & 9.7 & -7.2 & -9.6 \\
\hline & & & & $v-190$ & 0.05 & 0.7 & 0.051 & 1.052 & 0.167 & 6.53 & 6.95 & 6.67 & .53 .4 & -47.1 \\
\hline & & & & $v-200$ & 0.05 & 0.77 & 0.031 & 1.052 & 0.160 & 6.67 & 7.12 & 6.91 & -52.4 & -47.9 \\
\hline & & & & $v-210$ & 0.05 & 0.77 & 0.051 & 1.048 & 0.142 & 5.12 & 7.41 & 7.16 & -44.7 & +39.5 \\
\hline & & & & $v-220$ & 0.05 & 0.77 & 0.051 & 1.055 & 0.117 & 5.86 & 7.61 & 7.37 & -29.9 & -25.7 \\
\hline & & & & $v \cdot 230$ & 0.05 & 0.7 & 0.051 & 1.050 & 0.087 & 7.10 & 8.24 & 7.70 & -15.5 & $\cdot 9.7$ \\
\hline & & & & $v-240$ & 0.05 & 0.7 & 0.051 & 0.914 & 0.163 & 4.77 & 7.56 & 7.29 & -58.3 & -52.7 \\
\hline
\end{tabular}


TALLE 20 (Cont)

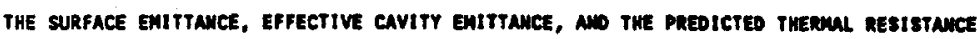

of SEVEMTEEM TEST CAVITIES COUTAIMIMG REFLECTIVE on MAS IMEULATION MATERIALS

\begin{tabular}{|c|c|c|c|c|c|c|c|c|c|c|c|c|c|c|}
\hline \multirow{3}{*}{$\begin{array}{l}\text { Teat } \\
\text { Panel }\end{array}$} & \multirow{3}{*}{$\begin{array}{l}\text { stud } \\
\text { Material }\end{array}$} & \multirow{3}{*}{$\begin{array}{l}\text { Mo. of } \\
\text { Atrspeces }\end{array}$} & \multirow{3}{*}{$\begin{array}{c}\text { Alrapace } \\
\text { E }\end{array}$} & \multirow{3}{*}{ Tese } & \multicolumn{3}{|c|}{ Ealttence } & \multirow{2}{*}{\multicolumn{3}{|c|}{$\begin{array}{l}\text { Predleted Cevity } \\
\text { Thernal Performance }\end{array}$}} & \multirow{2}{*}{\multicolumn{2}{|c|}{$\begin{array}{c}\text { Measured } \\
\text { Cowity te-Value, } \\
\text { hr } 4 t^{\wedge} \text { ? }\end{array}$}} & \multirow{2}{*}{\multicolumn{2}{|c|}{$\begin{array}{l}\text { x olfferenes, } \\
\text { pred. ve. mase. }\end{array}$}} \\
\hline & & & & & \multicolumn{2}{|c|}{ surfece } & \multirow{2}{*}{$\frac{\text { cevity }}{\varepsilon}$} & & & & & & & \\
\hline & & & & & 1 (MS) & $22(c 3)$ & & Hr & Me & $\boldsymbol{n}$ & $n(\|)$ & $n(1+\infty)$ & $R(11)$ & $R(1 \infty 0)$ \\
\hline \multirow[t]{30}{*}{128} & 1000 & 4 & 0.03 & $v-250$ & & & & & & 23.80 & 16.56 & 14.86 & 30.7 & 37.7 \\
\hline & & & & $v-250-c 1$ & 0.77 & 0.03 & 0.026 & 1.156 & 0.143 & 5.75 & 3.63 & 5.06 & 2.1 & 12.0 \\
\hline & & & & $v-250-c 2$ & 0.85 & 0.03 & 0.028 & 1.072 & 0.138 & 3.96 & 3.61 & 3.06 & 42.6 & 46.4 \\
\hline & & & & $v-250 \cdot c s$ & 0.03 & 0.85 & 0.020 & 1.025 & 0.135 & 6.10 & 1.89 & 1.70 & 69.1 & 72.2 \\
\hline & & & & $v-250-c h$ & 0.03 & 0.77 & 0.026 & 0.962 & 0.139 & 6.09 & 5.63 & 5.06 & 7.5 & 16.8 \\
\hline & & & & $v \cdot 260$ & & & & & & 24.02 & 17.32 & 15.39 & 27.9 & 35.9 \\
\hline & & & & $v-260 \cdot c 1$ & $0 . \pi$ & 0.03 & 0.026 & 1.136 & 0.142 & 5.23 & 5.97 & 3.31 & .2 .5 & 8.9 \\
\hline & & & & $v-260-c 2$ & 0.85 & 0.03 & 0.028 & 1.069 & 0.137 & 5.97 & 3.4 & 3.23 & 39.1 & 65.9 \\
\hline & & & & $v-260 \cdot \omega$ & 0.03 & 0.65 & 0.028 & 1.031 & 0.134 & 6.12 & 1.90 & 1.69 & 68.9 & 72.3 \\
\hline & & & & $v-260 \cdot c h$ & 0.03 & $0 . \pi$ & 0.026 & 0.980 & 0.138 & 6.91 & 5.80 & 5.16 & 5.0 & 15.6 \\
\hline & & & & $v \cdot 270$ & & & & & & 24.22 & 17.17 & 15.04 & 29.1 & 37.9 \\
\hline & & & & $v \cdot 270 \cdot c 1$ & $0 . \pi$ & 0.02 & 0.028 & 1.112 & 0.140 & 9.92 & 6.00 & 5.26 & -1.6 & 11.2 \\
\hline & & & & $v \cdot 270-c 2$ & 0.85 & 0.03 & 0.028 & 1.060 & 0.136 & 6.02 & 3.98 & 3.13 & 40.6 & 10.0 \\
\hline & & & & $v-270-e 3$ & 0.03 & 0.85 & 0.028 & 1.030 & 0.134 & 6.14 & 1.98 & 1.69 & 68.6 & 7.5 \\
\hline & & & & $v-270 \cdot c 6$ & 0.03 & $0 . \pi$ & 0.026 & 0.991 & 0.137 & 6.14 & 5.67 & 4.97 & 7.7 & 19.2 \\
\hline & & & & $v-200$ & & & & & & 24.66 & 18.07 & 15.63 & 26.1 & 36.1 \\
\hline & & & & $v+2=0-c 1$ & 0.7 & 0.03 & 0.026 & 1.005 & 0.137 & 6.04 & 6.61 & 3.34 & -6.1 & 8.2 \\
\hline & & & & $v \cdot 200-c 2$ & 0.85 & 0.03 & 0.028 & 1.053 & 0.135 & 6.00 & 3.82 & 3.31 & 37.1 & 45.6 \\
\hline & & & & $v \cdot 200 \cdot c 3$ & 0.03 & 0.85 & 0.028 & 1.035 & 0.133 & 6.15 & 2.10 & 1.82 & 65.8 & 70.4 \\
\hline & & & & $v \cdot 200 \cdot 06$ & 0.03 & $0 . \pi$ & 0.026 & 1.012 & 0.135 & 6.19 & 5.76 & 4.96 & 7.3 & 19.8 \\
\hline & & & & $v-290$ & & & & & & 24.62 & 18.42 & 16.67 & 25.2 & 32.3 \\
\hline & & & & $v \cdot 290 \cdot \mathrm{ct}$ & 0.77 & 0.03 & 0.026 & 1.069 & 0.135 & 6.13 & 6.50 & 5.95 & $\cdot 7.3$ & 2.9 \\
\hline & & & & $v \cdot 290-c 2$ & 0.85 & 0.03 & 0.028 & 1.053 & 0.134 & 6.12 & 3.95 & 3.57 & 35.5 & 41.7 \\
\hline & & & & $v \cdot 290 \cdot c 3$ & 0.03 & 0.85 & 0.028 & 1.043 & 0.133 & 6.16 & 2.26 & 2.06 & 63.4 & 66.9 \\
\hline & & & & $v-290-04$ & 0.03 & 0.77 & 0.026 & 1.031 & 0.134 & 6.21 & 5.44 & 5.10 & 9.2 & 17.9 \\
\hline & & & & $V-300$ & & & & & & 26.96 & 17.04 & 16.79 & 31.7 & 40.7 \\
\hline & & & & $v-300-c 1$ & 0.77 & 0.03 & 0.026 & 1.006 & 0.160 & 5.99 & 5.95 & 5.17 & 0.6 & 13.8 \\
\hline & & & & $v \cdot 300 \cdot c 2$ & 0.85 & 0.03 & 0.028 & 0.929 & 0.135 & 6.21 & 3.45 & 2.99 & 4.4 & 51.8 \\
\hline & & & & $v-300-c 3$ & 0.03 & 0.85 & 0.028 & 0.866 & 0.132 & 6.38 & 1.93 & 1.67 & 69.8 & 73.8 \\
\hline & & & & $v \cdot 300-c 4$ & 0.03 & $0 . \pi$ & 0.026 & 0.826 & 0.135 & 6.36 & 5.71 & 4.96 & 10.1 & 22.0 \\
\hline $12 c$ & 1000 & W/A & $m / a$ & $v-310$ & $0 . \pi$ & $0 . \pi$ & 0.626 & $\cdots$ & $\cdots$ & 16.91 & 17.27 & 15.40 & -2.1 & 8.9 \\
\hline $13 A$ & XEPS & 1 & 0.05 & $y-32 u$ & $0 . \pi$ & 0.05 & 0.051 & 1.048 & 0.588 & 1.56 & 1.72 & 1.76 & -9.9 & -12.7 \\
\hline & & & & $v \cdot 330$ & 0.77 & 0.05 & 0.051 & 1.060 & 0.550 & 1.66 & 1.81 & 1.86 & -9.3 & -12.6 \\
\hline & & & & $v-360$ & 0.7 & 0.05 & 0.051 & 1.050 & 0.67 & 1.88 & 1.96 & $1 . \%$ & .3 .0 & -4.1 \\
\hline & & & & $v-350$ & 0.77 & 0.05 & 0.051 & 1.069 & 0.418 & 2.12 & 2.12 & 2.19 & 0.0 & -3.0 \\
\hline & & & & $v-360$ & $0 . \pi$ & 0.05 & 0.051 & 1.050 & 0.430 & 2.07 & 2.55 & 2.57 & -23.3 & -26.3 \\
\hline & & & & $v \cdot 37$ & 0.77 & 0.05 & 0.051 & 0.959 & 0.57 & 1.60 & 1.69 & 1.76 & -5.9 & -9.1 \\
\hline
\end{tabular}


TABLE 28 (Cont)

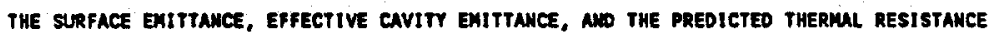
OF SEVEMTEEM tEST CAVITIES CONTAINING REFLECTIVE OR MSS IMSULATION MATERIALS

\begin{tabular}{|c|c|c|c|c|c|c|c|c|c|c|c|c|c|c|}
\hline \multirow{3}{*}{$\begin{array}{l}\text { Test } \\
\text { Panel }\end{array}$} & \multirow{3}{*}{$\begin{array}{c}\text { stud } \\
\text { Materiol }\end{array}$} & \multirow{3}{*}{$\begin{array}{l}\text { Mo. of } \\
\text { Airepaces }\end{array}$} & \multirow{3}{*}{$\begin{array}{l}\text { Airspace } \\
\text { E }\end{array}$} & \multirow{3}{*}{$\begin{array}{l}\text { Test } \\
\text { Number }\end{array}$} & \multicolumn{3}{|c|}{ Ealtence } & \multirow{2}{*}{\multicolumn{3}{|c|}{$\begin{array}{l}\text { Predicted Covlty } \\
\text { Thermal Derformance }\end{array}$}} & \multirow{2}{*}{\multicolumn{2}{|c|}{$\begin{array}{l}\text { Menesured } \\
\text { Covity R-Yalue, } \\
\text { hr te^2 Frotu }\end{array}$}} & \multirow{2}{*}{\multicolumn{2}{|c|}{$\begin{array}{l}\text { x Difference, } \\
\text { Pred. ve. Meas. }\end{array}$}} \\
\hline & & & & & \multicolumn{2}{|c|}{ surfece } & \multirow{2}{*}{$\frac{\text { Covlty }}{E}$} & & & & & & & \\
\hline & & & & & ol (ns) & $2(C s)$ & & Mr & Me & R & R $(\|)$ & $R(150)$ & $R(I 1)$ & $R(150)$ \\
\hline \multirow[t]{6}{*}{$13 \AA$} & XEPS & 1 & 0.05 & $v \cdot 380$ & 0.77 & 0.05 & 0.051 & 1.054 & 0.167 & 4.53 & 7.06 & 6.90 & .55 .9 & .52 .3 \\
\hline & & & & $v \cdot 390$ & 0.77 & 0.05 & 0.051 & 4.055 & 0.162 & 4.63 & 7.20 & 7.15 & -57.4 & -54.3 \\
\hline & & & & $v-400$ & 0.77 & 0.05 & 0.051 & 1.050 & 0.145 & 5.04 & 7.41 & 7.23 & .47 .2 & -43.5 \\
\hline & & & & $v-410$ & 0.77 & 0.05 & 0.051 & 1.061 & 0.116 & 5.87 & 7.90 & 7.75 & -34.6 & .32 .1 \\
\hline & & & & $v-420$ & 0.77 & 0.05 & 0.051 & 1.052 & 0.081 & 7.43 & 8.59 & 8.19 & $\cdot 15.7$ & -10.3 \\
\hline & & & & $v-430$ & 0.77 & 0.05 & 0.051 & 0.968 & 0.166 & 4.67 & 7.62 & 7.52 & .63 .0 & -60.8 \\
\hline \multirow[t]{28}{*}{138} & XEPS & 4 & 0.03 & $v-440$ & & & & & & 23.84 & 14.87 & 14.41 & 37.6 & 39.6 \\
\hline & & & & $v \cdot 640-c 1$ & $0 . \pi$ & 0.03 & 0.026 & 1.160 & 0.143 & 3.74 & 4.96 & 4.80 & 13.6 & 16.3 \\
\hline & & & & $V=640-c 2$ & 0.85 & 0.03 & 0.028 & 1.077 & 0.139 & 5.92 & 3.05 & 2.96 & 48.5 & 50.1 \\
\hline & & & & $v \cdot 440-c 3$ & 0.03 & 0.85 & 0.028 & 1.024 & 0.136 & 6.07 & 2.14 & 2.07 & 64.7 & 65.8 \\
\hline & & & & $v-460 \cdot c 4$ & 0.03 & 0.77 & 0.026 & 0.958 & 0.138 & 6.10 & 4.72 & 4.57 & 22.6 & 25.1 \\
\hline & & & & $v=450$ & & & & & & 26.12 & 15.63 & 15.10 & 35.2 & 37.6 \\
\hline & & & & $v \cdot 450 \cdot c 1$ & $0 . \pi$ & 0.03 & 0.026 & 1.123 & 0.141 & 5.86 & 5.33 & 5.15 & 9.0 & 12.1 \\
\hline & & & & $v \cdot 450 \cdot 02$ & 0.85 & 0.03 & 0.028 & 1.060 & 0.137 & 6.00 & 3.19 & 3.08 & 46.8 & 48.6 \\
\hline & & & & $v-650.03$ & 0.08 & 0.85 & 0.028 & 1.020 & 0.135 & 6.12 & 2.22 & 2.13 & 63.7 & 6.9 \\
\hline & & & & $v \cdot 450 \cdot 0 h$ & 0.05 & 0.7 & 0.026 & 0.970 & 0.137 & 6.15 & 4.80 & 4.72 & 20.5 & 23.2 \\
\hline & & & & $v-660$ & & & & & & 24.22 & 16.30 & 95.63 & 32.7 & 36.3 \\
\hline & & & & $v-460-21$ & 0.7 & 0.03 & 0.026 & 1.113 & 0.130 & 5.93 & 3.62 & 5.32 & 5.2 & 10.3 \\
\hline & & & & $v \cdot 660 \cdot c 2$ & 0.85 & 0.03 & 0.028 & 1.063 & 0.136 & 6.02 & 3.33 & 3.15 & 44.8 & 47.7 \\
\hline & & & . & $V \cdot 460-c 3$ & 0.03 & 0.85 & 0.028 & 1.033 & 0.134 & 6.12 & 2.29 & 2.17 & 62.6 & 64.6 \\
\hline & & & & $v \cdot 660-c 6$ & 0.03 & 0.7 & 0.026 & 0.996 & 0.136 & 6.16 & 5.07 & 4.80 & 17.6 & 22.0 \\
\hline & & & & $v-670$ & & & & & & 26.38 & 16.90 & 15.64 & 30.7 & 35.9 \\
\hline & & & $r$ & $V-470-C 1$ & 0.77 & 0.03 & 0.026 & 1.096 & 0.137 & 6.02 & 5.92 & 5.48 & 1.6 & 9.0 \\
\hline & & & $\mathbf{v}$ & $v \cdot 670 \cdot c 2$ & 0.85 & 0.03 & 0.020 & 1.063 & 0.135 & 6.06 & 3.43 & 3.17 & 43.4 & 47.7 \\
\hline & & & & $v \cdot 470 \cdot c 3$ & 0.03 & 0.85 & 0.020 & 1.043 & 0.134 & 6.13 & 2.32 & 2.14 & 62.2 & 65.0 \\
\hline & & & & $v \cdot 670 \cdot c 6$ & 0.03 & 0.7 & 0.026 & 1.018 & 0.135 & 6.97 & 5.23 & 4.84 & 15.2 & 21.6 \\
\hline & & & & $v-400$ & & & & & & 26.63 & 20.31 & 18.33 & 17.5 & 25.6 \\
\hline & & & & $V \cdot 480 \cdot c 1$ & 0.77 & 0.03 & 0.026 & 1.067 & 0.135 & 6.13 & 7.15 & 6.45 & -16.6 & -5.3 \\
\hline & & & & $V-480-c 2$ & 0.85 & 0.03 & 0.028 & 1.050 & 0.136 & 6.13 & 3.95 & 3.56 & 35.5 & 41.8 \\
\hline & & & & $v-480-c 3$ & 0.03 & 0.85 & 0.028 & 1.039 & 0.133 & 6.16 & 2.82 & 2.55 & 54.2 & 58.7 \\
\hline & & & & $v-480-c h$ & 0.03 & 0.77 & 0.026 & 1.025 & 0.136 & 6.21 & 6.39 & 5.7 & -2.9 & 7.1 \\
\hline & & & & $y-400$ & & & & & & 25.01 & 16.65 & 16.09 & 33.4 & 35.7 \\
\hline & & & & $v-490-c t$ & 0.77 & 0.03 & 0.026 & 0.998 & 0.140 & 6.02 & 5.69 & 5.50 & 5.6 & 8.7 \\
\hline & & & & $v-490 \cdot c 2$ & 0.85 & 0.03 & 0.028 & 0.925 & 0.135 & 6.22 & 3.32 & 3.21 & 46.6 & 48.4 \\
\hline & & & & $v-490-c 3$ & 0.03 & 0.85 & 0.028 & 0.881 & 0.132 & 6.37 & 2.33 & 2.25 & 63.5 & 66.7 \\
\hline & & & & $v=490-c 4$ & 0.03 & 0.7 & 0.026 & 0.826 & 0.135 & 6.39 & 5.31 & 5.13 & 16.9 & 19.7 \\
\hline 136 & XEPS & $N / \boldsymbol{A}$ & $H / A$ & $v-500$ & $0 . \pi$ & $0 . \pi 7$ & 0.626 & $\cdots$ & $\cdots$ & 16.91 & 16.22 & 16.00 & 4.1 & 5.4 \\
\hline
\end{tabular}


TABLE 29

THE FIT COEFFICIENTS USED TO DESCRIBE THE PREDICTED CAVITY THERMAL RESISTANCE AS A FUNCTION OF CAVITY TEMPERATURE DIFFERENCE

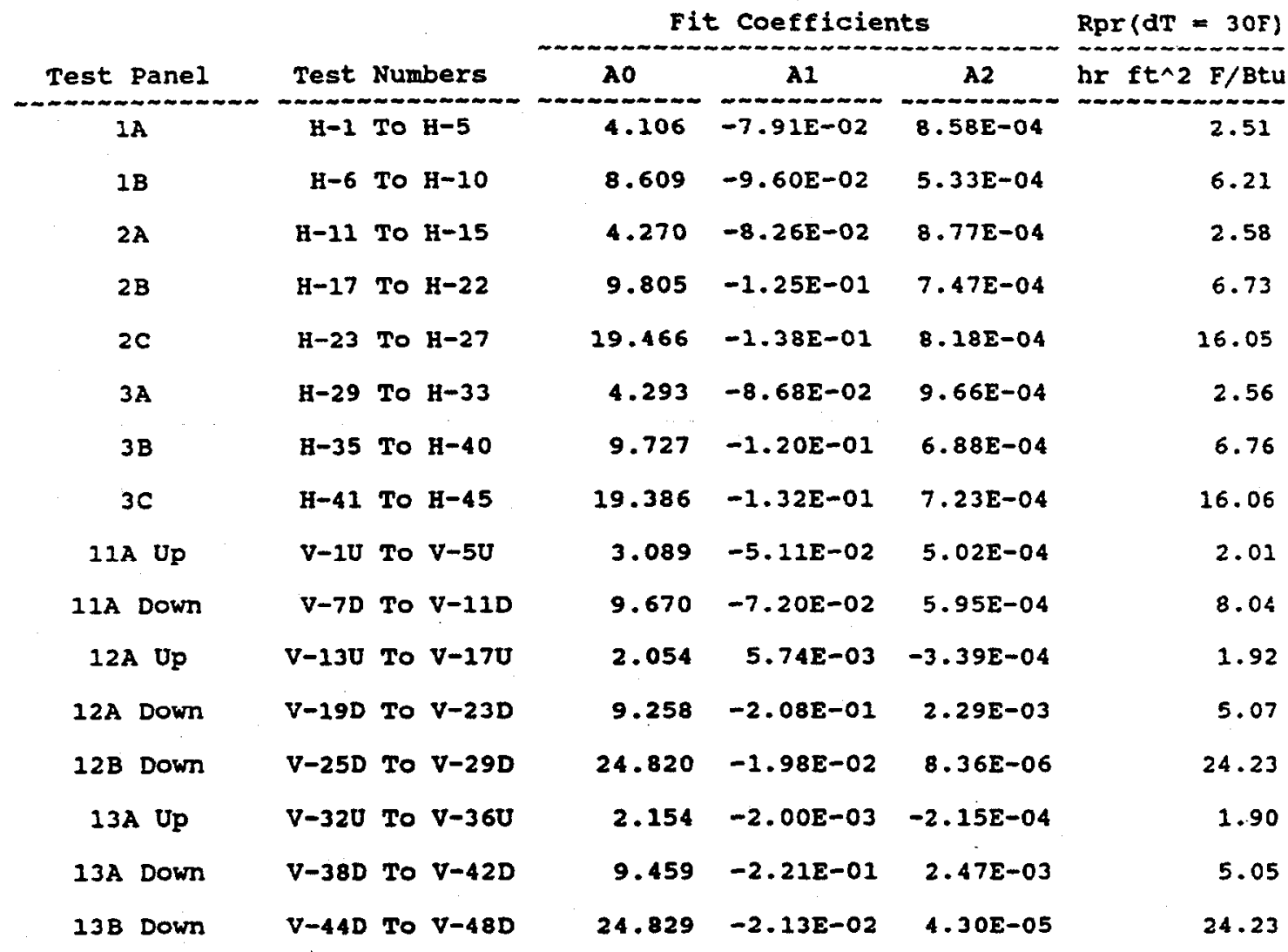

Notes: 1. $R=A 0+A 1 \star d T+A 2 \star d T \wedge 2$ where:

$R=$ Cavity Thermal Resistance, hr ft^2 F/Btu, and $\mathrm{dT}=$ Cavity Temperature Difference, $\mathrm{F}$.

2. Rpr(dT = 30F) is the cavity thermal resistance calculated from the curve-fit coefficients for a temperature difference of $30 \mathrm{~F}$. 
where $T_{\text {mean }}$ is expressed in degrees Rankine. The combined conduction-convection coefficient of heat transfer $\left(\mathrm{H}_{C}\right)$ was determined at an airspace mean temperature of $50 \mathrm{~F}$ using Yarbrough's coefficients and were adjusted to the actual test airspace mean temperature by

$$
\left(H_{C}\right)_{T}=\left(H_{C}\right)_{50} *[1+0.001 *(T-50)]
$$

where $\left(\mathrm{H}_{\mathrm{C}}\right)_{T}$ is the conduction-convection coefficient of heat transfer at the test temperature, $\left(\mathrm{H}_{c}\right)_{50}$ is the conductionconvection coefficient of heat transfer at 50F, and $T$ is the airspace mean temperature in $\mathbf{F}$.

The differences between the predicted (Rpredicted) and measured ( $R_{\text {measured }}$ cavity thermal resistance expressed as a percentage were determined by

Difference $=\left\{\left[R_{\text {predicted }}-R_{\text {measured }}\right] / R_{\text {predicted }}\right\}$

The combined conduction-convection coefficient of heat transfer $\left(\mathrm{H}_{\mathrm{C}}\right)$ data reported by Robinson and Powlitch which forms the basis of the curve-fitting coefficients developed by Yarbrough were limited to a maximum airspace depth of 3.5 inches. Although this data is used to predict the cavity RValue of airspaces with a depth of up to 5.5 inches, it must be noted that this is an extreme extrapolation of the original data base. This extrapolation was used on test results from Test panels $12 \mathrm{~A}$ and 13A. The cavity thermal resistance predictions on data gathered on these two test panels is not included in any of the following discussions because an adequate prediction of the cavity thermal resistance for these panels is unavailable at this time. 
The predicted cavity thermal resistance, calculated from curve-fit coefficients for a temperature difference of 30F, are summarized below. Included in this table are cavity thermal resistances determined by the $R(||)$ and R(ISO) methods. Although listed in this table, results from test panels $12 \mathrm{~A}$ and $13 \mathrm{~A}$ are not included in any subsequent analysis.

Summary of Differences Between the Predicted and Measured Cavity Thermal Resistances

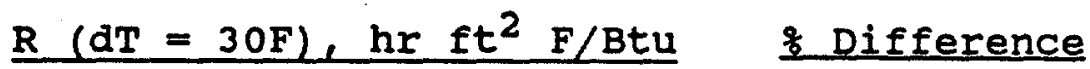

Panel

$1 \mathrm{~A}$

$1 B$

$2 A$

$2 B$

2C

$3 \mathrm{~A}$

$3 \mathrm{~B}$

$3 \mathrm{C}$

11A Up

11A Down

12A Up

12A Down

$12 \mathrm{~B}$ Down

13A Up

13A Down

13B Down
RC(1) RC(ISO) Rpr
2.39
4.68
2.60
5.37
5.95
2.77
5.82
6.13

2.00

7.85

1.80

7.34

17.48

1.93

7.48

16.03
2.42

4.78

2.58

5.44

5.83

2.83

5.85

6.17

2.06

7.70

1.84

7.11

15.23

1.97

7.34

15.23
2.51

6.21

2.58

6.73

16.05

2.56

6.76

16.06

2.01

8.04

1.92

5.07

24.23

1.90

5.05

24.23
$\underline{R C(\| 1)}$ RC(ISO)

$\begin{array}{rr}4.6 & 3.4 \\ 24.6 & 23.0 \\ -0.7 & 0.1 \\ 20.3 & 19.2 \\ 62.9 & 63.7 \\ -8.3 & -10.6 \\ 13.9 & 13.4 \\ 61.8 & 61.6\end{array}$

$0.4 \quad-2.6$

$2.4 \quad 4.3$

$6.3 \quad 4.2$

$-44.9 \quad-40.3$

$27.9 \quad 37.2$

$\begin{array}{ll}-1.6 & -3.7\end{array}$

$-48.0 \quad-45.3$

$33.8 \quad 37.1$

13.1 EFFECT OF TEMPERATURE DIFFERENCE ON CAVITY THERMAL RESISTANCE

To test the effect of cavity temperature difference on the accuracy of the cavity thermal resistance measurement, 
all of the differences between the calculated cavity and the predicted $R$-Value data for one-airspace cavities were plotted as a function of cavity temperature difference and are shown in Figure 29. This analysis was limited to just the one-airspace systems because dissimilar cavity temperature differences were used for test panels with 2and 4-airspace cavities. Data from Test Panels 1A, 2A, 3A, and $11 \mathrm{~A}$ were utilized for this analysis. For cavity temperature differences of $20 \mathrm{~F}$ or greater, the ability to measure the temperature difference does not appear to significantly impact the quality of the measurement. A cavity temperature difference of $20 \mathrm{~F}$ or greater should be used when analysing these products.

13.2 EFFECT OF HEAT FLOW DIRECTION ON CAVITY THERMAL RESISTANCE

The percent difference between the predicted and measured cavity thermal resistance as a function of the test heat flow direction is shown schematically in Figure 30 and is summarized below. The thermal resistances for the prediction $\left(R_{p r}\right)$ and measured cavity $\left(R_{\|}\right.$and $\left.R_{I S O}\right)$ were determined using the curve-fit coefficients and were calculated for a $30 F$ cavity temperature difference. Results from Test Panels $12 \mathrm{~A}$ and $13 \mathrm{~A}$ are excluded from these comparisons. 


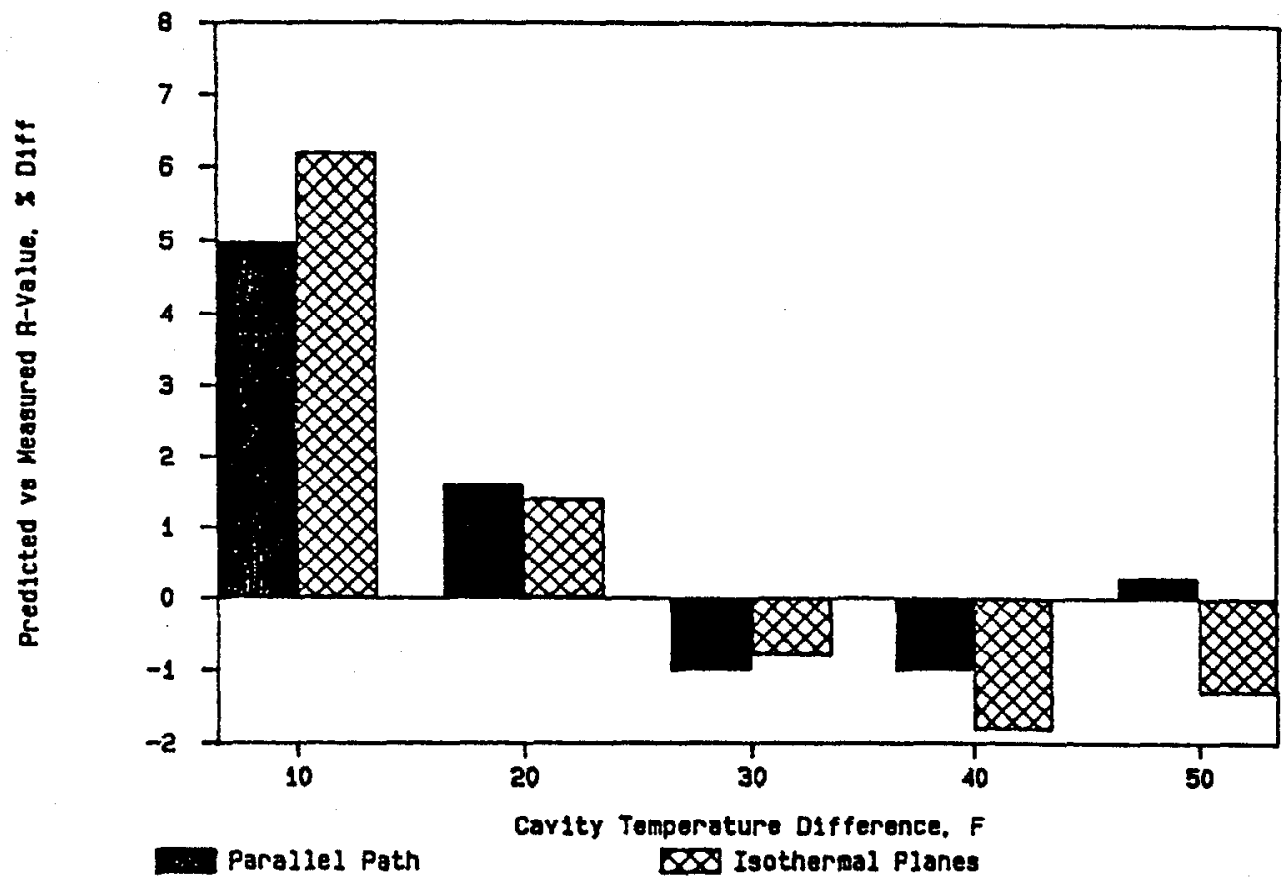

Figure 29: The percent difference between the average predicted and measured cavity thermal resistances for 1airspace cavities as a function of the cavity temperature difference calculated by the parallel path and isothermal planes methods. 


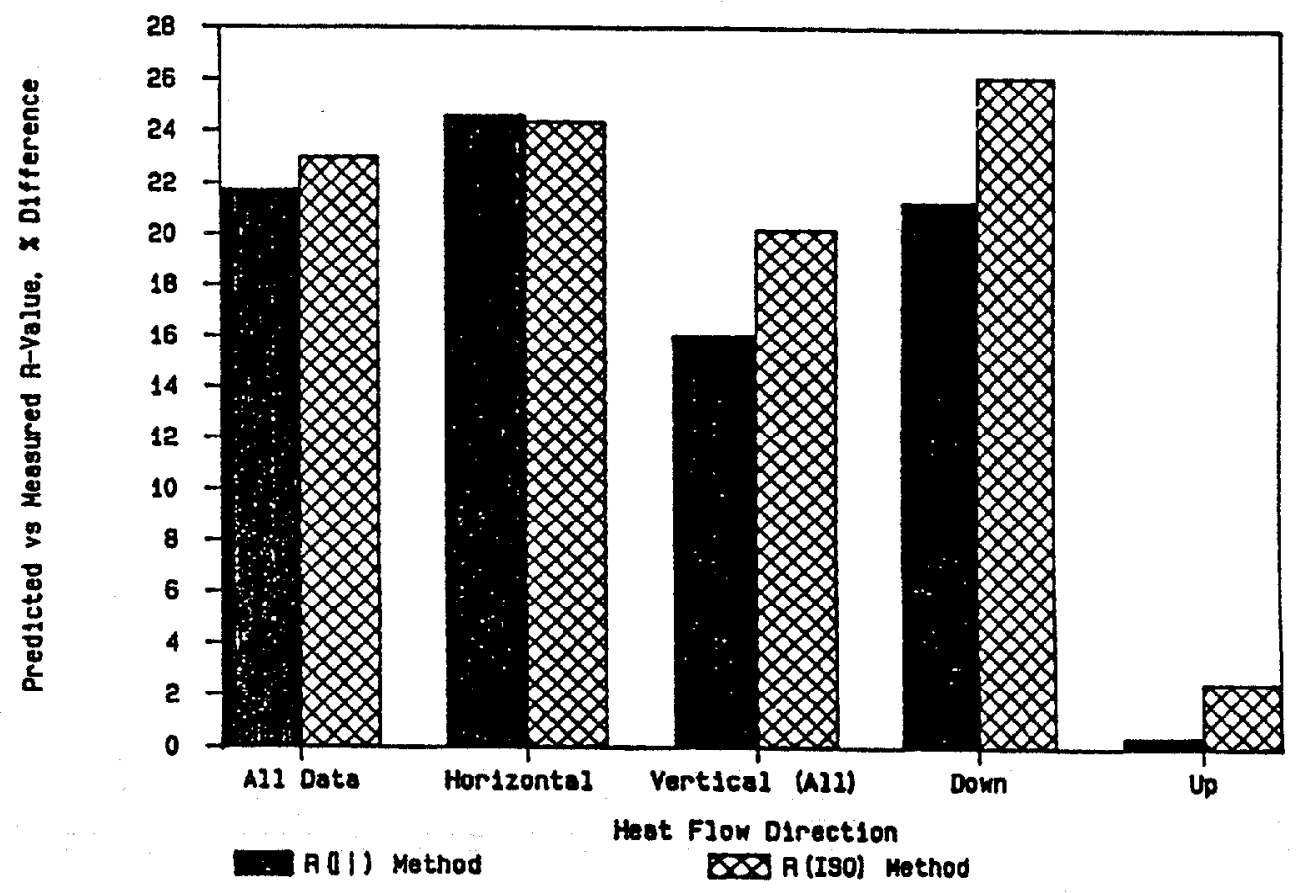

Figure 30: The percent difference between the average predicted and measured cavity thermal resistances as a function of the heat flow direction calculated by the parallel path and isothermal planes methods. 
Differences Between the Predicted and Measured [ $R C(||)$ and Rc(ISO)] Cavity Thermal Resistance as a Function of Heat

Flow Direction

\section{Panel}

All Data (Excluding $12 \mathrm{~A}$ and 13B)

Horizontal ( $1 A-3 C)$

Vertical (11A, 12B, 13B)

Down (11A, 12B, 13B)

Up (11A)

$\frac{q \text { Difference }}{\operatorname{RC}(\perp \perp)}$

21.8

23.0

24.6

24.4

16.1

20.3

21.4

26.2

0.4

Note: $\quad$ o Difference $=[$ (Predicted-Measured $) /$ Predicted $] * 100$

The average difference for all the experiments was 21.8 and 23.0 percent for the parallel path $\left(R_{\mid l}\right)$ and and isothermal planes ( $R_{I S O}$ ) models respectively. Differences based on the parallel path calculations for smaller data sets were 24.6 and 16.1 percent for the horizontal and vertical heat flow experiments respectively and 21.4 and 0.4 percent for the heat flow down and heat flow up experiments. For the isothermal planes model, the differences between the predicted and measured cavity thermal resistances were 24.4 and 20.3 percent for the horizontal and vertical heat flow experiments respectively and 26.2 and 2.6 percent for the heat flow down and heat flow up experiments.

The agreement between the measured and calculated cavity thermal resistance for the heat flow up experiments is excellent (better than 5 percent). For the other heat flow directions, the agreement is poor. However, the heat flow up direction included only single airspace cavities while the other heat flow directions contain data from multiple airspace cavities. When a mixture of cavities with a variable number of airspaces is averaged, there does.not appear to be a significant difference in the agreement 
between the predicted and measured cavity thermal resistance as a function of heat flow direction.

13.3 EFFECT OF NUMBER OF AIRSPACES ON CAVITY THERMAL RESISTANCE

The percent difference between the predicted and measured cavity thermal resistance as a function of the number of airspaces comprising the cavity is shown schematically in Figure 31 and is summarized below. The curve-fits, calculated for a temperature difference of $30 \mathrm{~F}$, were again utilized for this comparison.

Difference Between the Predicted and Measured Cavity Thermal Resistance as a Function of the Number of Airspaces comprising the Cavity

\section{Panel}

All Data (Excluding $12 A$ and 13A)

1 Airspace (1A, 2A, 3A, 11A)

2 Airspaces $(1 B, 2 B, 3 B)$

4 Airspaces (2C, 3C, 12B, 13B)
$\%$ Difference RC(II) RC(ISO)

21.8

3.3

23.0

4.2

19.6

18.6

46.6

Note: $*$ Difference $=[($ Predicted-Measured $) /$ Predicted $] * 100$

Both measured results determined by the two calculation methods agreed extremely well with the predicted thermal resistance for single airspaces: 3.3 percent for $R(||)$ method and 4.2 percent for the R(ISO) method. The predicted thermal performance of the two- and four-airspace cavities were significantly higher than either measured values by either calculation method. Average differences of 19.6 and 18.6 percent for the two-airspace cavities and 46.6 and 49.9 


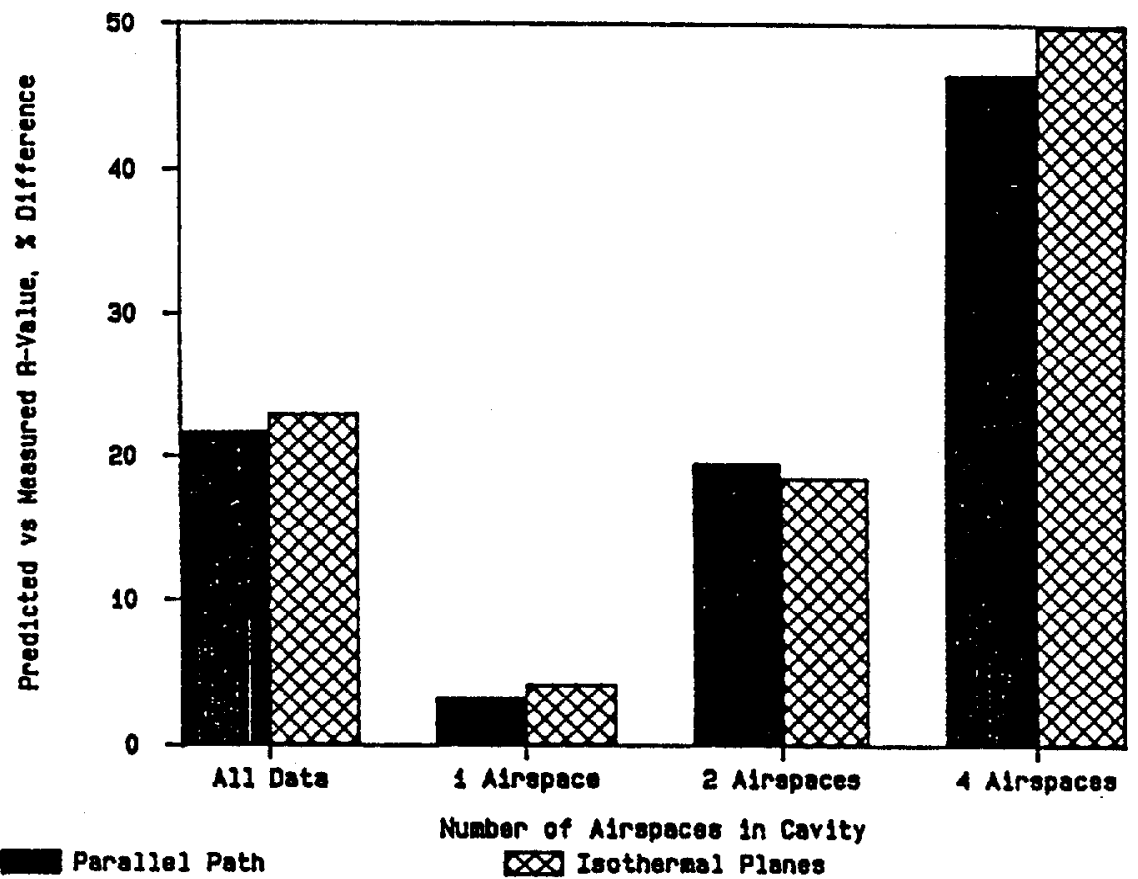

Figure 31: The percent difference between the average predicted and measured cavity thermal resistances as a function of the number of airspaces comprising the cavity calculated by the parallel path and isothermal planes methods. 
percent for the four-airspace cavities were noted for the parallel path and isothermal planes models respectively.

13.4 EFFECT OF FRAMING MATERIAL ON CAVITY THERMAL RESISTANCE

The percent difference between the predicted and measured cavity thermal resistance as a function of the the framing material and the number of airspaces comprising the cavity is shown schematically in Figure 32 and is summarized below. As with the previous sections, the curve-fits, calculated for a temperature difference of 30F, were used for this comparison.

Difference Between the Predicted and Measured Cavity Thermal Resistance as a Function of Framing Material

Panel

XEPS; AII (1A, 1B, 3A, 3B, 3C, 11A, 13B)
XEPS, 1AS (1A, 3A, 11A)
XEPS, 2AS (1B, 3B)
XEPS, 4AS (3C, 13B)
Wood, AII (2A, 2B, 2C, 12B)
Wood, 1AS (2A)
Wood, 2AS (2B)
Wood, 4AS (2C, 12B)

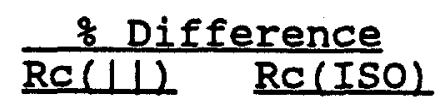

18.7

3.9

19.3

47.8

19.5

5.2

18.2

49.4

27.9

0.7

30.0

20.3

45.4

0.1

19.2

50.4

Note: $\quad$ Difference $=[($ Predicted-Measured $) /$ Predicted $] * 100$

The average differences beween the predicted and measured cavity R-Values (by the $R(||)$ method) for XEPS and wood studs were 18.7 and 27.9 percent respectively. For the XEPS framing members, the average differences for the 1-, 


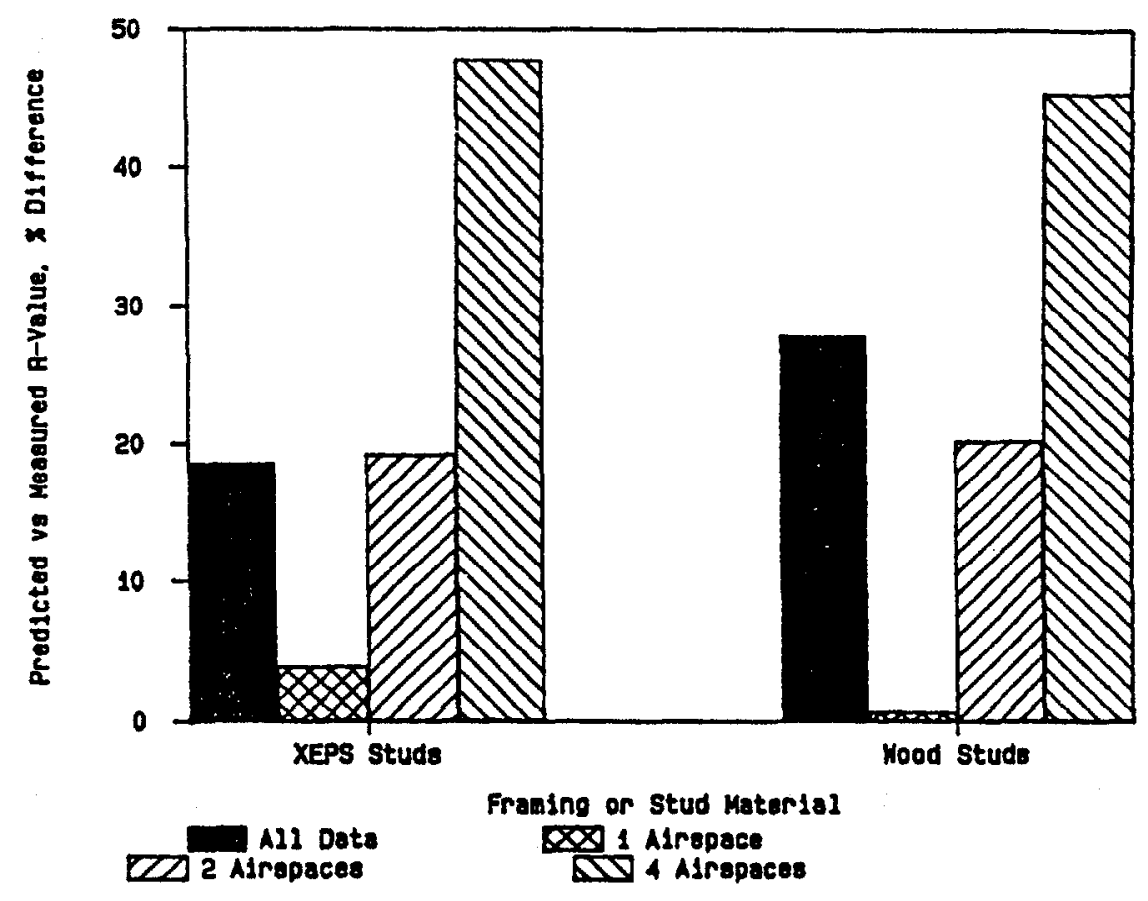

Figure 32: The percent difference between the average predicted and measured cavity thermal resistances as a function of the framing material and the number of alrspaces comprising the cavity calculated by the parsllel path method. 
2-, and 4-airspace R-Values were 3.9, 19.3, and 47.8 percent respectively. For the wood framing members, the average differences were $0.7,20.3$, and 45.4 percent respectively.

For the $R$ (ISO) method, the average differences beween the predicted and measured cavity R-Values for XEPS and wood studs were 19.5 and 30.0 percent respectively. For the XEPS framing members, the average differences for the 1-, 2-, and 4-airspace R-Values were 5.2, 18.2 , and 49.4 percent respectively. For the wood framing members, the average differences were $0.1,19.2$, and 50.4 percent respectively.

The agreement between the predicted and measured cavity R-Values was better for test panels constructed. with XEPS framing materials. This difference in the overall averages is in part due to the fact that there was a larger number of 1-airspace data weighted into the overall average for XEPS studs. As can be seen from the individual airspace data, there is little systematic difference between the wood and XEPS stud framing.

As the number of airspaces forming the cavity increases, the heat flow through the stud becomes a larger percentage of the total heat flow and any errors due to uncertainities in the stud thermal resistance should be magnified. For any particular configuration, the heat flow correction due to the framing members is significantly smaller for the XEPS studs due to its higher thermal resistance. The inability to note any significant improvement in the prediction of the cavity thermal resistance due to a reduction in the stud heat flow by substituting a high resistance material for the stud suggests that accurate information regarding the thermal resistance of the framing material was obtained. If this information is unavailable, reducing the stud heat flow by 
material substitution would reduce the importance of this lack of knowledge.

14. HANDBOOK ON REFLECTIVE INSULATIONS FOR RESIDENTIAL AND COMMERCIAL USES

An important goal of Department of Energy in its funded research programs is to ensure that the results are communicated to the appropriate technical and consumer audience. In the case of work related to energy conservation in buildings, those most directly involved are the architect, designer, home builder, weatherization contractor, and the ultimate building/home owner.

In order to attain this goal for the present study, one of the tasks was the preparation of a draft booklet on reflective insulations. Subsequently this would be printed and distributed widely by DOE to the above group, as one in its series of informational fact sheet publications relating to energy conservation.

The contents of the proposed booklet, while including some brief theoretical background, were to emphasize practicality. In particular, it would discuss thermal performance both in the laboratory and when installed in a building, the effects of framing members on performance, specific circumstances relating to applications and use of reflective and bulk insulations and would include, where relevant, some of the results of the current experimental program. The basic criteria of the approach were relative simplicity of text accompanied with numerous illustrations.

A table of measured cavity R-values of building envelope systems containing low emittance airspaces was 
included in the handbook. The data supplied in this table was derived from this experimental work. The numerical values in this table were determined by averaging all of the appropriate $R_{\mathrm{C} \mid \text { | }}(30)$ values (see Table 27 ) for the configuration in question. For example, the cavity R-value reported for a $2 \times 4$ inch cavity with horizontal heat flow ( $R=2.6 \mathrm{hr} \mathrm{ft}^{2} \mathrm{~F} / \mathrm{Btu}$ ) was determined by averaging the $R_{C||}(30)$ values for test panels $1 A, 2 A$, and $3 A(2.42,2.58$, and $2.83 \mathrm{hr} \mathrm{ft}^{2} \mathrm{~F} / \mathrm{Btu}$ ) respectively.

The final draft of this booklet is attached as Appendix c.

15. THE ADVISORY PANEL

An Advisory Panel of industry experts was established to oversee the performance of this program. Individuals from industry, government, and academia were invited to participate. Each member of the panel had some relevant experience in the subject of reflective insulations. The invited members are listed in Table 30. The membership list includes reflective insulation manufacturers, a representative from the Reflective Insulation Manufacturers Association (RIMA), mass insulation manufacturers, individuals who have performed experimental and /or analytical work involving reflective insulations, government officials involved in the enforcement of the R-value labelling requirements, and the project monitors.

The purpose of the Advisory Panel was to comment on the experimental plan, monitor the progress of the experimentation by receiving periodic updates of the data as it was being accumulated, comment on the development and 
Table 30

REFLECTIVE INSULATIONS ADVISORY RANEL MEMBERSHIP

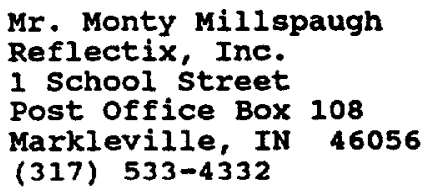

Mr. Philip Fairey

Florida Solar Energy Center 300 State Road 401 Cape Canaveral, FL 32920 (305) 783-0300

Mr. Kent Howerton

Federal Trade commision 6th and Penn Avenue, NW Washington, DC 20580 (202) 326-3013

Dr. David McElroy

Martin Marietta Energy Systems Oak Ridge National Laboratory Post office Box $x$ Oak Ridge, TN 37831 (615) 574-5976

Dr. David Yarbrough

Tennessee Technological Univ. Post office Box 5013

Cookvilie, TN 38505

(615) $574-5139$

(615) $372-3494$
Mr. John Numaw

Owens-Corning Fiberglas Corp.

Post office Box 415

Granville, OH 43023

(614) $587-0610$

Dr. Gerry Miller

Jim Walter Research Corporation 10301 9th Street North

st. Petersburg, FL 33702

(813) 576-4171

Mr. Roy Reinhart

Bonneville Power Administration Post offlce Box 3621 RMRD

Portland, OR 97208

(503) 230-5491

Mr. Paul Juneau

Alfol. Inc.

Post office Box 7024

Charlotte, NC 28217

(704) 588-2170

Dr. Ken Wilkes

Martin Marietta Energy Systems Oak Ridge National Iaboratory

Post office Box $X$

Oak Ridge, TN 37831

(615) 574-5931

Mr. Andre Desjarlais

Holometrix, Inc.

99 Erie street

Cambridge, MA 02139

(617) 868-8050 
content of the Reflective Insulation Handbook, and assist in the development of a list of additional tasks which were required to fully understand the thermal performance of reflective insulation materials.

The Advisory Panel officially met on six occasions. Five of these meetings were held in conjunction with an ASTM C 16 meeting: October 1987 in Toronto, April 1988 in Atlanta, and september 1988 in Tucson, April 1989 in Kansas city, and october 1989 in Hartford. The sixth meeting was convened in February 1988 at Holometrix. A representative from Holometrix did not attend the Kansas city meeting due to travel delays. Agendas and minutes of the meetings, along with handouts that were circulated at the meetings, are presented in Appendix D.

The initial meeting in Toronto was convened shortly after the contract award. The purpose of this meeting was primarily informational. The panel was updated on the program goals, the experimental plan, and the assumptions that were made in the development of the plan. The second meeting at Holometrix was held so that the members could view the laboratory facilities, test panels, and proposed instrumentation plan. At this meeting, it was decided to poll the members on their opinions of additional work which would assist in the understanding of the thermal performance of reflective insulation materials.

A ballot was circulated to the attendees requesting a prioritization of nine previously identified areas of further study, their estimate of the required effort to satisfy the requirement, and the identification of any additional items that should be included on the 1 ist. 
The third meeting, held in Atlanta, was used to update the members on the experimental work, the ballot results, and the status of the handbook. A scoring system had been developed to rank the ballot items. A high priority item was given a low score. Two research items, a reproducibilty experiment and an experiment to determine the effect of fasteners, were identified through the balloting process as being critical in the view of the panel. These two items were removed from the ballot, additional items identified during the first ballot were added, and a second ballot was circulated shortly after the Atlanta meeting.

The fourth meeting, held in Tucson, was used to continue the discussions on the handbook, update the panel on the growing data compilation, and to discuss the second ballot. Prior to this meeting, the first draft of the handbook had been severely critisized. A format for the second draft was agreed upon. The second ballot results indicated no clear preferences regarding the priority of the tasks listed on the ballot.

Discussions at the fifth meeting primarily addressed the form and style of the handbook. The final meeting of the Advisory Panel, held in october 1989, discussed the second draft of the final report.

\section{RECOMMENDED TEST PROTOCOL FOR REFLECTIVE INSUIATIONS}

The test panel design and testing procedure used in this program addresses all of the special requirements involved in measuring reflective insulations and determining the cavity or reflective insulation thermal resistance. The experience gathered to date is limited to the use of guarded 
hot boxes; however, most of this experience can be directly incorporated into test plans using calibrated hot boxes.

\subsection{THE TEST PANEI AND INSTRUMENTATION}

The recommended test panel configuration does not need to be strictly detailed. This program has demonstrated that there does not appear to be a significant amount of interaction between the studs and the cavity; this finding suggests that the selection of stud material and spacing is not critical. However, the effect of stud spacing has not yet been quantified and, until this information is available, it is recommended that different stud spacings be measured separately.

The present study indicated that there was no significant difference in the derived cavity thermal resistance from test panels fabricated from XEPS and wood studs. Each stud type offers advantages. Since the XEPS studs are more thermally resistive, any uncertainty in the stud thermal resistance impacts results on test panels fabricated with XEPS studs to a lesser extent. From an accuracy standpoint, XEPS studs are therefore recommended. However, the difficulty involved in the attachment of reflective insulation products to XEPS studs suggests that wood studs would reduce the cost of test panel construction. From a cost standpoint, wood studs are preferred.

The thermal resistance of the building materials used to construct the test panel must be accurately measured. ASTM C 518 has been found suitable for this purpose. Handbook thermal performance values should not be substituted for direct measurements; differences of up to 
nine percent between measured and handbook values for the building materials used in this test program were found.

The method of holding the sheathing in place (screws for wood studs, nylon threaded rod for XEPS studs) should be simulated in the preparation of the material $R$-value test sample. This data more directly represents the thermal resistance of the stud as it is used in the test panel.

Internal temperature instrumentation must be applied to the inside of each sheathing material and ideally on each major internal surface. For the test facilities used in this program, it was experimentally determined that instrumenting one cavity with a three by three array of temperature sensors was found to be sufficient for measuring an average temperature for the instrumented surface. This finding should be verified on other test facilities prior to utilizing this recommended internal instrumentation layout. see Figures 9 through 13 for recommended instrumentation layouts.

Temperature instrumentation must be applied to at least one stud in the metering area to acurately measure the average temperature difference across the studs in the metering area. Instrumenting a single stud with a pair of temperature sensors on each side was found to be sufficient for this purpose.

For guarded hot boxes, the use of convective blocks is essential. The layout of these blocks is shown schematically in Figure 4. Temperature instrumentation should be applied across the convective blocks and framing materials forming the perimeter of the metering area. 'See Figures 9 through 13 for recommended metering area perimeter 
instrumentation layouts. The thermal resistance of the convective blocks and framing materials should be measured using the same procedures detailed for the building materials and this information, coupled with the temperature difference measurements across the convective blocks and framing materials, should be used to correct the metering area energy input.

\subsection{THE TEST PROCEDURE AND DATA ANALYSIS}

All experimentation performed for this program was undertaken in accordance with ASTM C 236. All of the requirements of the test method must be satisfied. Although present regulations require that testing be performed at a single temperature difference, it is recommended that multiple temperature differences be analysed. Additional testing assists the testing organization in guaranteeing that the test results are correct, and helps the manufacturer and user in understanding how these products will perform in service.

The cavity thermal resistance should be determined using the procedure outlined in the proposed ASTM standard specification for reflective insulations, the parallel path method. Although the two analytical procedures yielded comparable results for the cavity thermal resistance, the isothermal planes method is more dependent on the precharacterization of the building materials.

To verify the test results and supplement the existing data base, it is recommended that the cavity of the test panel under test be compared to the predicted cavity thermal resistance. 


\section{CONCLUSIONS}

The objectives of this program were to develop an acceptable test and evaluation protocol for reflective insulations, generate an initial data base on idealized reflective systems and extend the data base to include a limited number of commercial products.

The standard ASTM C 236 guarded hot box test procedure has been modified such that the cavity thermal resistance can be extracted from the test panel result. These results have also been compared to the widely accepted airspace thermal resistance data presently in the ASHRAE Handbook of Fundamentals.

The conclusions of this program have been subdivided into three sections. These sections address the experimentation techniques and test panel results, the derivation of the cavity thermal resistance from the test panel results, and the comparison of the derived and the predicted cavity thermal performance.

\subsection{THE EXPERIMENTAL PROCEDURE AND THE TEST PANEL RESULTS}

1. Additional instrumentation has been added to the standard ASTM C 236 test method to measure the amount of energy exchange between the metering and guard area inside of the test panel. The average metering to guard area energy exchange was less than 0.1 percent of the total metering area energy input. The highest exchange was 5.4 percent. ASTM C 236. guarded hot boxes can accurately measure test panels with large convective heat transfer 
components if the test panels are modified in the manner used for this program (Section 10, pp. 63-69).

2. Experiments were performed on four test panels whose cavities were filled with mass insulation. For test panels constructed with XEPS studs, the test panel R-Values for $31 / 2$ and $51 / 2$ inch deep cavities were 12.21 and 17.27 hr $\mathrm{ft}^{2} \mathrm{~F} / \mathrm{Btu}$ respectively. Substituting wood for XEPS studs decreased the test panel R-Value to 9.75 and $14.27 \mathrm{hr} \mathrm{ft}^{2}$ F/Btu, or 25 and 21 percent respectively (Section 11.1 , pp. 75-76).

3. For test panels constructed with XEPS studs and tested with horizontal heat flow, the test panel thermal resistance decreased 27 percent when the temperature difference imposed across the test panel was increased by a factor of 5, and generally increased with the number of airspaces comprising the cavity. The ratios of 4- and 2airspace cavities to 1-airspace cavities were approximately 1.8 and 1.9. The structure of the 4-airspace commercial product may negatively contribute its thermal performance. The test panel thermal resistance increased by 11 to 16 percent when decreasing the effective emittance of the cavity from 0.05 to 0.03 (Section 11.2, pp. 76-79).

4. For test panels constructed with wood studs and tested with horizontal heat flow, the test panel thermal resistance decreased 26 percent with a five-fold increase in temperature difference. The ratios of the 4- and 2-airspace cavities to the 1-airspace cavity was identical to the XEPS stud test panels (Section 11.3, pp. 80-82).

5. For test panels tested with vertical heat flow, the test panel thermal resistance decreased 25 and 13 percent 
for heat flow up and down respectively when the test panel cavity temperature difference was increased by a factor of 5 , increased by a factor of 2.7 to 2.9 when changing the heat flow direction from up to down, and increased by a factor of approximately 1.8 when increasing the number of airspaces in the cavity from 1 to 4 (Section 11.4, pp. 8289).

6. For single airspace cavities, the test panel thermal resistance decreased 0.2 percent per degree $F$ increase in mean temperature and varied from 3.46 to 3.04 to $8.99 \mathrm{hr} \mathrm{ft}^{2} \mathrm{~F} / \mathrm{Btu}$ for heat flow horizontal, up, and down respectively (Section 11.5, pp. 89-92).

7. The test panel thermal resistance increased by 0.4 , 0.9 , and $1.0 \mathrm{hr} \mathrm{ft}^{2} \mathrm{~F} / \mathrm{Btu}$ for $1-, 2-$, and 4-airspace cavities when substituting XEPS for wood studs (Section 11.8 , pp. 96-97).

8. Testing was performed at as many as six different temperature differences. Multiple testing provides a mechanism to describe the thermal resistance as a function of temperature difference through curve-fitting, which assists the tester, manufacturer, and analyst.

\subsection{DETERMINATION OF THE CAVITY THERMAL RESISTANCE}

To accurately compare reflective insulation to other insulation types, the cavity thermal resistance must be accurately separated from the test panel result. Two analytical procedures labelled $R(I \mid)$ and $R($ ISO) are outlined for this purpose and applied to the test panel results. 
1. The cavity thermal resistance determined from four test panels insulated with $R-11$ and $R-19$ fiberglass batts were within $+/-9$ percent of the directly measured thermal resistance of the materials and averaged 3.8 and 5.8 percent different for the $R(||)$ and $R$ (ISO) methods respectively. These results satisfy the acceptance criteria proposed in the draft ASTM material specification for reflective insulations for verifying the performance of the test panel. The agreement between the derived and directly measured thermal resistance is better for test panels constructed with XEPS studs by approximately 2 percent (section 12.1, pp. 106-110).

2. For horizontal heat flow, the 2- and 4-airspace cavity $\mathrm{R}$-Values are 2.1 and 2.3 times greater than the 1airspace R-value. There is excellent agreement between the two calculation techniques for cavity thermal resistances less than $6 \mathrm{hr} \mathrm{ft}^{2} \mathrm{~F} / \mathrm{Btu}$; differences are typically less than 2 percent and average approximately 1 percent. For similar constructions, the cavity R-Value derived from the test panels constructed with XEPS studs is higher than its counterpart constructed. with wood studs. Differences of approximately 6,8 , and 3 percent were noted for 1-, 2-, and 4-airspace cavities respectively (Sections 12.2 and 12.3 , pp. 111-116).

3. For vertical heat flow, the average agreement between the two calculation techniques is good, averaging about 6 percent different. The 4-airspace cavities exhibit the highest cavity thermal resistance measured in this project, $R=17.5$, and the greatest variation (approximately 9 percent) based on calculation method. The 4-airspace cavity is approximately 2.2 times more resistive than an 
equivalent 1-airspace cavity evaluated with heat flow down (Section 12.4, pp. 116-120).

4. The parallel path method requires accurate information regarding the heat flux through the stud; precise measurements of the stud $R$-Value and temperature difference across the stud are essential. The average heat flow through the stud for all experiments was 7.1 percent, ranging from a minimum of 3 percent for 1-airspace XEPS test panels to 20 percent for 4-airspace wood test panels. The XEPS test panels transferred only 31 percent of the stud heat flow measured on wood test panels (section 12.5 , pp. 121-124).

5. The calculation techniques exhibit their best agreement for cavity R-Values of approximately $4 \mathrm{hr} \mathrm{ft}^{2}$ F/Btu. At lower cavity R-values, the $R$ (ISO) method predicted higher cavity R-Values; lower cavity R-Values were determined by the $R$ (ISO) method as the cavity R-Value increased above $4 \mathrm{hr} \mathrm{ft}^{2} \mathrm{~F} / \mathrm{Btu}$ (Section 12.6, pp. 124-128).

\subsection{COMPARISON OF THE MEASURED AND PREDICTED CAVITY} THERMAL RESISTANCE

The prediction technique used in this program is presently limited to cavities having a maximum depth of 3.5 inches. Discussions in this section are therefore controlled by this limitation.

1. A cavity temperature difference of at least $20 \mathrm{~F}$ should be used when analysing these products. Below 20F, the effect of the temperature difference significantly impacts the quality of the measurement. This criteria 
should be applied to the cavity and not the test panel as it presently is employed in the FTC Trade Regulations (Section 13.1, pp. 138-139).

2. The average difference between the predicted and measured cavity thermal resistance for all the experiments performed was approximately 22 percent. As a function of the number of airspaces, the differences between the predicted and measured cavity thermal resistances were approximately 4, 19, and 48 percent for the 1-, 2-, and 4airspace cavities respectively. With the exception of two 1-airspace cavities, the predicted cavity thermal resistance is always higher than measured result. Multiple airspace cavities did not perform in a manner that can be predicted by suming nominally equivalent single airspace data (Section 13.2, pp. 139-143).

3. The agreement between the predicted and measured cavity thermal resistance is not significantly impacted by the stud material used in the test panel construction. The agreement between the prediction and the measured cavity RValue was slightly better for 1 - and 4-airspace cavities derived from test panels constructed with wood studs while the agreement for the 2-airspace cavities was better with test panels constructed with XEPS studs (Section 13.4, pp. 145-148).

\section{RECOMMENDATIONS}

Following the format of the conclusions section, this section has been subdivided into three subsections: test procedure and panel results, derivation of cavity thermal performance, and comparison to predicted cavity thermal 
performance. The Advisory Panel developed a list of additional research required to fully understand the thermal performance of reflective assemblies. Since a number of these recommendations were beyond the scope of this project, they are not listed in this section. See pages C-20 and C24 for a complete listing of the Advisory Panel's recommendations. Based on the conclusions obtained from this program, the following recommendations are made.

\subsection{THE EXPERIMENTAL PROCEDURE AND THE TEST PANEL RESULTS}

1. ASTM C 236 guarded hot box test method should be modified to include additional internal temperature instrumentation to measure the metering-to-guard energy balance when testing test panels which have a significant convective heat transfer component. A procedure for correcting any imbalance should be included. The proposed reflective insulation material specification should also include this requirement.

2. Tests on a homogeneous mass insulation has been used to determine the reproducibility of the guarded hot box test. These tests should be performed on a test panel insulated with reflective insulation. Given the manual effort required to install reflective insulation reproducibly, it is recommended that the ability to accurately repeat the installation process be tested.

3. Different types of fasteners were required to construct the XEPS and wood stud walls. Experiments should be performed to determine if a systematic bias has been introduced due to the fastener. 
4. All of the experimental work was performed unaer steady-state conditions. Given the sensitivity of the thermal resistance of airspaces to temperature difference and heat flow direction, an in-situ experiment is required to determine how applicable steady-state data is to actual applications.

5. Multiple experiments with varying temperature differences should be considered to quantify the thermal performance of reflective insulations.

\subsection{DETERMINATION OF THE CAVITY THERMAL RESISTANCE}

1. The cavity thermal resistance was determined from the test panel experiments using one-dimensional analyses. A more sophisticated analysis procedure should be applied to the data base to validate the conclusions derived from the simplified models.

2. The issue of airspace aspect ratio was not addressed as originally intended. The original plan included a comparison of the individual airspaces in the multi-airspace cavities. Since the multi-airspace cavities did not thermally perform as anticipated, these comparisons could not be made. Further experiments on test panels designed to create specific aspect ratios should be considered. Testing in a calibrated hot box should also be considered to extend the aspect ratio data base.

3. No direct comparison of commercial and idealized airspaces has been undertaken. The present data base suggests that significant improvements can be obtained through a redesign of the commercial product. A direct 
comparison with an equal number of airspaces would measure the potential energy savings due to product redesign.

4. The temperature conditions used in performing the bulk of the experimental work were not typical of southern climates where reflective insulations have their largest market share. Extension of the data base to include temperature conditions typical of southern climates is required.

5. The present program included measurements on cavities with up to 4 airspaces. Reflective insulations are produced with up to 9 airspaces installed in deeper cavities than measured in this program. Additional experiments to cover the range of products should be considered.

6. To develop a better understanding of the multiairspace systems, further experiments on test panels with multiple airspaces of varying effective emittance should be considered to determine whether their unanticipated thermal performance is due to the radiative heat transfer coefficient.

18.3 COMPARISON OF THE MEASURED AND PREDICTED CAVITY THERMAL RESISTANCE

1. The existing prediction method is limited to a maximum cavity depth of 3.5 inches. The useful range of this method should be expanded to at least 5.5 inches.

2. XEPS studs should be used in test panel construction because their higher thermal resistance reduces the necessity to accurately determine the stud temperature differences and thermal resistance. 


\section{ACKNOWLEDGEMENTS}

This program has been administered by the Energy Division of Oak Ridge National Laboratory; the DOE Project Manager is Dr. David L. McElroy. The project was supported jointly by ORNL/DOE and Bonneville Power Administration.

The authors wish to thank Dr. McElroy and Mr. Roy Reinhart of BPA for their support throughout the program, the members of the Advisory Panel for volunteering their time and energies in attending program status meetings and reviewing the documentation generated by this project, RIMA for their donation of reflective insulation materials, and Mr. Brian Robichaud of Holometrix for his careful experimental work. 
20. REFERENCES

1. Yarbrough, D.W. "Assessment of Reflective Insulations for Residential and Commercial Applications," ORNL/TM8891, October 1983.

2. Robinson, H.E. and Powlitch, F.J., "The Therma 1 Insulating Value of Airspaces," Housing Research Paper 32, United states National Bureau of standards, Project ME-12 sponsored by the Housing and Home Finance Agency, U.S. Government Printing office (1956).

3. Bejan, A. "A Synthesis of Analytical Results for Natural Convection Heat Transfer Across Rectangular Enclosures," Int. J. Heat Mass Transfer 23, 723 (1980).

4. ASHRAE Handbook of Fundamentals, American Society of Heating, Refrigerating and Air Conditioning Engineers, Inc., Chapter 22, (1989).

5. Hollingsworth, M.Jr. "Experimental Determination of the Thermal Resistance of Reflective Insulations," ASHRAE Trans. 1983,89 , pt. 1 .

6. Hollingsworth, M. Jr. "Thermal Testing of Reflective Insulation" Thermal Insulation Materials and Systems, Eds. F.J. Powell and S.M. Matthews, ASTM STP 922, ASTM, Philadelphia, pp. 506-517, 1987.

7. Miller, R.G., Oscar, D.S., Seiface, F., and Goss, W.P., "Methods for Determining the Thermal Performance of Reflective Insulation systems" Presented at ASTM C16 Symposium on Thermal Insulation Materials and Systems, Bal Harbour, FL, 6-9 Dec. 1987. In Course of Publication in ASTM STP 1030, ASTM, Philadelphia, PA.

8. Poppendiek, J.R., Connelly, D.J., and Fowler, E.W., "Some Remarks on Heat Transfer in Installed Foil Insulation Systems," ASHRAE Trans. 198389 pt. 1.

9. ASTM C 236-87, standard Test Method for "steady-state Thermal Performance of Building Assemblies by Means of a Guarded Hot Box," Volume 04.06, ASTM Standards, Philadelphia, PA, pp. 63-77.

10. Proposed ASTM Standard specification for "Reflective Insulation for Building Applications" under Development by ASTM Subcommittee C16.21 on Reflective Insulations, 1989. 
11. Iabeling and Advertising of Home Insulation, Trade Regulation Rules 16 CRF 460, 44 Federal Register 50242, August 27, 1979.

12. ASTM C 518-85, standard Test Method for "steady-state Heat Flux Measurements and Thermal Transmission Properties by Means of the Heat Flow Meter Apparatus," Volume 04.06, ASTM standards, Philadelphia, PA. pp. 201-217, 1988 .

13. Tye, R.P., Coumou, K.G., Desjarlais, A.O., and Haines, D.M., "Historical Development of Large Heat Flow Meter Apparatus for Measurements of Thermal Resistance of Insulations," Thermal Insulation: Materials and Systems, ASTM STP 922, F.J. Powell and S.L. Matthews, Eds., American society for Testing and Materials, Philadelphia, 1987, pp. 651-664.

14. Howard, J.K., K.G. Coumou, and TYe, R.P., "Direct Thermal Conductivity Instrument with Digital Read-out for Measurement of Heat Transmission in Cellular Plastics," J. Cellular Plastics, 9:226 (1973).

15. ASTM E 230-83, Standard "Temperature Electromotive Force (EMF) Tables for standardized Thermocouples," Volume 14.01, ASTM standards, Philadelphia, PA, 1988.

16. Yarbrough, D.W., and Cook, J., "Emittance Measurements Report," 1988.

17. ASTM C 177-85, Standard Test Method for "steady-State Heat Flux Measurements and Thermal Transmission Properties by Means of the Guarded-Hot-Plate Apparatus," Volume 04.06, ASTM Standards, Philadelphia, PA. pp. 21-36, 1988.

18. Sherman, M. "Aged Thermal Resistance (R-Value) of Foil-Faced Polyisocyanurate Foam Thermal Insulation Board," Thermal Performance of Exterior Envelopes of Buildings I, Ed., E.L. Bales, ASHRAE SP28, pp. 952-964 1981 .

19. Bales, E.L. "ASTM/DoE Hot Box Round Robin," Oak Ridge National Laboratory Report ORNL/Sub/84-97333/2, 1988 . 
$m$ 


\author{
APPENDIX A \\ PROPOSED STANDARD SPECIFICATION FOR \\ "REFLECTIVE INSULATION FOR BUILDING APPLICATIONS"
}




\section{.}

,

, 
July 1. 1989

WORK ING DOCLMENT FOK ASTM COMMITTEE USE UNLY. NUT EOR PUBLICATION EXCEPT AS EXPRESSLY APPROVED BY THE CHAIRMAN OP THE COMMITTEE, OR THE EXECUTIVE SECRETARY OF THE SUEIETY.

STASUARD SPECIELCAIION FUR

KEFLECTIVE INSULATION FUR BLILDING APPLICATIONS (TU 1U2)

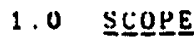

1.1 This specification covers the general requirements and physical properties of reflective insulations ior use in buliaing appilications. These insulation materials consist of one or more low emittance surfaces, such as metaltic foil or netailic deposits. Unaunced or mounced on substrates. Reflective insuiations verive theis thermal performance from surfaces with an enictance of 0.1 or less. facing enclosed air spaces.

1.2 This standard may invoive hazaraous materials. operations. and equipment. This standard noes not purport to address ali of the safety probiems assoclated with its use. It is the responsibility of users of this standard to establisn appropriace safety and heaith practices and determine the applicablitty of regulatory ilmitations prior to use.

2.0 REEERESCED DOCUMENTS

2. 1 Astu standards:

C 168 Definttlons of Terms Relating to Thermal Insulating Materiais.

c 177 standard Test Method for stendy state Heat Flux Measurenents and Thermal Transmission Properties by Means of the Guarded-Hot-Plate Apparatus 2

C 236 Test Method for steady state Thernal Performance of Buiding Assembilies by means of a Guaded Hot Box. 2

C 390 Standard Criceria for sampling and Acceptance of Preformer Thermal Insuiation Lots. 2

T Thts specification ls under the jurlsaiction ot Asty Commitee c-16 on Thermal Insuiation and is the direct responstbllity of subcommittee cla.zl on keflective Insulations. 


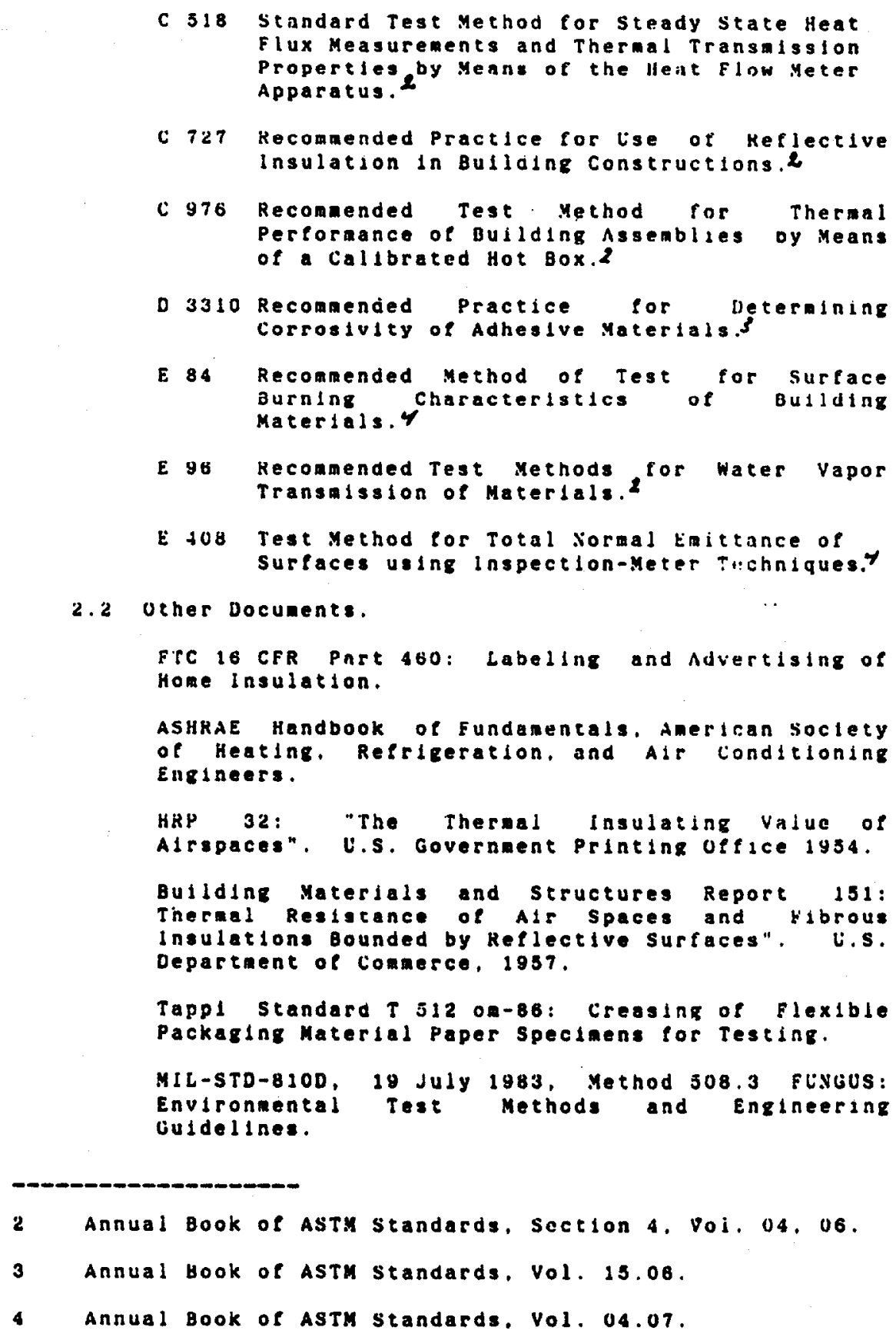

C 318 Standard Test Method for steady state heat Flux Measurements and Thermal Transalssion Propertles by Menns of the lient Flow Meter Apparatus. ${ }^{2}$

c 727 Recomended Practlce for lise of Keflective insulation in Bullaing Constructions.

c 976 Recomended Test Method for Thermal Perforance of Building Assemblizes oy Means of a callbreted Hot $90 x .2$ D 3310 Recomanded Practice for Determining
Corrosivity of Adheslve Materlals.

E 84 Recommended Method of Test for surface Burning characterlstics of Bullaing Matertals. 4

E go Recomended Test Methods for Water Vapor Transisision of Materlals. ${ }^{2}$ hater Vapor

E tor Test Method for Total liormal Enittance of Surfaces using inspection-Meter Tuchniques.7

2.2 Diher Documents.

FIC 16 CFR Pnst 460 : Labeling and Advertising of Home Insulation.

ASHRAE Handbook of Eundanentals. American soctety of Heating, Refrigeration, and Air conditioning Engineers.

HaP 32: "The Theraal insulating value of Alrspaces". U.S. Government Printing office 1934.

Buldidig Materials and structures Report 151: Thermal Resicrance of Atr spaces and yibrous Inaulations Bounded by Reflective surfaces". U.S. Department of commerce, 1957.

Tappl standaro T 312 on-86: creasing of Flexible Packaglng Material Paper Spectmens tor Testing.

MLL-STD-810D, 19 July 1983, Method 308.3 Flivius: Environmental Test Methods and Engineering culdelines.

Annual Book of ASTX standards, Section 4, Voi, 04, 06 .

Annual Hook of ASTM standards, Vol. 15.06 .

Annual Book of ASTM standards. Vol. 04.07. 
3. 0 IERRMINOLOGY

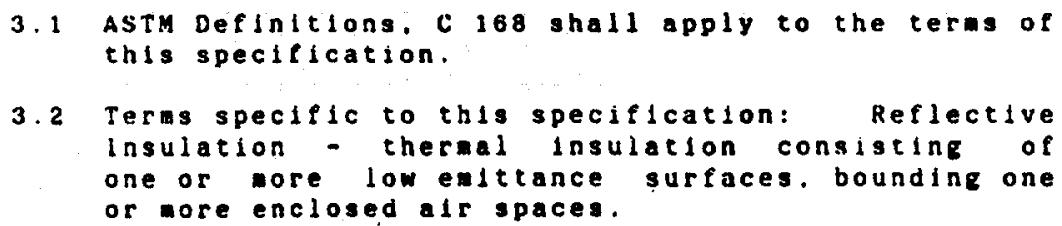

3.2 Terms spectilc to thls speciflcation: Reflective insulation - thermal insulation consisting of one or core low enlttance surfaces. boundine one or more enclosed air spaces.

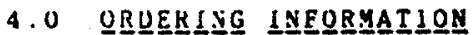

4.1 Prior to purchase, for sampling and acceptance procedures ASTM C 390 can be agreed to by purchaser and manufacturer.

4.2 specify the required thermal resistance by direction heat flow.

4.3 specify the width, depth and total area to be Insulated.

4.4 spectfy special markings if required.

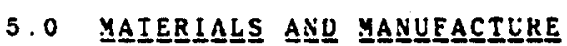

Reflectlve Insulation materlals shall consist of low emittance surface(s) in combination with substrates and adhesives required to meet the specified thermal performance and physical properties.

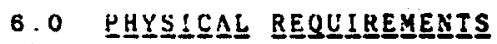

6.1 The low emittance ateriais sinall conforn to the pinsical properties listed In Table 1 and local building codes.

6.2 The refiective insulation nust have the following physical characteristics.

6.2.1 Water Vapor Transmission: If the reflective insulation is to serve as vapor retarder. the permeance of the aterial shall not exceed 1 pera. as deterained in accordance with ASTM E 96.

6.2.2 Multiple layer reflective insulations shall be designed to attain the intended separation of layers in normal application. such multiple layer insulation shall form an attachment flange sultable for stapling or other means of attachment. 
6.2.3 Widths: Ingulation shall be furnighed in wdths to $t$ it between traning nembers set at spacings standard in the construction Industry. or as spectelcally agreed upon between producer and buyer.

6.2.4 Surface burning characterlstics shall be determined in accordance with ASTM E 84 In a conflguration conslstent with the intended application.

6.2.5 Corrosivity: The laminates of the reflective insulation shall be tested in accordance with ASTM D 3310 . Evidence of corrosion shall be cause for rejection.

6.2.6 Adhestue Performance:

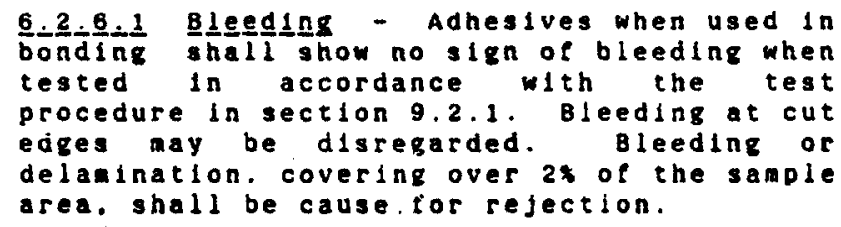

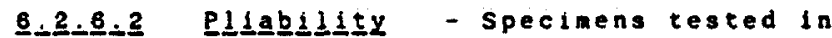
accordance with the test procedure in 9.2.2 shall not sow cracklng or delanination.

6.2.7 Mold and Mildew - Resistance shall be tested In accordance with MLL-STU-8108. The anples are then examined visualiy under $5 x$ agnification for the extent of nold growth and for indications of deterioration. The mold is not to have spread beyond the innoculated area, and no signiflcant growth of mold is to be observed. Material must not have delaninated.

6.3 Thermal Resistance.

Determine the thermal reslstance in accordance with procedures in section 9.1 .

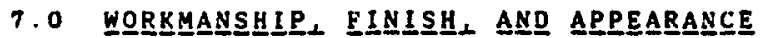

7.1 The Insulation shall be manulactured, packaged, and shlpped in such a ganer that, when received by the customer. It shall be sultable for installation in. accordance with ASTM Recomended Practice c 727. 
8.0 포프느느ㅁㅗㅡ

H. S Sappling sinal be pertoreed in accordance with Asty c 390 .

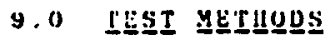

0.1 Therant terformance

The tinermal performance of reflective insulations shall be determined in arcorisace with asty test nethods $C$ 236 or $C$ g7b using the following criterin.

9.i.l The thermal test shail be portninga with an air to alr cenperature dititerence of jo dagrees $E$.

9.1 .2 In ordar to ceternine ine thermal perturnance of the reflective lasulation wateriais used in a test paneb. a uniform method of adjustment of the test panel results is needed.

9.1.3 The test pane, shali constst of woon trange wembers shearhed with $3 ; 4$ inch inlck plywood un ech tip. The wideh and aupth of the cavicles shall oe representacive of the installation tor which the insulation product lo Intended. Isee sectious 5 and 7 of Astr C z36I. The retiective insulation shals be inscalled in the test panel arcurding to the manufucturer's specticlcattons. The cesting of the rellective insulation shall be pertorined at a Dean temperature of $24 C(75)|w| t h$ h temperature difference across the insulated cavity. T ins of $17 \mathrm{C}(30 \mathrm{~F})$.

9.1.4 The thermal resistance of the franing matertal nust be known to within plus or ans $10 \%$ and each frating meaber in the metered area shall be instrumented with a ininum of three sets of sinsurs to measure the temperature difference across the framing members in the airoction of heat flow. The temperature sensors shall be uniformly distributed along the length of the framing member(s) wichin the meteres arca. 


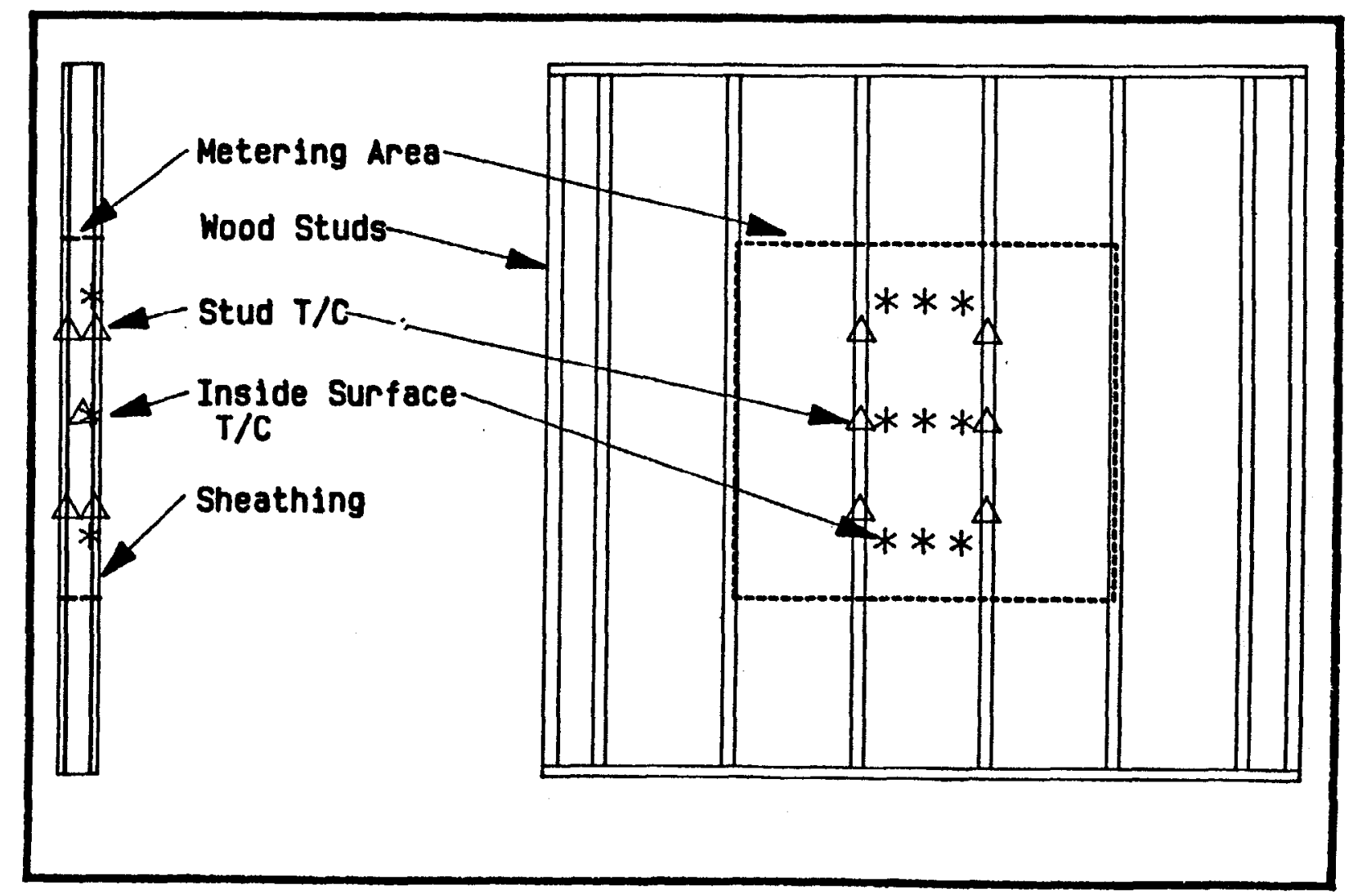

FIGURE 1: R-Value Test Panel Inside Surface and Stud T/C Layout. 
9.1.5 The steady-state heat flow through the retlectlve insulation in the cavity shall be determined from Equation (1).

Uins = Utotal - A Éga日e

where utotalis the total hiat flow rate across th test panel (BTUihr)

frame is the cross-sectionil area of the franing $(\in t)$

Irame is the average temperature ii fiterance across the traming (F)

Exime is the thermal cesistance ot tha framinglit. ine. E/BTL)

Qing is the tocnt heat fow late across the insulated cavity. (BTi/hr).

9.1.6 ine thermul resistance of the retlactive insulation. $K$ ins. shall be aetcrnisea from Equation (2).

Rins = Ins - insiQins 121

where ins is che conss-sectional alina of the insulated cavity (tet).

Ins is the aretrage across the insulated civity measured from the instat surface of the warn-side shearhing to the inside surface of the cool-side shanthilly.

9.1 .7 The heat flow correction due to the presenre of the framing meminers resulting from equation (1) shall be vertfied by repeating the hot box mensurement with a mass insulation aterial of known thermal resistance, which has becn verifled by laboratory tests in an ASTY C 518 or ASTM c 177 apparatis. The thermat resistince of the ass insuiation afrer correcting for the traning aenher acat tlux shall difter by no more than $10 \%$ from the laboratory derived thermaj resistance.

9.1.8 Reporting requirements: The repore sinali dncluae all the requirements of AsTx $C 236$ or c 976, as well as tne parameters listed in equations 1 and 2 of section 9 . The date of the last frame verification shall also be reported along with any specific test results aftecting the present experinent. 
9.2 Adhesive Performance.

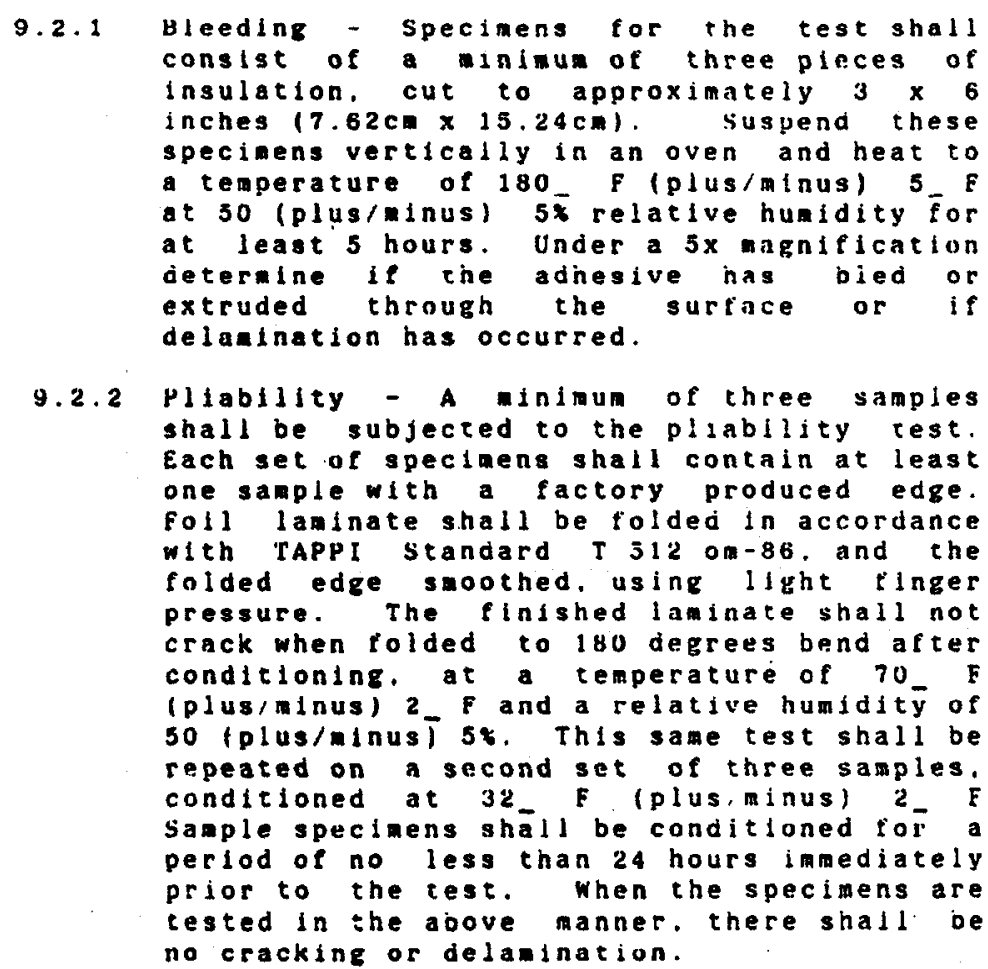

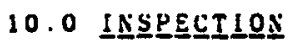

10.1 Inspection of the materlal shall be agreed upon between the purchaser and supplier as part of the purchase contract as specified in ASTM C 390 .

\subsection{RE IECI ION ANDQ REEEEARING}

21.1 Requirements Detersined by visual Inspection: samples shald be inspected visually for mechanical damage as follows:

11.1.1.Surface Punctures - not to excoed l puncture per $800 \mathrm{ft}$.

11.1.2 Danage (bleeding adhesive, corrosion) to reflective properties of surface coatings not to oxceed two percent of the insulated area. 
11.1 .3 crlakling fas cuidenced by numernus rianses and bends resulting in nonparallel surfaces) - not to exceed ive percant of linsulated area.

11.1.4 Evidence of corrosiun.

11.1 .5 improper assembly lwhen referenced to anufacturer's specificationsl - not to exceed one percent of area.

11.1 .6 Improper exponston to deslgned torm or size or both - not to exceed one percent of area.

11.2 if inspection of the samples shows tailure lo conform to the requirements of this specificaion. a second sample trom the same lot shall be tested and the results of this retest averaged with the results of the original test.

11.3 Lipon retest. as described in 11.2. material that iails to conform to the requirements of this specleication ay be rejected. Rejection should be reported to the producer or supplier promptiy and in writing. In case of dissatistactiun with the results of the test. the producer or supplier may wake a ciali for a rehearing.

11.4 In case of rejection. the manufacturer or supplies shall have the right to relnspect the rojected silipment or resuonit the iot after removal of that portion of the sinignent not conforming to the specitied requirements.

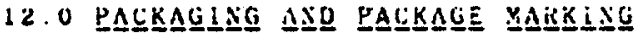

12.1 11 insulation products shail be packaged in a anner which wil protect the reflective surtaces from physical damage during storage and transportation.

\subsection{Package Marking}

12.2.1 All packages shall he marked to identify product origin.

12.2 .2 All packages shall be marked with a lot number.

12.2 .3 Thormal resistance values reterenced to this spectication will be glven for heat flow up. heat flow down. or heat low horizontal. as applicable. 
12.2 .4 Widh and length of matertal when installed.

12.2.5 Total aren. square teet (square meters) covered by tile package contents when instabled according to the nanufacturer's recuminendat 1008 .

12.3 Insulation Marking

12.3.1 Insulation shall be inprinted with the manufacturer's or dstributor's name andior trademark.

12.3.2 Insulation markings shall not reduce the stated thermal performance of the product. lnsulation markings shall be vepeated at intervals not exceeding $8 \mathrm{ft} .(2.4 \mathrm{~m})$

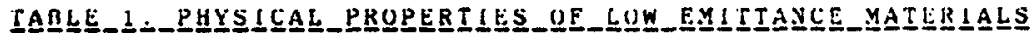

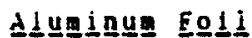

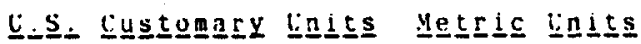

1. Thiciness (minimum)

(A) Exposed unsupported

$0.0004 \mathrm{in}$.

0.00035 in.

0. $1010 \mathrm{~mm}$

(B) Unexposea and unsupported

0.00025 in.

$0.009 \mathrm{~mm}$

(C) Donded to substrate

$0.006 \mathrm{~mm}$

2. puriey $=99 *$ mintaua

3. Enittance :

The surface entetance shall be determined by ASIX $E+408$.

Inls value shall be equal to or less than 0.1 


\section{APPENDIX B}

EMITTANCE TEST REPORTS 
This report concerns the compietion of the emittance neasurements for Dynatech $R \in D$ company. The emittances of che foans isamples $: 1$ and 12) and the woods (Sampies $13,24,15$, and 16) were measured three ways.

i) Heat 3alance Methoo - in " $x / \mathrm{k}$ " value is salculated. Then an iterative solution is used to find $E$."

2) Transient Yethod - i vs sime curve is extrapolated to $t=0$. This nethod fails since so inear portion of the curse exists to extrapolate."

3) Very Thin Silees Nere Cut - E varies with thickness of sampies (reaches equilibrium with. the heat sink easily but iransparency differs with thickness).

yarious papers and =ape were used as nasiss in Methods 1 and 2.

is expected, the emittance varied with meshods and "masks" is well $\mathrm{zcm}$

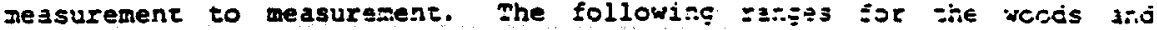
foams are recommendie as a result of the restit.s.

Foans: (Samples 11 and 12$) \quad \varepsilon=.45$ to $.57(.51 \pm .06$ )

Noods: (Samples $13,14,15$, and 16 ) $\leqslant . .7$ to $.32 ! .77=.05$ )

Four emittance measurements were mace for each of the soil specimens. The averace emittance yalues in this case are accurate to $=0.005$. All of the neasuremerts were jcre with a model $\lambda \vec{F}$ emissomezez built by Devices and sezriess Comgany of Dallas, Texas. The measis $r \neq$ ments were done in an senvirorment around $70^{\circ} \mathrm{g}$.

-Devices and Services Company, Technical vote -9-17 
SPECIMEN IST ECR EMI TTANCE IEST

Specimen No.

Jescrifrion

1
2
3
4
5
6
7
9
7
10
11
12
13
14
15
16
17
28
19

174" wide foll, $250^{\circ}$ into roil, "blotcin" surface 173" wide toil, 150" into ro:!, "shiney" surface 174" vide foil, 160" into roil, blotchy" surface 174" wide foll, 160" into roil, "shiney" surface 174" wide foil, 170" into reil, "blotehy" suriace

173" wide foll; 270 " into roil, "sininey" surface

Foil tape

Foil tass

Duct tags

33" wide foil, 25' into roll

Styrofose

Styrotoen

$1 / 4^{n}$ plywoed

i.4" plyured

3. $x+4$ stive

2" $x 4^{\circ}$ sezd

accordian foil, : 21 into roll

Accordian foll; $22^{\prime}$ into $=011$

Accordian foi: : $: 1$ into soi:

Nose: All foil specimens are labeled on outsite if roi:. 
3M:-TANCE

\begin{tabular}{|c|c|c|c|c|c|c|}
\hline 3AMP! & LE NO. & 11 & 12 & $\$ 3$ & 44 & Averave \\
\hline$\$ 1$ & $\begin{array}{l}\text { Outeide } \\
\text { Inside }\end{array}$ & $\begin{array}{l}0.09 \\
0.09\end{array}$ & $\begin{array}{l}0.09 \\
0.09\end{array}$ & $\begin{array}{l}0.09 \\
0.11\end{array}$ & $\begin{array}{l}0.09 \\
2.10\end{array}$ & $\begin{array}{l}0.09 \\
0.20\end{array}$ \\
\hline 12 & $\begin{array}{l}\text { Jutsida } \\
\text { Insida }\end{array}$ & $\begin{array}{l}0.03 \\
0.03\end{array}$ & $\begin{array}{l}0.04 \\
0.03\end{array}$ & $\begin{array}{l}0.05 \\
0.04\end{array}$ & $\begin{array}{l}0.04 \\
0.03\end{array}$ & $\begin{array}{l}0.04 \\
0.03\end{array}$ \\
\hline 13 & $\begin{array}{l}\text { Outside } \\
\text { Inside }\end{array}$ & $\begin{array}{l}0.05 \\
0.06\end{array}$ & $\begin{array}{l}0.05 \\
0.05\end{array}$ & $\begin{array}{l}0.05 \\
0.07\end{array}$ & $\begin{array}{l}0.06 \\
0.07\end{array}$ & $\begin{array}{l}0.05 \\
0.06\end{array}$ \\
\hline 44 & $\begin{array}{l}\text { Outside } \\
\text { Inside }\end{array}$ & $\begin{array}{l}0.04 \\
0.03\end{array}$ & $\begin{array}{l}0.03 \\
0.03\end{array}$ & $\begin{array}{l}0.03 \\
0.03\end{array}$ & $\begin{array}{l}0.03 \\
0.03\end{array}$ & $\begin{array}{l}0.03 \\
0.03\end{array}$ \\
\hline 15 & $\begin{array}{l}\text { Outside } \\
\text { Inside }\end{array}$ & $\begin{array}{l}0.06 \\
0.04\end{array}$ & $\begin{array}{l}0.08 \\
0.04\end{array}$ & $\begin{array}{l}0.07 \\
0.04\end{array}$ & $\begin{array}{l}0.07 \\
0.03\end{array}$ & $\begin{array}{l}0.07 \\
0.04\end{array}$ \\
\hline 16 & $\begin{array}{l}\text { Outside } \\
\text { Inside }\end{array}$ & $\begin{array}{l}0.06 \\
0.03\end{array}$ & $\begin{array}{l}0.05 \\
0.03\end{array}$ & $\begin{array}{l}0.04 \\
0.03\end{array}$ & 0.04 & $\begin{array}{l}0.05 \\
0.03\end{array}$ \\
\hline 47 & & 0.02 & 0.03 & 0.02 & 0.05 & 0.03 \\
\hline 18 & & 0.02 & 0.03 & 0.03 & 0.03 & 0.03 \\
\hline$\$ 9$ & & 0.75 & 0.68 & 0.69 & 0.69 & 2.70 \\
\hline 110 & & 0.02 & 0.03 & 0.03 & 0.03 & 0.03 \\
\hline 117 & & 0.02 & 0.02 & 0.03 & 0.03 & 0.025 \\
\hline$\$ 18$ & & 0.02 & 0.04 & 0.03 & 0.03 & 0.03 \\
\hline 419 & & 0.02 & 0.02 & 0.03 & 0.03 & 0.025 \\
\hline
\end{tabular}


EMITTANCE DATA ASSOCIATED WITH D. O, E. REFLECTIVE INSULATION PROJECT

Joe C. Cook and David W. Yarbrough
Department of Chemical Engineering
Tennessee Technological University

The Devices and Services Emissometer being used to obtain emittance measurements has been modified to give three significant digits of output instead of two. The calibration samples currently being used are the same as those used for the previously reported emittance.

\begin{tabular}{|c|c|c|c|c|c|c|c|}
\hline SPECIMEN & $\varepsilon_{1}$ & $\varepsilon_{2}$ & $\varepsilon_{3}$ & $\varepsilon_{4}$ & $\varepsilon_{b}$ & $\varepsilon$ & \\
\hline 1 inside & 0.129 & 0.120 & 0.118 & 0.114 & 0.112 & 0.119 & Repeat \\
\hline 1 outside & 0.080 & 0.106 & 0.092 & 0.114 & 0.095 & 0.097 & Repeat \\
\hline $\begin{array}{l}17 \text { inner } \\
\text { foit }\end{array}$ & 0.015 & 0.039 & 0.048 & 0.031 & 0.018 & 0.030 & \\
\hline inner paper & 0.842 & 0.837 & 0.844 & 0.858 & 0.919 & 0.860 & \\
\hline $\begin{array}{l}18 \text { inner } \\
\text { foil }\end{array}$ & 0.025 & 0.022 & 0.019 & 0.029 & 0.035 & 0.026 & \\
\hline inner paper & 0.846 & 0.835 & 0.866 & 0.893 & 0.855 & 0.859 & \\
\hline $\begin{array}{l}19 \text { inner } \\
\text { foil }\end{array}$ & 0.032 & 0.022 & 0.038 & 0.015 & 0.039 & 0.029 & \\
\hline inner paper & 0.833 & 0.861 & 0.844 & 0.826 & 0.812 & 0.835 & \\
\hline
\end{tabular}




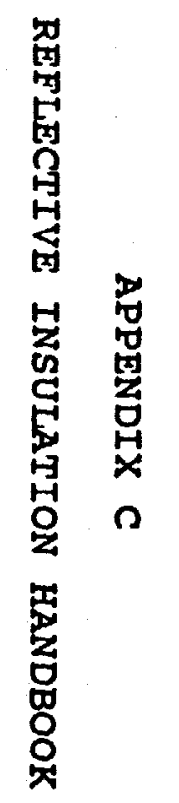





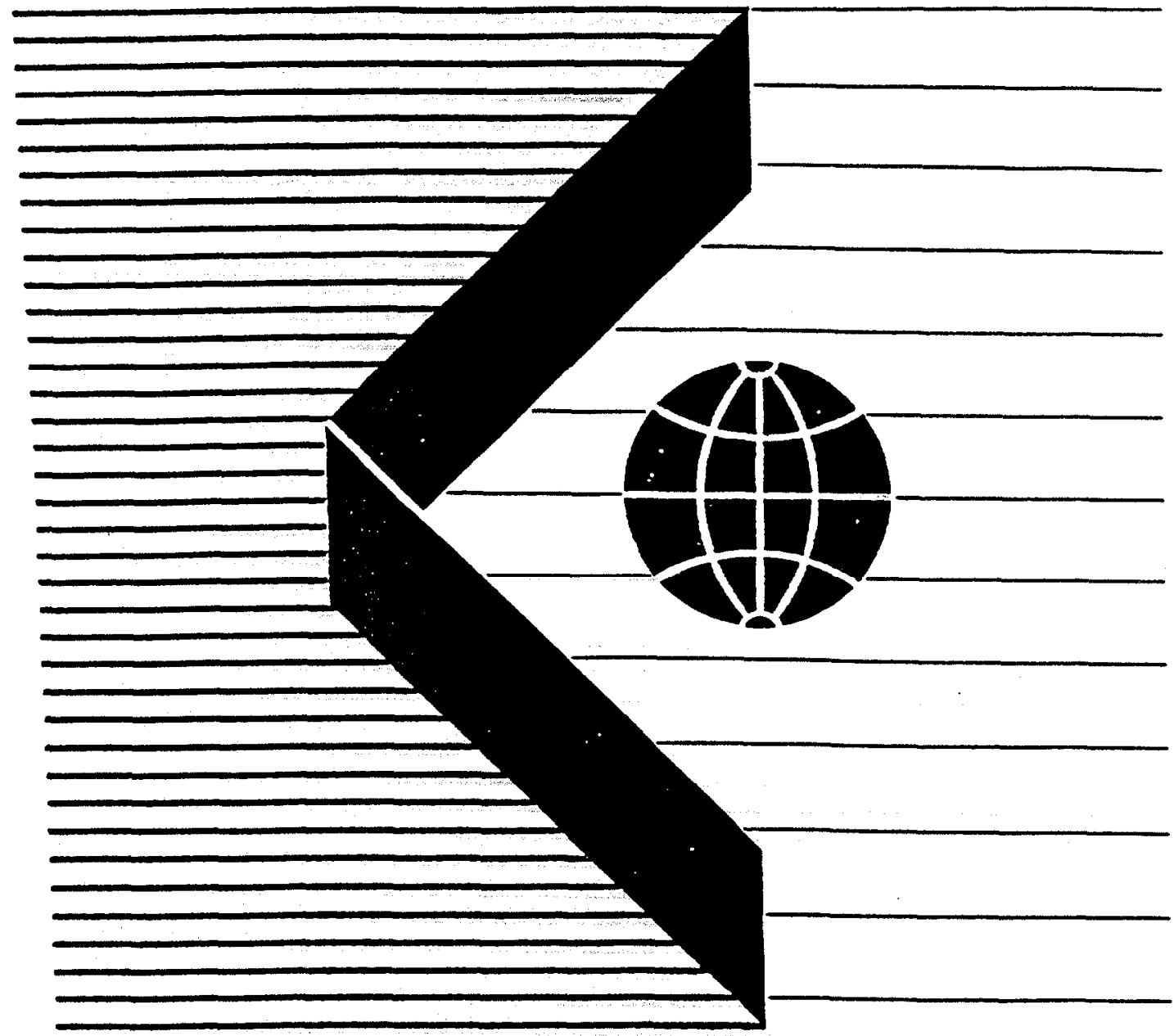


HANDBOOK ON REFLECTIVE INSULATIONS FOR RESIDENTIAL AND COMMERCIAL USES

\section{CONTENTS}

Section

Page

INTRODUCTION

HOW HEAT IS TRANSFERRED

THE FUNCTION OF AN INSULATION

WHAT IS REFLECTIVE INSUIATION?

TYPES OF REFLECTIVE INSULATION

WHERE REFLECTIVE INSUIATION CAN BE USED

INSTALIATION OF REFLECTIVE INSULATIONS

PRODUCT USES

THERMAL PERFORMANCE OF REFLECTIVE INSULATIONS

SUMMARY

USEFUL SOURCES OF INFORMATION

\section{IIST OF APPENDTCES}

Appendix

Page

A RADIATIVE HEAT TRANSFER

$A-1$

B INFORMATION SERVICES

B-1 


\section{LIST OF FIGURES}

Fiaure

Page

1 BASIC MODES OF HEAT TRANSMISSION

2

2 THE THREE MODES OF ENERGY TRANSFER

3

3 TYPICAL REFLECTIVE INSULATION USES IN A BUIIDING ENVELOPE.

4 SCHEMATIC OF REFLECTIVE INSULATION INSTALLED BETWEEN FRAMING MEMBERS

5 INSTALIATION OF MULTILAYER REFLECTIVE

9 INSULATION PLUS SINGLE LAYER CAP SYSTEM IAYER OR BUBBLEPACX)

7 TYPICAL ROOF OR FLOOR APPLICATION (MULTILAYER)

8 CONCRETE BLOCK WALC SYSTEMS, GARAGE AND 10 BASEMENT WALTS

9 TYPICAL BUBBLEPACK WALL APPLICATION 10

10 TYPICAL OBSTRUCTED WALL CAVITY ARPLICA- 11 TION

A1. REFLECTIVE MATERIALS PERFORM IRRESPECTIVE A-3 OF WHICH SIDE RECEIVES RADIATIVE HEAT

A2. APPROXIMATE PERCENTAGES OF HEAT TRANSMISSION A-4 MODES IN A BUIIDING CAVITY 


\section{IIST OF TABLES}

Table

Pages

1 MINIMUM THICKNESS OF ALUMINUM FOILS FOR REFLECTIVE INSULATION

2 MEASURED CAVITY R-VALUES OF BUILDING

15

ENVELOPE SYSTEMS CONTAINING LOW EMITTANCE AIRSPACES

A1. EMITTANCE AND REFLECTANCE VALUES FOR TYPICAL A-2 BUILDING MATERIAIS 


\section{INTRODUCTION}

Since 50\% to 70 \% of the energy used in the average home in the USA is for space heating and cooling, it makes sense to use thermal insulation to reduce the energy consumed, increase comfort and save money. Insulation effectiveness is measured in terms of thermal resistance, called R-value, which indicates resistance to heat flow: the higher the Rvalue, the greater the insulating power. Different types and forms of thermal insulation materials can be used. These are batts and blankets, loose-fills, rigid boards, sprayed on or blown in-place and reflective insulation.

This handbook focuses on reflective insulation as an effective way to achieve recommended $R$-values. It is intended to give the reader a general, knowledge of how reflective insulations work and a guide to installation. Detailed information concerning the mechanisms of radiant heat flow is contained in Appendix $A$ for the interest of those desiring a more in-depth understanding of the subject.

The U.S. Department of Energy "Insulation Fact sheet" (DOE/CE-0180, January 1988) provides recommended minimum Rvalues for attics, floors, and walls. These recommendations are based on an analysis of cost-effectiveness, using average local energy prices, insulating costs, equipment efficiencies, climate factors, and energy savings for both the heating and cooling seasons. Some energy codes now reguire higher levels to be used.

If you are buying or building a new home, you should ensure that recommended energy-saving features are included. The Federal Trade Commission (FTC) Home Insulation Rule, which went into effect in 1980 , requires that manufacturers of thermal insulation provide $R$-value and relevant information on a packaged product and on all fact sheets and advertising literature for the product. Furthermore, the seller of a new home must provide information on the type, thickness, and R-value of the insulation that will be installed in each part of the house in the sales contract. Insulation contractors are required to give their customers similar information. In many states and localities when older homes are sold, the seller has to provide information on the type and amount of thermal insulation in the home.

\section{HOW HEAT IS TRANSFERRED}

The performance of any thermal insulation system depends on how well it reduces heat flow. Heat moves from warm locations to cool locations in three ways: by conduction through solid or fluid material, by radiation from surface to surface through an air space, and by convection which involves the physical movement of the air. These are illustrated in Figures 1 and 2. Appendix $A$ discusses radiative heat transfer in detail. 


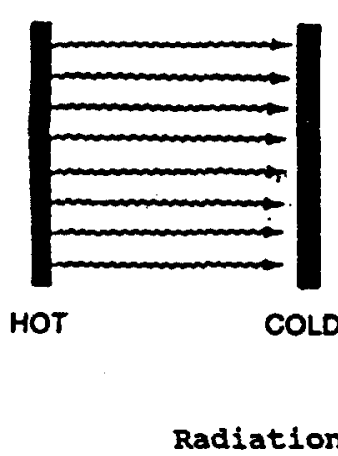

(a)

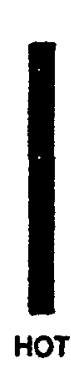

\section{FAST}

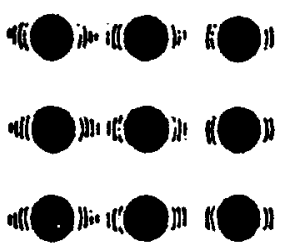

HOT
Conduction

(b)

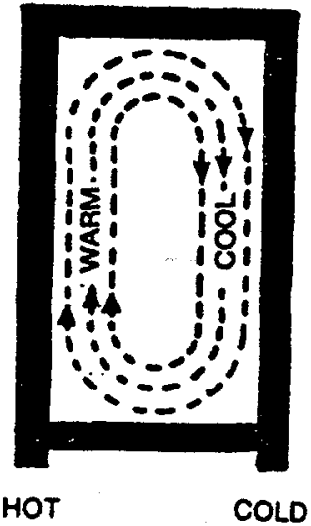

Convection

(c)

Fiqure 1. Basic Modes of Heat Transmission

(a.) RADIATION from heat source is transmitted through air or vacuum to a cold surface at 186,000 miles per second.

(b.) CONDUCrIoN through a solid material is caused by fast moving molecules on the hot side colliding with and transferring energy to slower moving molecules on the cold side.

(c.) CONvECTION occurs when fluid moves. Bouyant effects carry heat from hot to cold surfaces. Warm air rises and cold air falls to create a convective loop(s). 


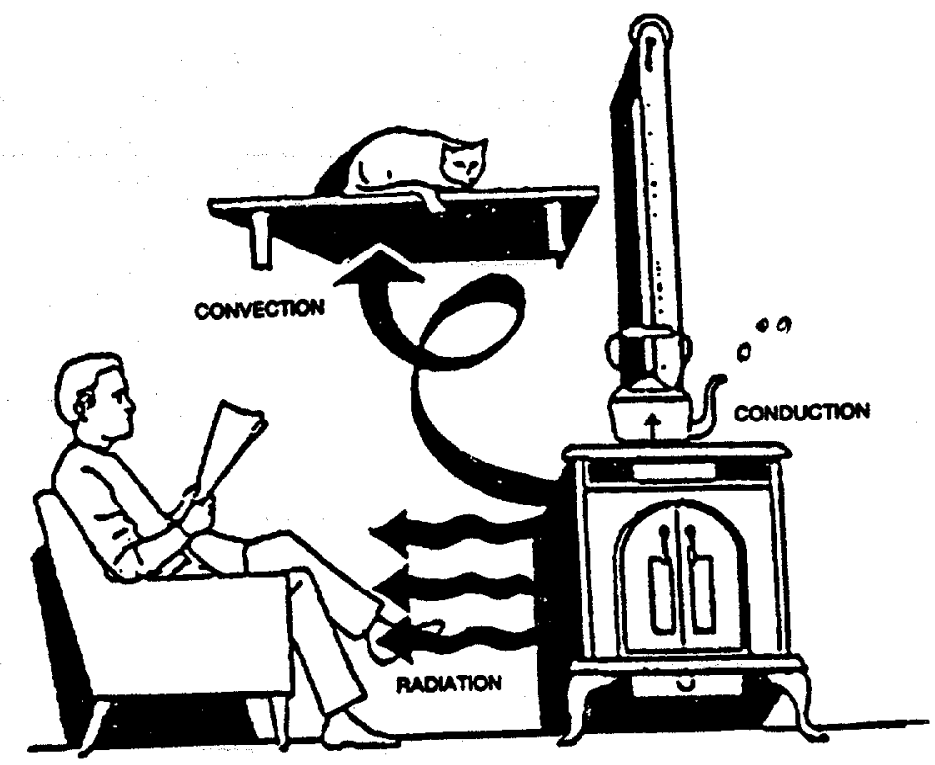

Flaure 2. The Three Modes of Fnergy Transfer

\section{THE FUNCTION OF AN INSUTATION}

When installed correctly, insulation reduces heat transfer through the envelope of a building. Whenever there is a temperature difference, heat flows naturally from a warmer to a cooler space. To maintain comfort in the winter, the heat lost must be replaced by your heating system. In the aummer the heat gained must be removed by your air conditioner.

Heat moves across empty wall cavities or between roofs and attic lloors by conduction, convection, and radiation. A reflective insulation reduces heat transfer by radiation to very low levels and in most products, reduces heat transfer by convection. Mass insulations reduce the convective part to a very low level, reduce the radiative transfer across the region occupied by the insulation and mimimize the increase in the conduction mode. Both types involve placing a solld material between the warm and cool regions to reduce heat flow across the insulated region.

The benefits of insulating all cavities within the building envelope are many, not only for the individual and national economic and energy conserving reasons but also for more liveable structures. Well insulated buildings, where effects of molsture condensation and air movement are minimized also require less maintenance and degrade more slowly. Various forms of thermal insulation exist, one of which is the reflective system. 
Different types of insulation products reduce these three types of heat transfer by varying amounts. Therefore, each provides different thermal performance and their Rvalues differ. The primary function of reflective insulation is to reduce radiative heat transfer across open spaces which is a major contributor to heat gain in the summer and heat loss in the winter. Reflective insulation greatly reduces heat flow by radiation in two ways. The low emittance metal (usually aluminum) foil surface(s) that forms part of the product, reflect a significant part (up to 95-97\%) of the incident radiation. Since these surfaces have a low emittance, they do not reradiate or emit heat well. A material with an emittance approaching a value of one radiates at the highest rate while a surface with an emittance close to zero radiates little energy. Aluminum surfaces generally have an emittance range of $0.03-0.05$ which means they radiate very little. The ideal product would be one with an emittance of zero and a reflectance near one (see Table $A l$ in the Appendix).

\section{WHAT IS REFLECTIVE INSULATION?}

Reflective insulation is a combination of aluminum foil and air spaces to provide reflective cavities with low values of radiant energy emission (emittance). These cavities may have faces of low emittance surface (foil), or encapsulated air spaces within the foil on both sides, such as a bubblepack product. Reflective insulation has been used in both residential and commercial applications for over forty years. These products provide an alternate or supplement to mass insulations such as mineral fiber, cellulose or foam in the building envelope.

Reflective insulation effectiveness depends on its ability to reduce the contributions of each of the modes of heat transfer. For example a typical multilayer reflective insulation divides a cavity into a set of smaller air spaces with paraliel high reflectance and low emittance surfaces. For a cavity, the cell dimensions are designed to minimize air movement and reduce convection. The low emittance of the facing surfaces minimizes direct radiative heat transfer across the cells. The effectiveness depends on cavity dimensions, the emissive properties of the facing layers, the direction of heat flow, e.g. horizontal or vertical, the temperature difference and to a lesser extent the mean temperature.

A reflective insulation system is different from most conventional mass insulation materials and products in that it:

(a.) is formed on-site as it is installed within the structure; and

(b.) is a combination of air spaces bounded by a highly reflecting surface within a cavity. 
TYPES OF REELECTIVE INSUTATION

There are several basic types:

(a.) aluminum foll;

(b.) aluminum foil-faced paper, paper product, or plastic film, with one or both exposed surfaces being reflective;

(c.) a composite of flat foil-faced paper layers which opens up in an accordion-like form with attachment flange(s) to provide multiple reflective air spaces: and

(d.) aluminum foil/polyethylene bubble pack combinations.

These are normally supplied as rolls with widths designed to fit over or between standard framing member spacings. some can also be cut to $f$ it into cavities of smaller widths. In addition, cellular plastic boards, may be supplied with reflective foils adhered to one or both surfaces and can be used in combination with an air space to augment system performance. Aluminum is preferred to other metals both for economic reasons and for its higher resistance to oxidation and other effects caused by the environment. The specified purity should be at least 998 and when used as a vapor retarder, the water vapor permeance should be one perm or less. Table 1 contains recommended minimum foll thicknesses for folls used in specific reflective insulation system applications.

Table 1. Minimum Thickness of Aluminum Foils for Reflective Insulation

Type

Minimum Thickness

millimeter Inch

Exposed and unsupported

0.010

0.009

0.0004

Unexposed and unsupported

0.006

0.00035

Bonded to substrate

0.006

0.00025

Building codes specify that reflective insulations like mass insulation have to satisfy necessary surface burning and other fire characteristics for their intended applications. They must also satisfy criteria for mold and mildew resistance, corrosion resistance, tear resistance, pliability, and adhesive performance. 


\section{WHERE REFIECTIVE INSUIATION CAN BE USED}

Since it is made for installation between or over framing members, reflective insulation is applicable to unfinished walls, in floors and ceilings in addition to many commercial and industrial applications. Figure 3 illustrates these applications.

The thermal performance of a reflective system can be varied by changing the number of enclosed reflective spaces within the cavity. Most current reflective systems range from a single reflective cavity to five cavities. These are shown schematically in Figure 4. Products with more than seven air spaces are available for higher thermal performance needs such as those in office bullaings and for cathedral ceilings.

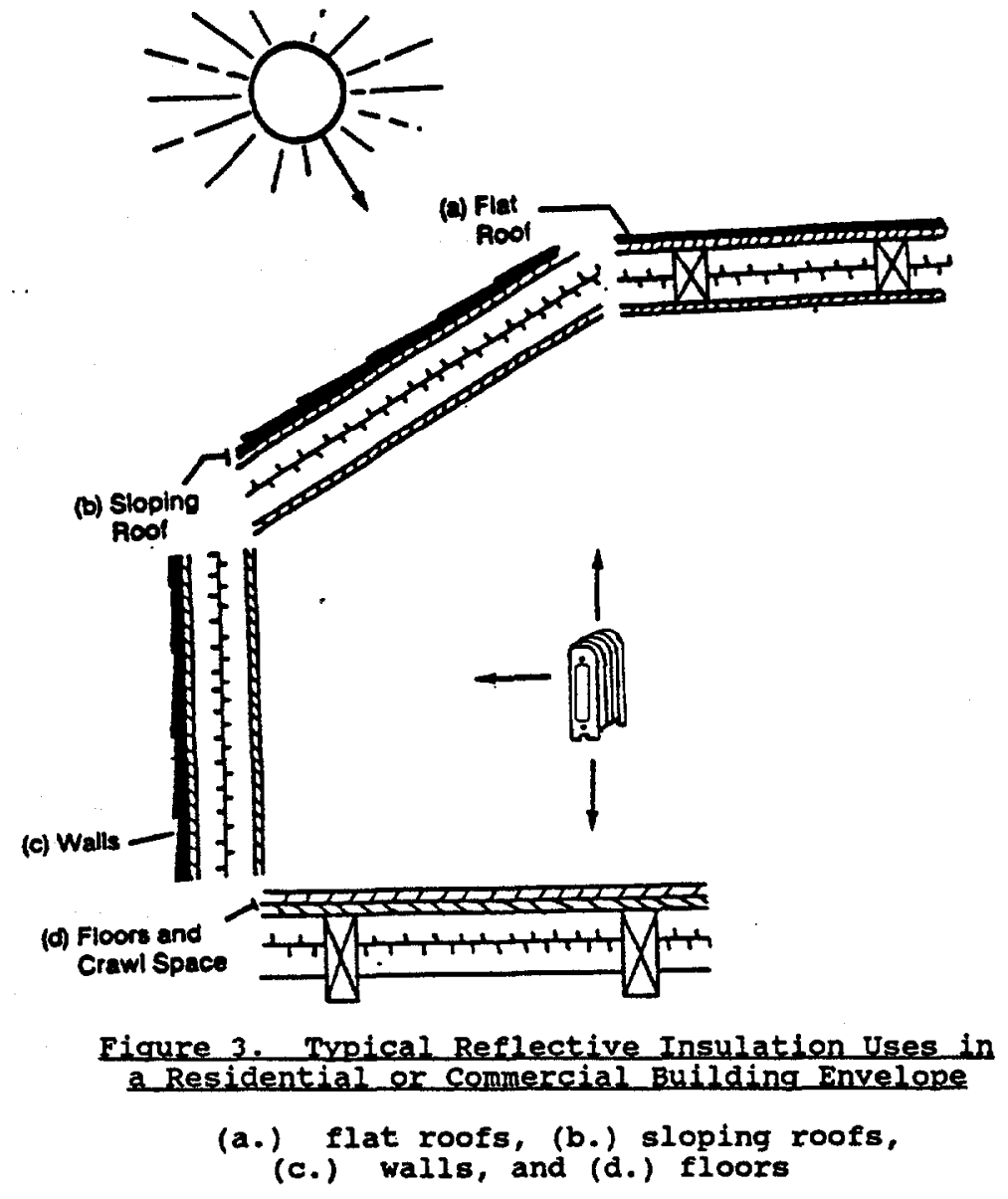




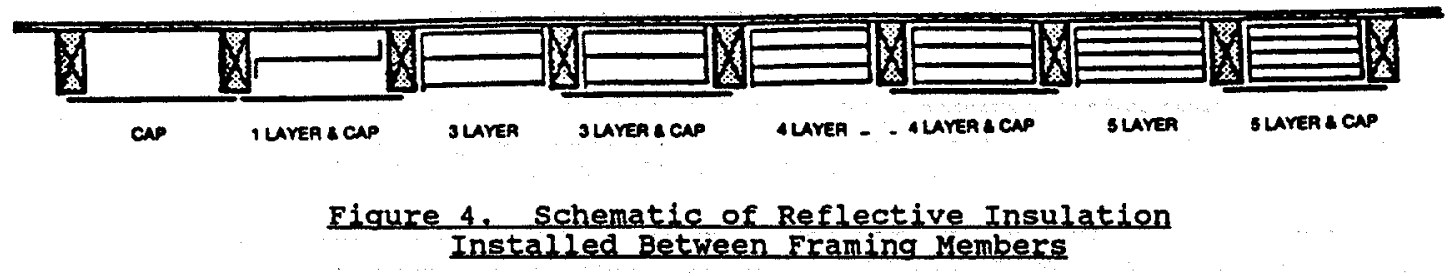

In general, the five and seven layer systems are used for cavities 5.5 inches or greater in depth. Since the thermal performance is dependent on orientation and direction of heat flow, a large variation in overall Rvalues can be obtained with the different combinations. (This is discussed in more detail in the section on thermal performance.)

There are other benelicial considerations for using reflective insulations. These relate to the fact that, in general, they consist of materials having very low water vapor and air permeances. When installed properly with joints taped, they act not only as a thermal barrier but can be both an efficlent vapor retarder and an effective barrier to air movement through the cavity. Since the reflective system can act as a vapor retarder, care must be taken to ensure that it is installed correctiy within the structure. correct installation depends upon the climatic conditions and moisture sources involved. Providing these factors are considered, and appropriate installation ensures that all joints and seams are butted against each other and taped or overlapped and taped, the possibility of moisture condensation within the cavity and resultant degradation in performance will be minimized.

\section{INSTALIATION OF REFIECTIVE INSULATIONS}

Reflective insulations are products incorporating trapped air spaces as part of their system. These air spaces, which may be layered or closed-cell, may result from the way the product is manufactured or the way it is installed. In either case, the advertised performance of the insulation requires that these air spaces be present after the product is installed. The labeled R-values will not be achieved if the product is not installed according to the instructions of the manufacturer. The basic tools required are a staple gun, coated staples, two inch minimum or wider aluminum reflective tape, scissors or utility knife, and a tape measure.

\section{(a.) General Guidelines}

As in any insulation installation, there should be a pre-installation inspection to ensure that specific hazards, including fire hazards, will not result from the following. 
- excessive heat bulld-up in recessed lights

- lack of adequate attic ventilation

- deterioration or failure of electrical wiring

- deterioration in structural components

- moisture accumulation

Since reflective insulations involve metallic surfaces, care must also be used to avoid direct contact with bare electrical wires or fittings. Where heat build-up is likely, appropriate blocking should be undertaken around all heat producing devices in accordance with Department of Housing and Urban Development Minimum Property Standards, local building codes, and National Fire prevention Assocation Guidelines.

\section{(b.) Specific Guidelines}

The area (cavity) to be insulated should be measured carefully and an appropriate length of insulation cut from the roll, allowing 2 to 3 inches extra for turning down or overlap where required. During installation, any overlapping areas, minor cuts and tears, should be sealed with aluminum reflective tape. A general rule for fastening reflective insulations is to staple at 4 inch - 8 inch on center, using a 5/16 inch $-9 / 16$ inch leg, 9/16 inch crown, corrosive resistant staple.

Figure 5 illustrates a typical installation procedure for a multilayer reflective insulation product including a cap layer. Figures 6-10 illustrate a number of typical installed applications for reflective insulations in the building envelope.

\section{PRODUCT USES}

The following are a number of applications where reflective insulations can be used.

\section{Residential Construction \\ (New and Retrofit)}

Walls, floors, basements, ceilings, roofs, and crawl spaces

\section{Manufactured Housing} (New and Retrofit)

Walls, floors, roofs, and crawl spaces
Commercial Construction (New and Retrofit)

Walls, floors, basements, ceilings, roofs, and crawl spaces

Qther Uses

water heater covers, cold storage units, poultry and livestock buildings, equipment sheds, pipe insulation and recreational vehicles 


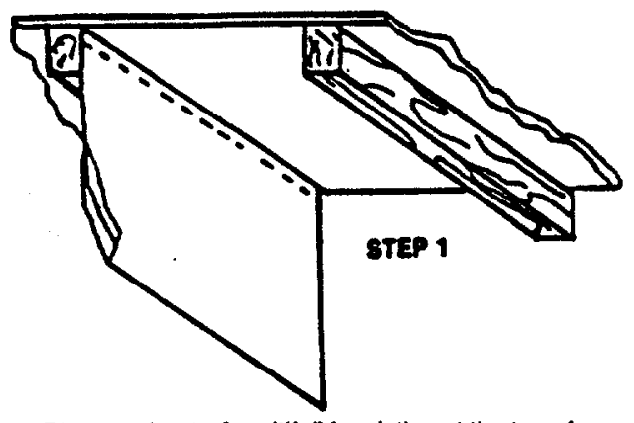

1. Place a sheet of mulliloll inaulation at the lop of the joists and up against the purtin. Make sure the sheet is butted againat the purtin.

2. Staple along the lop (about 3/4" down) acrose the length at intervals recommended.

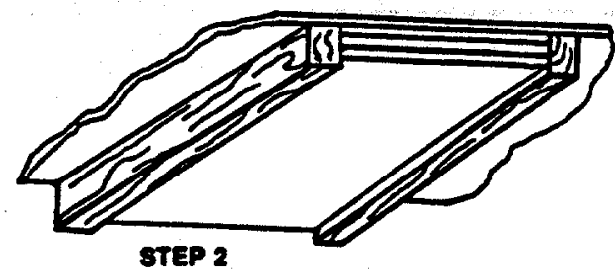

3. Lit and pull the material to the inside of opposile joist Be sure the material is laut and flush with the bottom of the joist so that layers ere unilorm. Alter "butting" the material againat the putin. staple across the bottom.

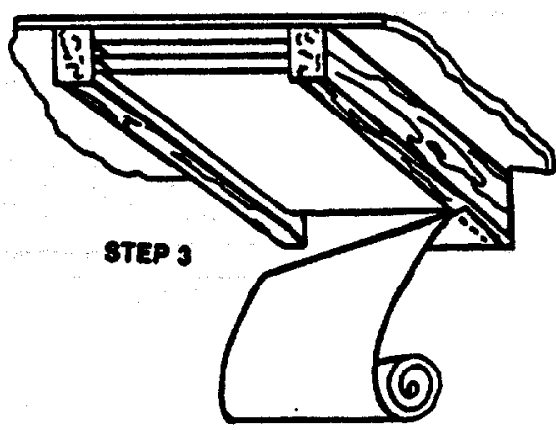

4. Place single foll sheet under the foltt as shown above. Be sure that $h$ is fush with the aide of the joist Allow about $11 / 2^{\prime \prime}$ to tum down on purlins and staple to the bottom of the joist three or lour times Cross to the diagonal opposite cormer.

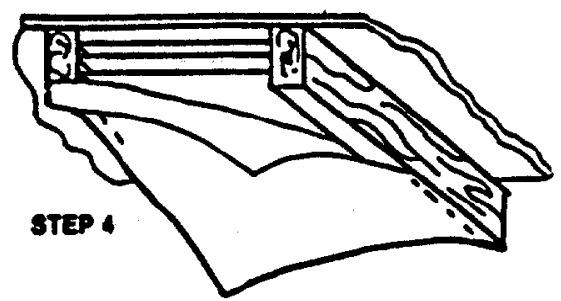

5. Extend the sheet and place it under the joist Be sure that the sheet is lush, along the side, with the joist Allow about hwo inches to turn down on purtin and pull taut and steple to the bottom of joist about three or four timea.

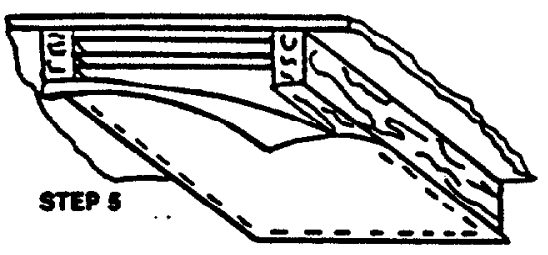

6. Extend the sheet and place it under the joist Pull but and staple three or four times. Place the folded edga againat the puttin and staple in placen

7. Croses to the diagond opposite corner.

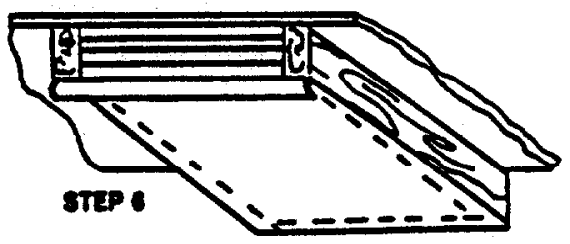

8. Extend the sheet and plece if under the foist Pull unt and atnole to the underside of the joists three or four timea. Place the folded edge againat the purtin end staple in place.

9. Saple dong edges a recommended distances lo secure correctly.

Figure 5

Installation of Multilayer Reflective Insulation Plus Single Layer Cap System Typically Used in

Panellized Commercial Roof Decks 


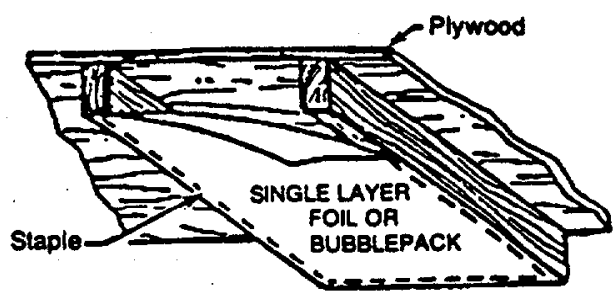

Figure 6

Typlcal Roof or Floor Application

(single Layer or Bubblepack)

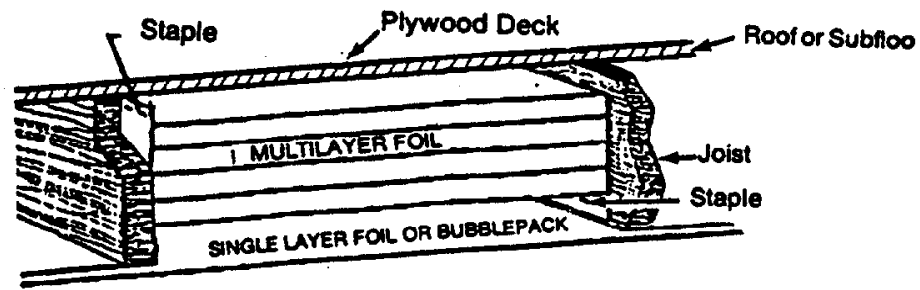

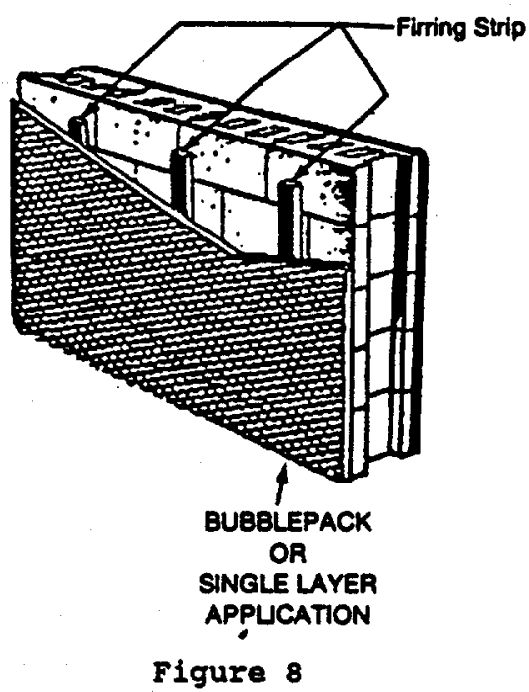

Concrete Block Wall System, Garage and Basement Walls
Figure 7

Typical Roof or Floor Application (Multilayer)

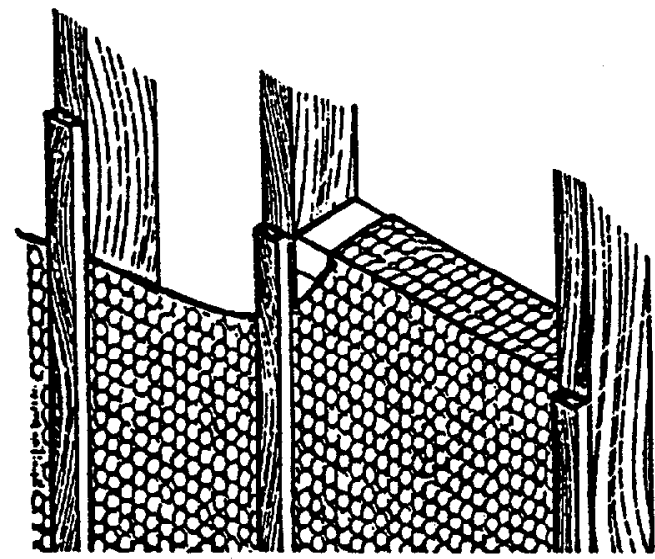

Trim out openings for doors and windows, leaving approximately three inches of overlap. When windowe and doors are set, the overlap will compact to provide en air-infiltration barrier.

Figure 9

Typical Bubblepack Wall Application 


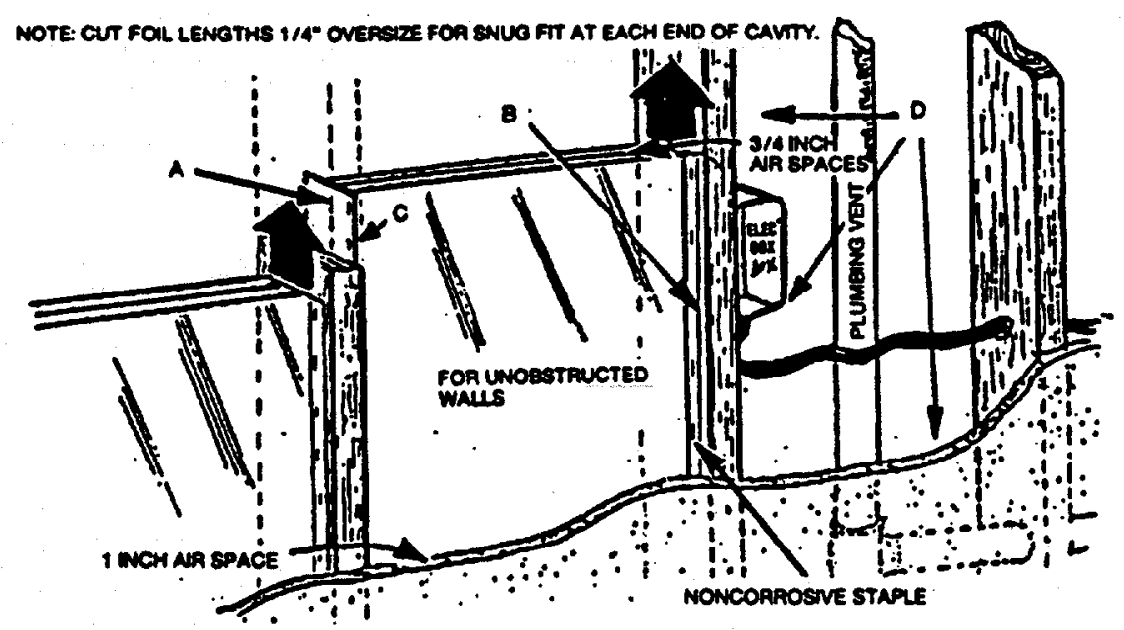

Figure 10. Tyolcal Obstructed wall Cayity Application

A. Start at and of bay, staple to other end.

B. Snap open foil and attach from center of bay to each end.

c. Staple from center of bay to each end.

D. Use mass insulation to $f 111$ narrow stud bays or bays obstructed with plumbing or electrical runs. Thls must be of equal or greater $R$-value as foil and must have vapor retarder. 
However you choose to use these products, it is very important to follow the manufacturer's suggested method of installation and safety advice. If you have any questions about using or installating these products, the manufacturers or their representatives should be contacted.

THERMAL PERFORYANCE OR REFIECTIVE INSULATIONS

To be effective for any orientation and heat flow direction, low emittance reflective materials must form a series of essentially parallel air spaces. Installation should ensure that all surfaces remain tautly stretched between their supports such that they do not touch each other. All reflective surfaces should be free of paint, grease, dust, and moisture, all of which reduce effectiveness by increasing the emittance. since aluminum reacts the alkalis and acids, the metal surfaces must not be allowed to come into contact with, for example, wet plaster unless protected by a coating. Finally, since the insulation system consists essentially of stili air spaces, circulation of air between cavities particularly at the ends of the reflective system installation, must be avoided. This is accomplished by taping with reflective foil or folding over the ends.

The thermal performance of any thermal insulation is described in terms of an $R$-value at $24^{\circ} \mathrm{C}\left(75^{\circ} \mathrm{F}\right)$; the higher the value the better its thermal insulation performance. The minimum R-values recommended for different building envelope applications in the USA are given in the Department of Energy "Insulation Fact sheet." Higher levels are written into the energy codes in particular areas, for example the Northwest Energy Code. These levels can be obtained with the various mass and reflective type products currently available.

To satisfy the requirements of the Federal Trade Commission Home Insulation Rule, manufacturers must include R-value information not only on the product itself but in all product literature. This makes it easier to compare the performance of the various insulation types. For reflective insulation products to be compared on the same basis as mass type insulation, it is necessary to obtain the $R$-value for the insulated region (cavity R-value).

As will be shown later in Table 2, the thermal performance of a reflective insulation depends on the application, orientation and the heat flow direction. When a reflective insulation $1 \mathrm{~s}$ installed, various factors including the number of reflective air spaces, the aspect ratio in the cavity (height to thickness), the emittance of all surfaces, the mean or average temperature, the temperature difference across the cavity, which in turn, affects that across each air space, and the thermal properties of the framing members all influence its thermal performance. Thus, the R-value of the reflective insulation 
product is determined usually from the results of tests undertaken on the installed system under conditions where the above parameters are representative of the application.

These system tests are carried out using either the standard $c-236$ guarded hot box or c-976 calibrated hot box test methods developed by the American society for Testing and Materials (ASTM). The contribution of the framing members and the inner and outer restraining materials (sheathings) is then determined using an accepted calculation method developed by American Soclety of Heating, Refrigerating and Air Conditioning Engineers (ASHRAE) using measured or handbook properties for the components of the system. The R-value of the reflective product alone is obtained by correcting the measured value for heat flow through framing members and subtracting the thermal resistance of any sheathing. Alternatively, the FTC rule allows the R-value of the reflective system alone to be derived using standard ASHRAE calculation procedures and measured emittance values for the different materials. The emittance values are measured using the ASTM E-408 method.

Experimental values of cavity thermal resistance of some reflective systems are shown in Table 2 . These were obtained as part of a research study initiated by the Department of Energy to investigate the quantitative effects of the major parameters discussed earlier. The study included validation measurements on some currently used systems for horizontal and vertical applications. The test systems consisted of 0.25 inch plywood sheathing on both sides of wood and cellular plastic studs. The cavity Rvalues are for a $30 \%$ temperature difference across the cavity.

These thermal performance values should be used for comparison and design purposes whenever the specific system and the particular application apply. However, since it is not feasible to generate experimental results for all systems and applications, the above values may also serve as one check on the validity of other measured or calculated values for the same systems. They may also be used in the first instance to check the reasonableness of measured or calculated values for other installed reflective systems.

\section{SUMMARY}

This booklet contains detailed information concerning reflective insulation systems used in bulldings for conserving energy. Subjects covered include the theory of operation, the types and forms of materials used, installation guidelines and instructions, thermal performance and factors influencing performance and results of tests on three systems. 

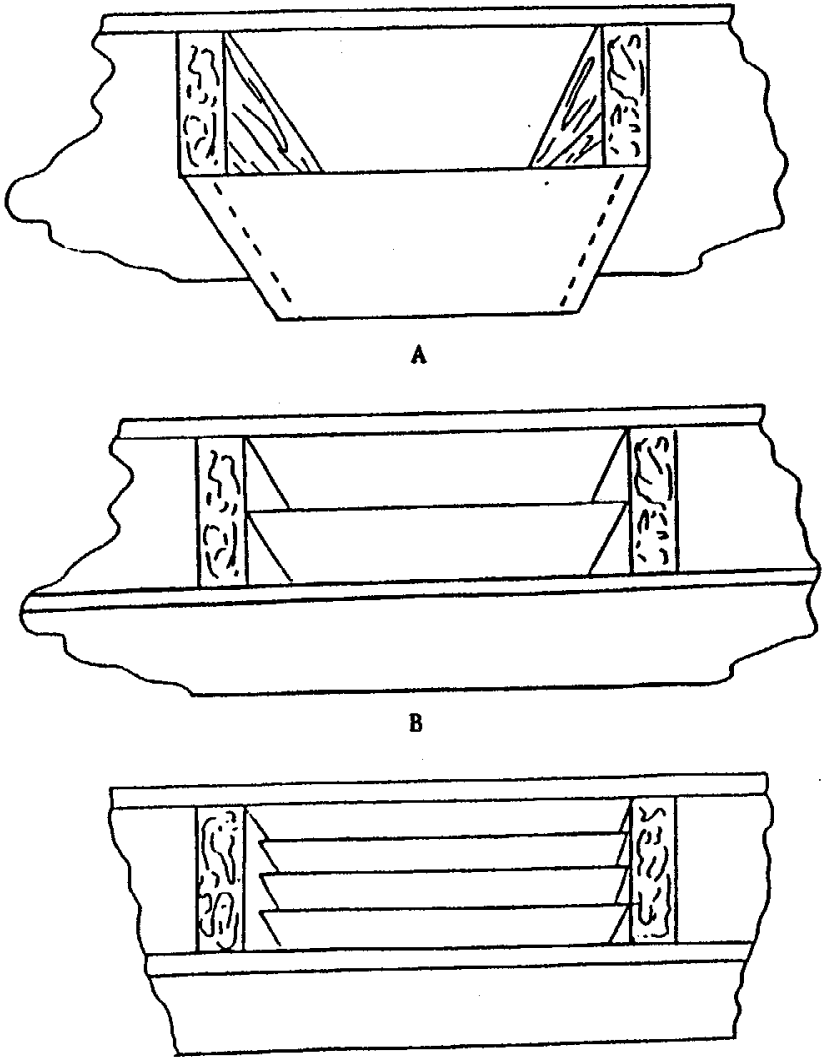

c
TABLE 2

MEASURED CAVITY R-VALUES OF BUILDING ENVELOPE SYSTEMS CONTAINING LOW EMITTANCE AIRSPACES

\begin{tabular}{|c|c|c|}
\hline & \multicolumn{2}{|c|}{$\begin{array}{l}\text { Cavity R-Value, } \\
\text { hr ft^2 F/Btu }\end{array}$} \\
\hline $\begin{array}{l}\text { Heat Flow } \\
\text { Direction }\end{array}$ & $\begin{array}{l}2 \times 4 \text { inch } \\
\text { Cavity }\end{array}$ & $\begin{array}{l}2 \times 6 \text { inch } \\
\text { Cavity }\end{array}$ \\
\hline $\begin{array}{c}\text { System A } \\
\text { UP } \\
\text { DOWN } \\
\text { HORIZONTAL }\end{array}$ & $\begin{array}{l}2.0 \\
7.9 \\
2.6\end{array}$ & $\begin{array}{c}1.9 \\
7.4 \\
\star\end{array}$ \\
\hline $\begin{array}{c}\text { System B } \\
\text { UP } \\
\text { DOWN } \\
\text { HORIZONTAL }\end{array}$ & $\begin{array}{c}\star \\
\star \\
4.7\end{array}$ & $\begin{array}{l}\star \\
* \\
*\end{array}$ \\
\hline $\begin{array}{c}\text { System C } \\
\text { UP } \\
\text { DOWN } \\
\text { HORIZONTAL }\end{array}$ & $\begin{array}{c}\star \\
\text { * } \\
6.0\end{array}$ & $\begin{array}{c}{ }^{\star} \\
\star\end{array}$ \\
\hline
\end{tabular}

Consult manufacturer's literature for data on systems designated with an $(*)$ and for other systems not included in this Table. 
(1.) ASTM Annual Book of standards, Volume 04.06, ASTM, Philadelphia, PA.

(2.) ASHRAE Handbook of Fundamentals, American Society of Heating, Refrigerating and Air-Conditioning Engineers, Inc., 1989, Chapter 23, ASHRAE, Atlanta, GA.

(3.) "California Insulation Quality Standards" state Energy Resources Conservation and Development Commission, State of California, sacramento, CA, Section $1553(\mathrm{~b} / 92)(1981)$.

(4.) Federal speciflcation HH-I-1252B, "Insulation, Thermal, Reflective (Aluminum Foli)" General services Administration, August 18, 1976. (Now withdrawn).

(5.) Iabeling and Advertising of Home Insulation, "Trade Regulation Rules, 16 CRF $460 ; 44$ Federal Reglster 50242 , August $27,1979$.

(6.) "The National Program Plan for the Thermal Performance of Building Envelope Systems and Materials," Ed. E. stamper, Building Thermal Envelope Thermal Coordinating Council, Washington, D.C. (1988).

(7.) Adams, L. " "Thermal Conductance of Air spaces," ASHRAE Journal 18, 37-38, (1976).

(8.) Bejan, A., "A Synthesis of Analytical Results for Natural Convection Heat Transfer Across Rectangular Enclosures," Int. J. Heat Mass Transfer 23, 723 , (1980).

(9.) Hollingsworth, M., Jr., "Experimental Determination of the Thermal Resistance' of Reflective Insulations," ASHRAE Trans. 1983,89 (pt. 1), Paper AC-82-12 No. 2.

(10.) Hollingsworth, M., Jr., "Thermal Testing of Reflective Insulations," Thermal Insulation: Materials and Systems, ASTM STP 922, F.J. Powell and S.I. Matthews, Eds., ASTM, Philadelphia, PA, 506-517, (1987).

(11.) Lund, C.E., "Heat Transfer Through Mineral wool Insulation in Combination with Reflective Surfaces," ASHRAE Journal 3, 47-54, (1961).

(12.) McAdams, พ.H., Heat Transmission, McGraw-Hill Book Company, Inc., New York, Third Edition, p. 63 (1954).

(13.) Poppendiek, J.R., Connelly, D.J and Fowler, E.W., "Some Remarks on Heat Transfer in Installed Foil Insulation Systems," ASHRAE Trans. 1983,89 (pt. 1) Paper AC-83-12 No. 1 . 
(14.) Robinson, H.E. and Powelitch, F.J., "The Thermal Insulating Value of Airspaces," Housing Research Paper 32, United States National Bureau of Standards Project ME12 sponsored by the Housing and Home Finance Agency, U.S. Government Printing office (1956).

(15.) Robinson, H.E., Cosgrove, L.A. and Powell, F.J., "Thermal Resistance of Airspaces and Fibrous Insulations Bounded by Reflective Surfaces," U.S. Department of Commerce NBS Building Materials and Structures Report 151, 19, 8-11, November 14, 1957.

(16.) Wilkes, G.B., Hechler, F.G. and Queer, E.R., "Thermal Test Coefficients of Aluminum Insulation for Buildings," Trans, Am. Soc, of Heating and Ventilating Engineers $46,109-121,(1940)$.

(17.) Yarbrough, D.W. and Sang G. Kim, "Thermal Resistance of Reflective Insulations Installed in a simulated wall Cavity," Thermal Performance of the Exterior Envelopes of Buildings II, Special publication 38 , ASHRAE, Atlanta, GA, 204-217, (1983).

(18.) Yarbrough, D.W., "Assessment of Reflective Insulations for Residential and Commercial Applications," ORNL/TM8891, October (1983). Oak Ridge National Laboratory, Oak Ridge, TN.

(19.) Desjarlais, A.O. and Tye R.P., "Research and Development Data to Define the Thermal Performance of Reflective Materials Used to Conserve Energy in Bullaing Applications," ORNL Report 1989.

(20.) Goss, W.P. and Miller, R.G. "Literature Review of Measurement and Predictions of Reflective Building Insulation System Performance; 1900-1989," ASHRAE Paper VA-89-08-4, 1989. 
Appendix A

Radiative Heat Transfer

Radiant energy (electromagnetic waves) is emitted by all bodies or surfaces that are at a temperature above absolute zero $\left(-273^{\circ} \mathrm{C}\right.$, or $\left.-459^{\circ} \mathrm{F}\right)$. This energy is then transmitted across space until it is received by another body or surface. Part of the radiant energy is absorbed and converted into heat, the rest is either reflected from or transmitted through the body. Any net energy transfer is always from the hotter to the colder body. The hot and cold bodies may be the sun and the earth $(93,000,000 \mathrm{miles}$ apart) or the two surfaces of a wall cavity (only a few inches apart). The radiative heat transfer rate is not affected appreciably by the distance between hot and cold surfaces.

Radiation is said to be generated by the process of emission. The conversion of radiation into heat is called absorption. Those waves not absorbed undergo reflection or transmission.

The emissivity (emittance) ( $(\epsilon)$ of a body is defined as the ratio of the radiant flux emitted by a body to the radiant heat flux emitted by a black body at the same temperature under the same conditions.

Emittance indicates the relative amount of radiation absorbed by a surface compared to a black body under identical conditions. A black body or surface absorbs all the radiation it receives. It does not reflect or transmit any, and is defined as having an emittance of unity. Thus, all other surfaces will have an emittance of less than one. For any given wavelength, the emittanoe of a body is equal to the absorptance of that body.

Table Al contains emittance and reflectance values for typical materials used in building construction. It is seen that polished metals such as aluminum and copper have much lower e-values than the other material surfaces.

\footnotetext{
*Emittance is the term applicable to surface properties of a material when it is used in the normal environment. Emissivity is applicable to a material when used in a vacuum, non-contaminating atmosphere.
} 


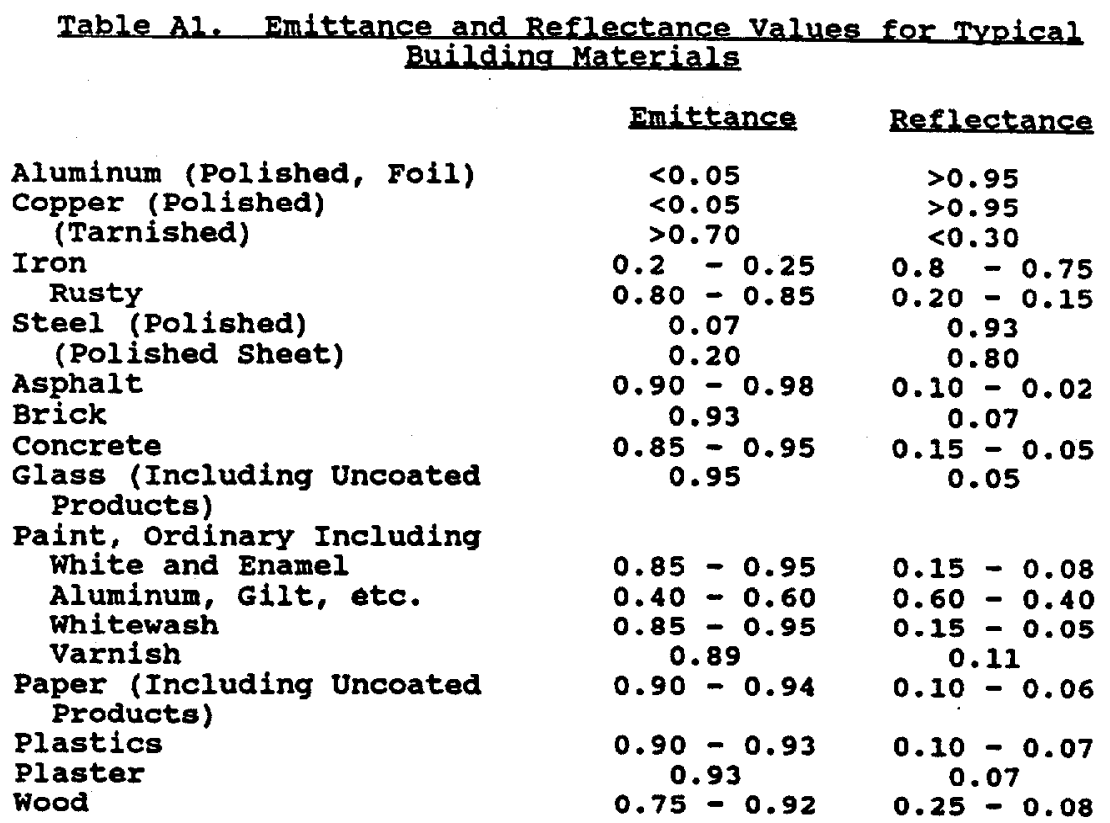

Since all radiative heat must be absorbed or reflected or transmitted the quantity absorbed plus that reflected and that transmitted must be equal to the amount received.

Absorptance, $\alpha$, is defined as the ratio of the radiant flux absorbed by a body to that incident upon the body.

Reflectance, $r$, is defined as the ratio of the reflected flux to that incident on the body.

Transmittance, $T$, is defined as the ratio of the transmitted radiant flux through the body to the incident radiant flux on the body.

$$
\begin{aligned}
& \alpha=\epsilon=1-r-T \\
& \alpha+r+T=1
\end{aligned}
$$

A material which is a good reflector is a poor emitter. For an air space, the rate of heat transfer by radiation is independent of whether the reflective surface is on the hot or cold side. If a reflective surface is mounted on a nonreflective material which first receives heat, its low emittance is as effective as its high reflectance would be if heat were recelved on its highly reflecting face. This is illustrated in Figure Al. 

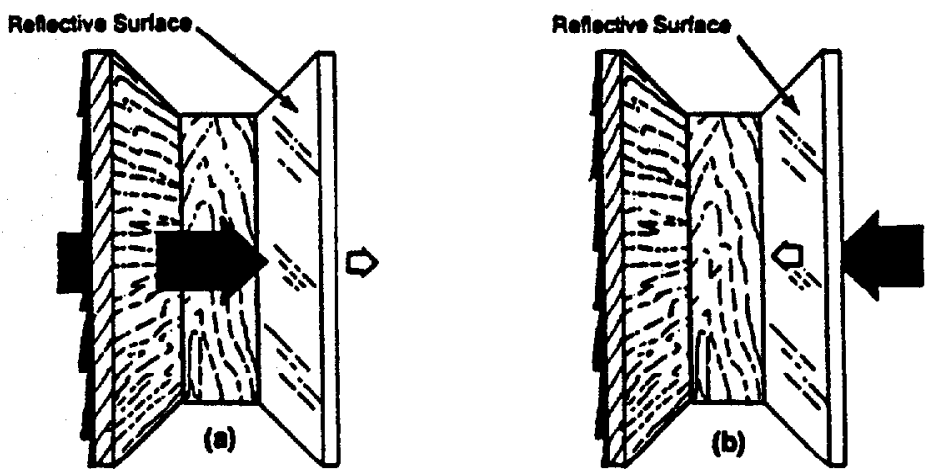

Figure Al, Reflective Yaterials Perform Irrespective of Which side Receives Radiat ive Heat

(a.) reflecting surface facing radiation source

(b.) emitting heat from other direction

All surfaces, regardless of their temperatures, radiate and receive heat by radiation. Heat transfer due to radiation is dependent upon the temperatures of the two bounding surfaces and their emittances. Only the net heat transfer between two surfaces is important. This heat transfer between two parallel surfaces of the same area is given by

$$
q_{r}=\operatorname{E\sigma A}\left(T_{1}^{4}-T_{2}^{4}\right)
$$

$g_{\mathbf{r}}$ is heat transferred by radiation

A is the surface area

$T_{1}$ and $T_{2}$ are absolute temperatures of radiating and receiving surfaces, respectively.

$\sigma$ is the stefan Boltzmann constant $\left(5.68 \times 10^{-8}\right.$

$\left.\mathrm{W} / \mathrm{m}^{2} \mathrm{~K}^{4}\right)$

$E$ is the effective emittance.

The E value is a combination of the individual emittances $\epsilon_{1}$ and $\epsilon_{2}$ of the two surfaces. Equation 3 is an example for large planar surfaces and the geometry of the system. 


$$
E=\frac{1}{\frac{1}{e_{1}}+\frac{1}{e_{2}}}-1
$$

These equations provide radiative heat transfer values for a reflective air space. The total heat flow is obtained by adding conduction and convection heat transfer to these values.

Using these equations and comparing results of
conduction and convection transfer, it is found that
radiative heat transfer is the dominant mode for typical
temperature conditions experienced by the building envelope.
For hot climates or typical sumer conditions, over 80 of of
the total heat transer across an empty cavity is by
radiation, whereas for cold climate and typical winter
conditions, this reduces to approximately $60 \%$. This is
illustrated in Figure B2.

Heat Flow

Down

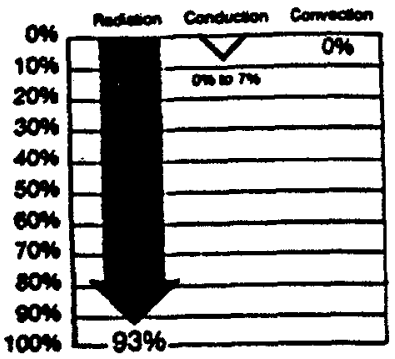

Heat Flow

Up

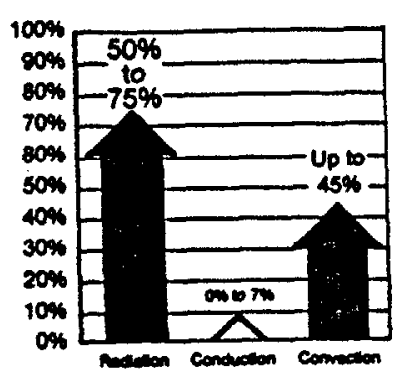

Heat Flow Horizontal

\section{Elqure B2, Approximate Percentages of Heat Transmission} Modes in an Empty Building Cavity

In all cases, the conduction contribution is somewhat less than $10 \%$ with convection and radiation providing the remainder. However, due to the effects of convection within the cavity, there is a directional effect. For the same temperature conditions, the total heat transfer for heat flow up is higher than that for the heat flow down and intermediate for the horizontal heat flow.

The thermal performance of a reflective thermal insulation depends upon reduction of radiant heat transfer across air spaces by using of one or more surfaces of high reflectance and low emittance. The highly reflective surface(s) are mounted within the cavity such that distinct air spaces are formed. Radiative heat transfer is thus 
within the cavity. A reflective insulation system can be used separately or in combination with one or more mass type materials. 
Appendix B

Information services

Additional and more detalled information concerning reflective thermal insulation in particular and energy conservation in bulidings in general is available from the following sources.

(A.) ORGANIZATIONS PRODUCING OR MARKETING REFLECTIVE INSUTATIONS

Alfol Inc., P.O. Box 7024, Charlotte, NC 28217.

(704) $-588-2170$.

Compac Corp., Old Flanders Road, Netcong, NJ 07857. $1-(800)-631-9347$.

Denny Sales Corporation, 3121 S.w. 15th Street, Pompano Beach, FL 33069. 1-(800)-327-6616.

Eagle Shield, 2006 North Highway, 360 Grand Praire, TX 75050. (214) $-641-9655$.

Energy Saver Imports Inc., P.O. Box 387, Broomfield, co 80020. (303) $-469-1787$.

Fi-Foil Co., Inc., P.O. Box 7046, Auburndale, FL 33823. (813) $-965-1846$.

Innovative Energy, Inc., 1119 West 145th Avenue, Crown Point, IN 46307. (219)-662-0737.

Lamotite, Inc., 2909 E. 79th Street, Cleveland, OH 44104. (216) $-883-8484$.

Lamtek Corp., P.0. Box 37, Flanders, NJ 07836. (201) $-584-3300$.

Parsec, Inc., P.O. Box 38534, Dallas, TX 75244. $(214)-681-1481$.

Princeton Packaging Inc., 1424 Proton Road, Dallas, TX 75244. (214)-387-0700.

Reflective Insulation Mnaufacturers Association (RIMA) 661 East Monterey, Pomona, CA 91767. (714)-620-8011.

Reflectix Inc., P.O. Box 208, Markleville, IN 46056. (317) $-533-4332$ 
R-Fax Technologies, Inc, 661 East Monterey, Pomona, CA 91767. (714) $-622-0662$.

Roy and sons, 1135 East woodlawn street, Ontario, CA 91761. $(714)-923-8558$.

Simplex Products Division, P.0. Box 10, Adrian, MI 49221. (517) $-263-8881$.

Superior Aluminum Insulation, Inc, 6441 Roland street, Buena Park, CA 90621. (714)-994-4641.

(B.) OTHFR RFFERENCE SOURCES

U.S. Department of Energy

office of Scientific and Technical Information

p.o. Box 62

Oak Ridge, IN 37830

National Appropriate Technology

Assistance Service

U.S. Department of Energy

P.O. Box 2525

Butte, MT 59702-2525

Telephone: 1-800-428-2525

1-800-428-1718 (In Montana only)

Conservation and Renewable Energy

Enquiry and Referral Service

P.O. Box 8900

Silver spring, MD 20907

Telephone: 1-800-523-2929 or 1-800-233-3071

Florida Solar Energy Center

300 State Road 401

Cape Canaveral, FI 32920-4099

National Association of Home Builders

15th \& M streets NW

Washington, DC 20005

Telephone: 202-822-0200

U.S. Department of Commerce

National Technical Information Service

5285 Port Royal Road

Springfield, VA 22161

Insulation Contractors Association of America

15819 Crabbs Branch Way

Rockville, MD 20855

Telephone: 301-926-3083 
National Institute of Building sciences

1015 Fifteenth $\mathrm{St}$. NW, suite 700

Washington, DC 20005

Telephone: 202-347-5710

\section{(C) PUBLICATIONS}

The following publications offer specific information on the costs, savings factors, and installation methods of energy-saving home improvements:

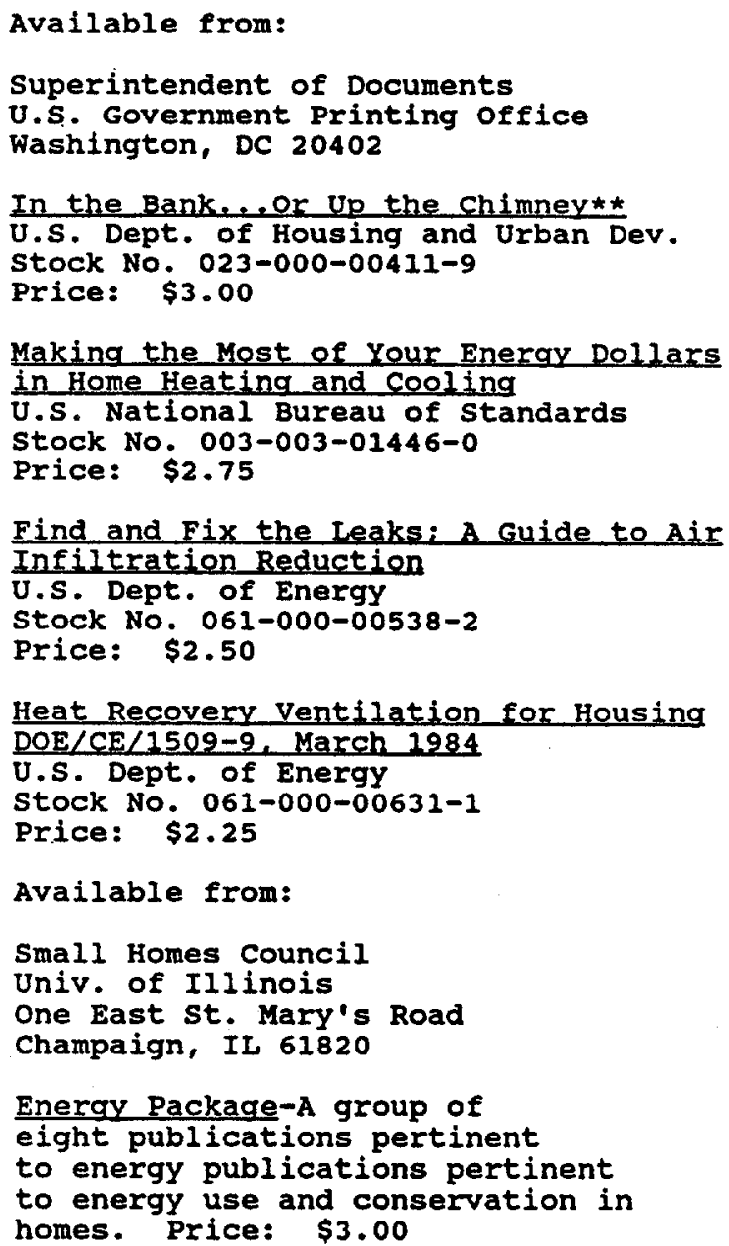

Making the Most of Your Energy Dollars

in Home Heating and cooling

U.S. National Bureau of Standards

Stock No. 003-003-01446-0

Price: $\$ 2.75$

Find and Fix the leaks: A guide to Air

Infiltration Reduction

U.S. Dept. of Energy

Stock No. 061-000-00538-2

Price: $\$ 2.50$

Heat Recovery Ventilation for Housing

DOE/CE $/ 1509-9$, March 1984

U.S. Dept. of Energy

Stock No. 061-000-00631-1

Price: $\$ 2.25$

Available from:

Small Homes Council

Univ. of Illinois

One East st. Mary's Road

Champaign, IL 61820

Energy Package-A group of eight publications pertinent

to energy publications pertinent

to energy use and conservation in

homes. Price: $\$ 3.00$ 
More for your Noney-Home Eneray

Sayings
Price: $\$ 2.50$
Available from:

Available from:

Mineral Insulation Manufacturer Association

1420 xing street, suite 410

Alexandria, VA 22314

How to Save Money by Insulating

your Home

Price: $\$ .50$

Insulation Manual: Homes

Apartments

Price: $\$ \mathbf{3} .00$

**This publication also available as a reprint titled "Insulate Your Home and save Fuel," from Dover Publications, Inc., 180 Varick st. : New York, NY 10014 Price: $\$ 2.75$ 



\begin{abstract}
APPENDIX D
ADVISORY PANEL AGENDAS, MEETING MINUTES, AND BALLOTING
\end{abstract}



MINUTES OF

FIRST REFLECTIVE INSULATION ADVISORY PANEL MEETING

KING EDWARD HOTEL

TORONTO, ONTARIO

11 OCTOBER 1987

MENBERS IN ATTENDANCE:

Mr. Monty Millspaugh
Dr. John Mumaw
Mr. Roy Akers
Dr. Gerry Miller
Mr. Joe Flores
Mr. Paul Juneau
Dr. David McElroy
Dr. Ken Wilkes
Dr. David Yarbrough
Mr. Andre Desjarlais

GUESTS IN ATTENDANCE:

Mr. Eric Carson

Mr. Floyd Eingland

Mr. James Hall

Mr. Bowen Hyma

Mr. Leit Isaksen

Mr. Foster Renwick
Reflectix, Inc.

owens-Corning Fiberglas

Roy and Sons, Ine.

Jim Walter Research Corporation Bonneville Power

Alfol, Inc.

Oak Rídge National Laboratory

Oak Ridge National Iaboratory

Tennessee Tech Oniversity

Dynatech scientific, Ine.

R-Fax Technologies, Inc. Consultant

TVA

Energy Saver Imports, Inc.

Aces, Inc.

Alfol, Ine 
1.1 The Advisory Panel met on Sunday, 11 October 1987 at 14:00. Ten members and six guests registered their attendance.

1.2 Dave Yarbrough reviewed the history of attempting to develop an ASTM standard specification for reflective insulations and what the Department of Energy and Oak Ridge National Iaboratory had done in an attempt to remove the roadblocks which were impeding progress on this issue. The purpose and reasons for funding the experimental effort were outlined.

1.3 Andre Desjarlais presented an overview of the experimental program, its goals, the specifics of the experimental plan, the schedule, and the underlying assumptions which were made prior to the generation of the test plan. A listing of the goals, assumptions, experimental plan, and schedule was given to the attendees, and a copy is attached to these minutes.

1.4 The floor was opened for discussion regarding the validity of the experimental plan vis-a-vis its goals. The following comments were recorded:

1. Philip Fairey pointed out that the proposed temperature levels for the experiments did not include levels that are typical for southern climates.

2. Mr. Fairey also remarked that the range of airspace aspect ratios did not extend up to 125 which is a typical value for reflective airspaces used in conjunction with masonry walls.

3. Mr. Akers and Mr. Juneau both commented on their concern about performing steady-state measurements when the real application of reflective insulations are under dynamic conditions. Is steady-state thermal performance data similar to dynamic thermal performance data?

4. John Humaw recommended that an experiment performed early during the prograw be repeated at the conclusion of the experimental phase to supply a comparison of data during the course of the program.

5. John Mumaw's second comment was that the selected test specimen configurations were limited to three layers (four airspaces) and did not include any examples of systems with a very large number of folls and airspaces. 
6. Gerry Miller suggested that the experimental plan be modified to include more vertical heat flow up experiments because the bulk of the vertical heat flow experiments in the original test plan were to be performed with heat flow down.

1.5 The possibility of an additional meeting was discussed. The necessity for this meeting is due to the fact that a significant amount of the experimental work would be completed prior to the next ASTM C16 meeting in April and several members expressed their desire to review the test data sooner. It was proposed that the Advisory panel meet In Boston in late January/ early February for this purpose.

1.6 The meeting was adfourned at 16:00. 
FIRST REFLECTIVE INSULATION ADVISORY PANEL MEETING 11 OCTOBER 1987

PROGRAM GOALS

THE PROGRAM IS DESIGNED TO SUPPLY INPUT TO AID IN ADDRESSING THE FOLLOWING ISSUES AND QUESTIONS.

1. QUANTIFICATION OF FACTORS AFFECTING THE THERMAL PERFORMANCE OF REFLECTIVE INSULATIONS.

DATA WILL BE GENERATED ON REFLECTIVE INSULATIONS AS A FUNCTION OF HEAT FIOW DIRECTION, ASPECT RATIO, CAVITY EMITTANCE, STUD THERMAI RESISTANCE, AIRSPACE TEMPERATURE, AND TEMPERATURE DIFEERENCE.

2. HOW SHOULD R-VALUES BE MEASURED IN THE LABORATORY.

COMPARISON OF DATA GENERATED ON THE EFFECTS OF THE PARAMETERS LISTED ABOVE WILL IDENTIFY THE SENSITIVITY OF R-VALUE TO VARIATIONS IN THESE PARAMETERS AND IS LIKELY TO DICTATE THE PARAMETRIC WINDOWS THAT SHOULD BE SPECIFIED IN THE LABORATORY TEST METHOD. INTEGRATION OF R-VALUE DATA OVER TYPICAL DIURNAL CYCIES WILL SUGGEST REPRESENTATIVE TEMPERATURE/ TEMPERATURE DIFFERENCE COMBINATIONS FOR THE LABORATORY EXPERIMENT.

3. VALIDATION OR REVISION OF PREDICTION METHODS FOR THERMAL PERFORMANCE.

ADDITIONAL THERMOMETRY APPLIED INSIDE THE TEST PANELS WILL ALIOW FOR THE EVALUATION OF ASSUMPTIONS THAT ARE MADE WHEN USING SIMPLE ANALYTICAL MODELS WHILE THE PRESENT PROGRAM WILZ CREATE THE REQUTRED DATA BASE FOR THE DEVELOPMENT OF A MORE SUITABLE (MULTI-DIMENSIONAL HEAT FLOW) MODEL.

4. RELATIONSHIP BETWEEN IABORATORY MEASUREMENTS AND THE THERMAL RESISTANCE OF THE MATERIAL USED IN BUIIDING APPLICATIONS.

THE DEVELOPMENT OF AN ACCURATE MODEL COUPLED WITH THE PARAMETRIC STUDY OF R-VALUE AS A FUNCTION OF TEMPERATURE AND TEMPERATURE DIFFERENCE WILL YIELD INFORMATION REGARDING FIELD PERFORMANCE. 
5. IDENTIFICATION OF A METHOD FOR EVALUATING FIELD PERFORMANCE AND SPECIFIC CIRCUMSTANCES WHEN MASS OR REFLECTIVE INSULATIONS ARE PREFERABLE.

KEY INFLUENCES ON THE THERMAL PERFORMANCE OF REFLECTIVE INSUIATIONS WILL BE QUANTIFIED AND KNOWLEDGE OF THE MAGNITUDE OF THESE INFLUENCES WILL AID IN THE DESIGN OF A TEST METHOD FOR DETERMINING FIELD PERFORMANCE AND SUGGEST WHEN ONE INSULATION TYPE MAY BE PREFERRED. 
FIRST REFLECTIVE INSULATION ADVISORY PANEL MEETING 11 OCTOBER 1987

BASIC TENETS OR BOLD ASSUMPTIONS

1. REFLECTIVE INSULATIONS IACR GENERAL ACCEPTANCE BECAUSE ASSOCIATED THERYAL RESISTANCE VALUES ARE UNCERTAIN.

2. REFLECTIVE INSULATIONS AND THEIR ENVIRONS FORM AN INSULATION SYSTEM THAT MUST BE EVALUATED AS A SYSTEY.

3. CONSENSUS STANDARDS FOR THE DETERMINATION OF THERMAL PERFORMANCE DO NOT EXIST. AREAS OF DISAGREEMENT INCLUDE WHETHER "MATERIAL" OR "SYSTEM" THERMAL PERFORMANCE SHOULD BE REQUIRED, WHAT SYSTEM SHOULD BE TESTED, AND HOW TO SEPARATE "MATERIAL" PERFORMANCE FROM "SYSTEM" PERFORMANCE SO THAT DIRECT COMPARISONS CAN BE MADE WITH MASS INSULATIONS.

4. THE DEVELOPMENT OF AN ACCURATE MODEL IS ESSENTIAL.

A. ASSISTS IN ELIMINATING THE WIDESPREAD USE OF SIMPLE INACCURATE MODELS PRESENTLY IN USE.

B. REDUCES THE PROHIBITIVE TESTING COSTS INVOLVED IN PERFORMING A LARGE NUMBER OF LARGE SCALE TESTS BY BEING USED TO PREDICT THERMAL PERFORMANCE OF REFLECTIVE INSULATIONS INSTALTED IN OTHER SYSTEMS AND IN-SERVICE.

C. CAN BE USED TO SEPARATE "MATERIAL" PERFORMANCE FROM "SYSTEY" DATA.

5. THERE IS A LACK OF DETAILED EXPERIMENTAL DATA IN THE LITERATURE TO SUPPORT THE DEVELOPMENT OF AN ACCURATE MODEL AND WHAT DATA IS AVAILABLE IS SOMETIMES CONTRADICTORY.

6. ASTM HOT BOX TESTING CAN ADEQUATELY MEASURE THE STEADY-STATE THERMAL PERFORYANCE OF BUIIDING SYSTEMS.

7. THERMAL PERFORMANCE OF REFLECTIVE INSULATIONS IS A FUNCTION OF HEAT FLOW DIRECTION, GEOMETRY, CAVITY EMITTANCE, TEMPERATURE DIFFERENCE, MULTI-DIMENSIONAL EFFECTS, AND SURFACE TEMPERATURE GRADIENTS. 
FIRST REFLECTIVE INSULATION ADVISORY PANEL MEETING

11 OCTOBER 1987

SUMALARY OF TASKS

1. FABRICATE TEST PANEIS CONSTRUCTED WITH MATERIALS THAT HAVE BEEN ANALYSED FOR THERMAI RESISTANCE (C518, F433) AND EMITTANCE.

2. INSTALL INSTRUMENTATION IX TEST PANEIS TO MEASURE INTERNAL TEMPERATURE FIELDS.

3. PERFORM ASTM C236 TESTS ON PANELS IN ACCORDANCE TEST MATRIX OUTLINED IN TABIE 1 .

4. ANALYSE TEST DATA TO ADDRESS PROGRAM GOALS.

5. DRAFT A BOOKLET IN IAYMAN'S TERMS WHICH SUMMARIZES THE EXPERIMENTAL FINDIXGS TO IIIUSTRATE THE FACTORS WHICH CONTRIBUTE TO THE EFFECTIVE DESIGN AND PERFORHANCE OF REFLECTIVE INSULATION SYSTENS.

6. ISSUE FINAL REPORT. 
TAMLE 1

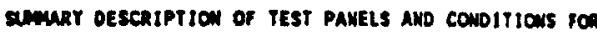
CuREED not LOX stur

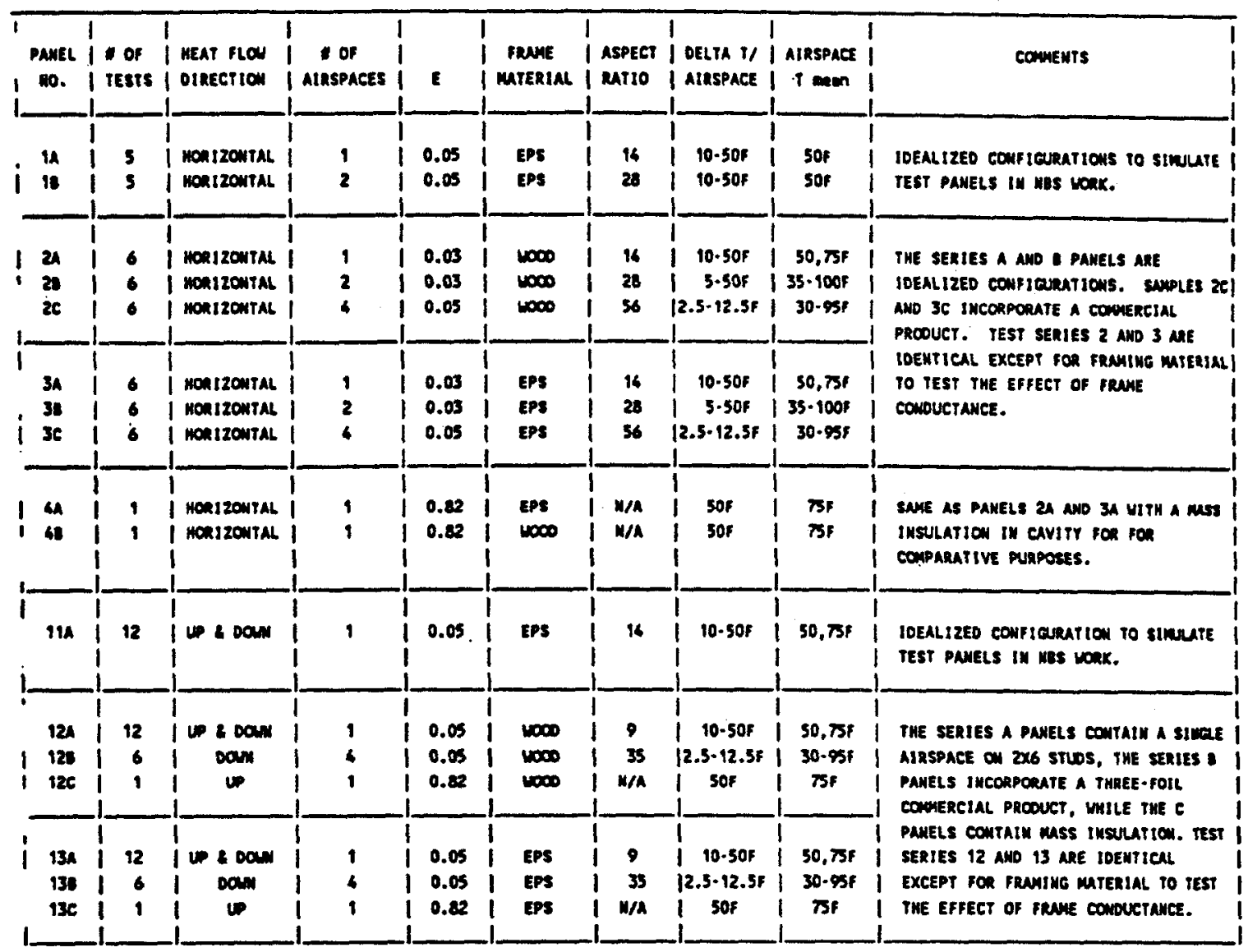

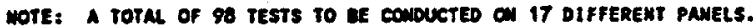


SECOND REFLECTIVE INSULATION ADVISORY PANEL MEETING

18 FEBRUARY 1988 9:30 - 15:00

DYNATECH SCIENTIFIC, INC

CAHBRIDGE, MA

1. REVIEW OF MINUTES FROM FIRST MEETING

2. RESPONSE TO ADVISORY PANEL COMNENTS

3. PRESENTATION OF EXPERIMENTAL DATA

4. DATA ANALYSIS PRESENTATION

5. LUNCH

6. TOUR OF LABORATORY FACILITIES 
SECOND REFLECTIVE INSULATION ADVISORY PANEL MEETING

DYNATECH SCIENTIFIC, INC.

CAMBRIDGE, MA.

18 FEBRUARY 1988

LEUBERS IN ATTENDANCE:

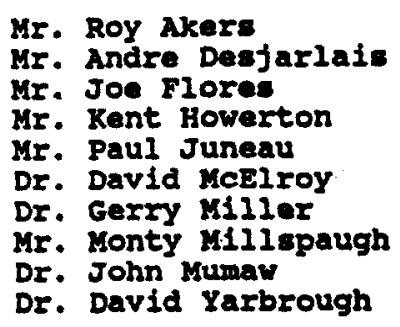

GUESTS IN ATTSNDANCE:

Mr. Bowen Hyma

Mr. Brian Robichaud

Dr. Stephen smith

Mr. Ron Tye

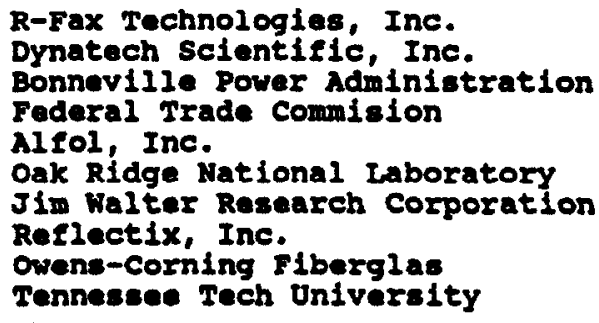

Energy Saver Imports, Ine. Dynatech scientific, Ine. Dynatech scientific, Ine. Dynatech scientific, Ine. 
2.1 The Advisory Panel met on Thursday, 18 February 1988 at 9:30. Ten members and four guests registered their attendance.

2.2 A. Desjarlais circulated a revised copy of the minutes of the first meeting for final review and comment. $P$. Juneau volced concern regarding the portion of the minutes that discusses reflective insulation as part of a system and the reguirement of systems testing and $R$. Akers wished to reserve judgement to a later time. G. Miller noted that the test matrix still contained errors. A Desjarlais will correct the errors in the test matrix and circulate a final copy of the minutes.

2.3 A. Desjarlais discussed the list of comments received from members of the Advisory panel regarding the validity of the test plan in addressing the goals of the subcontract. The specific topics that were brought up fall into two general categories: the completeness of the test plan and the applicability of steady-state experiments in predicting actual in-service performance. Additional comments were recorded:

1. G. Miller suggested an experiment on a 8 foot high airspace to test for height as well as aspect ratio.

2. I. Glicksman recommended an experiment where the emittance of the stud material was vagied to determine the radiative interaction between the stud and cavity.

3. J. Numaw recommended that an experiment be performed to determine the effect of fasteners on the thermal performance of the test panels since different fasteners were being used for the wood and XEPS stud systems.

2.4 It was proposed that a summary of all comments be circulated to the Advisory panel for comment and priorty ranking. An estimate of the effort that should be expended was also requested. A. Desjarlais will circulate this list by 7 March 1988 and requested that responses be forwarded by 1 April 2988 so that they can be tabulated and presented at the next Advisory Panel meeting.

2.5 It was reported that the NBS had proposed to ASHRAE to perform a study on reflective insulation systems which would include experiments that were complementary to work being performed under this subcontract. $R$. Akers volunteered to seek NBS approval to release this document to the members of the Advisory Panel for their review. 
2.6 D. Yarbrough reported that an experiment to measure the thermal performance of a reflective insulation system under a dynamic cycle is going to be performed by paul Shlpp of orwl using their climatic simulator. A guadrant of the 13 foot square test sample is comprised of $2 \times 8$ studs sixteen inches on center with a reflective foll on one side. Two adjolning central cavities are to be instrumented with heat flux transducers and temperature sensors. Steady-state and dynamic experiments are planned. The selection of the large airspace thickness is to extend the present data base to larger Rayleigh Numbers for the heat flow down configuration. It is also planned to insert a reflective foil at the midplane to more closely approximate the experiments being performed in this subcontract. R. Tye expressed concern regarding the potential for heat transfer between adjacent quadrants in the test sample.

2.7 A discussion regarding the meaning of "dynamic" thermal performance followed D. Yarbrough's presentation. It is generally agreed that there would be some effect due to the continuous change in the temperature difference across the reflective airspace but some members of the panel feel that the difference between steady-state and dynamic testing will be more significant than that.

2.8 A. Desjarlais presented thermal resistance data on the building materials used to construct the test panels and the mass insulations used in the mass-insulated test panels. J. Kumaw suggested that the mass insulation from the entire metering section be measured for density.

2.9 A test panel that will be used for the vertical heat flow experiments was described in detail. The test panel was open so that the panel members could view the internal instrumentation. Methods for attaching the sheathing to the wood studs (metal screws) and XEPS studs (nyion threaded rod) were discussed. Because of the difference in attachment techniques, J. Mumaw recommended that an additional experiment be considered to guantify the effect of fasteners.

2.10 Copies of the "data sheets" and thermal performance "summary sheets" were circulated to the members. The data sheet contains the average output of each individual sensor for the test in question. Because of the number of temperature censors involved in the testing, it was suggested that a sensor "map" be made available to the panel. The summary sheets contain the average air and surface temperatures for the test panel, cavity, and stud, the heat $f l u x$, the measured $R$-Value of the test panel, and the calculated R-value of the cavity using the 
experimental test panel data and the AShRAE Isothermal planes model or a parallel path model which utilizes the measured temperature differences and the $R$-value of the stud to determine the heat flux through the stud. For comparison, the R-Value of the cavity predicted by NBS HRP32 is oupplied.

2.11 A preliminary review of the test data suggested to several members of the panel that the correction for heat flux through the wood stud appeared to be too small and that posaibly the netal scrowe were responible.

2.12 R. Tye requested that the reflective insulation manufacturere forward any informantion they have regarding the application and Installation of reflectlve insulations for inclusion into the handbook. An outline of the handbook will be discussed at the next meeting.

2.13 The next meeting of the Advisory Panel has been scheduled for $14: 00$ on 17 April 1988 at Radisson Hotel Atlanta.

2.14 The guarded hot boxes were Inspected by the panel and a cursory tour of the laboratory was given.

2.15 The meeting adjourned at $14: 15$. 
REFIECTIVE INSUIATION ADVISORY PANEL

BALIOT

PRIORITIZATION OF IDENTIFIED AREAS OF ADDITIONAL WORK

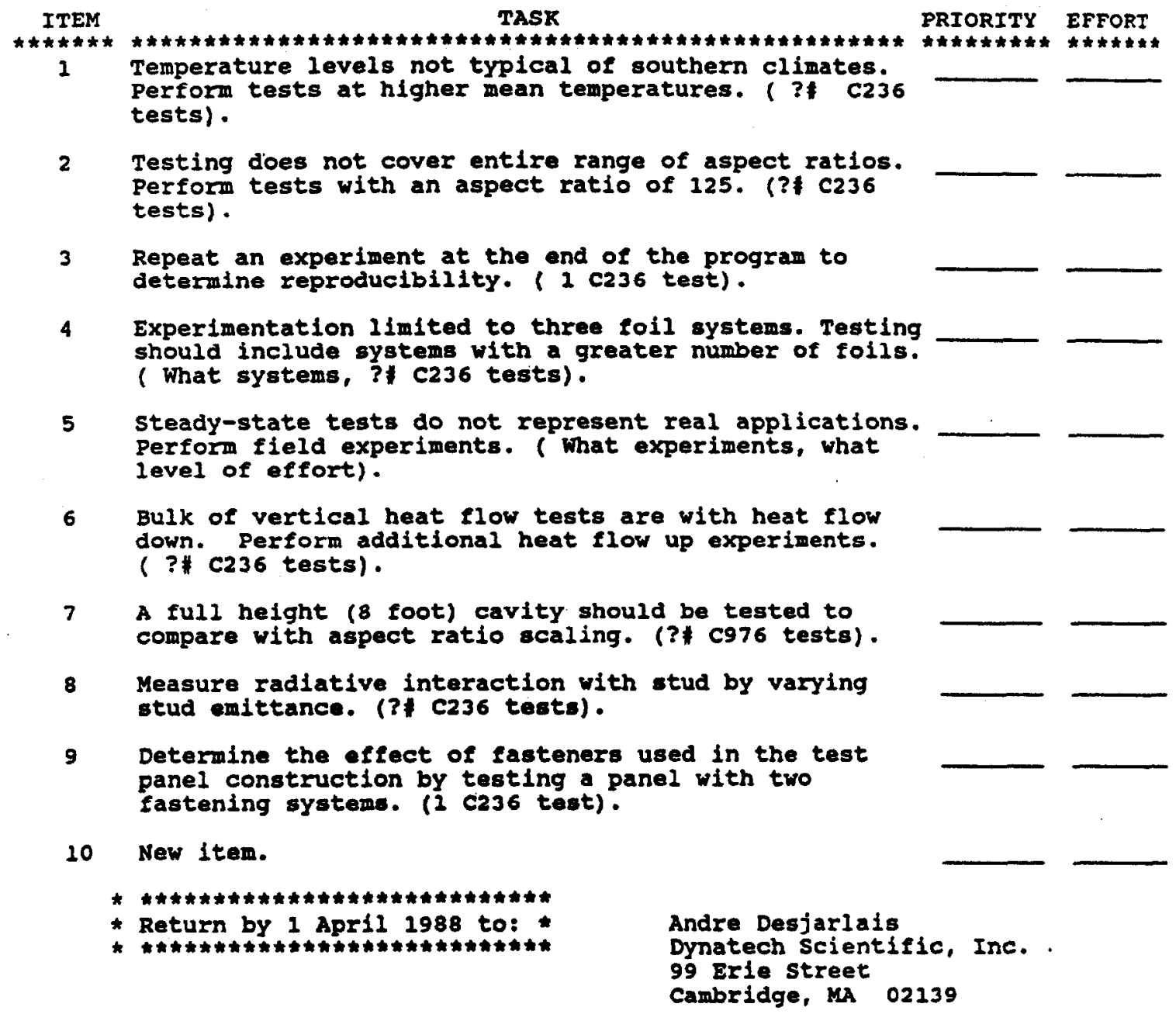


AGENOA

THIRD REFLECTIVE INSULATION ADVISORY PANEL MEETING

27 APRIL 1988 14:00-16:00

RADISSON HOTEL ATLANTA

ATLANTA, GA

1. REVIEW OF MINUTES FROM SECOND YEETING

2. DISCUSSION OF ADVISORY PANEL BALLOT

3. PRESENTATION OF EXPERIMENTAL DATA AND ANALYSIS

4. STATUS REPORT ON EANDBOOK 


\author{
MINUTES OF \\ THIRD REFLECTIVE INSULATION ADVISORY PANEL MEETING
}

\author{
RADISSON ATLANTA HOTEL \\ ATLANTA, GA \\ 17 APRIL 1988
}

MEMBERS IN ATTENDANCE:

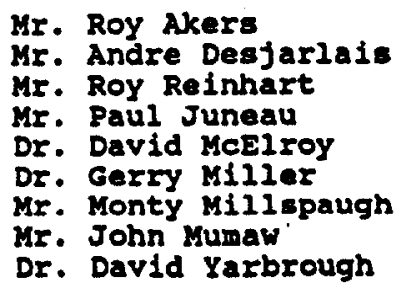

GUESTS IN ATTENDANCE:
R-Fax Technologies, Inc. Dynatech Scientific, Inc. Bonnevilie Power Administration Alfol, Ine.

Oak Ridge National Laboratory Jim Walter Research Corporation Reflect $1 x$, Inc.

Owens-Corning Fiberglas Tennessee Tech University

Oak RIdge National Labortory
Energy Saver Importe, Inc.
Energy Design Update
Manvilie Sales Corporation
Sparrell Engineering
U.S. Department of Energy
Dynatech Scientific. Inc.


3.1 The Advisory Panel met on Sunday, 17 Apr1] 1988 at 14:00. Nine members and seven guests registered their attendance.

3.2 A. Desjarlais circulated a copy of the minutes of the second meeting for Iinal review and comment. The minutes were accepted as presented.

3.3 A. Desjarlais circulated a copy of the ballot results for discussion. Seventy percent of the ballots had been returned. The results were tabulated by summing the rankings assigned to each ballot item (an item that was deemed most important was given a score of 1 , second most important a score of 2 , etc.). Two ballot items, the reproducibility experiment and the test to determine the impact of fasteners, were given the highest ranking (lowest score). It was decided to separate these items from the remainder of the ballot and recirculate the ballot for voting after relisting the items on the ballot in order of ranking.

3.4 Two new items were identified during the first balloting process: The effect of aging due to dust, moisture, and corrosion and the testing of a "bubblepack" type material. It was requested that responses be forwarded by 15 June 1988 so that they can be tabulated and reported to the Advisory Panel with the next mailing.

3.5 D. Yarbrough reported that the experiment to measure the thermal performance of a reflective insulation system under a dynamic cycle is presently underway at oRNL and that data may be available prior to the next Advisory Panel meeting.

3.6 A. Desjarlais reported that thermal resistance measurements on the wood studs with petal fasteners had been performed. The original samples that had been used to measure the thermal performance of the studs were modified such that there was an appropriate number of metal fasteners per unit area of stud. Testing was performed in accordance with ASTM C518. The thermal resistance of the $2 \times 4$ and $2 \times 6$ studs with metal fasteners were approximately 6 and 4 percent less than the studs without fasteners respectively.

3.7 Copies of the updated "data sheets" and thermal performance "summary sheets" were circulated to the members. It was noted that the previous version of the summary sheets had an error in the calculated R-value of the cavity by the ASHRAE isothermal planes model and that this had been corrected. This correction yielded much better agreement between the two calculation techniques being employed. The summary sheets contained new data on 
Test Panels $3 A$ (single vertical airspace with XEPS studs) 2C (4 vertical airspaces with wood studs), and $22 \mathrm{~A}$ (single horizontal airspace with wood studs).

3.8 Discussion centered around the test results on Panel 2C where the measured thermal resistance of the cavity of this panel was approximately 40 percent of the thermal resistance calculated from the NBS HRP32 report. R. Akers indicated that this was not suprising and that the application of reflective insulation in this configuration was rarely used for this reason.

3.9 R. Tye presented a cursory outline of the consumer-oriented handbook. It was agreed that a first draft of this handbook be forwarded to the members of the Advisory Panel by June 30 with comments due back by 15 August. A second draft will be sent two weeks prior to the ruscon meeting and will be discussed in detail at that meeting.

$3.10 \mathrm{R}$. Tye requested that the reflective insulation manufacturers forward any informantion they have regarding the application and installation of reflective insulations for inclusion into the handbook.

3.11 The next meeting of the Advisory Panel has been scheduled for $16: 00$ on 21 September 1988 at the ASTM meeting in Tuscon, NS.

3.12 The meeting adjourned at $16: 10$. 
REFLECTIVE INSULATION ADVISORY PANEL

BALLOT RESULTS

PRIORITIZATION OF IDENTIFIED AREAS OF ADDITIONAL WORK

\begin{tabular}{|c|c|c|c|c|}
\hline $\operatorname{ITEM}_{\star \star \star \star \star}$ & A & SC & ORE & \\
\hline 1 & $\begin{array}{l}\text { Temperature levels not typlcal of southern climates. } \\
\text { Perform tests at higher mean temperatures. }\end{array}$ & 50 & $(0)$ & $\begin{array}{l}\text { Two to four tests: } \mathrm{mm}=110 \mathrm{~F}, 3 \\
\text { different heat flow directions. }\end{array}$ \\
\hline 2 & $\begin{array}{l}\text { Testing does not cover entixe range of aspect ratios. } \\
\text { Perform tests with an aspect ratio of } 125 \text {. }\end{array}$ & 52 & $(0)$ & $\begin{array}{l}\text { Two to five tests: } A R=128: 256 \\
3 \text { different heat flow directions }\end{array}$ \\
\hline 3 & $\begin{array}{l}\text { Repeat an experiment at the end of the program to } \\
\text { determine reproducibility. }\end{array}$ & 22 & (2) & One test. \\
\hline 4 & $\begin{array}{l}\text { Experimentation limited to three coll systems. Testing } \\
\text { should include systems with a greater number of folls. }\end{array}$ & 38 & $(0)$ & $\begin{array}{l}\text { Three to six tests; "bubble pack" } \\
7-8 \text { layer. horizontal only. }\end{array}$ \\
\hline 5 & $\begin{array}{l}\text { steady-state tests do not represent real applications. } \\
\text { Perform field experiments. }\end{array}$ & 53 & (2) & $\begin{array}{l}\text { Big task, Independent from } \\
\text { present work, need comparison. }\end{array}$ \\
\hline 6 & $\begin{array}{l}\text { Bulk of vertical heat flow tests are with heat flow } \\
\text { down. Perform additional heat flow up experiments. }\end{array}$ & 39 & (1) & $\begin{array}{l}\text { Three to elght tests; modify } \\
\text { existing matrix or add on to } \\
\text { existing panels. }\end{array}$ \\
\hline 7 & $\begin{array}{l}\text { A full helght ( } 8 \text { foot) cavity ghould be tested to } \\
\text { compare with aspect ratio scaling. }\end{array}$ & 42 & $(0)$ & $\begin{array}{l}\text { Three to twenty tests; higher Af } \\
\text { different heat flow directions, } \\
\text { tests performed at NBS. }\end{array}$ \\
\hline 8 & $\begin{array}{l}\text { Measure radiative interaction with stud by varying } \\
\text { stud emittance. }\end{array}$ & 40 & $(0)$ & $\begin{array}{l}\text { One to four tests, different } \\
e \text {, cavity thickness. }\end{array}$ \\
\hline & $\begin{array}{l}\text { termine the effect of fasteners used in the te } \\
\text { inel construction. }\end{array}$ & 22 & (3) & ne $c 236$, one $\operatorname{c518} t$ \\
\hline
\end{tabular}

10 New items: Perform aging tests (dust, corrosion, molsture): test "bubblepack product". 
REFLECTIVE INSULATION ADVISORY PANEL

BALIOT \# 2

PRIORITIZATION OF IDENTIFIED AREAS OF ADDITIONAL WORK

ITEM

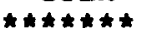

1 Experimentation limited to three foil systems. Testing
should include systems with a greater number of foils. (What systems, ?\# C236 tests).

2 Bulk of vertical heat flow tests are with heat flow down. Perform additional heat flow up experiments. ( ?\# C236 tests).

3 Measure radiative interaction with stud by varying stud emittance. (?\# C236 tests).

4

A full height ( 8 foot) cavity should be tested to compare with aspect ratio scaling. (? c976 tests).

5 Temperature levels not typical of southern climates. Perform tests at higher mean temperatures. ( ? 0236 tests).

6 Testing does not cover entire range of aspect ratios. Perform tests with an aspect ratio of 125. (? C236 tests).

7 Steady-state tests do not represent real applications. Perform dynamic experiments. ( What experiments, what level of effort).

8 Perform aging tests to determine effect of dust, corrosion, and moisture. (What experiments and level of effort).

9 Perform testing on "bubblepack" type products. (What experiments and level of effort).

10 Determine effect of foil spacing hardware by performing tests on a 4 airspace idealized system. (What tests and how many).

11 New Item.

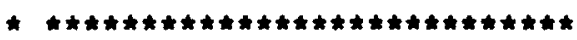

* Return by 15 June 1988 to: *

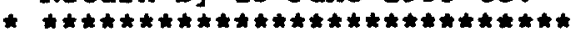

Andre Desjarlais Dynatech Scientific, Inc. 99 Erie street Cambridge, MA 02139 
REFLECTIVE INSULATION ADVISORY PANEL

TOP PRIORITY ITEMS FROM BALLOT \$ 1

1 Repeat an experiment at the end of the program to determine reproducibility. ( 2 c236 test).

2 Determine the effect of fasteners used in the test panel construction by testing a panel with two fastening systems. ( 1 C236 test 1 C518 test). 


\section{Fourth Meeting}

REFLECTIVE INSULATION ADVISORY PANEL

21 September 1988 16:00-18:00

Alamo Room

Sheraton Conquistidor Resort hotel

Tucson, AZ

\section{AGENDA}

1. REVIEW OF MINUTES OF ATLANTA MEETING

2. RESULTS OF ADVISORY PANEL BALIOT \$2

3. UPDATE ON EXPERIMENTAL DATA

4. DISCUSSION OF CONTENT AND FORMAT OF HANDBOOK
a. Cover, cover description, and Table of Contents
b. Introduction
c. Function of an insulation
d. Types of available reflective insulations
e. Uses of reflective insulations
f. Installation of reflective insulation
g. Factors affecting performance
h. Thermal performance
1. Summary and conclusions
j. Bibliography
k. Appendices 
PRIORITIZATION OF IDENTIFIED AREAS OF ADDITIONAL WORK

ITEM

1

1

2

3 Measure radiative interaction with stud by varying stud emittance.

4 A full height (8 foot) cavity should be tested to compare with aspect ratio scaling.

5 Temperature levels not typlcal of southern climates. Perform tests at higher mean temperatures.

6 Testing does not cover entire range of aspect ratios. Perform tests with an aspect ratio of 125 .

7 steady-atate tests do not represent real applications. Perform dynamic experiments.

8 Perform aging tests to determine the effect of dust, corrosion, and molsture.

9 Perform testing on "bubblepack" type products.

10 Determine effect on foll spacing hardware by performing tests on an idealized 4-airspace system.

11 Test with $3 / 4^{\prime \prime}$ plywood in an effort to compare to existing test data.
SCORE EFFORT

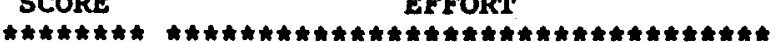

46 (0) Test max number of folls.

41 (3) Three to aight testes modify existing matrix or add on to.

55 (2) One to four tests, 2 or $3 e^{\prime} s$, 3 cavity thicknesses.

59 (0) ARs from 64 to 256, cavities frot 4 to 8 feet.

60 (0) 6 tests; $T m=40,110 \mathrm{~F}$, in 3 different heat fiow directions.

56 (0) Same comments as $\$ 4$.

51 (3) Home in midirest tested as a representative site.

63 (0) 4 tests to major task. RBS testing may be useful.

53 (0) Small of tests on a previously characterized single foll systen.

44 (2) 3 to 6 tests on oystem tested with conventional product.

3 ballots small of tests. 


\section{INTERNAL DISTRIBUTION}

$\begin{aligned} \text { 1. } & \text { R. A. Bradley } \\ \text { 2-6. } & \text { G. L. Burn } \\ \text { 7. } & \text { R. S. Carlsmith } \\ \text { 8. } & \text { K. W. Childs } \\ \text { 9. } & \text { J. E. Christian } \\ \text { 10. } & \text { G. E. Courville } \\ \text { 11. } & \text { P. S. Gillis } \\ \text { 12. } & \text { R. S. Graves } \\ \text { 13. } & \text { M. A. Kuliasha } \\ \text { 14. } & \text { J. M. MacDonald } \\ \text { 15. } & \text { D. L. MCElroy }\end{aligned}$

\author{
16. W. R. Mixon \\ 17-31. S. D. Samples \\ 32. R. B. Shelton \\ 33. R. I. Wendt \\ 34. K. E. Wilkes \\ 35-37. Laboratory Records \\ 38. Laboratory Records (RC) \\ 39. ORNL Patent office \\ 40. Y-12 Technical Library \\ 41. Central Research Library \\ 42. Document Reference Section
}

\section{EXTERNAL DISTRIBUTION}

43. R. Akers, RIMA, 5455 N. Irwindale Avenue, Irwindale, CA 91706

44. R. L. Alumbaugh, Naval Civil Engineering Lab, Port Hueneme, CA 93043

45. R. W. Anderson, 5083 street, Excelsior, MN 55331

46. J. Andrews, Custom Builder Magazine, Yarmouth, ME 04096

47. D. Arasteh, LBL, Berkeley, CA 94704

48. M. Autrey, Oklahoma State University, stillwater, OK 74078

49. E. I. Bales, New Jersey Institute of Technology, Newark, NJ 07102

50. C. G. Bankvall, Swedish National Testing Institute, Boras, Sweden

51. R. W. Barito, R. W. Barito \& Associates, Inc., Louisville, KY 40242

52. G. Barritt, Oregon Dept. of Energy, Salem, OR 97310

53. J. Barter, Bonneville Power Administration, Room 561, U.S. Court House, w. 920 Riverside Avenue, Spokane, WA 99201

54. M. Bomberg, National Research Council Canada, Ottawa, Canada

55. J. J. Boulin, DOE/CE, Washington, DC 20585

56. M. Bradfield, NCMA, Herndon, VA 22070

57. S. Braun, MIMA, Alexandria, VA 22314

58. B. Bromley, American Rockwool, Inc., Spring Hope, NC 27882

59. G. Brower, Knauf Fiberglas, Shelbyville, IN 46176

60. W. C. Brown, National Research Council of Canada, ottawa, Ontario 
61. B. Buchanan, University of Pittsburgh, Pittsburgh, PA 15260

62. J. H. Cable, John Cable Associates, Alexandria, VA 22314

63. P. C. Clark, State of New Jersey Department of Commerce, Newark, NJ 07102-5102

64. R. Classen, LCB, Bonneville Power Administration, P.O. Box 3621, Portland, OR 97208

65. M. Cunningham, Building Research Association, Private Bag, Porirua, New Zealand

66. E. F. Cusick, Jr., RockWool Manufacturing Co., Leeds, AL 35094

67. J. J. Cuttica, Gas Research Institute, Chicago, IL 60631

68-72. B. D'Alessandro, Custom Builder, Peterborough, NH 03458

73-82. A. Desjarlais, Holometrix, Inc., Cambridge, MA 02139

83. J. G. Driggans, TVA, Chattanooga, TN 37402-2801

84. G. Durkin, National Center for Appropriate Technology, Butte, MT 59702

85. W. M. Edmunds, Owens-Corning Technical Center, Granville, OH 43023

86. W. P. Ellis, Standards Consultant, Harleysville, PA 19438

87. F. England, Floyd England and Associates, Waco, TX 76715

88. D. M. Evans, Jr., Steven winter Associates, Inc., New York, NY 10001

89. P. Fairey, Florida Solar Energy Center, 300 state Road 401, Cape Canaveral, FL 32920

90. T. A. Farkas, NAHB, Washington, DC 20005

91. M. Feirer, Fine Homebuilding, Newtown, CT 06470

92. H. A. Fine, 949 Wishbone Circle, Lexington, KY 40502

93. P. Fisette, University of Massachusetts, Amherst, MA 01003

94. J. Flores, RMID, Bonneville Power Administration, P.O. Box 3621, Portland, OR 97208

95. D. R. Flynn, NIST, Gaithersburg, MD 20899

96-100. M. Foisy, Innovative Energy, Rancho Cordova, CA 95742

101. P. A. Gibson, Alkay Roofing systems, Inc., Angola, IN 46703

102. L. R. Glicksman, MIT, Cambridge, MA 02139

103. F. C. Gorham, Roofing Services, Incorporated, Springfield, VA 22152-1621

104. T. Grether, Owens-Corning Fiberglas Corp., Toledo, OH 43659

105. J. R. Hagan, Jim Walter Research, st. Petersburg, FL 33716

106. D. A. Harris, NIBS, Washington, DC 20005

107. J. Harris, Northwest Power Planning Council, Portland, OR 97204

108. T. Harris, BASF, Ontario, Canada 
109. R. Haynes, 2155 Eagle Drive, Charleston, SC 29411

110. B. Howard, NAHB National Research Center, Upper Marlboro, MD 20772-8731

111. K. C. Howerton, Federal Trade Commission, Washington, DC 20580

112. B. Huson, Hull \& Company, Greenwich, CT 06830

113. M. Jackson, RMRD, Bonneville Power Administration, P.O. Box 3621, Portland, OR 97208

114. J. E. Janssen, 4840 Gaywood Drive, Minnetonka, MN 55345

115. L. Johnson, Chevron U.S.A., Pascagoula, MS 39567

116. D. Jones, Dupont, Richmond, VA 23261

P. Juneau, Alfol, Inc., P.O. Box 7024, Charlotte, NC 28217

117. J. P. Kesselring, Electric Power Research Institute, Palo Alto, CA 94303

118. W. A. Kirn, Rohm and Haas Co., Spring House, PA 19477

119. R. F. Krajewski, Brookhaven National Lab, Upton, NY 11973

120. M. Krarti, Steven winter Associates, Inc., Norwalk, CT 06854

121. K. Labs, Progressive Architecture, Stanford, CT 06904

122. J. I. Lach, Manville Corporation, washington, DC 20006

123. M. B. Lacher, CertainTeed Corporation, Valley Forge, PA 19482

124. E. Leger, P.O. Box 549, New Boston, NH 03070

125. W. Linander, EURIMA, Roskilde, Denmark

126. J. Istiburek, Dames Hoore, Trow, Park Ridge, IL 60068

127. R. A. Lucas, Tremco, Lexington, MA 02173

128. R. Mack, Dow Chemical, Freeport, TX 77541

129. J. E. Magowan, Roof Industry Consultants, Inc., Dublin, CA 94568

130. P. C. Martin, Manville Sales Corporation, Denver, Co 80217

131. R. F. Martin, Roof Maintenance Systems, Farmingdale, NJ 07727

132. S. Martin, Suburban Insulations, Hagerstown, MD 21740

133. W. F. Martin, Roof Design Works, Knoxville, TN 37919

134. J. Mccorkle, 6720 s. Steele street, Littleton, Co 80122

135. D. McGuire, Regal Industries, Crothersville, IN 47229

136. M. McManus, University of Tennessee, Knoxville, TN 37901

137. G. Miller, Jim Walter Research Corp., st. Petersburg, FL 33716

138. M. Millspaugh, Reflectixs, Inc., Markleville, IN 46056

139. M. Modera, Lawrence Berkeley Laboratory, Berkeley, CA 94720

140. D. E. Morrison, Michigan State University, E. Lansing, MI 48824-11111 
141. J. R. Mumaw, Owens-Corning Fiberglas, Granville, OH 43023-1200

142. B. Nelson, Minnesota Dept. of Public Service, Energy Division, st. Paul, MN 55101

143. N. Nisson, Energy Design Update, Ansonia Station, New York, NY 10023

144. R. E. Norris, Building Technology, Albany, CA 94706

145. R. E. Oliver, DOE/CE, Washington, DC 20585

146. H. F. Poppendiek, Geoscience, Ltd., Solana Beach, CA 92075

147. F. J. Powell, 9919 Mayfield Drive, Bethesda, MD 20817

148. F. Pratt, RMRC, Bonneville Power Administration, P.O. Box 3621, Portland, OR 97208

149. R. J. Ray, Manville Sales Corp., Denver, co 80217

150. R. Reinhart, RMRD, Bonneville Power Administration, P.O. Box 3621 , Portland, OR 97208

151. T. Roberts, Bonneville Power Administration, 201 Queen Anne Avenue North, Suite 400, Seattle, WA 98109-1030

152. P. Robinson, Owens-Corning Fiberglas, Redwood City,

153. J. A. Roux, University of Mississippi, University, MS 38677

154. M. Russo, RSI Magazine, cleveland, OH 44130

155. R. C. Schroter, Product Technical Service Associates, Orinda, CA 94563

156. M. P. Scofield, DOE, Washington, DC 20585

157. G. Scott, Bonneville Power Administration, 101 West Poplar, Walla Walla, WA 99362

158. E. R. Shank, Burt, Hill, Kosar, Rittelmann Associates, 400 Morgan Center, Butler, PA 16001

159. M. Sherman, Jim Walter Corporation, st. Petersburg, FL 33742-2010

160. C. J. Shirtliffe, National Research Council, Ottawa, Ontario, Canada

161. A. Skinner, Roofing Service Assoc., Knoxville, TN 37919

162. H. S. Smith, Cellin Manufacturing, Inc., Elkwood, VA 22718

163. J. A. Smith, DOE/CE, Washington, DC 20585

164. L. L. Smith, New York State Energy Office, 2 Rockefeller Plaza, Albany, NY 12223

165. M. K. Snyder, 9107 Outlook Drive, Overland Park, KS 66207

166. I. G. Spielvogel, Wyncote House, Wyncote, PA 19095-1499

167. R. Sterling, University of Minnesota, Minneapolis, MN 55455

168. E. Stern, BPCo, Inc., Quebec, Canada

169. E. Story, Insultray, Redmond, WA 98073-3111

170. N. Strawn, SERI, 1617 Cole Avenue, Golden, Co 80401 
171. A. Tenwolde, U.S. Dept. of Agriculture, Forest Products Lab, Madison, WI 53705-2398

172. S. Tewes, University of Illinois at Urbana, Champaign, II 61820

173. J. R. Thomas, VPI and State University, Blacksburg, VA 24061

174. P. Thor, RMRD, Bonneville Power Administration, P.O. Box 3621 , Portland, OR 97208

175. T. W. Tong, Arizona State University, Tempe, A2 85287

176. G. A. Tsongas, Portland state University, Portland, OR 97207

177. A. Tuluca, Steven Winter Associates, Norwalk, CT 06854

178-187. R. P. Tye, Thermatest Division of Holometrix, Inc., Cambridge, MA 02139

188. C. R. Vander Linden, Vander Linden \& Associates, Littleton, Co 80123

189. M. G. Van Geem, Construction Technology Laboratories, Inc., skokie, IL 60077

190. B. Wilcox, Berkeley Solar Group, Oakland, CA 94610-1924

191. M. Williams, Northern Ilinois University, DeKalb, II 60115

192. D. W. Yarbrough, TN Tech University, Cookeville, TN 38505

193. Office, Assistant Manager, Energy Research and Development, DOE/ORO, Oak Ridge, TN 37831-8600

194-203. Office of Scientific and Technical Information, U.S. Department of Energy, Oak Ridge, TN 37831

[For distribution by microfiche as shown in DOE/OSTI-4500, Distribution Category UC-350 (Energy Conservation in Buildings and Community systems)] 


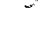

$=$

$s$

$x$

क 